Portland State University

PDXScholar

Spring 5-29-2019

\title{
Development of a Readiness Assessment Model for Evaluating Big Data Projects: Case Study of Smart City in Oregon, USA
}

Husam Ahmad Barham

Portland State University

Follow this and additional works at: https://pdxscholar.library.pdx.edu/open_access_etds

Part of the Technology and Innovation Commons

Let us know how access to this document benefits you.

\section{Recommended Citation}

Barham, Husam Ahmad, "Development of a Readiness Assessment Model for Evaluating Big Data Projects: Case Study of Smart City in Oregon, USA" (2019). Dissertations and Theses. Paper 4996. https://doi.org/10.15760/etd.6872

This Dissertation is brought to you for free and open access. It has been accepted for inclusion in Dissertations and Theses by an authorized administrator of PDXScholar. Please contact us if we can make this document more accessible: pdxscholar@pdx.edu. 
Development of a Readiness Assessment Model for Evaluating Big Data Projects: Case Study of Smart City in Oregon, USA

\author{
by \\ Husam Ahmad Barham \\ requirements for the degree of \\ Doctor of Philosophy \\ in \\ Technology Management \\ Dissertation Committee: \\ Tugrul U. Daim, Chair \\ Timothy R. Anderson \\ Richard C. Sperry \\ Dara Shifrer
}

A dissertation submitted in partial fulfillment of the

Portland State University

2019 


\begin{abstract}
Big data projects are facing an alarmingly high percentage of failure, with severe consequences related to the cost of this type of projects, the waste of resources and efforts in doing it, and the competitive disadvantage caused by the lack of big data analytics capabilities in comparison with competitors. Furthermore, there is a decent amount of research on the main challenges facing big data projects. However, there is a lack of research on how to leverage on this knowledge to evaluate an organization's readiness for a big data project, more specifically, how to systematically assess an organization's current status against known reasons that might cause a big data project to fail. Hence, identifying shortcomings that need to be addressed before the project start, to reduce chances of failure for that project.
\end{abstract}

Therefore, the primary goal of this research is to help any organization, which is planning to transform to the big data analytics era, by providing a systematic and comprehensive model that this organization can use to better understand what factors influence big data projects. Also, the organization's current status against those factors. Finally, what enhancements are needed in the organization's current capabilities for optimal management of factors influencing an upcoming big data project. However, big data applications are vast and cover many sectors, and while most of the factors influencing big data projects are common across sectors, there are some factors that are related to the specific circumstances of each sector. Therefore, this research will focus on 
one sector only, which is the smart city sector, and its generalizability to other sectors is discussed at the end of the research.

In this research, literature review and experts feedback were used to identify the most critical factors influencing big data projects, with focus on smart city, Then, the HDM methodology was used to elicit experts judgment to identify the relative importance of those factors. In addition, experts' feedback was used to identify possible statuses an organization might have regarding each factor. Finally, a case study of four projects related to the City of Portland, Oregon, was conducted to demonstrate the practicality and value of the research model.

The research findings indicated that there are complicated internal and external, sometimes competing, factors affecting big data projects. The research identified 18 factors as being among the most important factors affecting smart-city-related big data projects. Those factors are grouped into four perspectives: people, technology, legal, and organization. Furthermore, the case study demonstrated how the model could pinpoint shortcomings in a city's capabilities before the project start, and how to address those shortcomings to increase chances of a successful big data project. 


\section{DEDICATION}

To my beloved parents:

My father and role model, Ahmad Barham, who instilled in me the notion that sky is the limit, and anything is possible with hard work and passion.

My mother, Aqsam Ijmail, whose unshakeable belief in me and my ability to achieve success in anything I engage in, have always ignited me to do more and keep trying to be better every day.

To my dear wife, Asmaa Hamadmad, whose endless love, support, and compassion allowed me to overcome all the challenges I faced throughout my Ph.D. journey.

To my kids, Ahmad, Salah, and Mariam, who are the stars of my life. 


\section{ACKNOWLEDGMENTS}

I cannot begin to express my thanks and gratitude for every person who supported me while doing my research, these are people who dedicated time and effort that I leveraged to conduct this research, and without them, I would not be able to finish it successfully. I am eternally grateful to all of them.

I am deeply indebted to my advisor and committee chair Prof. Tugrul Daim; it would not have been possible to reach where I am today without his guidance, mentoring, and endless support. He is one of the best and brightest minds in the technology management discipline, and I am privileged to be one of his students.

I would also like to express my deepest appreciation to my committee members, Dr. Tim Anderson, Dr. Richard Sperry, and Dr. Dara Shifrer. I am grateful to all the time, effort, advice, and encouragement they offered me while doing my dissertation.

I would also like to acknowledge Dr. Wilfred Pinfold, CEO at urban.systems, and John MacArthur, Sustainable Transportation Program Manager at TREC for their valuable insights and feedback regarding my research topic. Furthermore, I wish to thank Kevin Martin, Smart City PDX Manager, and Hector Dominguez, Open Data Coordinator at the City of Portland for their help and valuable insights. Moreover, I would like to extend my sincere thanks to all the experts who participated in my subjectmatter-expert panels, their time, feedback, and insights were critical for my research to move forward.

In addition, I am grateful to all the faculty members and staff in the ETM department; they were always available to answer questions and clarify any issue. Also, 
other Ph.D. students who helped me by offering advice and support at each stage of my research.

Finally, I am sure to forget someone, as the support I received was tremendous. To anyone I failed to mention, please accept my apologies and thanks for your time and effort. 
TABLE OF CONTENTS

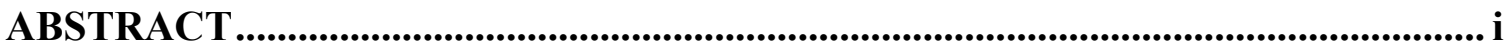

DEDICATION.........................................................................................................ii

ACKNOWLEDGMENTS .............................................................................................. iv

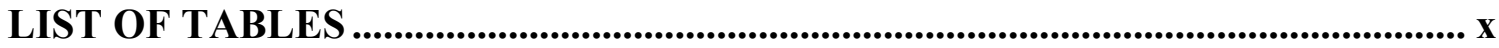

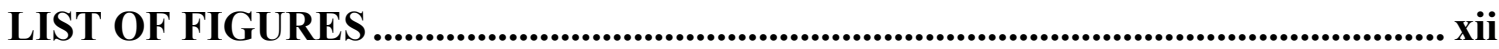

CHAPTER 1: INTRODUCTION.................................................................................... 1

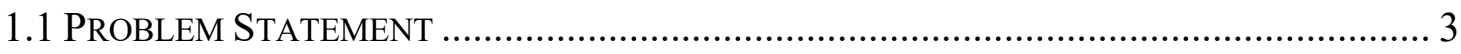

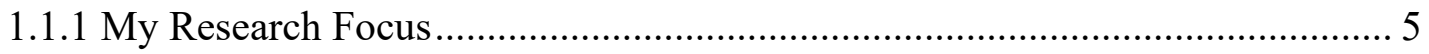

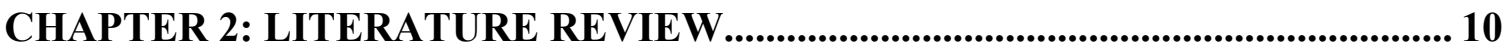

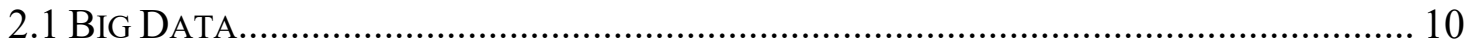

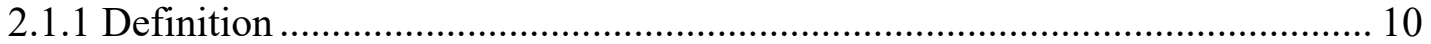

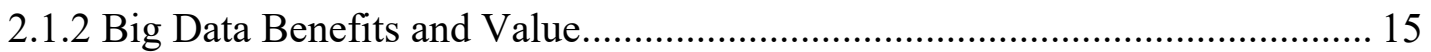

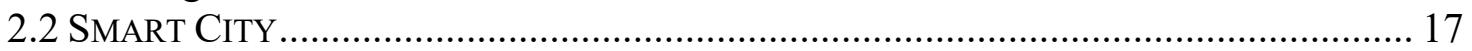

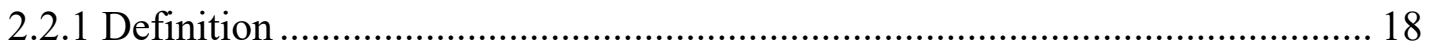

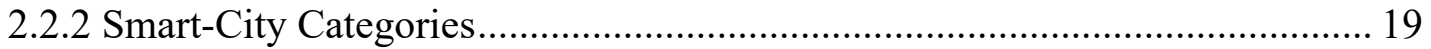

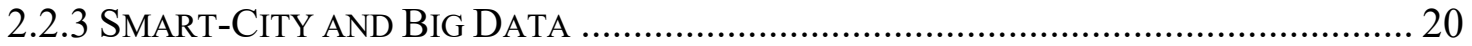

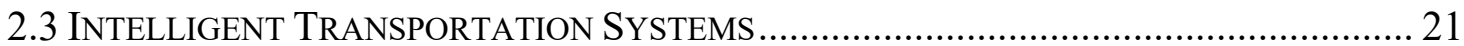

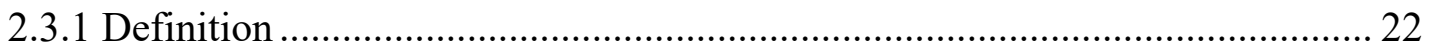

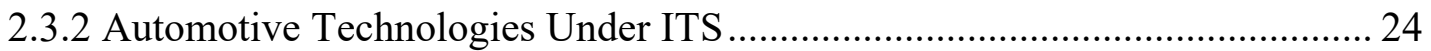

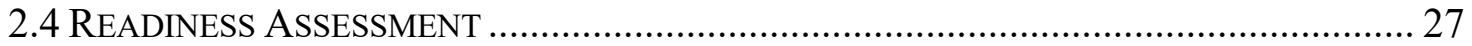

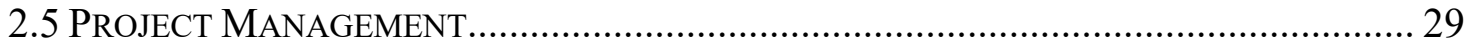

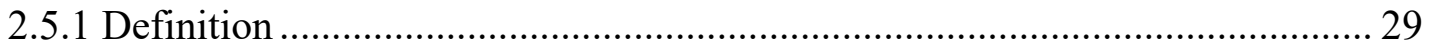

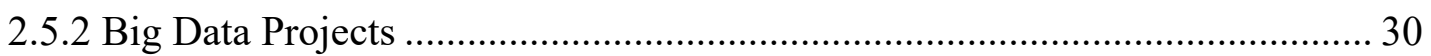

2.5.3 Readiness Assessment Phase ……………………...................................... 30

2.6 CRITICAL FACTORS AfFeCtING Big DATA ProJECTS ................................................ 31

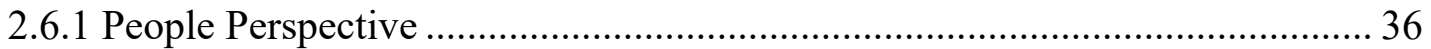

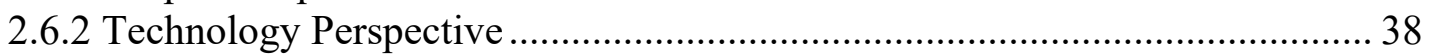

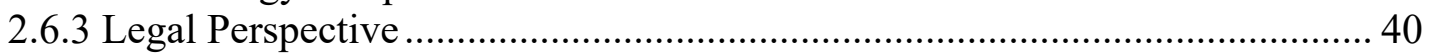

2.6.4 Organization Perspective ………………………........................................ 42

2.7 Big Data Projects vs. LARge-SCALE IT PROJECTS IN the PUblic SeCtoR .......... 45

CHAPTER 3: RESEARCH OBJECTIVES, QUESTIONS, AND METHODOLOGY

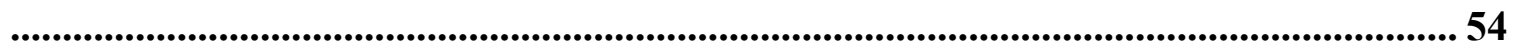

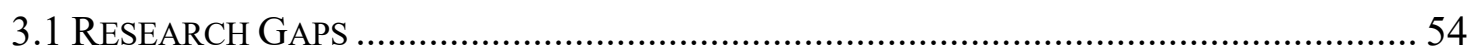

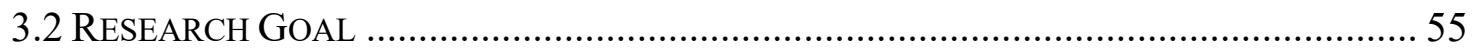

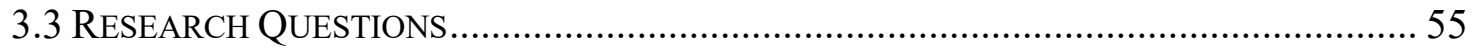

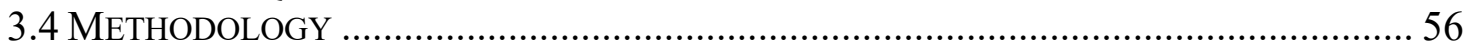

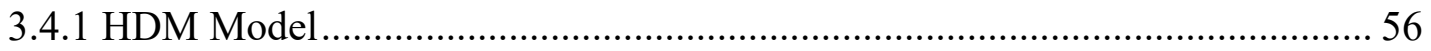




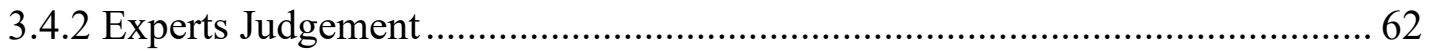

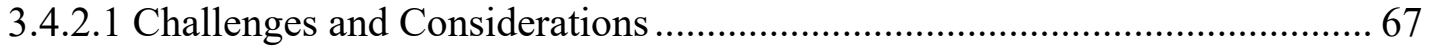

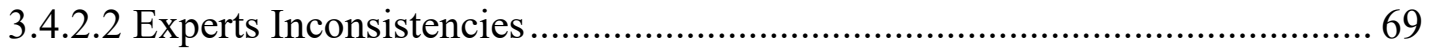

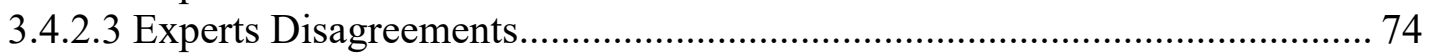

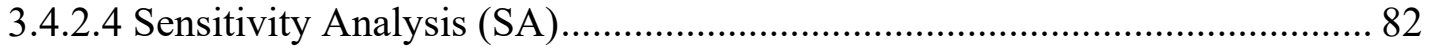

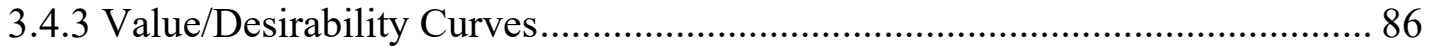

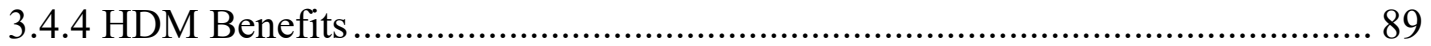

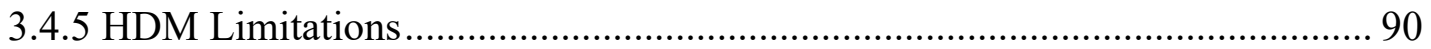

3.4.6 City's Index of Readiness to Conduct a Smart-city-related Big Data Project. 92

3.4.7 Methodology Justification and Comparison with other Methodologies.......... 94

CHAPTER 4: RESEARCH DESIGN ................................................................. 104

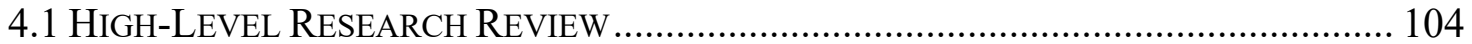

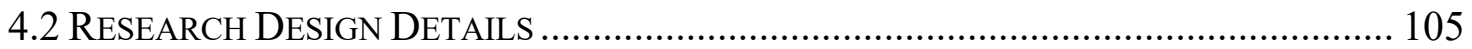

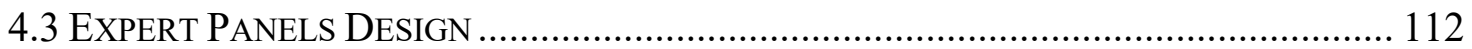

4.3.1 Expert Panels Format......................................................................... 112

4.3.2 Potential Experts …………………………………................................. 118

CHAPTER 5: RESULTS OF MODEL VALIDATION AND QUANTIFICATION

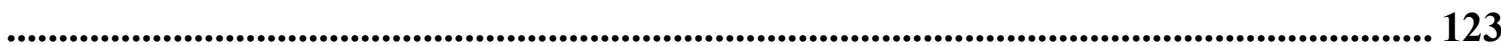

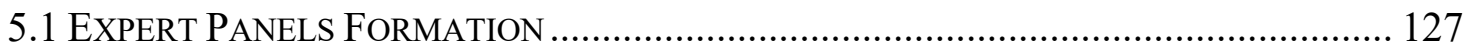

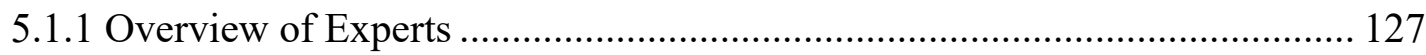

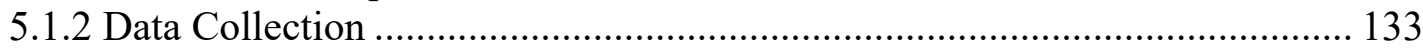

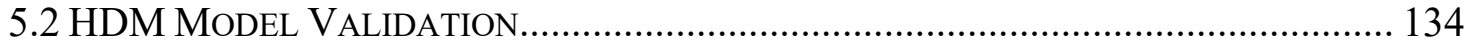

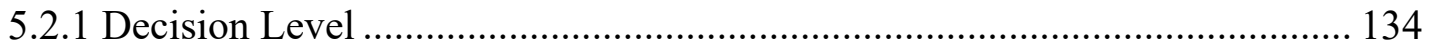

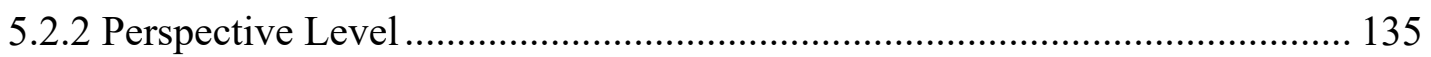

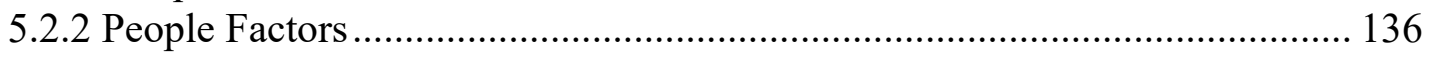

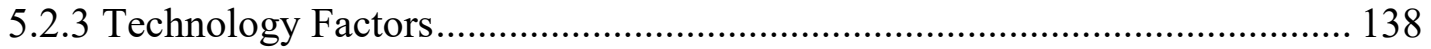

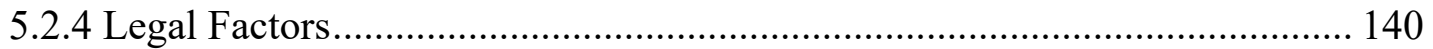

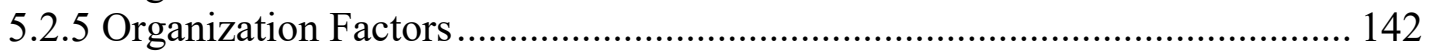

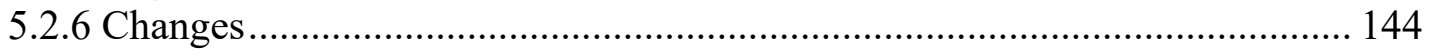

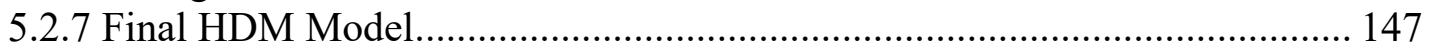

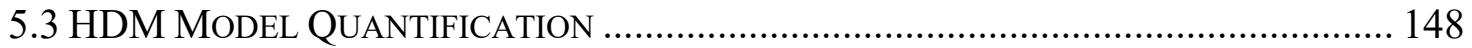

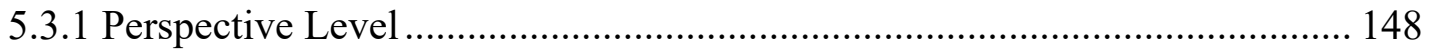

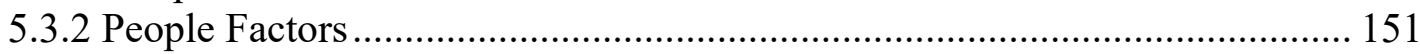

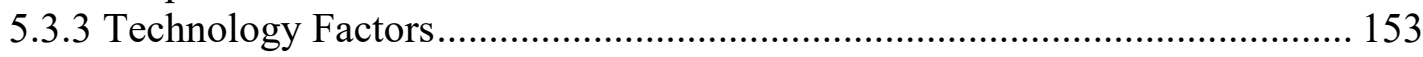

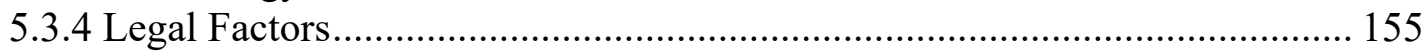

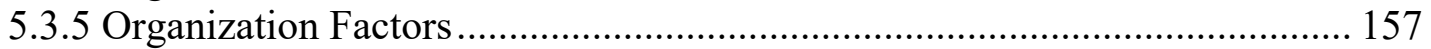

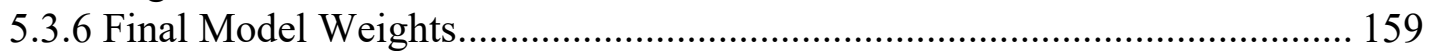

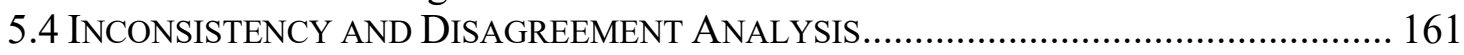

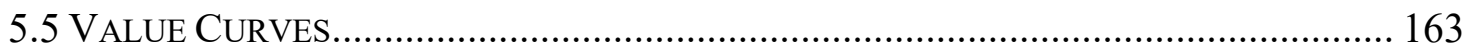

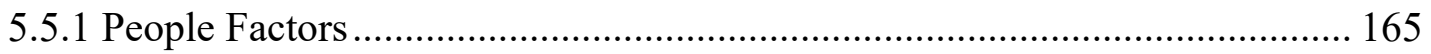

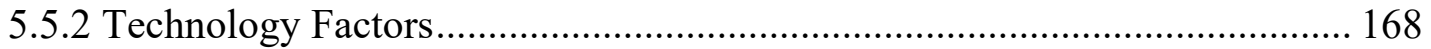

5.5.3 Legal Factors............................................................................................ 171 


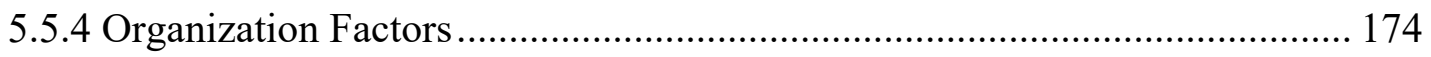

CHAPTER 6: CASE STUDY ......................................................................................... 177

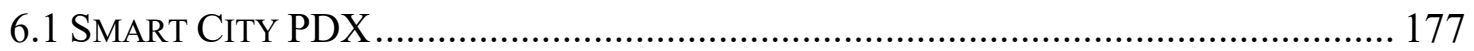

6.2 CASe Study SMart-CiTy Related Big Data ProjectS .................................... 178

6.2.1 Proj1: Traffic Safety Sensor Project (IQ Center)........................................... 178

6.2.2 Proj2: Air Quality Sensor Testing \& Deployment......................................... 179

6.2.3 Proj3: Connected Streetcar Project .............................................................. 179

6.2.4 Proj4: Pollution Prevention Technical Assistance for Idle Reduction and Electrification of Refrigerated Transport ............................................................. 180

CHAPTER 7: ANALYSIS OF CASE AND SENSITIVITY ANALYSIS.................. 182

7.1 CiTY'S INDEX OF READINESS TO CONDUCT A SMART-CITY-RELATED BIG DATA

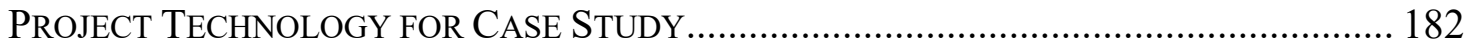

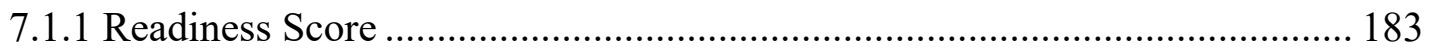

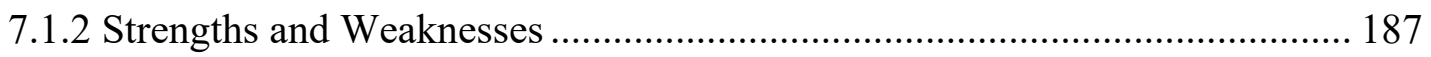

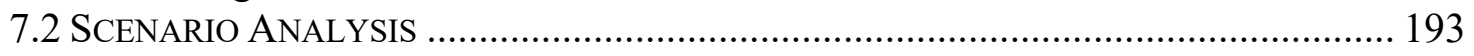

7.3 What CAN BE DONE TO IMPROVE READINESS SCORE (AND INCREASE THE POTENTIAL FOR SUCCESSFUL BIG DATA PROJECT)?............................................... 202

CHAPTER 8: RESEARCH VALIDITY ...................................................................... 211

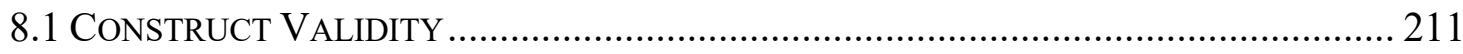

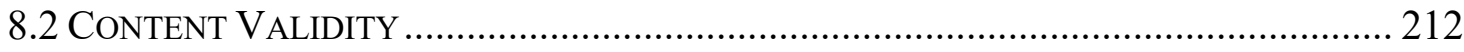

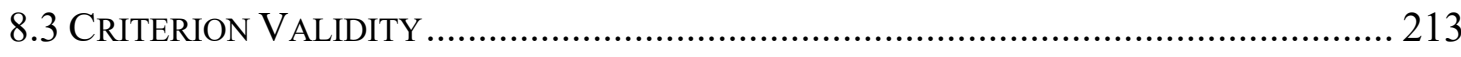

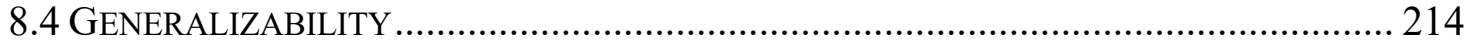

CHAPTER 9: DISCUSSION ..................................................................................... 215

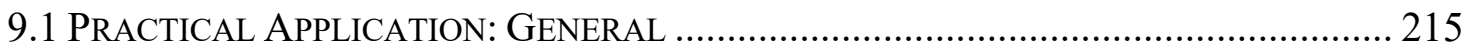

9.2 Practical APPLICATION: PeOPle PersPeCtive.................................................. 217

9.3 Practical APPLICATION: TeChNology PersPeCtive......................................... 218

9.4 PRACTICAl APPLICATION: Legal PERSPECTIVE ………….................................. 218

9.5 PRACTICAL APPLICATION: ORGANIZATION PERSPECTIVE ....................................... 219

9.6 CAN THE MOdEL BE USED FOR OTHER SECTORS? .............................................. 220

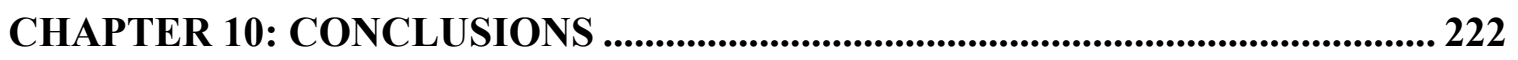

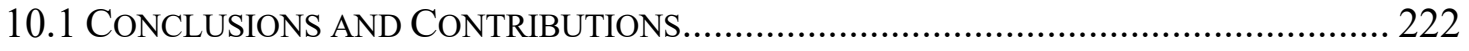

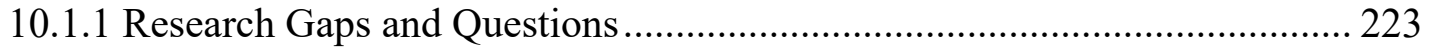

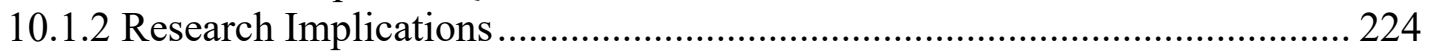

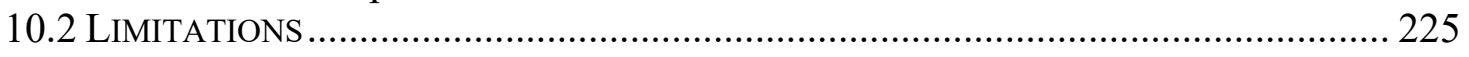

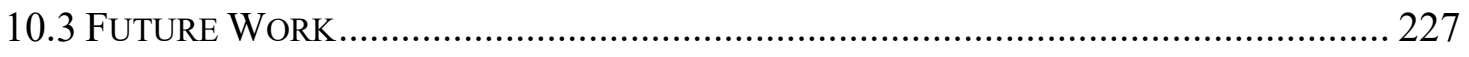

REFERENCES........................................................................................................... 228

APPENDIX A: LETTERS OF INVITATION TO EXPERTS................................... 256 
APPENDIX B: QUALTRICS SURVEYS TO EVALUATE AND QUANTIFY THE

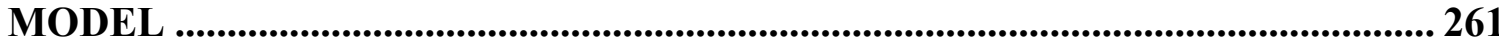

APPENDIX C: HDM SOFTWARE TOOL ................................................................. 301

APPENDIX D: R PACKAGE FOR BIBLIOMETRIC AND SNA ANALYSIS..... 304 


\section{LIST OF TABLES}

TABle 1. Comparison of Big Data AND Big IT Project ChallengeS ......................... 49

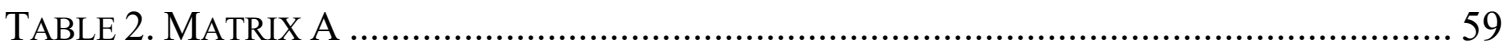

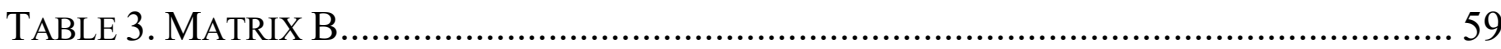

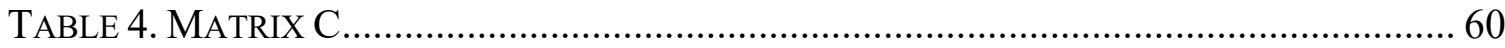

TABLE 5. Potential DeCISION-MAKING METHODS CoMPARISON ……………………..... 98

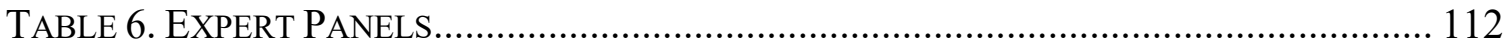

TABLE 7. EXPERTS BACKGROUNDS FOR EACH PANEL ……………................................... 118

TABLE 8. Perspectives of FaCtors AfFecting SMART-CITY-Related Big Data

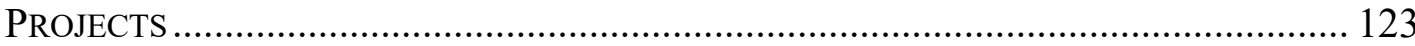

Table 9. Critical Factors AfFecting SMART-City-Related Big Data Projects.. 124

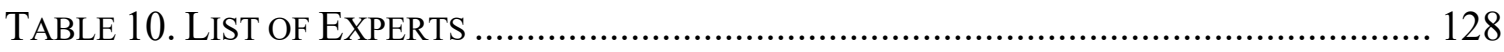

TABle 11. Perspectives Validation Summary By P1 Panel. ..................................... 135

Table 12. Perspectives Detailed Validation by P1 Panel....................................... 135

TABLE 13. PEOPLE-RELATED FACTORS VALIDATION SUMMARY BY P2 PANEL.................. 136

Table 14. People-Related Factors Detailed Validation By P2 Panel.................. 136

TABLE 15. TeChNOLOGY-RELATED FACTORS VALIDATION SUMMARY BY P3 PANEL. .... 138

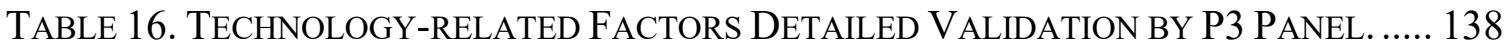

TABLE 17. LEGAL-RELATED FACTORS VALIDATION SUMMARY BY P4 PANEL.................. 140

TABLE 18. Legal-RELATED FaCtors DetaILED VALIDATION BY P4 PANEL. .................. 140

TABle 19. Organization-Related FaCtors VAlidation SUMMARY By P5 PANEL... 142

Table 20. ORganization-Related Factors Detailed VAlidation By P5 Panel. . 142

TABLE 21. ChANGES VALIDATION SUMMARY BY P6 PANEL. .......................................... 146

TABLE 22. Changes DetaILED VALIDATION BY P6 PANEL............................................ 146

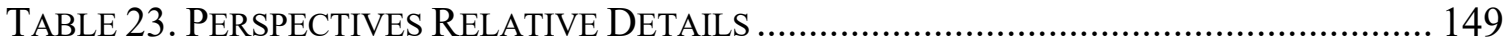

TABLE 24. People Related Factors WeightS - Details …………………………...... 151

TABLE 25. TEChNOLOGY ReLATEd FACTORS WEIGHTS - DetaILS ................................. 153

TABLE 26. LEgAL RELATED FACTORS WEIGHTS - DETAILS............................................ 155

TABLE 27. ORGANIZATION RELATED FACTORS WEIGHTS - DETAILS................................ 157

TABLE 28. HDM MODEL FINAL WEIGHTS............................................................... 159

TABLE 29. DESIRABILITY CURVE MATRIX............................................................... 163

TABLE 30. People Related Factors DesirabiLITY CURVES....................................... 165

TABLE 31. TEChNOLOGY RELATED FACTORS DESIRABILITY CURVES .............................. 168

TABLE 32. LEgAL RELATED FACTORS DESIRABILITY CURVES ......................................... 171

TABLE 33. ORGANIZATION RELATED FACTORS DESIRABILITY CURVES .......................... 174

TABLE 34. PROJ1 READINESS ASSESSMENT SCORE................................................... 183

TABLE 35. PROJ2 READINESS ASSESSMENT SCORE.................................................... 184

TABLE 36. PROJ3 READINESS ASSESSMENT SCORE................................................... 185

TABLE 37. PROJ4 READINESS ASSESSMENT SCORE...................................................... 186

TABLE 38. STRENGTHS AND WEAKNESSES FOR EACH SCENARIO .................................... 187

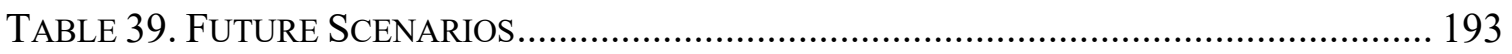

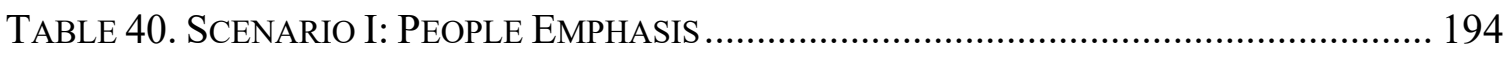




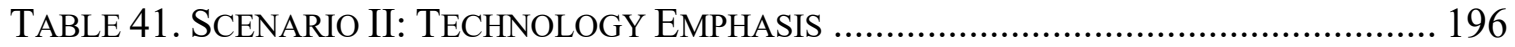

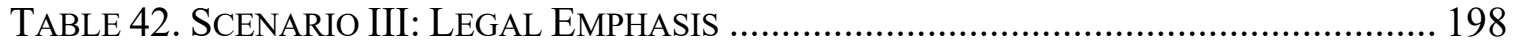

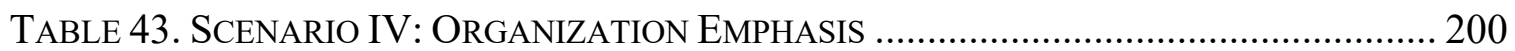

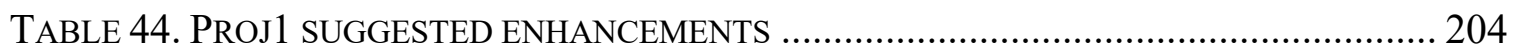

TABLE 45. PROJ2 SUGGESTED ENHANCEMENTS ........................................................... 205

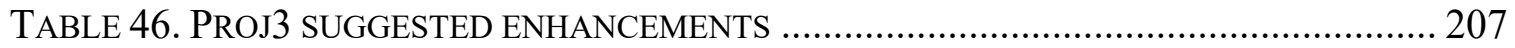

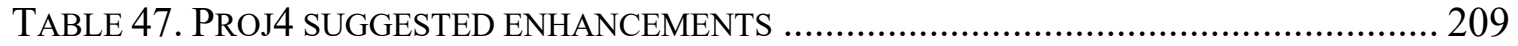

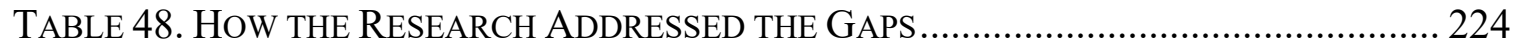

TABLE 49. How THE RESEARCH ADDRESSED THE QUESTIONS ..................................... 224 


\section{LIST OF FIGURES}

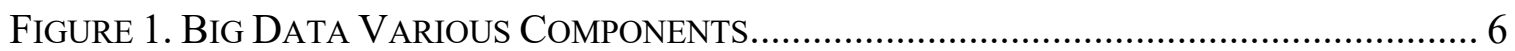

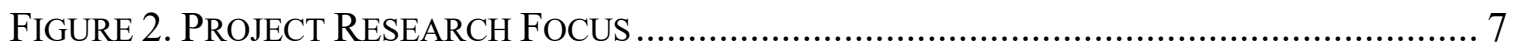

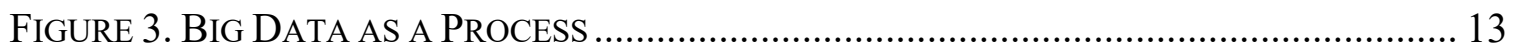

FIGURE 4. BIG DATA ANALYTICS.......................................................................... 14

Figure 5A. WEB OF SCIENCE SEARCh RESULtS FOR THE KEY WORDS: BIG DATA ............ 32

Figure 5B. Web of SCIENCE SEARCH RESUlts FOR THE KEY WORDS: BIG DATA

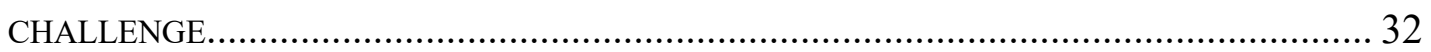

Figure 5C. Web of Science SEARCh Results For THE Key Words: Big DATA AdOPT. 33

Figure 5D. WEB of SCIENCE SEARCH RESUltS FOR THE KEY WORDS: BIG DATA

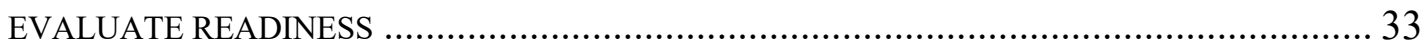

Figure 5E. WEB OF SCIENCE SEARCH RESUlts FOR THE KEY WORDS: BIG DATA

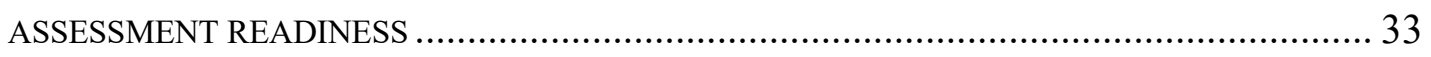

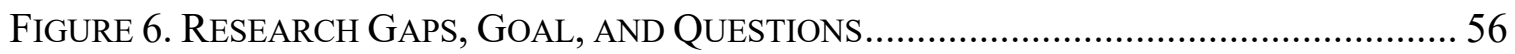

FigURE 7. EXAMPLE OF MOGSA (KOCAOGLU 1983) ...................................................... 57

Figure 8. CONCEPTUAL HDM MODEL DESIGN (ESTEP 2017; GiBSON 2016; ABOTAH 2014;

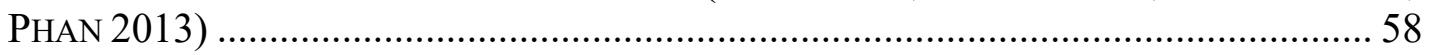

FIGURE 9. PAIRWISE COMPARISON …................................................................... 70

Figure 10. CONCEPTUAL HDM MODEL WITH DESIRABILITY CURVES............................. 87

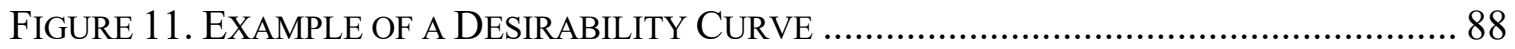

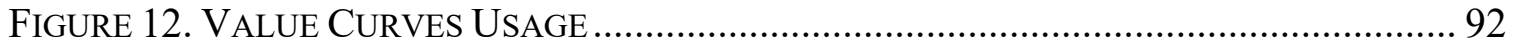

Figure 13. CONCEPTUAL HDM MODEL WiTH DeSIRABILITY CURVES............................. 93

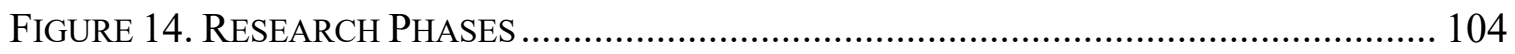

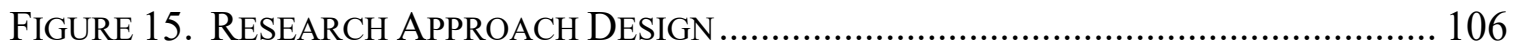

FIGURE 16. HDM MODEL FOR CITY'S READINESS ASSESSMENT FOR A SMART-CITY-

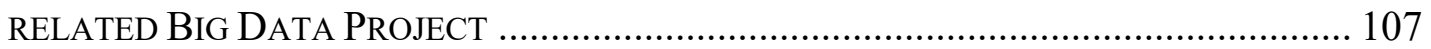

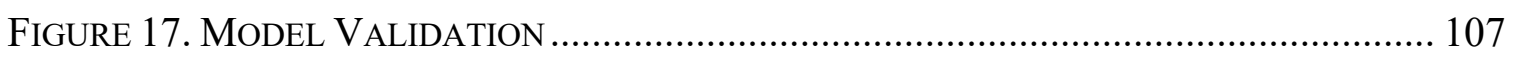

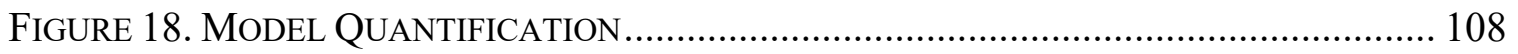

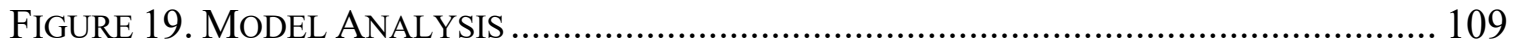

FIGURE 20. IDENTIFYING EXPERTS PROCESS (GARCES ET AL. 2017)............................. 121

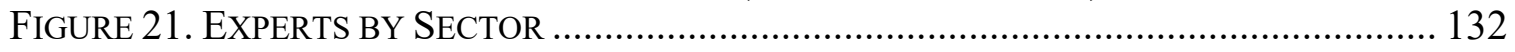

Figure 22. EXPERTS By Type (The SAme ExPert CAN HAVE Multiple TyPes).......... 132

Figure 23. THE FinAL HDM MODEL ................................................................... 147

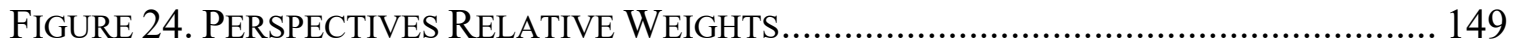

Figure 25. PEOPLE RELATED FACTORS WEIGHTS ......................................................... 151

Figure 26. TECHNOLOGY RELATED FACTORS WEIGHTS.............................................. 153

FigURE 27. LEGAL RELATED FACTORS WEIGHTS ....................................................... 155

FigURE 28. ORGANIZATION RELATED FACTORS WEIGHTS .......................................... 157

FIGURE 29. FACTORS THAT HAVE CRITICAL IMPACT ON SMART-CITY-RELATED BIG DATA

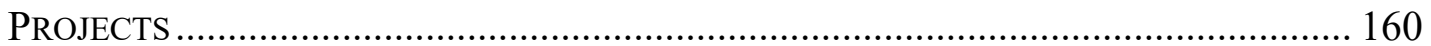

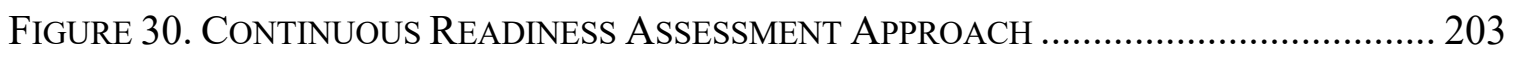

FigURE 31. CONTINUOUS IMPROVEMENTS USING VCS............................................. 203 


\section{CHAPTER 1: INTRODUCTION}

Data is being generated about almost everything around us in an unprecedented exponential rate. According to IBM (2017), in 2017, 90\% of the data in the world has been generated in the last two years, with 2.5 quintillion $\left(10^{18}\right)$ bytes of data generated every day. This massive influx of data is being fueled by the accelerated advances in information and communication technologies that affected every aspect of the modern, quick-paced life. For example, in 2018, every minute, the internet users did 3,877,140 searches using Google, posted 473,400 tweets on Twitter, shared 2,083,333 photos on Snapshot, and watched 4,333,560 videos on YouTube, to name a few examples (James, 2018).

We are struggling to catch up and make sense of this phenomenon, as data being generated in continuously-increasing volume, velocity, and variety, making it beyond our capability to catch up and make sense of (Ransbotham and Kiron 2017; McAfee et al. 2012). Hence, big data emerged, a field in the information technology sector, in response to this phenomenon; to offer ways to understand and make use of this data.

Big data offers a viable way to understand the modern world and to transform this influx of data into usable information and insights that allow for better decision making, and in the case of businesses, to achieve competitive advantage over competitors. Big data promises to provide the means to help making the right decision at the right time based on faster, more accurate, more efficient, and more effective aggregation and analysis of comprehensive internal and external sources of data, in ways that are 
unparalleled in human history (Barham 2017; Ransbotham and Kiron 2017; McAfee et al. 2012; LaValle 2011).

According to Gartner Inc., big data is one of the leading IT technologies in recent years (Cearley 2016). It is now part of decision making in all aspects of business, on the strategic, operational, and business processes levels. Big data is being utilized in commercial, industrial, social, governmental, and academic sectors. Some of the sectors where big data is thriving include healthcare, banking, government, and municipal planning and management, manufacturing, telecommunication, academic research like sociology and psychology, and marketing, just to name few (Ransbotham and Kiron 2018; Ethirajan et al. 2017; Rosculet et L. 2017; Wang et al. 2017; Etzion and AragonCorrea 2016; Groves 2016; Chen and Zhang 2014; Burrows and Savage 2014; Kitchin 2014; Walker 2014; Sagiroglu and Sinanc. 2013; Boyd and Crawford 2012).

In addition, a NewVantage survey of the fortune 1000 firms found that $92 \%$ of those firms are increasing their spending on big data analytics in 2019, also the survey found that $55 \%$ of firms are spending over $\$ 50 \mathrm{M}$ on resources related to big data and AI (NewVantage Partners 2019). Furthermore, a survey by MIT Sloan Management Review, with thousands of participants from several sectors, sizes, and location, found out that $55 \%$ of the surveyed firms are using insights from big data to make decisions, $49 \%$ are "analytical Practitioners", and 17\% are "Analytical Innovators" (Ransbotham and Kiron 2017). Another survey by Harvard Business Review of the fortune 1000 firms' CEOs found that: $70 \%$ of the CEOs reported that big data is of critical importance to their firms and $63 \%$ of the firms reported having Big Data in production (Bean 2016). 


\subsection{Problem Statement}

The literature review has much evidence of the businesses value of big data, and how big data creates a competitive advantage for organizations against competitors (refer to section 2.1 for more details). However, studies indicate that more than half of big data projects fail, conservative studies indicate that $50 \%$ of big data projects fail, up to $85 \%$ by other studies (NewVantage Partners 2019; NewVantage Partners 2017; Ransbotham and Kiron 2017; Walker 2017; Iron Mountain 2015). A big data project fails when it never finishes or does not generate the expected outcome. In addition, in a recent survey of the fortune 1000 firms, $77 \%$ of respondents indicated that they are facing challenges in adopting big data (NewVantage Partners 2019).

The failure of such projects has a serious impact on the organization, as big data projects are generally expensive and require dedicating core organization's resources to implement, not to mention the disadvantage against competitors who have successfully implemented big data into their organizations (NewVantage Partners 2019; Adrian et al. 2017; NewVantage Partners 2017; Bean 2016; Iron Mountain 2015; Winter et al. 2013). In fact, a recent survey indicated that $78 \%$ of the respondents indicated that they fear disruption or displacement due to competitors and new entrants being more successful in using big data (Davenport and Bean 2018).

The reasons behind this high percentage of failure were the subject of many

studies in the past few years (Barham 2017; NewVantage Partners 2017; Ransbotham and 
Kiron 2017; Bean 2016; Saltz and Shamshurin 2016; Buckley 2015; Iron Mountain 2015; Marr 2015b; McAfee et al. 2012).

Big data projects are considered large-scale IT projects (Chen et al. 2014; Martinez 1994) (please refer to section 2.7). The same consequences of a big data project failure also apply to any large-scale IT project. In addition, some reasons for failure and counter measurement of any big IT project fit for big data projects. However, literature clearly indicates that big data projects have many unique challenges (for example, the shortage of data scientists and the lack of data strategies), as well as, challenges that are, while common to most big IT projects, are more impactful when it comes to big data projects (for example, data integration complexities and data privacy issues). Therefore, realizing big data projects specific nature while addressing its challenges would lead to solutions that are more effective.

Consequently, before organizations implement big data projects to move to the big data analytics era, they need to make sure that the chances of success of such projects are reasonably high. Since the consequences of failure are severe and include financial loss due to the cost of the projects itself and the waste of resources time, usually the best personnel in the organization, that would be allocated to work on those projects.

Therefore, there is a need for a model that can help organizations to be more confident and readier before initiating a big data project, and such a model should be able to:

- Identifies potential common factors that have a significant impact on the success or failure of big data projects. 
- Assesses the organization's readiness against each of those factors.

- Points where corrective/preventive actions are needed, based on the assessment, before starting the project.

\subsubsection{My Research Focus}

As big data applications have expanded over many sectors and industries, building a general model that can fit all kinds of big data projects, while doable, will need years of testing and validation. So, it is more practical to build a model that is directed at a specific sector that can be generalized later on. Hence, the focus of this research is on developing a model that addresses one sector, where big data plays an important role, and where the challenges as mentioned earlier are clearly evident. The sector this research is focusing on is smart cities. As cities trying to adopt smart city initiatives, face the same consequences when smart city-related big data projects fail. The financial cost could be high against their tight budgets, the city will have to assign its best people to work on the project, sometimes for years, and cities with failed big data projects will be less attractive than other cities that leverages big data to become smart and offer better quality of life to its citizens (Al Nuaimi et al. 2015; Neirotti 2014).

Based on the above discussion, my research will aim to identify the main challenges that could cause smart-city-related big data projects to fail. Big data projects, in this research context, refers to projects that aim at creating or enhancing the city's big data analytical capabilities to support a smart city initiative. In this kind of project, the outcome is an information management system that will acquire data from various resources (internal, external, structured, and unstructured), cleanse it, reformat it, 
aggregate it, and store it, as well as, building analytical tools to offer insights based on the acquired data, see Figure 1.

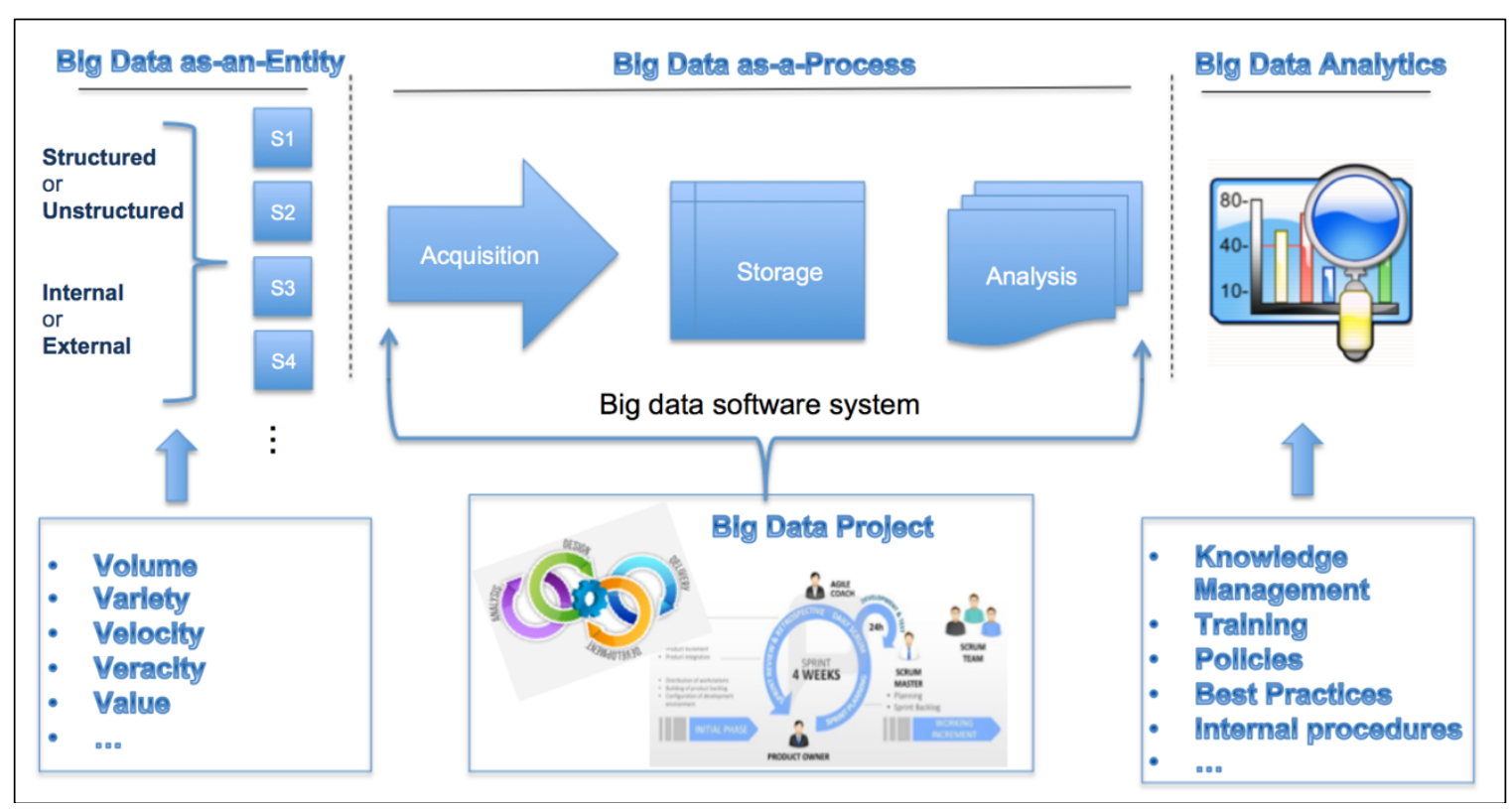

Figure 1. Big Data Various Components

More specifically, in this research the focus will be on:

- Identifying the critical issues that are key factors in influencing a smart-cityrelated big data project, to be a success or a failure, based on literature review and experts' judgment.

- Developing a model that can be used to assess a city's readiness against these issues, by using the HDM methodology and expert panels.

- Validating and quantifying the model, with the help of subject-matter experts, to make sure the model is reliable and vigor. 
- Finally, testing the model in a real situation, by working with the City of Portland regarding the city's smart-city initiative related to big data projects. My approach to testing the model will be two folds:

- First, sharing the model with the City of Portland personnel supervising the smart city initiative and get their feedback on what value this model present for them.

- Second, if possible, evaluating past projects under the model, and compare the model evaluation with what really happened in those projects, to find out how aligned the model is with real scenarios.

This research will allow project managers and cities to better understand their ability to conduct big data projects. Hence, allowing for better preparing for the upcoming project and higher chances of successful implementation, see Figure 2.

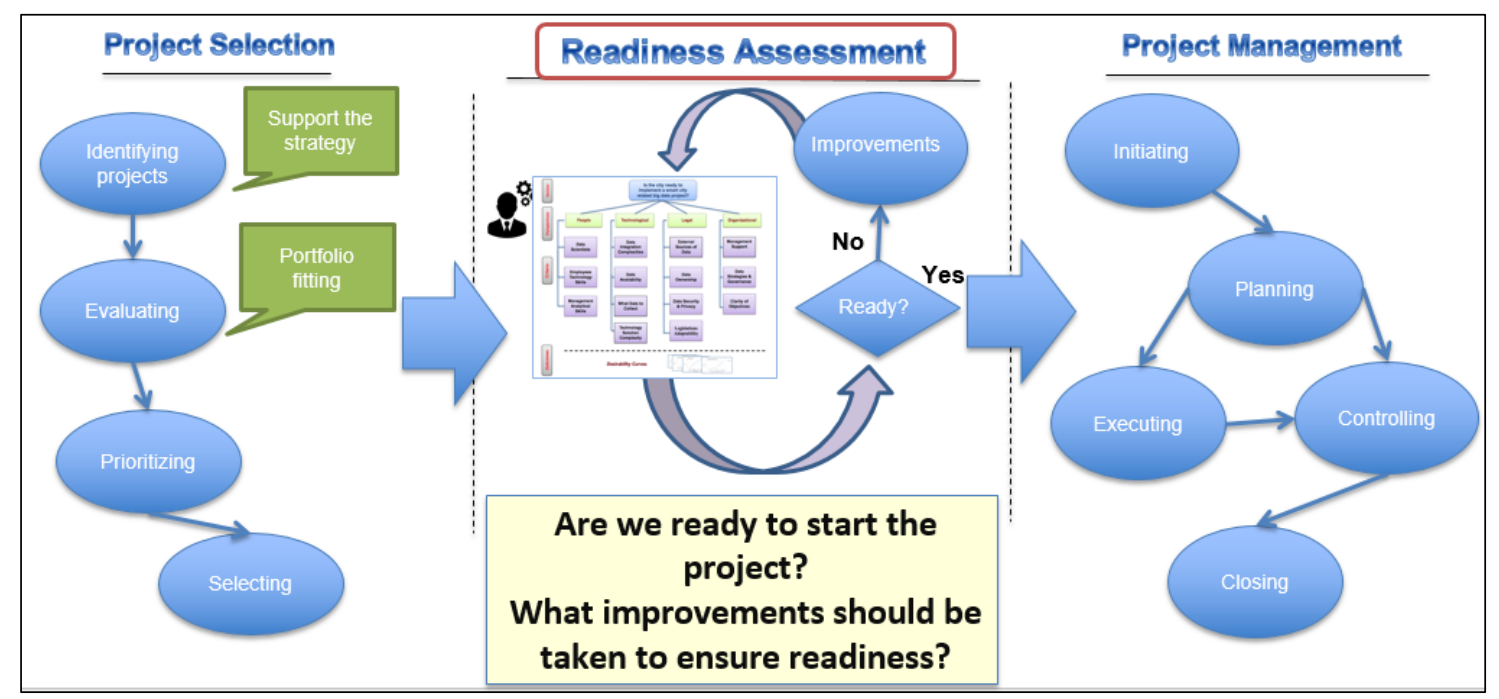

Figure 2. Project Research Focus 
In the following sections, first, in Chapter 2 an in-depth literature review is offered, that covers the background of the subject, the gap, and the gap's importance. The literature review includes: what is big data and why it is important, what is smart city, big data as part of smart city, intelligent transportation systems (ITS) as an application of big data under smart cities, what is readiness assessment, what is a big data project, and finally what are the main factors that can contribute to making a big data project a success or a failure, as identified in literature. Then, in Chapter 3, the research gaps, objective, and questions are presented, as well as, the methodology that this research used to answer the research questions to achieve the research goal, which is the HDM methodology. The HDM methodology was used to build a model that can be used by cities, planning to implement a smart-city-related big data project. The model will structurally and thoroughly assesses and determines the city's readiness to implement a big data project and will identify areas of concern that might cause the upcoming project to fail, in order to take preventive actions toward those issues before starting the project.

Moreover, Chapter 4 provides the research design that was used to achieve the research goals. Furthermore, Chapter 5, presents the data gathering phase, based on the design explained in Chapter 4. Chapter 5 includes expert panels formation, model validation and quantification by experts and the analysis of experts' reliability.

In addition, Chapter 6 and Chapter 7 covers the case study, that was used to demonstrate the model. The City of Portland, OR was used as a case study, since this city is currently one of the leading cities in the USA in regards of smart city initiatives. 
Finally, Chapters 8,9 , and 10 go through a discussion of the results of the research and its validity, as well as, how this research outcome is beneficial and what are its academic contribution to the body of knowledge. 


\section{CHAPTER 2: LITERATURE REVIEW}

\subsection{Big Data}

\subsubsection{Definition}

The roots of big data can be traced back to the late 1980s when the term business intelligence became known. According to Davenport (2006), "business intelligence ... encompasses a wide array of processes and software used to collect, analyze, and disseminate data, all in the interests of better decision making." Also, as more advances were achieved in computer hardware capabilities and capacity, telecommunications, and data storage and mining, the term business analytics emerged in the 2000 s, where software tools start doing more complex operations including predictive analysis and future planning (Bartlett 2013). Leading to the emerging of the big data term in the late 2000s, were far huge influx of datasets of different sources and structures, or no structure for that matter, are now being aggregated, processed, and analyzed, using far more complex processes and techniques, to achieve better decision making (Ransbotham 2016; Chen et al. 2012; McAfee et al. 2012). In fact; Mayer-schönberger and Cukier (2014) argue that big data is making a shift in the way we analyze phenomena, as big data scan and process all the data related to a phenomenon from multiple sources, instead of just samples, and also deals with types of data that are not readily accessible for current methods of analysis, like social media content for example, that has no clear structure and has a sentimental value in the same time, allowing for new ways of analysis based on correlation rather than causation. 
The literature review of academia, business, and IT vendors publications revealed that there are several definitions of big data. Most of the definitions fall under one of the following categories: big data as an entity, big data as a process, and big data analytics (Barham 2017; Ransbotham and Kiron 2017; Bean 2016; IBM 2016b; Oracle 2016; Rajaraman 2016; Tsai et al. 2016; Marr 2015b; Narayanan 2014; Stubbs 2014; Arthur 2013; Chen et al. 2012; Dumbill 2012; Parise et al. 2012; LaValle et al. 2011; Laney 2001). Following is an overview of each category:

Big data as an entity: Refers to data that cannot be handled (i.e., capturing, storing, and handling) by traditional analytical approaches, due to its volume, velocity, and variety, or what Lany called the 3V's (2001). Over the years, more V's were introduced and become widely accepted, including veracity, and value. Following is a review of the most common V's (Bean 2016; Tsai et al. 2016; Marr 2015b; Zikopoulos and Eaton 2012; Laney 2001):

- Volume: is the most known attribute of big data, it is referring to the massive amount of the data being generated and is relevant to any subject, organization, or individual being analyzed. It is worth mentioning here that data coming from unstructured sources such as social media, internet logs, and internet-of-things devices are far more tremendous than data coming from traditional structured sources such as an ERP system.

- Velocity: The rate of receiving the data and when we need to act upon it.

- Variety: data about any subject, organization, or individual is now being generated from multiple sources, including unstructured data that usually comes 
from sources like social media, web behavior logs, and internet-of-things (IoT) devices. The challenge is how to understand data meaning and correctly identify related metadata, as well as, how to integrate and aggregate data coming from different sources.

- Veracity: How reliable the data is, especially data coming from sources like social media or Wikipedia, where anybody could post anything without much validation or review, making such sources, in many cases, generators of fake facts and news.

- Value: Data has an intrinsic value embedded in it. The challenge is how to reveal such value and build on it to offer the right information to decision makers. There are several stages under big data to extract value from data including discover, ingest, process, persist, integrate, analyze, and expose.

- More V's: According to Firican (2017) other V's are introduced, representing more detailed focus areas under the original V's, including visualization, variability, validity, vulnerability, volatility,

Big data as a process: To make the right decision, the decision maker needs the right information at the right time. Organizations collect/generate data from various sources, they collect more than what they know about or can process. So, big data aim is to take a holistic information management approach to consume and integrate data, whether the data is structured (e.g., transactional records) or unstructured (e.g., social media and web behaviors) from multiple internal and external sources. Then, identifies relations among them, and creates insights that allow for sophisticated analysis and future predictions, which ultimately will result in higher probability of making the right decision, and hence 
leapfrog competitors and lead the market, Figure 3 demonstrates the workflow of data in a typical big data system (Shapiro 2018; Barham 2017; Bean 2016; Erevelles 2016; García et al. 2016; IBM 2016b; Oracle 2016; Stubbs 2014; LaValle et al. 2011).

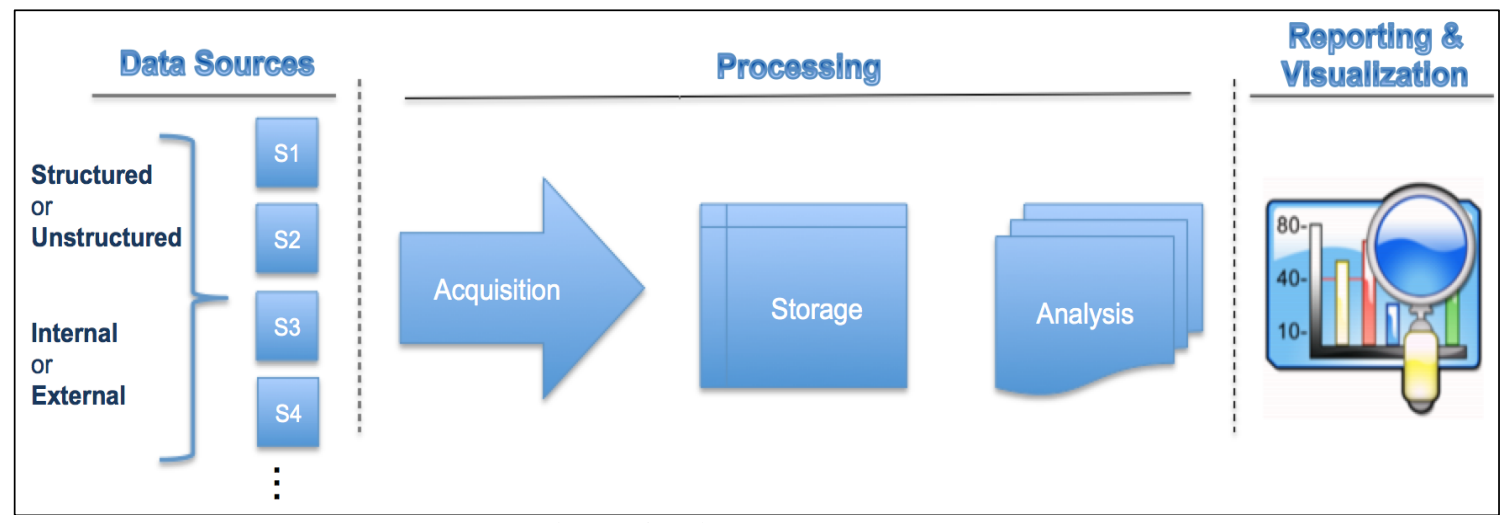

Figure 3. Big Data as a Process

Big-data-as-a-process offers viable ways to handle big-data-as-an-entity, by leveraging on advances in scaling-up technologies, that can orchestrate a cluster of inexpensive processors to work in parallel to perform the extracting, processing, and analyzing tasks, as well as, to store the data in distributed storage units using formats that can handle unstructured data properly. There are many technologies behind Big-data-as-a-process, examples include Apache Hadoop, MapReduce, NoSQL, Apache HDSF, in-memory database and so on (Rajaraman 2016; Chen and Zhang 2014; Zikopoulos and Eaton 2012).

Big data analytics: Big data analytics is the modern advanced version of business intelligence (BI), it offers the ability to apply advanced analytical techniques on big data (data that has massive volume, being generated frequently, and comes from various sources). Big data analytics shift the analysis focus from hindsight-analysis of what 
already happened (for example, last year sales statistics), and insight-analysis of why it happened (for example, why are we losing sales), towards a more advanced foresightanalysis of what will happen next and how can we benefit from it (for example, how can we leverage future events to generate more revenue in coming years) as illustrated in Figure 4. However, this is not a linear path; trying to become more analytically advanced and moving from hindsight to foresight is very difficult and few organizations were able to achieve that (Ransbotham and Kiron 2017; Sivarajah et al. 2017; Suthaharan 2016; Tsai et al. 2016; Niemeijer 2014; LaValle et al. 2011; Russom 2011).

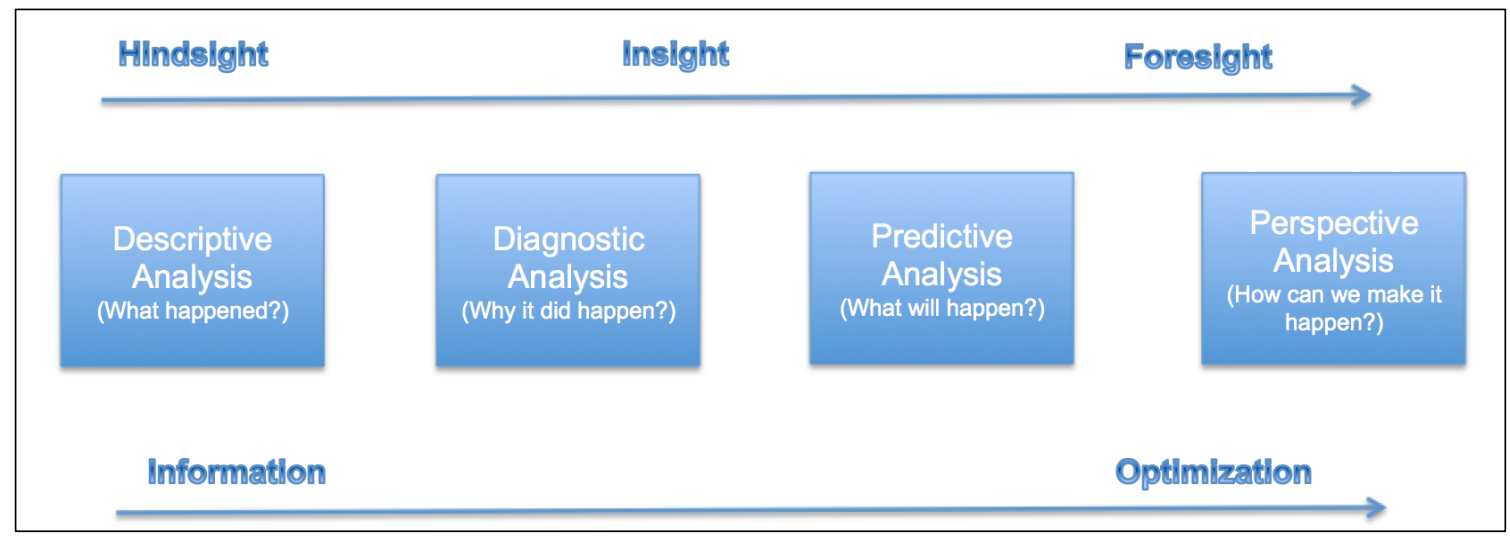

Figure 4. Big Data Analytics

According to a study conducted by LaValle et al. (2011), organizations can be classified, based on the level of big data maturity and the use of analytics in making decisions, into three categories:

Aspirational: Organizations in this category have minimum big data adoption, and their information technology focus is more on automation and efficiency.

Experienced: Organizations in this category have already achieved automation and have efficient processes in place, and now they are going beyond the use of information 
technology to aid operations, by injecting some analytics processes and tools to aid in making some decisions.

Transformed: Organizations in this category have implemented analytical processes and tools to support most of the decisions making processes in the organization, on the strategic and operational levels.

The same study found out that transformed organizations are three times more likely to outperform competitors than aspirational organizations.

\subsubsection{Big Data Benefits and Value}

A report by Data Science (Swanson 2017) indicated that organizations, which adopted big data, has seen $41 \%$ improved customer experience, and $38 \%$ better business decisions. Furthermore, A recent report by Harvard Business Review (Bock 2017) indicated that organizations with advanced big data and data analytics capabilities, called "Digital Leaders" by the report, are 2.6x more likely to prescribe business actions to limit customer churn, are $1.5 \mathrm{x}$ more likely to optimize production runs based on demand forecast, and are $2.3 \mathrm{x}$ more likely to inform product design by capturing data on how their products are used in comparison to competition. Moreover, another study by Keystone Strategy (Iansiti and Lakhani 2016) showed that organizations that utilize big data analytics have $18 \%$ higher gross margins $4 \%$ higher operating margins than competitors.

There is a lot of discussion in the literature about how big data can generate benefits for organizations against competitors, and this section summaries the main points that many literature references agreed on (Barham 2017; Bock et al. 2017; Ransbotham 
and Kiron 2017; Flood et al. 2016; Lim 2015; Tan et al. 2015; Nasser and Tariq 2015;

Columbus 2014; Guangting and Junxuan 2014; Prescott 2014; Bell and Zaric 2013; McAfee et al. 2012; McGuire et al. 2012).

Mainly, big data enables effective data analytics by aggregating data from various internal and external sources, and then it applies data analytics to it to discover relations and hidden information, that otherwise would not be found, this will allow for many benefits, including:

- First and foremost, increasing decision maker's chances of making the right decision at the right time. For example, in a commodity market like personal hygiene, big data can get and analyze consumers' behavior and feedback momentary, allowing the organization to make small changes to its products, as soon as possible, and before competitors realize that there is a shift in the market or new need, which is usually a small window in such markets. Another example, in the aviation sector, an airline can use big data to look for historical destinations demand, current economic status, weather forecasts, and social media feedback to predict which destinations are expected to be more utilized in the near future, and hence, run more trips or use bigger planes for those destinations. Also, big data can allow consumers to make better decisions; for example, a patient can compare the efficiency of alternative drugs that treat her illness, not just in general, but also, for patients who are similar to her age, race, and gender, among other factors.

- Doing better risk management: By running robust and quick future predictive scenario analysis. For example, an oil company can use big data to generate future scenarios depending on current production rates, market demand, historical price trends, and other factors, to predict future oil prices for better budget and financial forecasting. 
- More accurately identifying narrow market segments and niches: Which will allow for quicker response to such market's needs. For example, big data could reveal that senior citizens in a particular city, spend more time in their backyards planting vegetables, instead of the general flowers trend common in other cities, and hence correctly targeting this market segment needs.

- Better follow up and monitor of products: Big data can tell organizations immediately about defects and new uses of their products, as soon as that happened in the market. For example, a pharmaceutical company could use big data to analyze the feedback on a recently launched drug and find out new side effects, bad or good, that were not known at the pre-launch trials.

- Detecting frauds and act on it immediately: For example, banks can use big data to detect transactions abnormality that might be a result of stolen bank accounts, or better analyze loans risks and hence make better lending decisions.

- More efficient production processes: Big data can pinpoint where waste is being generated, delays are happening, or high costs are incurred in a production process, allowing management to address those areas and increase the production efficiency. For example, a giant manufacturer with multi factories in several countries can find in real time, which factory is generating more cost, which part of its process in all factories generates more waste, and which raw materials cost more in each country where the factories are.

\subsection{Smart City}

Urban areas are changing due to the unprecedented advances in information and communication technology applications used within those areas. Such applications are used to automate services related to city planning and management, infrastructure, and people, with the focus on improving services offered by cities, quality of life for citizens, 
and cities resiliency against urban changes (Castelnovo et al. 2016; Meijer and Bolivar 2013; Batty et al. 2012).

\subsubsection{Definition}

The term smart city is fuzzy and has several definitions in the literature. Most definitions focus on features and dimensions or perspectives and aspects (Castelnovo et al. 2016; Al Nuaimi et al. 2015; Meijer and Bolivar 2013; Batty et al. 2012; Tranos and Gertner 2012). A concise but comprehensive definition of smart-city by Harrison et al. $(2010,1)$ is: "connecting the physical infrastructure, the IT infrastructure, the social infrastructure, and the business infrastructure to leverage the collective intelligence of the city.” Another definition by Caragliu et al. (2011:70) is: ‘... [A] city to be smart when investments in human and social capital and traditional (transport) and modern (ICT) communication infrastructure fuel sustainable economic growth and a high quality of life, with a wise management of natural resources, through participatory governance.'

Across the globe, cities are adopting smart-city initiatives, to achieve several goals. These goals include, enhancing the quality of life for the city's citizens and visitors, increase the efficiency of infrastructure usage, making city's essential resources, like water, electricity, and mobility infrastructure more sustainable for future generations, making city's services more equitable, and to have more resilience by being able to quickly identify emerging problems within the city, and respond to them effectively (Belanche 2016; Puiu 2016; Al Nuaimi et al. 2015; Batty et al. 2012; Caragliu 2011). However, smart city initiatives face the same challenges mentioned in "2.6 Big Data Adoption Challenges" section, as well as, other challenges like the need to update 
regulations and policies to enable smart-city, and the infrastructure investment high cost to enable and maintain many of the crucial smart city components (Al Nuaimi et al. 2015; Kramers et al. 2015; Neirotti 2014).

According to Batty et al. (2012), cities can be smart by leveraging on the massive amount of operational data being generated from city infrastructure, by urban applications of technology and communications. This data to be further used by cities to monitor, understand, analyze, and plan for the services offered by the city, to make the services more efficient and effective, while offering better equity and quality of life for the city citizens. Furthermore, it is common for cities to have data from its infrastructure that is being generated by separated technologies, as each of those technologies is focused on the particular area of infrastructure it serves. So, in a smart-city, this data can be integrated and combined to address big-picture issues across all sectors within the city (Batty et al. 2014; Caragliu 2011; Harrison et al. 2010).

To achieve these goals, smart city initiatives aim at integrating the city's infrastructure data to be more effective in offering insights that can allow decision makers to make better decisions that can enhance the quality of life of citizens while making optimal use of the city's infrastructure. As well as, to identify emerging problems early, or before they even become problems, and proactively address them (Batty 2013).

\subsubsection{Smart-City Categories}

Smart city initiatives cover several areas of interest, or categories, in urban setups including infrastructure, people, and planning and management. By leveraging insights from related collected and integrated data, following is an overview of the city main 
challenges under those categories that smart-city initiatives are targeting: (Chowdhury and Dey 2016; Fitzgerald 2016; Al Nuaimi et al. 2015; Schuurman et al. 2012;

Dimitrakopoulos and Demestichas 2010; Harrison et al. 2010)

Infrastructure: Addressing transportation traffic jams, shortage of parking lots, and time-wastage on the road, also, the related environmental impact of vehicles spending more time on the road due to those issues. As well as, creating an efficient, clean, cheap, sustainable, and steady stream of energy and water.

People: Offering cheap, high quality, and individually customized health care, education, and social programs for the city's citizens while maintaining equity and more effectively addressing the needs of the underserved neighborhoods.

Planning and Management: Smart city aim to leverage data to improve government administration, city planning and operations, buildings, and public safety.

\subsubsection{Smart-City and Big Data}

Big data is in the heart of what makes smart cities truly smart cities (Lim et al. 2018); big data is used to enhance the infrastructure operation management by analyzing data to offer better insights and understanding of those operations. For example, using traffic data, from sensors and vehicle tracking devices, to analyze traffic demand that can be used for optimal configuration of traffic lights. Moreover, big data can be used to address the city's challenges. For example, reducing crime rates by taking proactive measures, through analyzing crime patterns and locations to predict future crime locations, and hence, more efficient allocation of policing resources in those locations. Another example is intelligent navigation, by utilizing feedback from traffic sensors, 
navigation application like google maps (trip time by others who previously went to the same destination at the same time of the day), weather data, reported accidents, public transit data, and so on, to determine the best route to reach the required destination. Fleet management is another example, where IoT devices attached to trucks can generate detailed data about trips that can be used to influence driver's behavior, for more efficient use of fleet trucks. Furthermore, big data allows for the customization of services to address individual needs. For example, people who have certain respiratory conditions can get alerts, on the spot, when certain areas of the city have dangerous levels of pollution (Lim et al. 2018; Hashem 2016; Maglio and Lim 2016; Puiu 2016; Al Nuaimi et al. 2015; Kitchin 2014; Batty 2013; Khan et al. 2013).

Many big data-based solutions that are already implemented or actively being developed to enable smart-city. Examples include smart grid, intelligent transportation systems, smart education, smart healthcare systems, and smart safety systems, to name few (Lim et al. 2018; Hashem 2016; Maglio and Lim 2016; Puiu 2016).

\subsection{Intelligent Transportation Systems}

Intelligent transportation systems (ITS) is a growing technology sector as part of smart cities. According to some industry analysts, it is expanding at a $13 \%$ rate annually and is expected to reach $\$ 47.5$ billion by 2020 (Global Market Insights 2016). ITS is becoming popular as it holds the promise of solving key modern traffic challenges, including safety, congestions, and pollution by leveraging on advancements in information and communications technologies (Moral-Munoz 2016; Lim et al. 2015; Dimitrakopoulos and Demestichas 2010). 
The demand for transportation is continuously increasing due to increased human population and the accompanying mobility needs, which is further fueled by transportation becoming more affordable in recent decades. In the same time, the expansion of transportation infrastructure to meet this demand is not sufficient as adding more infrastructure capacity is expensive and requires time. This led to several problems, including increased traffic incidents, time wastage on the road, pollution, and economic losses. In the United States, for example, there are more than 6 million traffic accidents annually, including fatality accidents that kill more than 30 thousand people (DOT 2016). Also, every year, time wastage due to road congestion results in 1.9 billion gallons of wasted fuel and more than $\$ 100$ billion in economic costs, due to time loss and fuel bills. In fact, it is estimated that about 4.8 billion hours are being lost annually on the roads in the United States (FHWA 2017; US Census Bureau 2017; DOT 2016; Thomopoulos and Givoni 2015; Dimitrakopoulos and Demestichas 2010).

\subsubsection{Definition}

ITS refers to the application of advanced information and communications technology to surface transportation in order to achieve enhanced safety and mobility while reducing the environmental impact of transportation (DOT 2017). ITS is used to manage the traffic and to influence driving decisions and behaviors by utilizing cognitive networking principles and data analytics to creates management mechanisms with learning capabilities (Chowdhury and Dey 2016; Saito 2016; Dimitrakopoulos and Demestichas 2010). 
ITS uses information and communication technologies to collect and analyze the traffic data. Traffic data is broadcasted by sensors and computing capabilities embedded in vehicles and road elements. Also, traffic data are generated from interactions among vehicles and between vehicles and the transportation infrastructure. This data is captured and analyzed by ITS to generate analytics that can be used to manage traffic and advise drivers on better driving decisions (Chowdhury and Dey 2016; Yu 2016; US Government Accountability Office 2015; Joseph et al. 2006; Weiland and Purser 2000).

It is worth mentioning here that wireless communication technologies are the backbone of ITS technologies, ITS significantly benefited from the recent advances in wireless communication technologies since leverage on different types of wireless communication technologies to read and report traffic data, to further enable cooperative systems and dynamic data exchange using a broad range of advanced systems and technologies (Sill 2011).

ITS has several benefits (Asselin-Miller et al. 2017; Alam et al. 2016; Chowdhury and Dey 2016; Yu 2016; US Government Accountability Office 2015; Dar et al. 2010; Dimitrakopoulos and Demestichas 2010):

- Reducing time wastage on the road: ITS helps reduction traffic congestions and commute time wastage by effectively managing the traffic and guiding cars to optimal routes from source to destination based on real-time feedback on traffic and road elements conditions.

- Increasing safety: By minimizing the risk of accidents, or at least, reduce the severity of accidents using technologies like incident management and collision 
avoidance. As well as, increasing safety for pedestrians, by adding smart capabilities to vehicles to identify and avoid pedestrians.

- Reduce environment pollution: by helping reducing average traffic time, ITS helps reduce pollution as well, since vehicles will burn less fuel. Furthermore, ITS can create better environmental traffic patterns, for example, by spreading the traffic around the city and make sure vehicles, especially vehicles with diesel engines, are not condensed in certain areas and so on.

- Cost savings: less time on the road means more time to work, less time to reach clients, and of course fewer fuel costs.

- Efficient use of infrastructure: ITS manages traffic to better optimize the utilization of transportation infrastructure, which reduces the need to launch expensive and time-consuming projects to increase traffic capacities in response to increased traffic demands.

\subsubsection{Automotive Technologies Under ITS}

As explained earlier, ITS is a ubiquitous information and communication system that monitors, collects, and broadcasts data about the vehicle, as well as, connecting and facilitating communications between vehicles, between vehicles and road elements, and between vehicles and the infrastructure, while collecting and broadcasting data about those interactions. The data is then analyzed to create insights that will be used to manage the traffic and help drivers (Cheng 2015).

So, ITS consist of a wide range of technologies, from standard common technologies like ABS systems to complex centralized artificial intelligence systems 
capable of machine learning and making decisions based on traffic data to optimize the traffic. Generally, ITS technologies are grouped into three categories: within the vehicle, between vehicles, and between vehicle and infrastructure (Gaffney 2017; Cheng et al. 2015; Linkov 2015; Thomopoulos and Givoni 2015; US Government Accountability Office 2015; Youngmin et al. 2013; Fogue et al. 2012; Rooyen et al. 2011; Coelho and Rouphai 2010; Dimitrakopoulos and Demestichas 2010; Weiland and Purser 2010; Papadimitratos 2009).

- Technologies within the car itself: These technologies help reducing traffic accidents and increasing driving efficiency. Technologies within the car usually serve one or both of the following purposes: offering driving assistance to the driver by providing information about the status of the car, or even help driving the car, e.g., auto parking, also by offering passive safety against road conditions. Examples of commercially available technologies within the car include GPS based navigation, anti-lock braking, collision avoidance, objects detections, and auto braking, rear cross-traffic alerts, blind-spot monitoring, adaptive headlights, drowsiness detection, park assist (automatic, rear cameras, back sensors). Technologies within the car are the base enablers for the future autonomous driving.

- Vehicle-to-vehicle (V2V) communication technologies: Drivers typically rely on other drivers' behavior to make many driving decisions. For example, a driver deciding on whether to hit the braking pedal or accelerate the car based on tail brake light and distance of the car immediately ahead. However, this is not 
necessarily the best strategy as drivers cannot tell what is going in front of the next vehicle ahead and might not react to emergencies fast enough [26]. V2V technologies address this issue by using sensors feedback to identify and analyze the current situation around the vehicle and then to disseminate safety messages to nearby vehicles by leveraging on vehicular ad-hoc networks (VANETs). So, drivers can respond to emerging situations properly and at the right time.

- Vehicle-to-infrastructure (V2I) communication technologies: technologies that gather data generated by vehicles and road elements, mainly from sensors, and broadcast it to a central location. Then the data is merged with pre-existing information about the road and is analyzed to draw the big-picture view of the road and its conditions, and generate information and suggestions to drivers in real time. Such information and suggestions could be as simple as notifying drivers about an accident or traffic jam ahead of the road and suggest alternative routes. To more sophisticated directives and behavior, suggestions aim at more efficient use of roads to reduce time on the road, in general, across a city, as well as, to reduce the environmental impact of transportation. 


\subsection{Readiness Assessment}

US Dept. of Health and Human Resources defines readiness assessment as:

"Measuring readiness is a systematic analysis of an organization's ability to undertake a transformational process or change. A readiness assessment identifies the potential challenges that might arise when implementing new procedures, structures, and processes within a current organizational context” (HRSA 2018).

One known method to assess technology readiness, that was developed by NASA in the mid-1970s and was extended in the mid-1990s, is Technology Readiness Assessment (TRA). TRA identify 9 levels of maturity that R\&D programs can use to assess the readiness level of a technology being developed. This method looks for several technology and non-technology factors to determine the maturity level of a technology, and whether it is ready to be transferred to the next step in technology development life cycle (Mankins 1995; Mankins 2009).

It can be seen from HRSA definition of readiness assessment, and other discussion about technology readiness in literature, that the emphasis is on the concept that there are multiple internal and external challenges or factors affecting the readiness of a technology and must be assessed to identify the maturity and readiness of a technology (HRSA 2018; Lavoie \& Daim 2018; GAO. 2016; DoD 2011; Razmi et al. 2009; Al-Omari and Al-Omari 2006; Snyder-Halpern 2001; Parasuraman 2000). The discussion about readiness in other disciplines also points to assessing current status against internal and external factors to determine readiness level. For example, children readiness to go to school (Maxwell and Clifford 2004). Another example is patient 
readiness to be discharged from hospital (Titler and Pettit 1995). Another example is organization readiness for knowledge management (Mohammadi et al. 2009).

Based on the above discussion, readiness assessment within the context of this research points to the process of conducting a systematic analysis of a particular city's ability to carry a particular smart-city-related big data project, by evaluating that city's current capabilities against the needs of that project, with reference to a list of internal and external factors that are known to be critical to the success of this type of projects. The ultimate goal is to increase chances of successful smart-city-related big data project implementation, by identifying and properly addressing the sources of weaknesses in the city's capabilities that otherwise, would most likely hinder the upcoming project. 


\subsection{Project Management}

\subsubsection{Definition}

Project management is a widespread discipline that gains popularity in recent decades. Project management as a practice has several definitions, one common definition is by Olsen (1971): "Project Management is the application of a collection of tools and techniques (such as the CPM and matrix organization) to direct the use of diverse resources toward the accomplishment of a unique, complex, one-time task within time, cost and quality constraints. Each task requires a particular mix of these tools and techniques structured to fit the task environment and life cycle (from conception to completion) of the task." Project Management Institute (PMI), stressed on the temporary and unique nature of projects and identified five process groups under project management: initiating, planning, executing, monitoring and controlling, and closing. PMI also identified ten knowledge areas that project management draw from integration, scope, time, cost, quality, procurement, human resources, communications, risk management, and stakeholder management (PMI, 2017). Initially, project management focus was mainly on the triple constraints of scope, time, and cost. However, a gradual interest, in the last two decades, was shifted toward quality, risk, and resources, with an overall focus on how to generate value to the customer, instead of being rigidly constrained by the triple constraint (Meredith 2017; Schwalbe 2015; Kerzner 2013; Cobb 2011; Atkinson 1999). 


\subsubsection{Big Data Projects}

In this research, the focus is on big data projects. Based on the above definitions, big data projects are projects that aim at creating or enhancing organizational big data analytical capabilities, by building information management systems that will acquire

data, cleanse it, reformat it, and store it, such data would be coming from various resources. As well as, building analytical tools to offer insights based on the acquired data.

\subsubsection{Readiness Assessment Phase}

This research is focusing on the phase between project selection and project management. The project selection process includes identifying potential projects that can support organizational strategic objectives, conducting a feasibility study for each project, and evaluating and prioritizing the projects against the organization's current projects portfolio and selection criteria. Leading to a selection decision (Kaiser et al. 2015; Rosacker and Olson 2008; Stoemmer 2006).

So, this research is focusing on the phase after the project selection phase and before the initiation phase of project management as illustrated by Figure 1 (in the section "1.1 Problem Statement"). This is an important phase, where there is a need to make sure that the organization is ready to conduct the already-selected project, and if there are any potential "showstoppers," to deal with them now before starting the actual project. 


\subsection{Critical Factors Affecting Big Data Projects}

According to a recent study by NewVantage Partners (NewVantage Partners 2017), more than $50 \%$ of big data projects fail. Many researchers addressed big data projects failure phenomenon. Mainly, investigating the reasons behind big data projects tend to fail. The literature includes research related to what kind of challenges are particular to big data projects and big data adoption within organizations. Many big data projects never completed or did not generate the expected outcome, causing severe impact on the organization; due to the high cost of obtaining and running big data systems, the time-waste of personnel assigned to work on these projects (usually the best in the organization), and the competitive disadvantage of not having big data analytics, while competitors do. The following references are samples from literature about research done around the challenges of big data (NewVantage Partners 2017;

Ransbotham and Kiron 2017; Saltz and Shamshurin 2016; Ransbotham 2016; Angrave et al. 2016; Bean 2016; Iron Mountain 2015; Thabet and Soomro 2015; Buckley 2015; Nasser and Tariq 2015; Mayer-Schönberger and Cukier 2014; Chen et al. 2014; Katal et al. 2013; Chiolero 2013; McAfee et al. 2012; LaValle 2011).

Web of Science engine (https://webofknowledge.com) was used for an overview of literature related to big data. As illustrated by Figure 5a, the Web of Science engine indicated that there is enormous research related to big data in recent years. Furthermore, Web of Science engine search results for the keywords "big data challenge" show that a decent number of big data research is about its challenges, almost $25 \%$ in the last three years, as illustrated by Figure 5b. However, most of this research is about challenges that 
big data can address, as the number of research related to "big data adopt" is meager in compare, as illustrated by Figure 5c. Moreover, when searching the keywords "big data evaluate readiness," the results were minimal; it included only ten papers in the last ten years, and the search by the keywords "big data assessment readiness" produced even fewer results, as illustrated by Figure 5d and Figure 5e. Moreover, only two of those papers were indeed related to big data readiness (Klievink et al. 2017; Olama et al. 2014). The rest of the papers were about using big data to evaluate the readiness of other applications and programs. Google Scholar search with the same keywords did only reveal one extra paper (Lam et al. 2017).

\begin{tabular}{|c|c|c|c|}
\hline 2008 & 1261 & $2.559 \%$ & $\square$ \\
\hline 2009 & 1461 & $2.965 \%$ & $\square$ \\
\hline 2010 & 1581 & $3.208 \%$ & $\square$ \\
2011 & 1647 & $3.342 \%$ & $\square$ \\
2012 & 2046 & $4.152 \%$ & $\square$ \\
2013 & 3395 & $6.890 \%$ & $\square$ \\
\hline 2014 & 5349 & $10.855 \%$ & $\square$ \\
\hline 2015 & 8608 & $17.469 \%$ & \\
\hline 2016 & 10994 & $22.311 \%$ & \\
\hline 2017 & 6932 & $14.067 \%$ & \\
\hline
\end{tabular}

Figure 5a. Web of Science Search Results for the Key Words: big data

\begin{tabular}{|c|c|c|c|}
\hline 2008 & 127 & $1.419 \%$ & I \\
\hline 2009 & 156 & $1.743 \%$ & $\|$ \\
\hline 2010 & 174 & $1.945 \%$ & $\|$ \\
2011 & 186 & $2.079 \%$ & $\|$ \\
\hline 2012 & 285 & $3.185 \%$ & \\
2013 & 625 & $6.985 \%$ & $\square$ \\
\hline 2014 & 1133 & $12.662 \%$ & \\
\hline 2015 & 1963 & $21.938 \%$ & \\
\hline 2016 & 2459 & $27.481 \%$ & \\
\hline 2017 & 1535 & $17.155 \%$ & \\
\hline
\end{tabular}

Figure $5 \mathrm{~b}$. Web of Science Search Results for the Key Words: big data challenge 


\begin{tabular}{|r|c|c|c|}
\hline 2010 & 2 & $0.213 \%$ & I \\
\hline 2011 & 3 & $0.320 \%$ & I \\
\hline 2012 & 12 & $1.279 \%$ & I \\
\hline 2013 & 52 & $5.544 \%$ & $\square$ \\
2014 & 98 & $10.448 \%$ & \\
\hline 2015 & 211 & $22.495 \%$ & \\
\hline 2016 & 295 & $31.450 \%$ & \\
\hline 2017 & 241 & $25.693 \%$ & \\
\hline
\end{tabular}

Figure 5c. Web of Science Search Results for the Key Words: big data adopt

\begin{tabular}{|c|c|c|c|}
\hline 2011 & 1 & $7.692 \%$ & \\
\hline 2013 & 2 & $15.385 \%$ & \\
\hline 2014 & 3 & $23.077 \%$ & \\
\hline 2015 & 1 & $7.692 \%$ & \\
\hline 2016 & 3 & $23.077 \%$ & \\
\hline 2017 & 1 & $7.692 \%$ & \\
\hline
\end{tabular}

Figure 5d. Web of Science Search Results for the Key Words: big data evaluate readiness

\begin{tabular}{|lll|l|}
\hline 2014 & 2 & $28.571 \%$ & \\
\hline 2015 & 2 & $28.571 \%$ & \\
\hline 2016 & 1 & $14.286 \%$ & \\
\hline 2017 & 2 & $28.571 \%$ & \\
\hline
\end{tabular}

Figure 5e. Web of Science Search Results for the Key Words: big data assessment readiness

For the papers related to big data readiness evaluation: Klievink et al. (2017) suggested a framework to evaluate public organizations' big data readiness based on three categories: Organizational capabilities, Organizational alignment, and organizational maturity. On each of those categories an assessment of 5 points from " 1 : Very Low" to "5: Very High" was suggested based on assessing the public organization's current status against a set of big data challenges under each of those categories. Then the 
scores are to be aggregated for an overall score between 3 and 15 . The authors suggested that this framework can be used to rank public organizations against each other, for benchmarking, as well as, to identify weak areas that need improvements before starting a big data project. In the (Olama et al.2014) paper, the authors focused on the data integration phase of big data (big data as a process). The paper introduced an Integration Level Model (ILM) to measure how mature is the organization and its datasets against various levels of data integration by assessing data governance within the organization. The ILM tool can be used to score nine organizational functions related to data integration to identify organizational readiness and areas that need improvement. Finally, in the (Lam et al. 2017) paper, the focus was about the relation between front-end users' small data and the big data of the organization, and how to make sure that the small data generated by front-end users is being effectively captured for the needs of organization's big data analytics. The authors offered a framework based on absorptive capacity and knowledge management theories, which can be used to assess and enhance the capturing of these small data.

While there is not much literature about big data readiness evaluation or assessment, there is still an enormous amount of research about big data challenges, as illustrated by Figure 5b. Most of this literature can be categorized into the following:

- Surveys: Several papers conducted surveys targeting CEOs and high-ranking executives of organizations from several industries and with varying sizes. Other surveys targeted practitioners from the information technology industry. Surveys main target is to identify the most significant challenges facing big data adoption, 
and then offer discussion on how to overcome those challenges. Following are some examples: (Shapiro 2018; Bock et al. 2017; NewVantage Partners 2017; Ransbotham and Kiron 2017; Bean 2016; Flood et al. 2016; Buckley 2015; Burrows and Savage 2014; Chen 2104; Chen and Zhang 2014; LaValle et al. 2010).

- Literature review: Papers in this category investigated the challenges of big data by identifying patterns of challenges discussed in other academic papers, books, and IT vendors' publications. Some of the papers investigated factors influencing the successful adoption of big data, which complement the challenges discussion. Papers that are based on a literature review usually include discussion and recommendations about the reasons behind those challenged and how to overcome them based on the authors' academic background. Following are some examples: (Bertino and Ferrari 2018; Adrian et al. 2017; Barham 2017; Carillo 2017; Nunan and Domenico 2017; Sivarajah et al. 2017; Flood et al. 2016; Thabet and Soomro 2015; Saltz and Shamshurin 2016; Ebner et al. 2014; Philip Chen and Zhang 2014; Adrian 2013; Kaisler et al. 2013; Katal et al. 2013; Boyd and Crawford 2012).

- Talking to experts or using personal experience: Literature in this category is based on "fieldwork." It describes challenges related to big data based on discussion/interviews with experts in the field or based on the authors' personal experience doing big data projects. This kind of research is usually combined with a literature review to bolster the findings and prove that the findings have a degree 
of generalization. Following are some examples: (DalleMule and Davenport 2017; Lam et al. 2017; Angrave et al. 2016; Bughin 2016; Ransbotham 2016; Marr 2015b; Tallon 2013; Bartlett 2013; Berman 2013; Brown and Willmott 2013; Chiolero 2013; Labrinidis and Jagadish 2012).

- Case Studies: This kind of papers will investigate a particular case study and use it to draw conclusions and recommendations on what are big data challenges and how to handle them. Following are some examples: (Klievink et al. 2017; Fitzgerald 2016; Lim et al. 2015; Laurila et al. 2012).

Finally, few papers tried to categories the challenges facing big data projects, but those papers did not try to quantify or qualify the relation among those factors and how important each of them in comparison with the others. Following are some examples: (O’Halloran et al. 2018; Adrian et al. 2017; Sivarajah 2016).

Following is a review of some of the most common factors that influence the likelihood of implementing a big data project successfully, as indicated by the literature review. They are divided into four perspectives: Personal, Technical, Political, and Management.

\subsubsection{People Perspective}

This perspective covers people-oriented factors that affect big data projects. Data Scientists: Data scientists are the minds that can realize what type, size, and frequency of data need to be captured; they devise the predictive analysis algorithms that maximize data value, with realization of organizational goals, as well as, internal and external factors around the organization. According to IBM (2016b): "Good data 
scientists will not just address business problems, they will pick the right problems that have the most value to the organization." However, the problem is, there is a shortage of such smart people globally (Ransbotham and Kiron 2018; Shapiro 2018; Carillo 2017; Strawn 2016; Davenport and Patil 2012; McGuire 2012; Manyika et al. 2011).

Employees' Technological Skills: The skills of other employees are also important for the success of big data projects. They play a significant role in pushing and pulling data into and from the system. Employees who do not feed correct data, or data at all, to related systems, will cause analytics based on those systems data to generate results that are inaccurate and misleading (Carillo 2017; Lam et al. 2017; Stubbs 2014; Kwon et al. 2014; Brown et al. 2013; McAfee et al. 2012; LaValle et al. 2011; LaValle et al. 2010). Public Acceptance: This factor considers whether the public will perceive the upcoming project as a "good" project. And would the project be negatively or positively impacted by the potential public perception. Privacy is a major issue in regard to this factor, when the public perceive a smart-city-related big data project as violating their privacy and is meant to spy on them, the project will face resistance. There is a need to be transparent and create awareness among the public to gain their trust and support for the upcoming project (Dabab et al. 2018; Roh 2017; Van Staa et al. 2016; Bright and Margetts 2016; Van Dijck 2014).

Management's Analytical Skills: Management should have a minimum level of analytical skills to be able to use and make sense of the analytics generated by big data systems. However, big data analytics requires a long learning curve from nontechnology-background managers. The managers, who have limited analytical skills, 
would probably find it challenging to use big data system's analytical capabilities, and as a results, would be alienated from utilizing it to make decisions, making that system useless (Carillo 2017; Lam et al. 2017; Stubbs 2014; Kwon et al. 2014; Brown et al. 2013; McAfee et al. 2012; LaValle et al. 2011; LaValle et al. 2010).

\subsubsection{Technology Perspective}

There are several technical challenges that are unique to big data projects due to the nature of big data itself, and its characteristics (volume, velocity, variety, value, and so on.).

Data Integration Complexities: For big data to generate real value, it must consume data from many sources and aggregate it to generate new unseen values. However, different data sources have a different data structure or even do not have structure at all, as well as, different storage mechanisms, making the integration of such data and make it available as a single, uniformed entity ready for analysis a non-trivial task. For example, a system might use metric units while another system that has additional related data is using imperial units, and the data is linked to user tweets were some of them would not use measurement units at all, but rather, statements like "very large" or "very huge." Furthermore, real-world databases that exist for some time, tend to have data that is noisy, inconsistent, and incomplete, so; there is a need for data integration and cleansing processes that can remove the noise and the inconsistency. Another data integration challenge comes from social media and online feedback forums, where data have a sentimental dimension that is difficult to be measured. For example, if somebody commented on a company's product saying "great!" this user might be sarcastic, and he 
meant the opposite (Lim et al. 2018; Ransbotham and Kiron 2018; Ransbotham 2016; Chen and Zhang 2014; Kadadi et al. 2014; Jagadish et al. 2014; Mayer-Schönberger and Cukier 2013).

Data Availability: Availability refers to a system's data, software, and even hardware resources being accessible when needed by the authorized individuals, even if there is a security breach or technical problems. The related challenge facing many big data projects is whether the data coming from various sources can be accessed in a timely manner to make meaningful results. From a technical perspective, the data volume and velocity, for each source of data can affect its timely accessibility. Thus, hindering the effectiveness of the analytics (Jernigan et al. 2016; Chen et al. 2014; Jagadish et al. 2014; Laurila et al. 2012; Zikopoulos and Eaton 2012).

What Data to Collect: Big data aims at discovering hidden values in large rapidly changing sets of data coming from multiple sources. But, this task is really tricky, getting and trying to aggregate all the available data means time and resources costs, however; capturing minimal amount of data, could mean losing hidden values that were not known before it was captured (Ebner et al. 2014; John Walker 2014; Adrian 2013; MayerSchönberger and Cukier 2013).

Technology Solutions Complexities: In big data projects, the goal the project is trying to achieve and the nature and sources of data related to the project dictate what type of tools needed. When the mix includes several tools, the probability of incompatibility becomes higher leading to software bugs and technical issues, not to mention the challenge of 
finding software engineers that are experts in all the tools needed (Lim et al. 2018; Jernigan et al. 2016; Jagadish et al. 2014; Berman 2013; Kaisler et al. 2013).

\subsubsection{Legal Perspective}

There are particular legal and somewhat political factors that, if not appropriately addressed, might undermine any project in general. Following factors have high impact when it comes to big data projects. These factors are external environment issues, mainly due to data being owned and managed by different external entities, as well as, affecting external entities (Kaisler et al. 2013). These factors need to be handled through negotiation and consideration for external parties' needs.

External Sources of Data: An important aspect that affects big data ability to offer real value is getting data from different internal and external sources. So, to gain access to external sources of data, including, data available at clients, suppliers, and other entity ends, organizations depend on other entities willing to share their data. Organization's management should negotiate with those entities to get access to their data by making sure to understand their needs and concerns. The best way to get external entities to share their data is by looking for mutual benefits and creating win-win situations (Ransbotham and Kiron 2018; Jernigan et al. 2016; Mathieu 2015; Jagadish et al. 2014; Kwon et al. 2014; McAfee et al. 2012).

Data Ownership: Big data generates statistics and analyses based on data coming from internal and external sources, and that creates challenges regarding the ownership of the data and the analysis created based on it, and what degree of freedom an organization has in sharing the data. For example, can organization share analyses, including one supplier 
data, with another competing supplier? Also, who can access this information within the organization itself?

So, organizations need to balance between sharing the analysis results, in order to achieve the required goals, and avoid conflicts with data sources' owners that could result in losing access to these sources (Bertino and Ferrari 2018; Nunan and Domenico 2017; Harris 2015; Andrejevic 2014; Jagadish et al. 2014; Kaisler et al. 2013).

Data security and privacy: Even after making beneficial agreements about data ownership and sharing, organizations still face challenges related to make sure the data is secure, privacy is appropriately considered, and the way the data is being handled is not breaking any related regulations. External entities are more willing to share their data if they know that their data is well protected. Moreover, any breach in data privacy could result in legal and public image damages with severe consequences (Bertino and Ferrari 2018; Lim et al. 2018; Nunan and Domenico 2017; Etzion and Aragon-Correa 2016; Andrejevic 2014; Jagadish et al. 2014; Tallon 2013). The following resource has many known such cases (Reddy 2014).

Legislations Adaptability: This challenge is more specific to smart cities; a big data project under a smart city initiative, usually requires collecting new types of data or use data already being collected for other purposes in the city. In both cases, regulations need to be changed to allow the required capturing and manipulation of data, as well as, the dissemination of the resulting analytics and insights. A city's inability to introduce new legislation promptly to keep up with the upcoming project will lead that project to failure (Castelnovo et al. 2016; Al Nuaimi et al. 2015; Kramers et al. 2015; Neirotti 2014). 


\subsubsection{Organization Perspective}

This perspective covers what need to be considered by management to enable successful and sustainable big data adoption within organizations and overcome barriers to this adoption. Management failure to realize and act upon those issues will have a severe impact on the organization's ability to carry a successful big data project (Etzion and Aragon-Correa 2016).

Management Support: Organizational change can face many obstacles, especially by internal resistance to change. Management support is an essential driving factor to override obstacles to change. Management support also helps expedite and override any current bureaucracy that might hinder or slow the change (Burcharth et al. 2014; Katz and Allen 1982).

Big data projects often require significant internal changes, including new mechanisms of data collection and validation by employees on the frontline, as well as, new ways to do decision making based on data analytics and insights on the operational and managerial levels. Resistance to change is almost inevitable in such situations. Therefore, management support becomes crucial for these projects to be successful. Furthermore, only management can drive a cultural change from the traditional "What do we think" mentality to the big data "What do we know?" mentality. Hence, the chances of doing a successful big data project is highly affected by top management level of support and interest in the project (Ransbotham and Kiron 2018; Klievink et al. 2017; Lam et al. 2017; Etzion and Aragon-Correa 2016; Burcharth et al. 2014; McAfee et al. 
2012; LaValle et al. 2010; Young and Jordan 2008; Schneider et al. 1996; Katz and Allen 1982).

Data Strategies and Governance: Recent studies suggested that in most organizations, employees have access to data they should not, and analysts spend most of their time trying to discover and prepare data instead of doing actual analysis (DalleMule and Davenport 2017).

Organizations planning to adopt big data need to have a clear vision about the data surrounding them and is related to them and have proper strategies in addressing the data. Data strategies include identifying the sources of data clearly, what value the data have, how to collect it, who owns it, where to store it, how to handle it, how to transform it to analytics, how to share it, and how to protect it. Moreover, data can be structured or unstructured, from internal or external sources. Each of those data types has different approaches to manage it properly. Data strategies can be classified by business objectives and data types into the following categories: performance management, data exploration, social analytics, and decision science. Data strategies should also balance between flexibility and control to make sure that business needs are addressed while data is being handled in a proper manner.

Without clear data strategy, organizations run the risks of failing to identifying proper and valuable data for analytics, failing to provide analytics in timely manner, and failing to protect the privacy of individuals and entities the data represent (DalleMule and Davenport 2017; Short and Todd 2017; Ebner et al. 2014; McAfee et al. 2012; Parise et al. 2012). 
Clarity of Objectives: The overall success of any project is related to what value, the outcome of the project, delivers to the organization. So, when a project is conducted without a clear perspective on how the project is related to organizational mission and vision and how the project outcome is facilitating the achievement of organizational strategic goals, it will most probably not generate any real value to the organization, even if the project delivered on its scope, time, and budget requirements.

Unclarity regarding objectives is one of the main challenges for big data projects, due to the vagueness about what is big data and how it can help organizations. Some organizations jump into the big data train to keep up with competition and to generate a modern image around themselves. These are not sufficient reasons to do big data projects. Management, with the help of data scientists and other related stakeholders, should identify the right questions the organization need to ask concerning the challenges associated with strategic goals and operational needs, and then formulate big data project objectives that aim at delivering analytical capabilities to address those questions. As failing to do so will most likely result in a big data projects delivering an analytical system that is expensive and do not have any tangible value to the organization (Daim 2017; Klievink et al. 2017; Meredith 2017; Etzion and Aragon-Correa 2016; Marr 2015b; McAfee et al. 2012; Fenwick et al. 2009; Khan 2006; Thiry 2002). 


\subsection{Big Data Projects vs. Large-scale IT Projects in the Public Sector}

The literature review is concluded with a discussion about how big data projects are related to other types of large-scale IT projects in the public sector when it comes to project challenges.

Large-scale IT projects are projects that have two main characteristics: First, the outcome system affects/spans over several business areas or sections, whether within the organization or outside the boundaries of the organization. Second, the project has a high cost, requires a large team, or extended period (Bloch et al. 2012; Northrop et al. 2006; Vann 2004; Floricel and Miller 2001; Sumner 1999; Martinez 1994; Willcocks and Griffiths 1994).

Martinez $(1994,17)$ identified large-scale IT projects as projects that “.. [B]ig in all measurable terms. Duration is measured in years, total team size numbers in the hundreds (or more), and work effort is tracked in tens of thousands of workdays. Furthermore, large-scale projects directly affect-and significantly alter critical mainstream business functions. They, therefore, involve a broad cross-section of the business organization, uncover and address complex cross-functional issues, and fundamentally change core business operations."

Big data projects fit under this definition as they: spans multiple internal business units, as well as, external entities. They include acquiring data from multiple resources to make insights that, not only change the way decisions are made within the organization, but also have an effect on related internal and external entities. Furthermore, the technical solutions are complex, and a project to build big data capabilities usually requires 
considerable work hours to build, and engages a lot of technical and business resources, not to mention the high initial and operational cost (Chen et al. 2014; Katal et al. 2013; Tallon 2013; Zheng et al. 2013; LaValle et al. 2011).

Following is a review of some types of large-scale public IT projects, based on the author's experience and the following references (Adler-Milstein et al. 2015; Ahmadi et al. 2015; Razmi et al. 2009; Layne and Lee 2001; Sumner 1999; Cats-Baril and Thompson 1995):

ERP systems: ERP stands for enterprise resource planning. A typical ERP system covers the essential processes needed to run a business, including, but not limited to, accounting, invoicing, supply chain, inventory, HR, payroll, and customer relationship management. ERP systems are transactional based, with central DB, which links all the organizational operations together. GRP or government resource planning is a variation of ERP with more consideration to the specific characteristic of government/public organizations, like how to handle budget or how to conduct employees' evaluation. This type of systems requires changes across all sectors of the organization, usually expensive, and requires many work hours to build. Although today there are "off the shelf" ERP packages like Oracle Business Suite and SAP, however, those packages are highly general, and need considerable customization that in many cases match building from scratch.

Core Transactional Systems: Some government/public organizations require a customized type of systems to be able to offer the core services that these organizations are designated to do. Examples include Traffic management systems, called the Department of Motor Vehicles (DMV) in the USA, that covers driving licenses, motor 
vehicles, and related legal and citation services. Permits and IDs systems, systems that issue permits like business permits, building permits, visa permits, and so on, as well as, systems that issue passports, birth certificates, and other kinds of legal identification documents. Another example is public medical insurance coverage systems, similar to "Cover Oregon," that aim at offering public health insurance coverage to people. In the USA, this could mean qualified recipients and working with a middle layer of insurance providers, while in most other countries, it means all the citizens are getting services provided directly by the government.

Regardless of who is covered or how, such systems are massive, it includes acquiring data from several sources to determine the coverage level for each recipient, as well as, collecting medical records, by integrating with various types of medical service facilities and insurance companies.

A typical DMV system would cover the services provided by several departments like driving licenses and motor vehicles. It will also be used-by/integrate-with/haveimpact-on law enforcement agencies, immigration authorities, city traffic engineering departments, car rental services, insurance companies, mechanical shops, just to name few. Such systems are complex and expensive to build as they require integration with several entities. Moreover, they need to go in a big bang approach, i.e., DMV cannot start using the driving licensing part now, and add vehicle registration and traffic citations later on (it can be done, but it would be very complicated), which add even more complexity on how to do those kinds of projects. 
E-Government: Offering government/public services online is also another type of large-scale projects. In a typical e-government project, the core system that manages the organization's services will need to be rebuilt to accommodate offering the same services online. There are significant security requirements, and new workflows, as customers do not need to come to the organization anymore, so there should be a workflow management system, to make sure the service is going through the right cycle before it is completed. Furthermore, verifying customer identity and the authenticity of the supporting documents presented by the customer requires substantial software changes and integration with other entities. Overall, building complete government/public online services is complex and span multiple entities, not to mention that it is expensive and span over a long period.

Large scale IT projects, including big data projects, are characterized by high failure percent. For example, a study by NewVantage Partners (2017) found that more than half of big data projects never finish or do not deliver the expected value. Razmi et al. (2009) and Sumner (1999) indicated the same for ERP systems. In fact, a study by Mckinsey and Oxford (Bloch et al. 2012) found that 17 percent of large-scale IT projects go so bad, that they threaten the existence of the organization doing the project. Another study by Harvard Business Review (Flyvbjerg and Budzier 2011) found that a staggering $92 \%$ of large-scale IT projects in the US public sector face time and cost overruns.

As stated before, the failure of big data projects (and the large-scale IT projects for that matter) has severe consequences. Since they are expensive, require allocation of considerable resources, that would have been used elsewhere, and the project failure 
means that the organization is at a disadvantage with competitors who were able to conduct the same project successfully and now are reaping its benefits.

When comparing factors influencing big data project failure to factors affecting big data projects and large-scale IT projects (Big IT) from a public sector perspective, the factors fall into one of three categories:

- Similar to big IT completely

- Some similarity but might not have the same importance in other kinds of projects

- Unique to big data

So, while some reasons for failure and counter measurement of any big IT project fit for big data projects. However, the literature indicates that big data projects have some clearly unique challenges, as well as, challenges that are, while common to most big IT projects, is more impactful when it comes to big data projects. Table 1 presents the factors classifications, and then a discussion is offered on why each of those factors fell in a particular category. The discussion is based on the above literature review for big data, and the following references for other types of large-scale IT projects (Rizvi 2017; Greenhalgh et al. 2014; Bloch et al. 2012; Flyvbjerg and Budzier 2011; Razmi et al. 2009; Sumner 1999; Cats-Baril and Thompson 1995).

Table 1. Comparison of Big Data and Big IT Project Challenges

\begin{tabular}{|c|c|c|c|}
\hline \multicolumn{4}{|c|}{ Similar to big IT completely } \\
\hline People & Technology & Legal & Organization \\
\hline $\begin{array}{l}\text { - Employees' } \\
\text { Technological Skills }\end{array}$ & & $\begin{array}{l}\text { - Data security and } \\
\text { privacy }\end{array}$ & $\begin{array}{l}\text { - Management Support } \\
\text { - Clarity of Objectives }\end{array}$ \\
\hline \multicolumn{4}{|c|}{ Some similarity with different level of impact } \\
\hline People & Technology & Legal & Organization \\
\hline
\end{tabular}




\begin{tabular}{|c|c|c|c|}
\hline & $\begin{array}{l}\text { - Data Integration } \\
\text { Complexities } \\
\text { - Data Availability } \\
\text { - Technology } \\
\text { Solutions Complexities } \\
\end{array}$ & $\begin{array}{l}\text { - External Sources of } \\
\text { Data }\end{array}$ & \\
\hline \multicolumn{4}{|l|}{ Unique to big data } \\
\hline People & Technology & Legal & Organization \\
\hline $\begin{array}{l}\text { - Data Scientists } \\
\text { - Management's } \\
\text { Analytical Skills }\end{array}$ & - What Data to Collect & $\begin{array}{l}\text { - Data Ownership } \\
\text { - Legislation } \\
\text { Adaptability }\end{array}$ & - Data Strategies \\
\hline
\end{tabular}

\section{Similar to big IT completely:}

Employees' Technological Skills: Employees lack of technology skills can hinder any

IT system. New systems require learning curves that can be shorter for employees with advanced IT skill. Such employees can also provide better feedback about their daily work when requirements are gathered, and more meaningful feedback when the upcoming system is in the test stage. Furthermore, they would offer less resistance to change and will, more likely, be able to use the system in the way it is supposed to be used and feed it with the right data, that allow the system to achieve its goals.

Data security and privacy: Large-scale IT projects span several departments (and in some cases external entities as well), and are related to core operations of the organization. Therefore, security breaches and improper privacy handling can result in significant damage to the organization, its customers, and suppliers.

Management Support: Employees tends to resist change. Large-scale IT projects result in significant changes in the way the business is done and usually faced with resistance. Hence management support to drive the change, including motivating employees to embrace the change, removing bureaucracy, breaking silos, authorize required training, 
among other actions they can do, is an essential factor for any project of any type that brings significant changes to the organization.

Clarity of Objectives: If the overall picture about the motivation behind the new system and what value it is supposed to deliver is not clear, the system is doomed to failure. Making sure that any Large-scale IT project is aligned with the organizational goals and strategies, and addressing real problems, is vital and without it, the system will be just a waste of money and resources.

\section{Some similarity with different level of impact:}

Data Integration Complexities: Most large-scale IT projects include integrating data from other sources. For examples, a supply chain model within an ERP system would integrate with suppliers, to get inventory data. A DMV system would integrate with Homeland Security to verify social security number data. Integrating data from other sources is challenging as data have different formats or no format at all, and different meanings among different systems. This challenge is more critical in the case of big data than most other large-scale IT projects as: First, big data is mainly about acquiring data from other systems, while in most other large-scale IT projects, data from other systems are used to enhance the easiness of using the system. Second, big data integrate data from unstructured resources like social media and Internet logs that is far more complex to interpret and analyze.

Data Availability: This factor is closely related to the previous factor. An ERP system can continue functioning if a supplier's data is not coming on time, might not be as efficient, but it is still working. DMV operator would need to check a photo ID instead of 
using auto data coming from Homeland Security. However, big data real value is in its ability to create insights and suggestions when needed; otherwise, it loses most of its value.

Technology Solutions Complexities: When using several technologies to build a system, compatibility issues could arise. ERP systems are getting more and more standardized and comprehensive that this problem is becoming less important for this type of projects. However, other kinds of large-scale IT projects, that are built from scratch, as well as, big data projects that use technologies that are still evolving, well most likely need to accommodate several technologies and tools to achieve the required goal. Hence, compatibility issues are more likely to affect the chances of a successful project.

External Sources of Data: If a system heavily depends on external sources of data to generate value, however, the owners of data sources would not share the data, then the system will not be able to generate the required value. Big data projects are more likely to depend on external sources to generate real value, as the ultimate goal is to generate insights that take in consideration all, or at least, most of the factors surrounding the decision, including external ones. Other types of large-scale IT projects are more transactional than analytical, and hence less likely to be affected by external sources not sharing their data. Nevertheless, they could perform better with the presence of such external sources but not to the degree of diminishing the value of the system.

Legislation Adaptability: This factor is more important to big data projects in the public sector, as such projects require new ways of collecting and disseminating the data. If 
legislation cannot keep up with the new requirements, it will single-handedly kill the project. Some other types of large-scale IT projects are less or more affected by this factor based on their nature. For example, e-government services require a total of new ways to do the service and to verify the supporting documents. While an ERP system would mainly be internally and needs minimum legislation-related changes.

\section{Unique to big data:}

Following factors are unique to big data and are mainly serve big data systems' needs.

- Data Scientists

- Management's Analytical Skills

- What Data to Collect

- Data Ownership

- Data Strategies

In conclusion, while all large-scale IT projects (big IT), characterized by high failure percent and similar consequences of failure. The details and the importance/relevance of each factor influencing those projects are different, due to the nature of related technologies and the organizational problem/need that the project is trying to address. Therefore, readiness assessment depends on the nature of the project, and thus while this model could be used as a reference for other kinds of large-scale IT projects (big IT), it should be modified to accompany them. (In fact, it should also be modified for other kinds of big data projects, which are not meant for smart cities, as well). 


\section{CHAPTER 3: RESEARCH OBJECTIVES, QUESTIONS, AND METHODOLOGY}

There is evidence from the literature that project management approaches in disciplines that might be considered close to big data like software systems and operation research do not fit the unique needs of big data projects (Saltz 2015). Furthermore, Saltz and Shamshurin $(2016,1)$ assessed 10,028 papers regarding big data and found that the discussion about big data project management is "... scattered across numerous conferences and journals." So, there is a lack of research that addresses how to overcome the challenges of big data projects in a structured and systematic way. Based on the findings from the literature review Section 2.6. Following are the research gaps, objective and questions that will be addressing in this research, see also Figure 6.

\subsection{Research Gaps}

RG1: There is limited research about structured approaches to evaluate big data readiness: In Section 2.6 of the literature review, it was shown that most of the research about big data adoption and projects challenges is about identifying those challenges and suggest counter measurements for each challenge. However, there are only a few papers that actually tried to offer structured and systematic frameworks to address organizations' readiness to conduct big data projects.

RG2: There is limited research about evaluating big data project's challenges under different perspectives (for example, personal, technical, organizational, and so on...). It was shown from the literature review (see Section 2.6 for more details) that only a few papers even tried to group the challenges of big data adoption and projects into perspectives or categories. This classification can help greatly in understanding the big 
picture, and the actors around big data challenges for more proper addressing of those challenges.

RG3: There is limited research about the dynamics of internal and external factors surrounding big data project: most literature that identifies big data challenges would only list those challenges, based on the findings of the research, or just rank them (see Section 2.6 for more details). Nevertheless, the literature research did not reveal any publication where the relative importance of those factors against each other is discussed clearly, and how they affect each other.

\subsection{Research Goal}

The research aim is to develop a framework that can be used by cities, which are planning to adopt smart cities initiatives, to find out how mature and ready they are to implement big data projects under a smart city initiative. The model will be used to juxtapose the current situation at the city with a comprehensive model to find out the areas within the city that need to be improved/ properly addressed before starting the big data project to increase the chances of successful big data implementation.

\subsection{Research Questions}

RQ1: What are the main factors influencing smart-city-related big data projects?

RQ2: What are the weights (relative importance) of the factors affecting the successful implementation of smart-city-related big data projects?

RQ3: Does the proposed model offer an effective and practical way to evaluate the city's readiness to implement a big data project? 


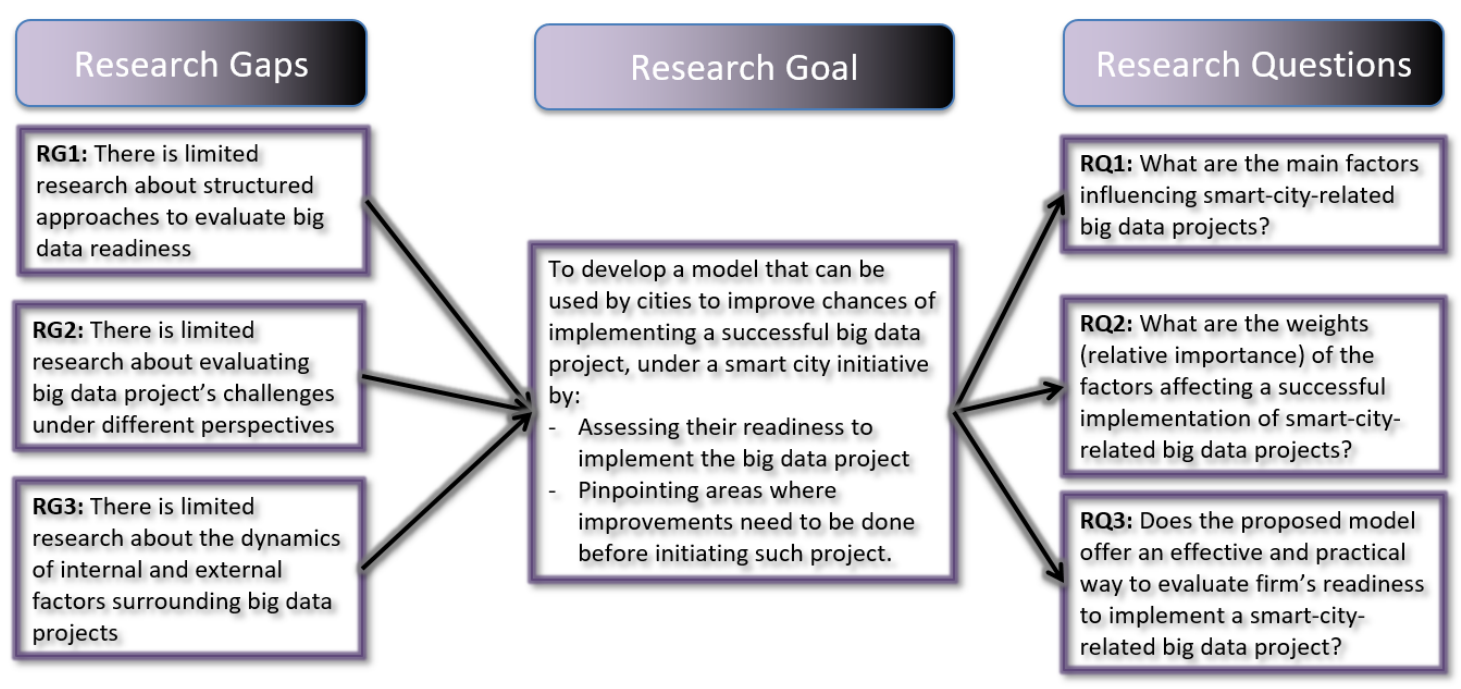

Figure 6. Research Gaps, Goal, and Questions

\subsection{Methodology}

\subsubsection{HDM Model}

HDM is a multi-criteria decision-making tool that helps to make decisions in complex situations when there are multi-level conflicting objectives and criteria. HDM was introduced by Kocaoglu in the early 1980s (Kocaoglu 1983). Multi-criteria decision models, in general, are used to select the best alternative from a pool of alternatives to solve a problem, by evaluating the attributes of the alternatives against the criteria of the problem (Hwang and Masud 1979).

HDM calculates the relative contribution/weight of criteria in making the decision, through a systematic process of eliciting and evaluating the subjective judgment of experts concerning those criteria. The subjective judgment is expressed in pairwise comparisons that are converted to relative weights in ratio scale to offer a sound evaluation of the criteria. This approach allows for better decision making that considers 
all elements of the situation with the appropriate realization of the various importance/impact of each of the elements. Then a comparison of the alternatives against the criteria allows for the alternative, that is best contributes to achieving the goal, to be determined. HDM basic concepts are similar to those of the Analytic Hierarchy Process (AHP) introduced by Saaty (Saaty 1997). However, it utilizes a different computational approach, by using the Constant-Sum calculations instead of the Eigenvectors.

HDM model suggests that decision criteria should be presented in a multi-level hierarchy, typically mission, objectives, goals, strategies, and actions, also known as MOGSA, Figure 7 is an example. However, this is not a hard requirement, and HDM is flexible when it comes to leveling. For example, several researchers used HDM with a hierarchy divided into levels analogues to mission, objectives under the mission, and goals under each objective as illustrated in Figure 8 (Estep 2017; Daim 2016; Gibson 2016; Abotah 2014; Phan 203; Chen and Kocaoglu 2008; Kocaoglu 1983; Cleland and Kocaoglu. 1981).

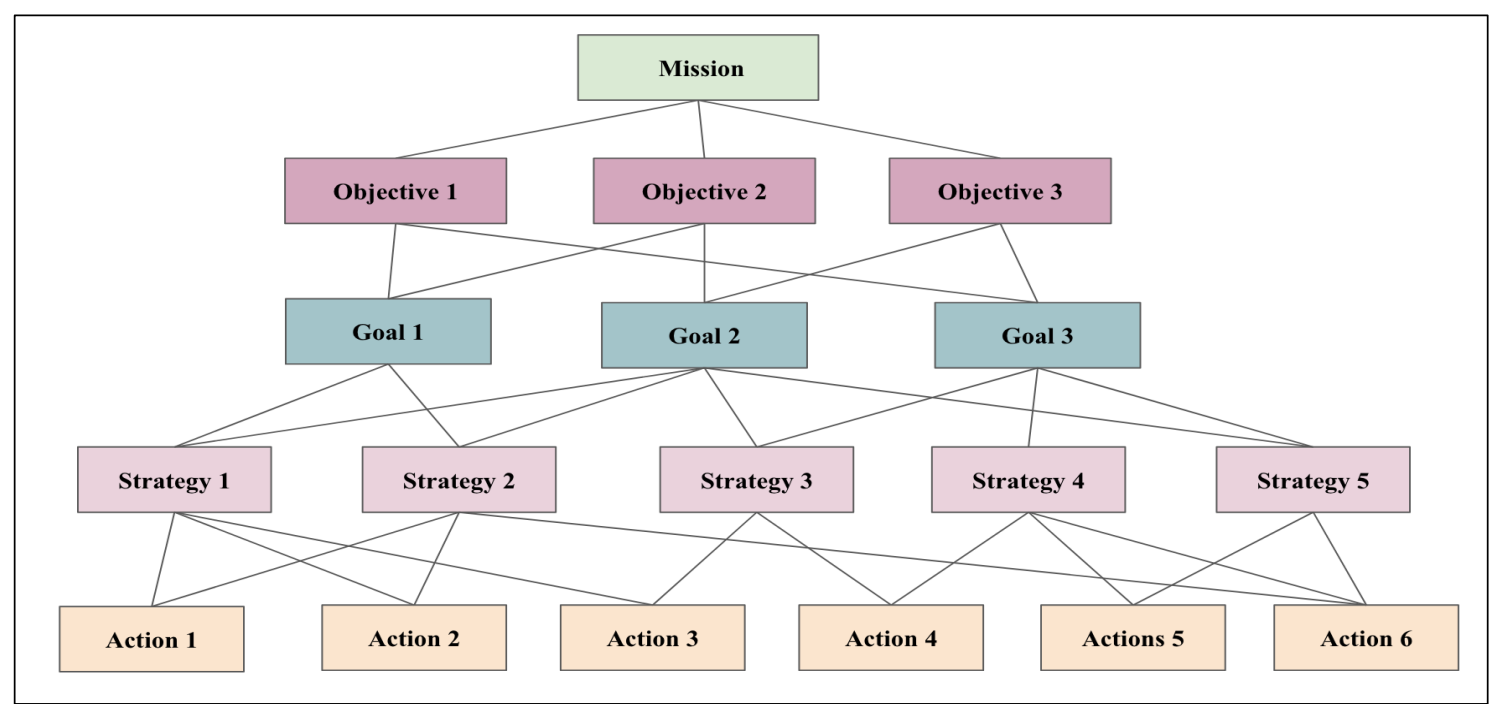

Figure 7. Example of MOGSA (Kocaoglu 1983) 


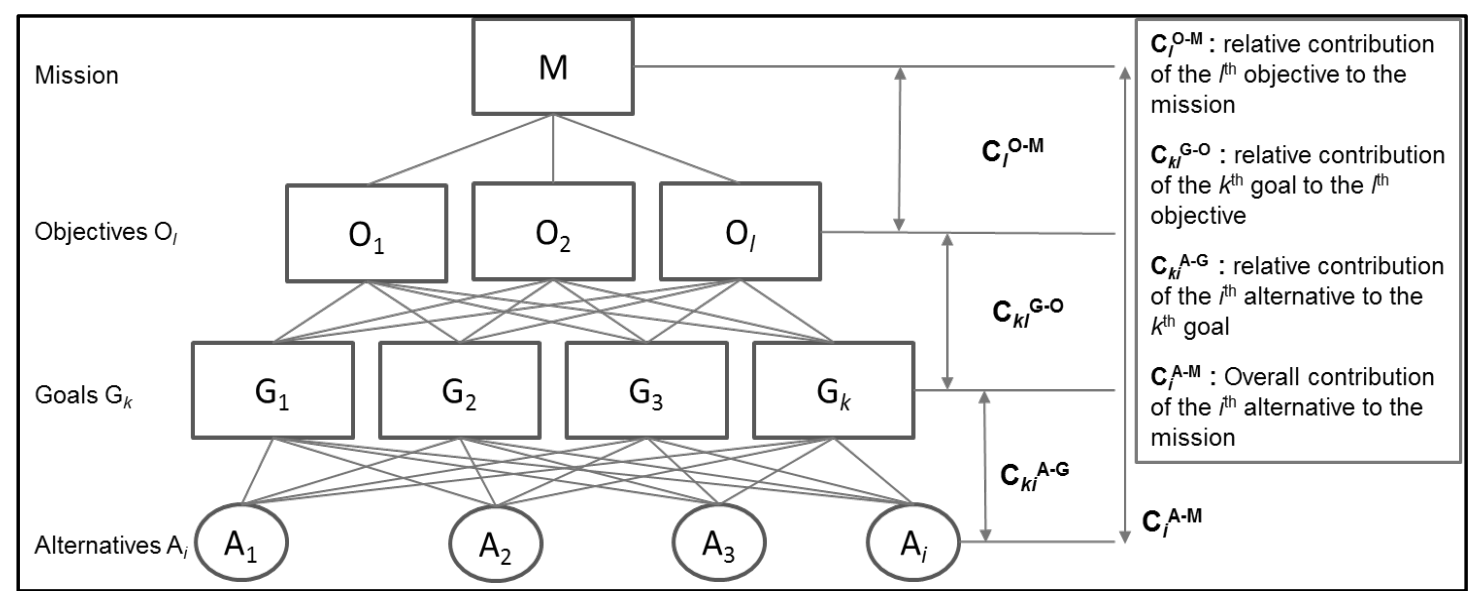

Figure 8. Conceptual HDM Model Design (Estep 2017; Gibson 2016; Abotah 2014; Phan 2013)

Constant Sum Method: Under the HDM model, subject-matter experts are asked to weigh/quantify the model. Each item in the model's hierarchy is given weight. Each item will have a "global" weight against all other items at the same level, and a "local" weight within its category. Then, the alternatives are evaluated against the lowest level of the hierarchy, which is the decision criteria, to find the best decision possible.

The constant sum method is used to collect expert's evaluation and weighing of the criteria hierarchy and alternatives. Experts are asked to conduct pairwise comparisons for every two elements within the same level in the hierarchy. They will compare n(n 1) $/ 2$ pairs, in random order, for $n$ elements under consideration. The comparison is made by distributing 100 points between the two elements, with the element that has higher priority/importance getting more points that reflect the degree of priority/importance. Then, using the constant sum method, experts' judgment will be aggregated to get weights, with the total sum of 1 , for each level within the hierarchy and on the whole hierarchy, as well as weights for the alternatives against each other for each criterion. 
Also, a final score for each alternative in comparison with the other alternatives based on the aggregated evaluations of all experts, to find out the best decision possible.

Following example show how the calculations are done: in this example, Expert 1 is asked to evaluate the perspectives $\mathrm{P} 1, \mathrm{P} 2$, and $\mathrm{P}$, following are his pairwise comparisons $\{\mathrm{P} 3$ 80:20 P1 $\},\{\mathrm{P} 1$ 40:60 P2 $\},\{\mathrm{P} 2$ 40:60 P3 $\}$. In this example, Expert 1 judged that $\mathrm{P} 3$ is four times more important than P1, Expert 1 also judged that $\mathrm{P} 3>\mathrm{P} 2>$ P1. All experts will do the same for each sub-criterion in a level that is related to an upper-level element. Finally, to calculate the overall weights, three matrices A, B, and C will be used:

Matrix A represents the elements against each other, see Table 2.

Table 2. Matrix A

\begin{tabular}{|l|c|c|c|}
\hline & P1 & P2 & P3 \\
\hline P1 & X & 60 & 80 \\
\hline P2 & 40 & $X$ & 60 \\
\hline P3 & 20 & 40 & $X$ \\
\hline
\end{tabular}

Matrix B represents the ratio of comparisons for each pair from Matrix A, P1/P3 = 20/80 $=0.25, \mathrm{P} 3 / \mathrm{P} 1=80 / 20=4.0$, see Table 3 .

Table 3. Matrix B

\begin{tabular}{|l|c|c|c|}
\hline & P1 & P2 & P3 \\
\hline P1 & 1.0 & 1.5 & 4.0 \\
\hline P2 & 0.67 & 1.0 & 1.5 \\
\hline P3 & 0.2 & 0.67 & 1.0 \\
\hline
\end{tabular}


Matrix C represents the results of dividing each element in a column of Matrix B by the element in the next column.

Table 4. Matrix C

\begin{tabular}{|l|c|c|}
\hline & P1/P2 & P2/P3 \\
\hline P1 & 0.67 & 0.375 \\
\hline P2 & 0.67 & 0.67 \\
\hline P3 & 0.3 & 0.67 \\
\hline Mean & 0.55 & 0.57 \\
\hline Std. Dev. & 0.21 & 0.17 \\
\hline
\end{tabular}

Then, a value of 1 is assigned to P3 (the element missing from the table 4), and other elements values are calculated based on it, by the ratios indicated as the mean of each column in Matrix $\mathrm{C}$ as follow:

\section{P3: 1}

$\mathrm{P} 2: 0.57 * 1=0.57$

$\mathrm{P} 1: 0.55 * 0.57=0.3135$

Finally, normalize the resulting values to get the relative weights/importance for each element.

$$
\begin{aligned}
& \text { Total }=1+0.57+0.3135=1.8835 \\
& \mathrm{P} 1=0.3135 / 1.8835 \approx 0.17 \\
& \mathrm{P} 2=0.57 / 1.8835 \approx 0.30 \\
& \mathrm{P} 3=1 / 1.8835 \approx 0.53
\end{aligned}
$$

If there were no inconsistency, each column in Matrix $\mathrm{C}$ would show the same value for each row. However, since that was not the case, this indicates an inconsistency. 
Section 3.4.2.2 discusses inconsistency, its meaning, and how to calculate it. Each expert in a panel will be asked to make the same pairwise comparisons.

Furthermore, in ideal utopia, all experts should generate the same results, however, in real life, disagreement among experts is expected, Section 3.4.2.3 discuss disagreement, its meaning, and how to calculate it. The final weight of each element is calculated by aggregating (averaging) experts' results. These weights are called "local weights," they, in turn, are multiplied by their parent element (or parent elements in case of several levels) weight(s) to obtain the "global weight" of each element.

Regarding Figure 8, the alternative that is best contributing to the mission can be calculated, by applying the following equation to all alternatives, to find the alternative with the highest contribution to the mission, as follow:

Let:

$O_{i}$ : Objectives, $i=1,2 \ldots \mathrm{I}$

$C_{l}^{O-M}:$ Relative contribution of the $L^{t h}$ objective to the mission. $G_{k}:$ Goals, $k=1,2 \ldots \mathrm{K}$ $C_{k l}^{G-O}:$ Relative contribution of the $K^{t h}$ goal to the Lth objective. $A_{i}:$ Alternatives, $i=1,2 \ldots \mathrm{I}$ $C_{i}^{A-M}$ : Overall contribution of the $i^{\text {th }}$ alternative to the mission. $C_{i k}^{A-G}$ : Relative contribution of the $i^{t h}$ alternatives to the kth goal. $C_{i l}^{A-O}$ : Relative contribution of the $i^{\text {th }}$ alternative to the kth objective. Then 


$$
C_{i}^{A-M}=\sum_{l=1}^{L} \sum_{k=1}^{K} C_{l}^{O-M} \cdot C_{k l}^{G-O} \cdot C_{i k}^{A-G}
$$

Equation 1

Under this approach, the alternative with the highest contribution should be selected (Estep 2017; Daim 2016; Estep and Daim. 2016; Gibson 2016; Phan 2013; Chen and Kocaoglu 2008; Kocaoglu 1983; Cleland and Kocaoglu. 1981; Saaty 1977; Guilford 1954).

\subsubsection{Experts Judgement}

Eliciting expert judgment is a common practice in academia for many reasons. For instance, to validate/review research results and findings in term of quality and legitimacy. Also, to identify key issues and forecast future trends related to a research topic. Moreover, expert judgment can prove helpful, when there is a need to get information about model parameters or characterize uncertainty in a model. Finally, expert's judgment is commonly used to develop and evaluate research projects at various stages including: hypothesis generation, sample design, model development, and interpretation of results (Gastel and Day 2016; Martin et al. 2012; Runge et al. 2011; Saaty 2008; Beecham et al. 2005; Cho et al. 2006; Fazey and Fazey 2005; Okoli and Pawlowski 2004; Langfeldt 2002; Mumpower and Stewart. 1996; Carroll 1994; Lyles 1990; Cleland and Kocaoglu 1981; Dalkey and Helmer 1963).

In general, the main benefit of experts' judgment is when definitive evidence is not available, so experts can offer inference and insights that go beyond the available data that allow for better understanding of the research subject and potential ways to address it. In the case of evaluating research models, expert panels benefits include identifying 
research parameters, and address research uncertainty, as well as, to validate the findings and validate the proposed model to answer the research questions. Experts do this by judging how accurate the model is in addressing the research gap/problem, and whether it is the right model, in the first place. There are different methods to capture experts' judgments. One approach includes asking experts to conduct a peer-review validation of research results before publishing it in a primary journal. Another approach is based on sending surveys to experts.

Moreover, it is common to create expert panels, and capture the panel evaluation of the findings, using different methods, like Delphi or pairwise-comparison-based methods (Gastel and Day 2016; Martin et al. 2012; Runge et al. 2011; Saaty 2008; Beecham et al. 2005; Cho et al. 2006; Fazey and Fazey 2005; Okoli and Pawlowski 2004; Langfeldt 2002; Mumpower and Stewart. 1996; Carroll 1994; Lyles 1990; Cleland and Kocaoglu 1981; Dalkey and Helmer 1963). Sections 4.2 and 4.3 explain the approaches followed in this research to capturing experts judgment.

Forming expert panels to cultivating their expert judgment is a process in which the researcher should conduct the following steps (Estep 2017; Martin et al. 2012; Cho et al. 2006; Duffield 1993; Fink et al. 1984; Brown 1963):

- First, deciding what is the research subject to be addressed; having a clear picture of the purpose of the research, what information is required, and whether expert's judgment is a viable alternative to extract the required information.

- Then, determining what judgment need to be elicited from the experts, what criteria should be there in an expert to be a good panelist, how many panels are needed, and how many experts per panel. 
- Then, creating the elicitation process that best helps to elicit judgment from the experts.

- Then, identifying and contacting the suitable experts that can offer the required judgment.

- Then, conducting the elicitation itself.

- Finally, encoding and aggregating the elicited information to inform a decision, either directly or for use in a model.

Section 4.3 explains the approach of forming expert panels that was used in this research. Identifying and selecting the experts, is one of the most important steps in forming expert panels, as the quality and the reliability of research results are as good as the experts making the judgments that led to the results or validated the results. Such quality can be measured in terms of how closely the judgment is to reality and the degree of uncertainty in the judgment. The expert panel should include experts that are representatives of their peers in relation to the research subject and have the power to implement the results. Hence, their judgment is not likely to be challenged (Daim et al. 2014; Martin et al. 2012; Burgman et al. 2011; Kuhnert et al. 2010; Baker et al. 2006; O’Hagan et al. 2006; Carroll 1994; Cooke 1991; Fink et al. 1984; Kocaoglu 1983).

So, what makes a person an expert, so their judgment is not likely to be challenged? There is a plethora of discussion about this in literature. For instance, Feigenbaum and McCorduck discussed what does it mean to be an expert: "[T]he matters that set experts apart from ... beginners are symbolic, inferential, and rooted in experiential knowledge. ... Experts build up a repertory of working rules of thumb, or 'heuristics,' that, combined with book knowledge, make them expert practitioners"' 
(Feigenbaum and McCorduck 1984: 64). An extensive discussion about the experts was offered by Dreyfus and Dreyfus (2005). They argued that a person could acquire or build skill, and therefore, becomes expert, by going through five stages of learning:

Novice: The initial phase of learning the abstract facts about the skill. For example, the basics of driving a car, including how to accelerate and slow down car speed.

Advanced beginner: Understanding the relevant context by coping with real situations. For example, actual driving of a car and realizing the importance of the context, including things like the need to slow down when taking an exit.

Competence: Learning more about the elements of the skill and how to prioritize it. For example, while driving and the driver is about to take an exit, he/she recognizes that for the car to slow down, they should either use a brake pedal or just let up the accelerator, the decision depends on several factors like, current speed, needed speed on the exit, and road conditions. The driver will make a choice and hope it is the right one, without proper justification.

Proficiency: The person in this stage would have situational discrimination, accompanied by associated responses (think about what to do rather than about why to do it). For example, in the car taking the exit example, the driver will realize, without thinking about it, that there is a need to slow down, but he/she still need to think about slow down options and then take the proper choice and not a random one.

Expertise: In this stage, a person sees immediately what needs to be achieved and how to achieve it intuitively. For example, an expert car driver will know as soon as he decided 
to take the turn, what speed is needed and how to achieve it most optimally without extra consideration or debate.

Furthermore, for some skills, there are many experts, while for others there are a limited number of experts. Depending on whether the skill is crude; have a large margin of error and time to make corrections (like driving a car), or subtle; where a tiny difference would make different results that can hardly be corrected (like Athletes, surgery) (Dreyfus and Dreyfus 2005).

Dreyfus and Dreyfus's theory is not without criticisms. For example, Day (2002) argued, with extended details, that it is not necessarily to make decisions based on intuition solely to make a person an expert. Furthermore, he emphasized that experts do not become experts just by the accumulation of practice; they also need to have different kinds of practices, to build both cognition and its context.

Other definitions focused on expert knowledge, identifying an expert as a person holding information about a subject and can be referred to, to interpret issues related to that subject. Additionally, an expert is a person who has up-to-date knowledge of the topic under investigation. Moreover, an expert should be able to recognize features and patterns related to the research subject, and relate it to central ideas, with the realization of context, in ways that non-experts cannot (Martin et al. 2012; Kuhnert et al. 2010; Fazey et al. 2005; Jairath 1994). Weinstein (1993) argued that there are two types of experts, based on the type of their expertise. Experts are either epistemic; their expertise is a function of what they know, or performative; their expertise is a function of what they do. Other publications investigated expert judgment. One definition of expert judgment is 
"Informed opinion on a technical problem based on an expert's training and experience" (Meyer and Booker 2001).

\subsubsection{Challenges and Considerations}

When eliciting expert's judgment by forming expert panels, there are challenges and issues to be considered:

Challenges:

- The value and quality of expert's judgment depend on how informative the decision is; how close it is to reality and how certain it is. However, such expert judgment quality can be undermined by several factors including bias, and selfserving. Mahoney (1977) identified bias as "[T]endency to emphasize and believe experiences which support one's views and to ignore or discredit those which do not." Furthermore, some experts might try to influence the opinions of other experts if they have the ability to discuss it with them. Also, there are 'silent bystanders' who would not offer proper judgment in a panel discussion. Methods like Delphi and HDM handle such problem by eliciting experts judgment anonymously. However, experts' judgment still could be subject to self-interests and personal biases, making his/her judgment more reflective of their personal interests or biases rather than reflecting reality.

- Another challenge is related to the expert's availability and willingness to participate, not to mention, that the process is slow.

- Communicating research goals to experts could be a challenge as well, if the research objective is not appropriately communicated, judgment will not be accurate, however, over-communicating could have the "lead the witness' effect, where researcher could, accidentally, influence expert's judgment while explaining to him/her the expected outcome of the research.

- Eliciting judgment techniques is another challenge, as it could restrict expert's ability to provide additional valuable feedback, while other techniques that allow 
flexible feedback face the problem of how to quantify and properly use that feedback to server research objectives.

- Finally, other issues related to expert panels, include the disagreements and inconsistency in responses, which is an inevitable outcome of using expert panels. Several methods can be used to validate expert's judgment; including identifying the accuracy of individual expert's judgment by means of measuring the inconsistency in their feedback (more details about inconsistency and how to measure it can be found in section 3.4.2.2). Also, by measuring disagreement among experts (more details about disagreement and how to measure it can be found in Section 3.4.2.3). Furthermore, sensitivity analysis offers a measurement of how confident and robust the aggregated feedback is (more details about sensitivity analysis and how to conduct it can be found in Section 3.4.2.4).

\section{Considerations:}

- Several researchers highlighted the importance of having experts from different backgrounds and audience groups, to make sure there is a balance in the panel outcome and proper representation of various stakeholders. This diversity allows for an outcome that is much closer to reality as possible.

- In addition, several researchers highlighted the importance of using electronic communication tools, like specialized software, email, and phone conference, as an alternative to a physical group meeting that includes all the experts. Since, such group meeting might have the negative impact of bias by "loud voice": one person influencing the group's opinions, as well as, silent bystander's effect of some people who would not participate effectively with the presence of others.

- Finally, there is some argument about the optimal size of an expert panel; Okoli and Pawlowski (2004) suggested that an ideal panel should include between 10 and 18 people. However, several technology management dissertations suggested the use of between 6 and 12 experts if there are enough experts, and when the 
number of experts is limited (for instance only two people are expert in a particular subject), then that is the ideal number to be used.

Following references cover the above points: (Estep 2017; Lingga 2016; Gibson 2016; Phan 2013, Sheikh 2013; Martin et al. 2012; Kuhnert et al. 2010; Kynn 2007; O’Hagan et al. 2006; Smith 2006; Okoli and Pawlowski 2004; Kerkering 2002; Kitchenham et al. 2002; Langfeldt 2002; Lauesen and Vinter 2001; Meyer and Booker 2001; Cooke 1991; Kocaoglu 1983).

Finally, to conclude the discussion about critical issues related to expert panels, Smith (2006) argued that expert judgment is an inherently flawed process, which is most likely to remain in the central of science due to the lack of viable alternatives.

\subsubsection{Experts Inconsistencies}

According to Merriam-Webster (2018a), inconsistency, in general, can be defined as "not compatible with another fact or claim, inconsistent statements or containing incompatible elements or not satisfiable by the same set of values for the unknowns."

Experts are human, and their opinions are subjective. If an issue is complex enough, experts are most likely to make different views on its strengths, weaknesses, and importance if asked to re-evaluate the same issue. Moreover, experts, like any other human being, cannot juggle many ideas in their heads in the same time, so they might give inaccurate assessment if they are trying to judge several things in the same time. Estep (2017) identified expert inconsistency in general as “... disagreement within an individual's evaluation" (Smith 2006; Martin et al. 2012; Kuhnert et al. 2010). 
In the context of this research, experts' judgment will be elicited through asking them to conduct pairwise comparisons, to evaluate the HDM model. A simple example is presented here to build a proper context for the discussion about inconsistency: In reference to Figure 9, an expert is asked to judge the factors affecting decision A. Three factors were identified: $\mathrm{fl}, \mathrm{f} 2$, and $\mathrm{f} 3$. The expert is asked to identify the relative importance of each of those factors in making the A decision in pairwise comparisons, by distributing 100 points between every two factors. The expert will do something similar to the following:

$\{$ f1 75:25 f2 $\},\{f 275: 25 \mathrm{f} 3\},\{f 190: 10 \mathrm{f3}\}$

What the experts basically saying is: $\mathrm{f} 1$ is three times more important/relevant than $\mathrm{f} 2$, and $\mathrm{f} 2$ is three times more important/relevant than $\mathrm{f} 3$, and $\mathrm{f} 1$ is nine times more important/relevant than $\mathrm{f}$, such judgment is considered consistent as it maintains the logic of:

$\mathrm{f} 1>\mathrm{f} 2>\mathrm{f} 3$ and the proper proportion.

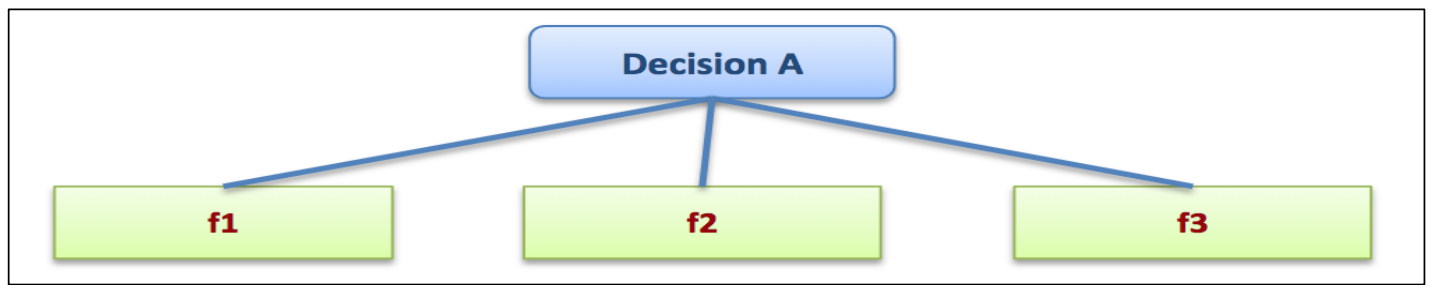

Figure 9. Pairwise comparison

Inconsistency in expert's judgment in term of pairwise comparison is defined as: "Inconsistency is a slight or gross, deliberate or unintentional error in the elicited pairwise judgment related to the rank order and mutual preference proportionality of alternatives" (Abbas 2016:11). So, based on this definition, Inconsistency occurs when an 
expert, conducting pairwise comparisons, violates one or both of two rules, those rules are called the ordinal and cardinal rules of consistency.

Ordinal: Inconsistency happens in this case when the rank of importance/priority is not maintained. In Figure 9 example, if the expert ranked f1 three times more important than $\mathrm{f} 2$, then $\mathrm{f} 2$ three times more important than $\mathrm{f} 3$. However, he/she judged that $\mathrm{f} 3$ is two times more important than $\mathrm{fl}$, then the expert violated the ordinal consistency rule. Cardinal: Inconsistency happens in this case when the preservation of preference proportion is not maintained. In Figure 9 example, if the expert ranked $\mathrm{fl}$ three times more important than $\mathrm{f} 2$, then $\mathrm{f} 2$ three times more important than $\mathrm{f} 3$. However, he/she judged that $\mathrm{f} 1$ is only two times more important than $\mathrm{f} 3$, then the expert violated the cardinal consistency rule. It can be seen that if the ordinal rule is violated, the cardinal rule is violated as well, but the opposite is not necessarily true.

While conducting pairwise comparisons, experts are likely to make inconsistent judgments, especially when the model is complicated. So, identifying and measuring inconsistency is critical to validate the quality of the decision. A small percent of inconsistency might be acceptable. A threshold must be identified, however. So, inconsistency in experts judgment can be captured and checked to make sure it does not exceed the threshold, as a way to have confidence in the judgment validity (Estep 2017; Abbas 2016; Lingga 2016; Saaty 2008; Alonso and Lamata 2006; Aguarón and MorenoJiménez 2003; Koczkodaj 1993). 
Following is a review of how to calculate inconsistency under the HDM methodology (Estep 2017; Abbas 2016; Lingga 2016; Chan 2013; Phan 2013; Kocaoglu 1983):

In HDM, inconsistency is measured by calculating the sum of the standard deviations. Let us assume that we are conducting pairwise comparisons. First, $n$ ! vectors of relative values $r 1, r 2, r 3, \ldots, r n$ based on constant sum calculation of the factors are built. Each vector represents an orientation of the elements. Example: if we have three factors $\mathrm{f} 1, \mathrm{f} 2, \mathrm{f} 3$ then we will do $3 !=6$ orientations as follow: $\mathrm{fl} f 2 \mathrm{f} 3$, $\mathrm{fl} 1 \mathrm{f} 3 \mathrm{f} 2, \mathrm{f} 2 \mathrm{fl} f 3$, $\mathrm{f} 2 \mathrm{f} 3 \mathrm{fl}, \mathrm{f} 3 \mathrm{f} 1 \mathrm{f} 2$, and $\mathrm{f} 3 \mathrm{f} 2 \mathrm{fl}$. So, if the expert was consistent, each orientation should lead to the same relative values. However, if he/she were inconsistent, different orientations would lead to different relative values. Hence, inconsistency can be measured by the variance of relative values. 
Phan (2013) summarized the equations as follow:

Let

$r_{i j}$ : relative value of the $i^{\text {th }}$ element in the $j^{\text {th }}$ orientation for an expert.

$\underline{r}_{i}$ : mean relative value of the $i^{\text {th }}$ element for that expert

$$
\frac{1}{n !} \sum_{j=1}^{n !} r_{i j}
$$

Inconsistency in the relative value of the $i^{\text {th }}$ element is

$$
\begin{gathered}
\sqrt{\frac{1}{n !} \sum_{j=1}^{n !}\left(\bar{r}_{i}-r_{i j}\right)^{2}} \\
\text { for } \mathrm{i}=1,2, \ldots, \mathrm{n}
\end{gathered}
$$

Variance of the expert in providing relative values for the $\mathrm{n}$ elements is

$$
\text { Inconsistency }=\frac{1}{n} \sum_{i=1}^{n} \sqrt{\frac{1}{n !} \sum_{j=1}^{n !}\left(\bar{r}_{i}-r_{i j}\right)^{2}}
$$

Equation 2

So, what is an acceptable inconsistency threshold? Abbas (2016) argued that it depends on how critical the decision is, he also introduced a new mechanism to calculate inconsistency based on the Root of the Sum of Variances (RSV). Preceding work followed a 0.1 rule of thumb, i.e., the value of inconsistency should be between 0.0 and 1.0. This rule has its root in an old recommendation by Saaty (1977). When an expert has high inconsistency (exceeding the threshold), a decision must be made to either cancel that expert's input completely or ask him/her to redo the evaluation again. A discussion 
with each expert with high inconsistency will be conducted to make sure he/she clearly understand what is required. Then they will be asked to redo their quantification. If the inconsistency continues, the expert will be removed, and his/her judgment will be canceled.

\subsubsection{Experts Disagreements}

According to Merriam-Webster (2018b), disagreement, in general, can be defined as "the state of being at variance or differ in opinion."

Hammond (2000) discussed the experts' disagreement. He identified three main sources for expert's disagreement, incompetence, venality, and ideology. Following is a summary of each:

Incompetence: Dispute might occur if one or more experts do not have enough expertise related to the research subject, they might lack the qualifications, credentials, or intelligence to make a quality judgment that matches reality. In such cases, the experts' identifying and selection process need to be revisited and amendments to be added to it. Venality: Dispute might occur if one or more experts are favoring their self-interests instead of the truth. It could be their own self-interests, the self-interests of the employer they are working for, or the self-interests of third-party entities that fund them or collaborate with them.

Ideology: Dispute might occur if one or more experts are making judgments that reflect their political, religious, or ethical beliefs. So, experts are allowing their personal sympathy to take precedence over what their expertise is telling them is the reality. 
Furthermore, even without having any of those three sources of disagreement, still, a degree of disagreement among experts is inevitable. Mumpower and Stewart (1996) discussed other reasons for disagreement when experts are competent and disinterested:

Different Ways of Thinking: As a human, experts' judgment is still subjective and related to their experience and their way of thinking. Which obviously differ from one person to another.

Poor Feedback: Poor communication of research goals will mislead the experts and cause them to make a judgment based on a wrong understanding of what is being judged. Poor Data: Even if research goals and what needs to be judged is well communicated to experts if the data provided to them is inaccurate or wrong, their judgment will only reflect that.

Difficulty in Evaluating the Quality of One's Own judgment: Some people have a tendency to overestimate their expertise and knowledge. Thus they might not ask for more clarifications about the research and would give their judgment, even if they do not have a clear picture of what they are asked to judge, leading to false judgment.

False Agreement: In this case, an agreement might occur between two or more experts for the wrong reasons, i.e., due to poor communication and feedback, the first expert is making the judgment based on partial information A, while another expert is making the judgment on partial information B, they both offer the same judgment. However, if each of them considered both A and B information, they would give different judgment. 
While a good identification and selection process might reduce the possibility of disagreement due to incompetence, it still cannot eradicate it, either address disagreement due to venality or ideology. Moreover, proper communication and availability of data can address most of the other concerns, but it also cannot eradicate those reasons for disagreement completely. Furthermore, a high level of disagreement puts the validity and trustworthiness of the experts' judgment to question, hence, the validity and trustworthiness of the research topic/ model being evaluated as well. Therefore, there is a need to measure disagreement among experts, as well as, identify and justify or take actions against the sources of the disagreement (Cowan 2017; Estep 2017; Gibson 2016; Abotah 2014; Amer and Daim 2013; Meyer and Booker 2001; Hammond 2000; Mumpower and Stewart 1996; Brehmer 1976).

In the context of this research, the primary source of experts' disagreement would occur while conducting pairwise comparisons of factors (perspectives or criteria as explained in the model). Different experts might have a different evaluation of what factors are the most important and to what degree.

Following is a review of how to calculate disagreement under the HDM methodology (Estep 2017; Gibson 2016; Abotah 2014; Iskin 2014; Sheikh 2013; Mumpower and Stewart 1996; Koch 1982; Bartko 1976; Fleiss and Cohen 1973):

Disagreement is being calculated using a statistical method called the Intraclass Correlation Coefficient (ICC). This method calculates the degree of disagreement among experts for a relative number of elements. Under this method, ICC represents the degree to which $x$ experts agree with one another on the relative importance of $n$ elements. 
Let

$M S_{B J}$ : Mean square between experts.

$S S_{B J}:$ Sum of square between experts.

$d f_{B J}$ : Degree of freedom between experts.

$M S_{B S}$ : Mean square between decision elements.

$S S_{B S}$ : Sum of square between decision elements.

$d f_{B S}$ : Degree of freedom between decision elements.

$M S_{\text {res }}$ : Mean square residual.

$S S_{\text {res }}$ : Sum of square residual.

$d f_{\text {res }}$ : Degree of freedom residual.

$k$ : Number of experts.

$n$ : Number of decision elements.

The equations for calculating ICC are as follow:

$$
r_{i c}=\frac{M S_{B S}-M S_{\text {res }}}{M S_{B S}+(k-1) M S_{\text {res }}+\frac{k}{n}\left(M S_{B J}-M S_{\text {res }}\right)}
$$

Equation 3

Where:

$$
M S_{B J}=\frac{S S_{B J}}{d f_{B J}}
$$

Equation 3a 


$$
M S_{B J}=\sum_{j=1}^{k}\left[\frac{\left(\sum X_{j}\right)^{2}}{n}\right]-\frac{\left(\sum X_{T}\right)^{2}}{n k}
$$

Equation $3 b$

$d f_{B J}=k-1$

Equation 3c

$$
M S_{B S}=\frac{S S_{B S}}{d f_{B S}}
$$

Equation 3d

$$
S S_{B S}=\sum_{i=1}^{n}\left[\frac{\left(\sum S_{i}\right)^{2}}{k}\right]-\frac{\left(\sum X_{T}\right)^{2}}{n k}
$$

Equation 3e

$$
d f_{B S}=n-1
$$

\section{Equation $3 \mathrm{f}$}

$$
M S_{\text {res }}=\frac{S S_{\text {res }}}{d f_{\text {res }}}
$$

Equation 3g

$$
S S_{\text {res }}=S S_{T}-S S_{B J}-S S_{B S}
$$

Equation $3 \mathrm{~h}$

$$
S S_{T}=\sum X_{r}^{2}-\frac{\left(\sum X_{T}\right)^{2}}{n k}
$$




$$
d f_{\text {res }}=(n-1)(k-1)
$$

Bartko (1976) suggested that the ICC value $r_{i c}$ should fall between $-1 /(k-1)$ and +1 . If the value of $r_{i c}=1$, then there is a total agreement between experts. While a value of zero or negative number means total disagreement. However, any value between zero and one, indicates a degree of disagreement, that is more intense towards zero and less intense towards one.

Building on this discussion, the HDM software tool (used in this research) calculates disagreements based on the hierarchical agglomerative clustering (HAC) as follow (Gibson 2016; Iskin 2014):

Let

$m$ : The number of experts, $k=1 \ldots \mathrm{m}$

$n$ : The number of decision elements, $i=1 \ldots \mathrm{n}$

$\bar{r}_{i k}$ : The mean relative value of the ith element for kth expert

$R_{i}$ : The group relative value of the $i$ th element for $\mathrm{m}$ experts is

$$
R_{i}=\frac{1}{m} \sum_{k=1}^{m} \bar{r}_{i k} \text { for } i=1,2, \ldots, n
$$

Equation 4

The disagreement among the $\mathrm{m}$ experts for $\mathrm{n}$ decision variables is: 


$$
d=\sqrt{\frac{1}{n \cdot m} \sum_{k=1}^{m} \sum_{i=1}^{n}\left(R_{i}-\bar{r}_{i k}\right)^{2}}
$$

Equation 5

As suggested by previous research that used the HDM methodology, a threshold of $d=0.1$ is used to decide if the disagreement is acceptable or not.

If disagreement exceeds the threshold, several actions can be done:

- If one or a few experts are causing the disagreement, they could be simply eliminated. Identifying who is causing the disagreement can be done by analyzing the standard deviation for each expert for each factor.

- Alternatively, a discussion about the disagreement can be conducted with the expert(s), causing the disagreement, to identify the reasons behind it. If such reasons are valid, then, using Delphi approach, the reasoning can be shared with the rest of the experts and then a series of iterations can be conducted to reduce the disagreement, after sharing the feedback with other experts.

- Another approach, used in previous research, is based on the hierarchical agglomerative clustering (HAC), where disagreement is calculated for each subcluster and compared against the threshold until the disagreement level is satisfied. This bottom-up approach allows for similarities and differences among expert sub-groups to be identified, hence; identifying the reasons behind the disagreement by analyzing the sub-groups common attributes. Then the various sub-groups identified with acceptable disagreement can be analyzed. If those subgroups represent homogeneous background, then the overall disagreement can be attributed to this reason and assumed acceptable. (Gibson 2016; Abotah 2014; Iskin 2014; Lukasová 1979).

- Finally, some previous research used the F-test approach to decide if a disagreement beyond 0.1 is acceptable or not. F-test is a statistical test that is 
mostly used to decide if a statistical model as a whole is significant and is the best fit for a set of data using the least squares (Estep 2017; Lingga 2016; Phan 2013; Sheikh 2013; Sweet and Grace-Martin 2012; Shrout and Fleiss 1979).

In this approach, F-test is used to determine whether $r_{i c}$ is equal to zero. The null hypothesis is defined as follow:

Let

$r_{i c}$ : Intraclass Correlation Coefficient (see equations 3.2 to 3.14 )

$M S_{B S}$ : Mean square between decision elements.

$M S_{\text {res }}$ : Mean square residual

Null Hypothesis:

$H_{0}: r_{i c}=0$

Equation 6

Alternative Hypothesis

$H_{a}: r_{i c}>0$

Equation 7

The $\mathrm{F}$ value is computed as follow:

$$
\text { as } F_{B S}=M S_{B S} / M S_{\text {res }}
$$

Equation 8

F-Critical is the critical F-value the statistic must exceed to reject the test. In this case a significance level of $5 \%(\alpha=0.05)$ is considered. So, the hypothesis test would be:

If $F_{B S}>F_{\text {critical }}$ at $\alpha=0.05$ then $H_{0}$ is rejected. 


\subsubsection{Sensitivity Analysis (SA)}

SA can be used to analyze the impacts of potential changes in values. Baker (2016: 108) described sensitivity analysis as “... we ask what-if questions regarding the choice of a specific parameter, looking for the effects on the objective function and the effects on the optimal choice of decision variables." Saltelli et al. (1999:39) defined sensitivity analysis as "to ascertain how a given model (numerical or otherwise) depends on its input factors."

SA has many benefits; it helps to understand the behavior of a model, the coherence between a model and the world, how different parts of the model interplay, to identify input factors with negligible influence, the quantifying of uncertainty in model output, and to conduct model calibration.

There are two approaches to apply SA, including local SA approach and global SA approach. In the local SA approach the focus is on varying inputs one at a time while holding the others fixed to a nominal value. The objective is to assess how uncertainty in the model impacts its performance. More precisely, how model performance changes when moving away from some optimal or reference parameter set. In global SA approach, the focus is broader and includes a simulation based on varying several inputs together or/and by averaging the different output over the variation of all inputs. SA can be used for many applications. Examples include: support model calibration, prioritize efforts for uncertainty reduction, analyze the dominant controls of a system, and support sound decision-making (Pianosi et al. 2016; Iooss and Lemaître 2015; Chen and Kocaoglu 2008; Saltelli et al. 1999; Turányi 1990; Cacuci 1981; Dantzig 1963). 
Furthermore, there are many SA methods. Pianosi et al. (2016) classified them under the following categories based on their purpose and complexity:

- Perturbation and derivatives methods

- Multiple-starts perturbation methods

- Correlation and Regression analysis methods

- Regional Sensitivity Analysis (or Monte-Carlo filtering)

- Variance-based methods

- Density-based methods

In the context of this research, SA will be used to analyze the impact of potential changes in the values at the perspectives level of the HDM model and what are the stability intervals for the weights of the factors in each level of the hierarchy. In hierarchical decision-making models, like HDM, the local contribution of factors is seldom known at $100 \%$ confidence level since it is based on human subjective judgment. Also, it is subject to variations as the environment change, or new experts are introduced. SA analysis will be used to study the effect of changes in priorities of the objectives or goals on the ultimate decision, by assessing the impact of experts' disagreement and the potential impact of making changes to the expert panel on the overall model robustness. Furthermore, SA analysis will be used to find out allowable ranges of perturbations at the perspectives and criteria levels that would provide insight into circumstances where readiness assessment would keep the original score (Estep 2017; Abotah 2014; Chen and Kocaoglu 2008).

Chen and Kocaoglu (2008) identified the following benefits of SA when used with the HDM: 
- Help visualize the impact of changes at the policy and strategy levels on decisions at the operational level

- Test the robustness of the recommended decision

- Identify the critical elements of the decision

- Generate scenarios of possible rankings of decision alternatives under different conditions

- Help judgment providers (the experts) reach consensus

- Offer answers to "what if" questions.

Following is a review of how to calculate SA under the HDM methodology. This HDM SA algorithm was introduced by Chen and Kocaoglu (2008):

The following equation can be used to calculate the overall contributions of each alternative (Ai) to the mission (M) in a four level HDM model:

Let

$C_{l}^{O-M}:$ Local contribution of the Lth objective to the mission

$C_{k l}^{G-O}:$ Local contribution of the kth goal to the Lth objective

$C_{i}^{A-M}:$ Overall contribution of ith alternative to the mission

$C_{i k}^{A-G}$ : Local contribution of ith alternative to the Kth goal

$C_{i l}^{A-O}:$ Global contribution of ith alternative to the Lth objective

$$
C_{i}^{A-M}=\sum_{l=1}^{L} \sum_{k=1}^{K} C_{l}^{O-M} \cdot C_{k l}^{G-O} \cdot C_{i k}^{A-G}
$$

Equation 9

In this research: 
- Mission: Readiness assessment score to implement a big data project

- Objectives: Represented by the "Perspectives" in my model

- Goals: Critical factors affecting smart-city related big data projects

- Alternatives: Smart-city-related big data projects to be assessed, and since desirability curves are used, they would not be alternative projects against each other, but instead projects with independent scores.

Moreover, SA in HDM calculates parameters that would explain the effect of any changes to any level of the hierarchy (perspectives or criteria) of the projects being assessed for readiness. The goal is to find out allowable ranges or perturbations at the perspectives and criteria levels that will not affect the final decision, or what is called the tolerance of the model. It could be done as follow:

Let:

$P_{l *}^{o}:$ The perturbations imposed on one of the objectives $\left(C_{l}^{O}\right)$,

where $\left(-C_{l *}^{O} \leq P_{l *}^{o} \leq 1-C_{l *}^{O}\right)$, the original ranking (readiness score of each big data project) $A_{r}$ and $A_{r+n}$ will not change if

$$
\begin{gathered}
\lambda \geq P_{l}^{o *} \lambda^{o}, \quad \text { where } \lambda=C_{r}^{A}-C_{r+n}^{A} \\
-C_{l *}^{o} \leq P_{l *}^{o} \leq 1-C_{l *}^{o} \text { (Feasibility condition) } \\
\lambda^{o}=C_{r+n, l *}^{A-O}-C_{r l *}^{A-O}-\sum_{l=1, l \neq l *}^{L} C_{r+n, l}^{A-O} \times \frac{C_{l}^{o}}{\sum_{l=1, l \neq l *}^{L} C_{l}^{o}}+\sum_{l=1, l \neq l *}^{L} \frac{C_{r l}^{A-O}}{\sum_{l=1, l \neq l *}^{L} C_{l}^{o}}
\end{gathered}
$$

Equation 10

The ranking of all alternatives will stay the same if the above equations are satisfied for all $n=1$, and $r=1,2 \ldots \mathrm{I}-1$. If only the first alternative is important to remain 
unchanged, the condition will be that $r=1$ and $n=1,2, \ldots, \mathrm{I}-1$. The sensitivity coefficient refers to the strength of the current decision and how flexible the objectives values can be without changing the ranking: Allowable range of perturbations on $C_{l}^{O}$ to keep the current ranking is

$\left[\delta_{l-}^{o}, \delta_{l+}^{o}\right]$, Sensitivity coefficient is calculated by $1 /\left|\delta_{l+}^{o} \vdash \delta_{l_{-}}^{o}\right|$

Another method to judge model reliability under HDM is to use scenario analysis with the "boost" approach. This is a "what if" oriented approach, in which, an analysis is conducted by boosting one factor to the maximum to see what the effect of that factor is if it turned out to be the most important factor in reality. Several such scenarios are conducted to find out how the overall index score of each alternative is changed, and whether that would result in re-ranking of alternatives (Estep 2017; Gibson 2016; Abotah 2014; Chen and Kocaoglu 2008; Triantaphyllou 2000; Saltelli et al. 1999).

\subsubsection{Value/Desirability Curves}

In cases where the model will be used more than once, value/desirability curves can be used. Value curves with HDM, in its current format, was initially introduced by Phan (2013).

Value curves are used to identify an index of useful values for each factor/criterion, those values can be called levels or metrics (Estep 2017; Gibson 2016; Abotah 2014; Phan 2013). Each level represents a typical situation an entity might have for that particular factor. For example, Typical situations cities might have for each factor related to a big data project. Under the value curves approach, experts will be asked to identify and evaluate common levels/metrics for each criterion (desirability matrix), and 
give each level a scaled quantitative value (between 0 and 100). Allowing to normalize the evaluation results by experts across all the criteria, see Figure 10, also, Figure 11 is an example of a value curve.

When running the HDM model, each entity being evaluated by the HDM model (a city's readiness for a big data project in this research case), can be assigned to a level that best fit it for each criterion. For example, a city's current situation for each factor affecting a big data project will be identified by the project manager after investigating the city's capabilities. Then the project manager will use the value curve of each factor to determine which level in that value curve is representing the city's identified situation and based on that the city will be assigned that level's score.

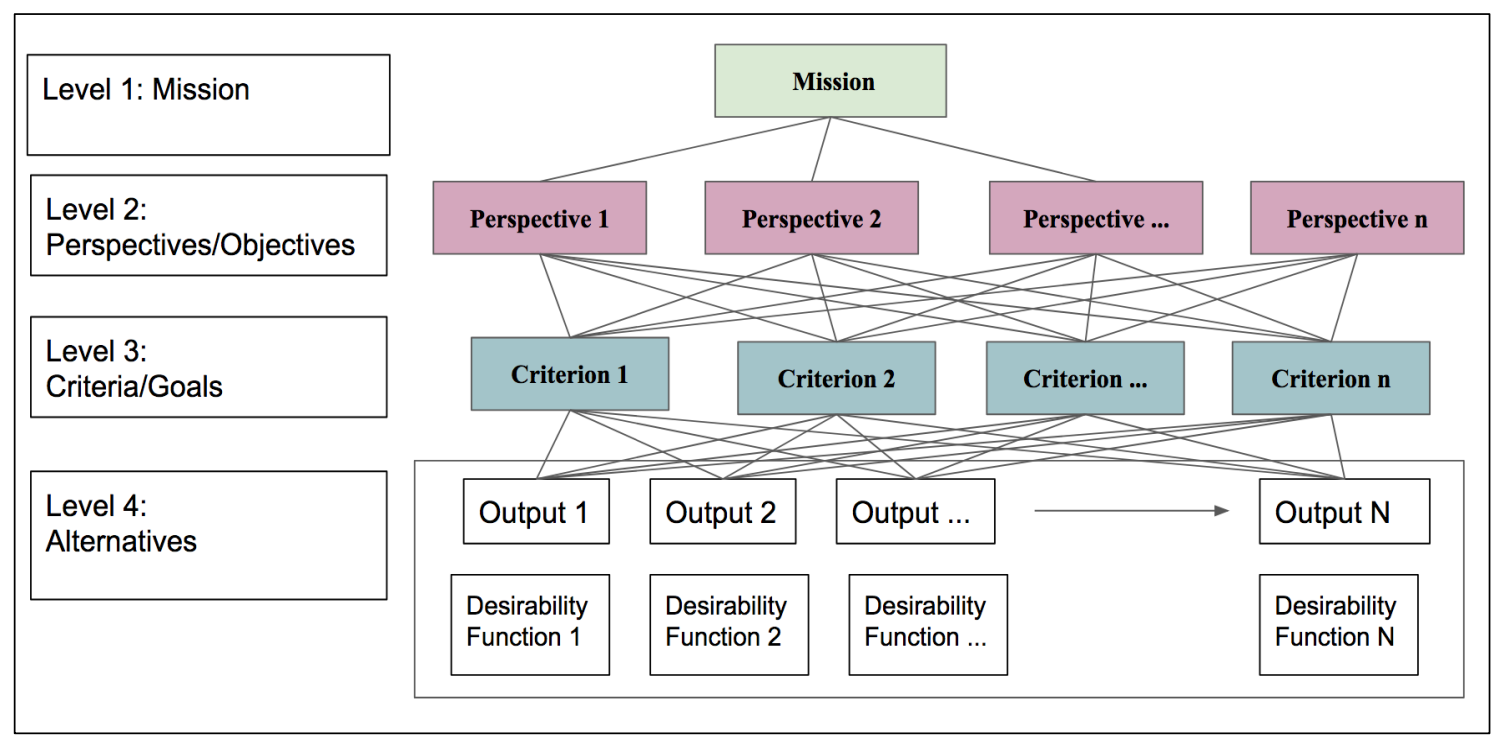

Figure 10. Conceptual HDM Model with Desirability Curves 


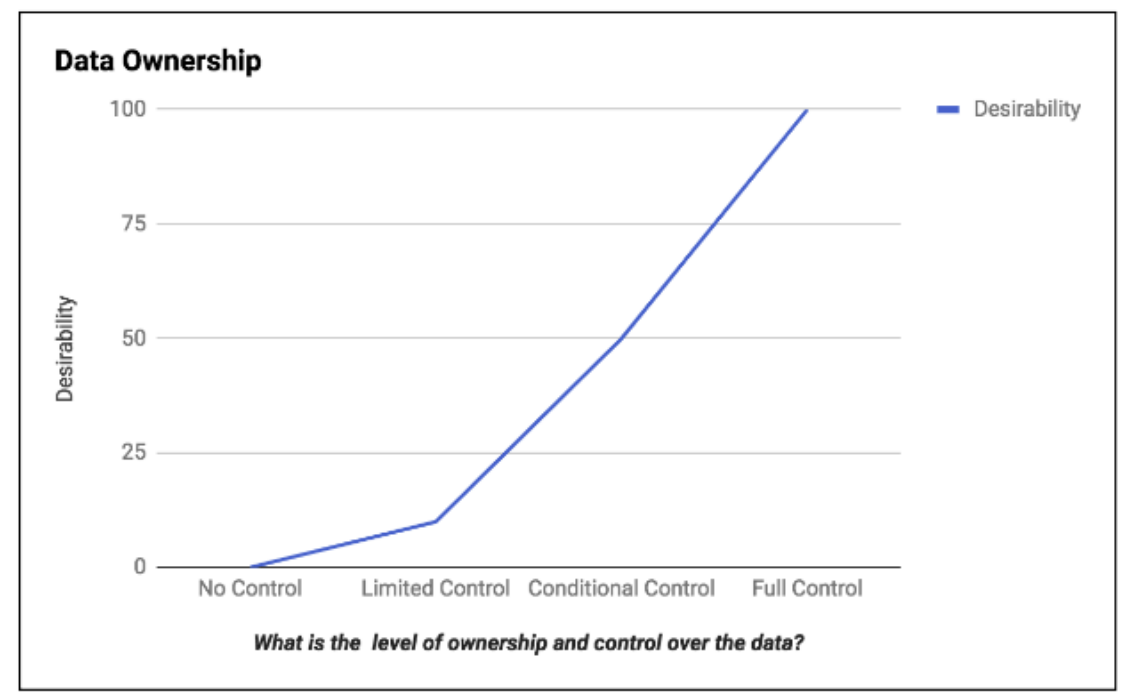

\begin{tabular}{|l|c|}
\hline Description & Desirability \\
\hline No Control & 0 \\
\hline Limited Control & 10 \\
\hline Conditional Control & 50 \\
\hline Full Control & 100 \\
\hline
\end{tabular}

Figure 11. Example of a Desirability Curve

Regarding Figure 10, an overall score for each entity can be calculated as follow:

Let:

I: Number of entities. In this research, an entity is a city conducting a smart-city-related big data project, if the same city is doing several smart-city-related big data projects, then the combination of the city and each project represents and entity.

C: Number of criteria (called factors in this research).

P: Number of perspectives.

$E\left(a_{i}\right)=$ The readiness score of entity $i$.

$P_{p}$ : The degree (weight) to which perspective $p$ contributes towards the mission (the mission is readiness assessment of a city for a smart-city related big data project). 
$C_{c}^{p}$ : The relative contribution of criterion $c$ under perspective $p$ towards the mission. $d\left(m_{i}, c p\right)$ : Desirability of performance metric of entity $(i)$ for $c^{t h}$ criterion under perspective $(p)$.

Then

$E\left(a_{i}\right)=\sum_{p=1}^{P} \sum_{c=1}^{C} P_{l} C_{k}^{l} d\left(m_{i}, c p\right) \quad$ for $i=1, \ldots, \mathrm{I}$

Equation 11

(Estep 2017; Gibson 2016; Abotah 2014; Phan 2013).

\subsubsection{HDM Benefits}

HDM offers many benefits. Here is a review of the main benefits of HDM:

- Effective decision-support tool. HDM helps make the right decision under uncertainty, where there are multiple complex competing objectives and criteria.

- HDM is a robust method that can capture the subjective judgment of experts and convert it into quantitative numbers that in turn can be analyzed and used effectively.

- HDM Aggregates opinions of diverse experts to create a meaningful and wellrepresented decision.

- Under HDM, experts are not affected by the "loudest voice" in the room.

- Everybody contributes to the decision, no "silent bystanders."

- No need for physical meetings.

- Experts' judgment can be tested for inconsistency and disagreement, allowing for more trust and reliability in the generated model.

- A model generated using HDM can be tested for flexibility and sensitivity to changes.

- Models generated by HDM are intuitive and practical. Such models can be used, after being built, in real life by users who do not possess high analytical and 
academic knowledge (Section 3.4.6 illustrates how this research model will be used in practice).

- HDM model applications cover virtually any sector or applications. Its use in technology management related fields over the years spans many sectors, covering areas like technology assessment, strategic planning, national technology planning, and decision-making tools.

(Estep 2017; Gibson 2016; Phan 2013; Chen and Kocaoglu 2008; Tran and Daim 2008; Kocaoglu 1983).

Following are some examples of sectors where HDM was used:

- Energy (Kocaoglu et al. 2016; Van Blommestein and Daim 2013; Sheikh et al. 2011; Wang et al. 2010).

- Health (Imondi et al. 2018; Mudavadi et al. 2016; Hogaboam et al. 2014).

- Policymaking (Abotah and Daim 2017; Daim et al. 2010).

- Transportation (Fenwick and Daim 2011).

- Telecommunications (Aldhaban et al. 2016).

- Human Resources (Harell and Daim 2010; Kennedy and Daim 2010).

\subsubsection{HDM Limitations}

While HDM offers significant value, it also has limitations, here is a review of the main limitation of HDM, and the mitigate plan for each of them in this research:

- HDM is based on the subjective judgment of experts and, as explained section 3.4.2, experts judgment can be affected by bias, whether due to personal bias or by the influence of others. Bias can be mitigated by carefully selecting the experts and make sure that they represent different backgrounds and entities, also, by separating the experts and eliciting their judgment individually.

- Another issue related to experts is the tendency to make an inconsistent judgment, especially when there are many complex factors to be considered. Inconsistency 
can be mitigated by carefully selecting the experts, and by using mathematical inconsistency equations to catch inconsistency in experts' judgment, and then address it as explained in Section 3.4.2.2.

- Furthermore, most probably, experts would disagree among themselves, that might render the results of their judgment irrelevant. Disagreement mitigation can be done, through proper clarification of the research goals, carefully selecting experts, and identifying disagreement mathematically and respond to it as explained in Section 3.4.2.3.

- Moreover, finding experts who are a "good fit," and are willing to commit to the research at the same time, is a challenge that is not easy to address. Mitigation could be to make sure that selected experts are motivated and have something to gain (for example: sharing the final results with them).

- Another limitation to HDM is the number of pairwise comparisons, the experts are expected to do, for each level in the HDM hierarchy, there are $n *(n-1) / 2$ comparisons, if the criteria, for example were 10, then there are 45 comparisons. A large number of comparisons will exhaust the experts, making them tired or bored, which means they will probably offer less accurate judgments. Mitigation would be to make sure that there is a reasonable number of elements in each level, however; that might mean in some cases, losing essential elements that affect the reliability of the decision, the model offer.

- Furthermore, in the case of comparing alternatives against each other; the introduction of new alternative might radically change the results, which desirability curves solve completely.

- Finally, HDM models might show lack of flexibility; if the conditions under which the model was developed change (application or time), the model become inaccurate. Sensitivity analysis can show how flexible the model is to change. Mitigation, in this case, is to re-conduct the pairwise comparisons again, when it is determined that elements with high sensitivity have seen change. 
(Estep 2017; Gibson 2016; Abotah 2014; Iskin 2014; Lima Junior et al. 2014;

Kenny 2013; Tran and Daim 2008).

\subsubsection{City's Index of Readiness to Conduct a Smart-city-related Big Data Project}

For a project manager to assess a city's readiness to conduct a smart-city-related big data project, and as illustrated in Figure 12, the first step is to evaluate the city's current situation and capabilities for each factor in the model. Then, the project manager should consult the value curve of each factor, to find out which value curve's level matches the city's current situation and capabilities, and hence assign that level's score to the city.

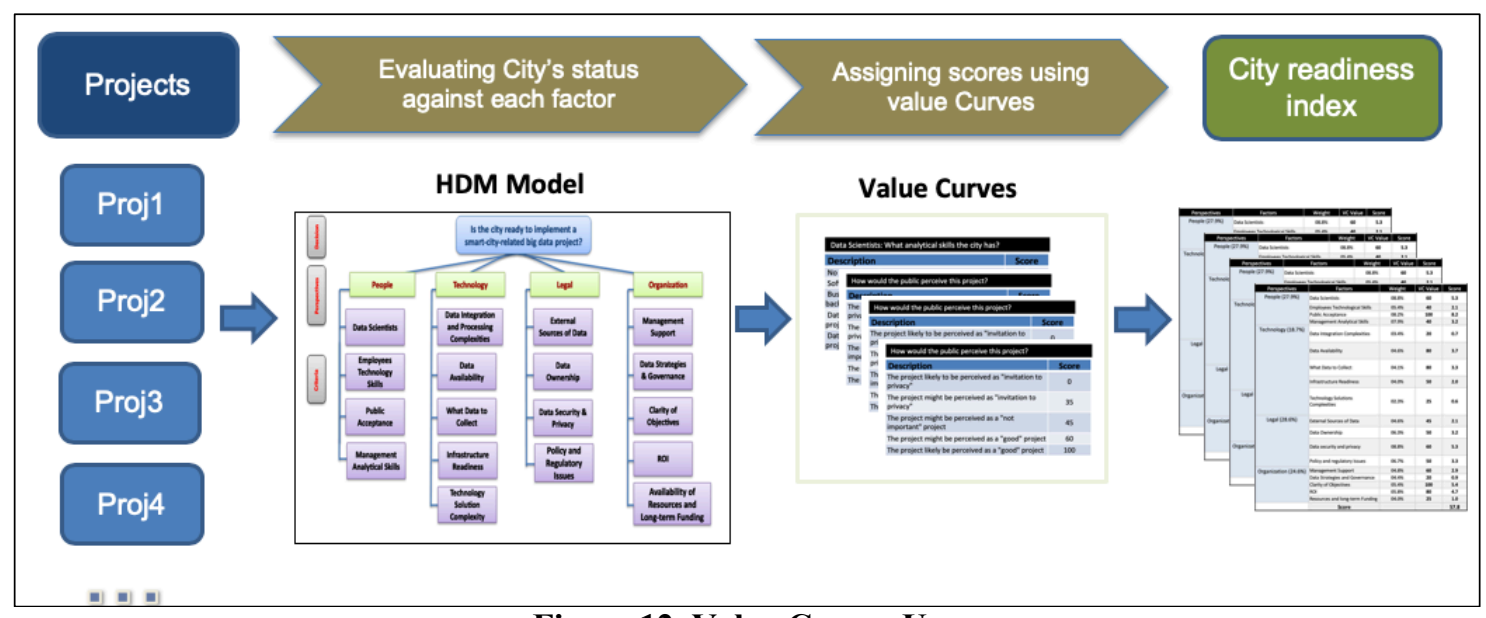

Figure 12. Value Curves Usage

Based on the discussion in Section 4.3.3, following is the equations that will be used to calculate the city's readiness for a smart-city-related big data project. Figure 13 illustrates the conceptual model behind the equation 12): 


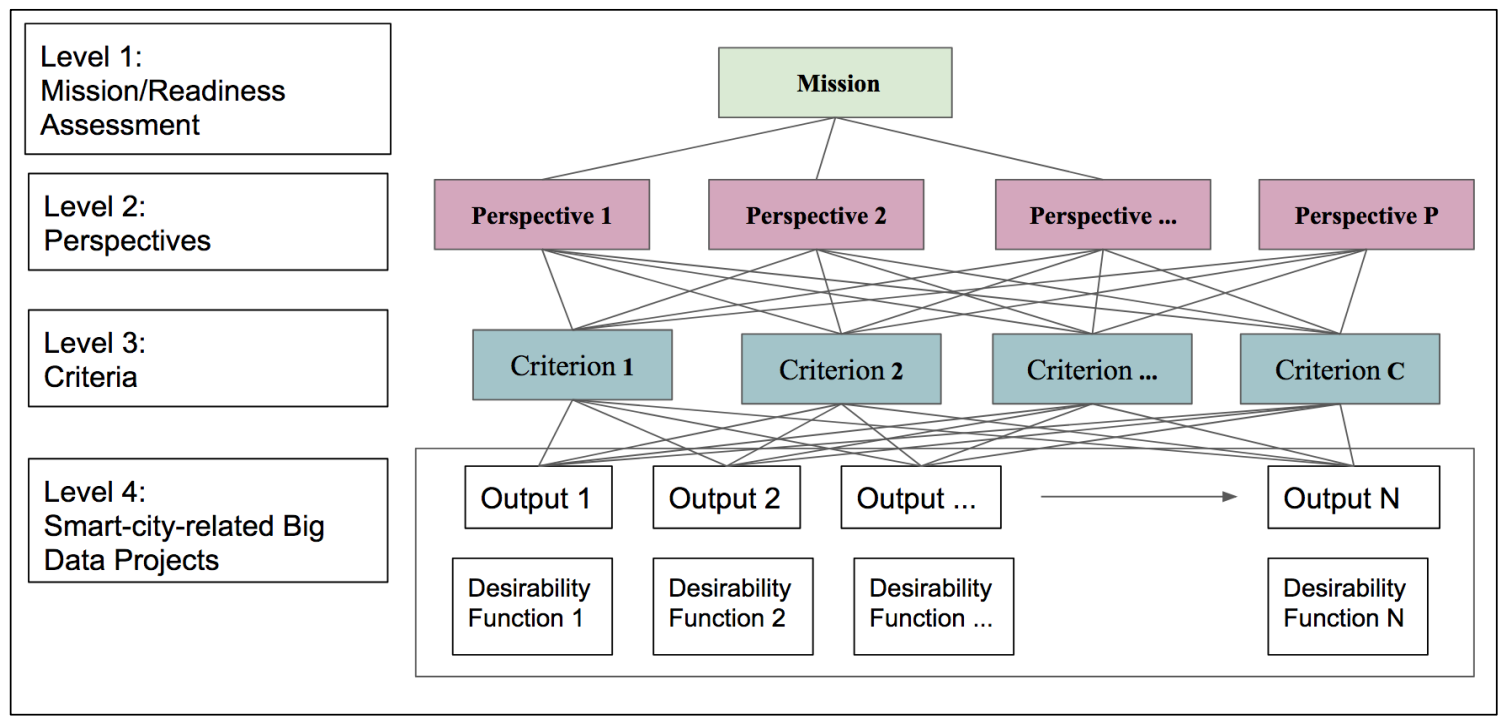

Figure 13. Conceptual HDM Model with Desirability Curves

Let:

C: Number of criteria (called factors in this research).

P: Number of perspectives.

I: Number of entities. In this research, an entity is a city conducting a smart-city-related big data project, if the same city is doing several smart-city-related big data projects, then the combination of the city and each project represents an entity

$E\left(\boldsymbol{a}_{\boldsymbol{i}}\right)$ : The readiness score of a city for a smart-city-related big data project $\boldsymbol{a}_{\boldsymbol{i}}$.

$a_{i}$ : a smart-city-related big data project, $i: 1 \ldots \mathrm{I}$

$P_{p}$ : The degree (weight) to which perspective $p$ contributes towards the mission (the mission is readiness assessment of a city for a smart-city related big data project). $C_{c}^{p}$ : The relative contribution of criterion $c$ under perspective $p$ towards the mission. $d\left(m_{i}, C_{c}\right)$ : Desirability of performance metric of $\boldsymbol{a}_{\boldsymbol{i}}$ for $c^{t h}$ criterion.

Then 


$$
\mathrm{E}\left(a_{i}\right)=\sum_{p=1}^{P} \sum_{c=1}^{C} P_{p} C_{c}^{p} d\left(m_{i}, c\right)
$$

Equation 12

\subsubsection{Methodology Justification and Comparison with other Methodologies}

This research aim is to introduce a framework to be used to conduct a readiness assessment of a city's ability to implement smart-city-related big data project.

Based on the discussion about readiness assessment in Section 2.5, following is a list of other potential approaches, quantitative and qualitative, that were used in literature before to address challenges affecting successful information technologies implementation, hence, might be possible candidates. Furthermore, Table 5 shows a list of pros and cons and sample research that used each method. The pros and cons are not an exhaustive list, but rather showing important points when considering each of these approaches for this research:

Delphi Method: This method aims at achieving the best possible consensus of a group of experts on a particular subject using a structured, iterative, and sequential communication approach. According to Linstone and Turoff (1975), "Delphi may be characterized as a method for structuring a group communication process so that the process is effective in allowing a group of individuals, as a whole, to deal with a complex problem. To accomplish this 'structured communication,' there is provided: some feedback of individual contributions of information and knowledge; some assessment of the group judgment or view; some opportunity for individuals to revise views; and some degree of anonymity for the individual responses." 
Usually, under this method, two or more rounds of getting experts' answers on questions and justification for those answers are conducted by a facilitator. In each round, the answers are recorded and then shared anonymously with the group. Then, experts are asked to revisit their answers after hearing the justification of other experts' answers. Rounds of collecting experts answers, review them and ask them to revise their answers, continue until criteria are met, like a certain number of rounds, or satisfactory agreement. Delphi method is typically used for forecasting or decision making when there is a high level of uncertainty and speculation (Tran and Daim 2008; Okoli and Pawlowski 2004; Linstone and Turoff 1975).

Technique for Order of Preference by Similarity (TOPSIS): TOPSIS method is a multi-criteria decision-making method. TOPSIS determines the ideal solution and the negative-ideal solution. The ideal solution maximizes the benefit criteria and minimizes the cost criteria, whereas the negative ideal solution maximizes the cost criteria and minimizes the benefit criteria. TOPSIS then selects the alternative with the shortest distance from the ideal solution and the farthest distance from the negative-ideal solution as the best alternative. Opricovic and Tzeng explained the mathematical equations of TOPSIS neatly (Opricovic and Tzeng 2004). TOPSIS basically uses an aggregation function to represent closeness and distance from reference points (Puthanpura et al. 2018; Lima Junior et al. 2014; Opricovic and Tzeng 2004; Chen 2000; Chen and Hwang 1992).

Analytic Network Process (ANP): This multi-criteria decision-making method was introduced by Saaty as a generalization of the AHP method (Saaty 2013). While AHP 
and HDM assume that each element in the criteria is independent of the other elements, and the hierarchy goes in one direction, ANP, on the other hand, allows dependency and bidirectional flow hence can be used in situations where this is the case. It does that by forming control hierarchy, strategic criteria, clustering criteria, supermatrix, and submatrices. More details about the math behind this method can be found here (Saaty 2013; Razmi et al. 2009).

\section{Preference Ranking Organization Method for Enrichment Evaluations}

(PROMETHEE): This multi-criteria decision method was introduced by Brans in the early 1980s (Brans et al. 1986). PROMETHEE is more focused on the ranking of alternatives and assumes the weights for the hierarchy were established beforehand. PROMETHEE has six options allowing the user different ways to express meaningful differences by minimum gaps between observations. The initial version of PROMETHEE was developed to show only the best alternative based on the positive and negative flows, later versions of the method show the rank of all options, and they are based on multicriteria net flow with consideration of indifference and preference thresholds (Brans and Smet 2016; Balali et al. 2012; Olson 2001; Brans et al. 1986).

Case Study: Case study methodology is used to establish meaningful characteristics about real-life events of a contemporary phenomenon by investigating the structure of the events underlying that phenomenon. The case study aim is to explain those events by asking the how and why questions through the utilization of tools such as interviews, questionnaires, reviewing archives and observations, with the realization of the contextual conditions affecting the phenomenon (Yin 2009). According to Eisenhardt 
(1989) "case study is a research strategy which focuses on understanding the dynamics present within single settings.”

The case study can be used to provide a description, testing theory, or generating theory, and it has been used in wide range of disciplines like psychology, political science, anthropology, social work, business, education and so on (Yin 2009; Eisenhardt 1989).

Surveys and Questionnaires: This method helps collect attributes and characteristics about a phenomenon, by asking people about their beliefs or attitudes concerning the phenomenon. Surveys typically contain highly structured and well-designed close-ended questions (Dalati and Gómez 2018; Dillman 1978).

Decision Models Based on Experts Feedback: A qualitative approach, in which experts are interviewed with open-ended questions about the phenomenon, and their answers are analyzed for common patterns of issues related to the decision, then a multi-criteria framework is established based on those criteria (Klievink et al. 2017). Technology Acceptance Model (TAM): According to Davis (1993) TAM: "specifies the causal relationships between system design features, perceived usefulness, perceived ease of use, attitude toward using, and actual user behavior." This method focuses on the factors affecting user's decision to accept new technology, by focusing on the factors that affect the "Perceived usefulness" and "Perceived ease-of-use" of new technology (Chuttur 2009; Legris et al. 2003; Davis 1993).

Cognitive Maps (FCM): Is a simple form of recursive neural networks, in which concepts are represented as nodes in a graph. Nodes are connected with arrows that show 
the direction of influence between nodes. A positive (negative) arrow pointing from the concept's node to another concept's node indicates how the first node causally increases or decreases the second node. It could be considered as "mental landscape" where "strength of impact" can be calculated (Jetter and Kok 2014; Stach et al. 2010; Kosko 1986).

Table 5. Potential Decision-Making Methods Comparison

\begin{tabular}{|c|c|c|c|}
\hline Name & Pros & Cons & Examples \\
\hline AHP & - Same pros for HDM. & $\begin{array}{l}\text { - In compare to HDM, the } 9 \\
\text { points scoring approach of AHP } \\
\text { can be confusing and reduce the } \\
\text { ability to make an accurate } \\
\text { judgment by experts. }\end{array}$ & $\begin{array}{l}\text { Majumdar et al } \\
\text { 2017; Oztaysi } \\
\text { 2014; Lai et al. } \\
2002\end{array}$ \\
\hline Delphi & $\begin{array}{l}\text { - Aggregate opinions of } \\
\text { diverse experts. } \\
\text { - Achieve consensus among } \\
\text { them. } \\
\text { - Experts are not affected by } \\
\text { the "loudest voice" in the } \\
\text { room. } \\
\text { - Everybody contributes to the } \\
\text { decision, no "silent } \\
\text { bystanders." } \\
\text { - No need for physical } \\
\text { meetings. }\end{array}$ & $\begin{array}{l}\text { - Requires good technical writing } \\
\text { skills. } \\
\text { - Response time can be long, and } \\
\text { some experts might drop out } \\
\text { between rounds. } \\
\text { - No clear criteria to determine } \\
\text { the acceptable level of consensus. } \\
\text { - Not practical when there is a } \\
\text { need to make decisions for } \\
\text { several separated cases at } \\
\text { different times. } \\
\text { - No proper quantification of } \\
\text { which factors are more or less } \\
\text { important in making the decision. } \\
\text { - No proper approach to follow up } \\
\text { after the decision is made. }\end{array}$ & $\begin{array}{l}\text { Kache and } \\
\text { Seuring 2017; } \\
\text { El-Gazzar et al. } \\
2016\end{array}$ \\
\hline
\end{tabular}




\begin{tabular}{|c|c|c|c|}
\hline Name & Pros & Cons & Examples \\
\hline TOPSIS & $\begin{array}{l}\text { - Similar benefits to Delphi } \\
\text { method (except it uses } \\
\text { mathematical equations to } \\
\text { aggregate experts judgment } \\
\text { instead of several rounds } \\
\text { questionnaires). } \\
\text { - Less number of comparisons } \\
\text { in compare to HDM and AHP. } \\
\text { - No limitation on the number } \\
\text { of criteria. }\end{array}$ & $\begin{array}{l}\text { - No structured approach to } \\
\text { weight the criteria. } \\
\text { - Does not consider the relative } \\
\text { importance of the distances. } \\
\text { - Do not pinpoint clearly on the } \\
\text { criteria that caused one alternative } \\
\text { to be closer to the ideal solution } \\
\text { or the negative-ideal solution in } \\
\text { comparison to other alternatives. }\end{array}$ & $\begin{array}{l}\text { Puthanpura et } \\
\text { al. 2018; Bhutia } \\
\text { and Phipon } \\
\text { 2012; } \\
\text { Mahmoodzadeh } \\
\text { et al. 2007; }\end{array}$ \\
\hline $\begin{array}{l}\text { Analytic } \\
\text { Network } \\
\text { Process }\end{array}$ & $\begin{array}{l}\text { - Same pros for HDM (see } \\
\text { Q5.a). } \\
\text { - More generalized (bi- } \\
\text { directional and inter- } \\
\text { connectivity). }\end{array}$ & $\begin{array}{l}\text { - More complex. } \\
\text { - If elements are independent, } \\
\text { then there is no extra value of } \\
\text { using it in comparison to HDM or } \\
\text { AHP. }\end{array}$ & $\begin{array}{l}\text { Shieh et al. } \\
\text { 2015; Razmi et } \\
\text { al. } 2009\end{array}$ \\
\hline PROMETHEE & $\begin{array}{l}\text { - Relatively simple: Requires } \\
\text { less interaction with decision } \\
\text { makers. }\end{array}$ & $\begin{array}{l}\text { - No structured approach to } \\
\text { weight the criteria. } \\
\text { - Do not show clearly what } \\
\text { criteria contributed to the best- } \\
\text { alternative choice, and one } \\
\text { approach of this method shows } \\
\text { only the best alternative with no } \\
\text { ranking for other alternatives. } \\
\text { - There is not much value in this } \\
\text { method when evaluating one } \\
\text { alternative at a time. }\end{array}$ & $\begin{array}{l}\text { Shukla et al. } \\
\text { 2016; Kilic et } \\
\text { al. } 2015\end{array}$ \\
\hline Case Study & $\begin{array}{l}\text { - Helpful in drawing } \\
\text { conclusions from one case, } \\
\text { that can be the base for more } \\
\text { generalization. } \\
\text { - Helpful as an exploratory } \\
\text { method. }\end{array}$ & $\begin{array}{l}\text { - This method analyzes one setup } \\
\text { (or few setups) only, so it cannot } \\
\text { be generalized with enough } \\
\text { reliability. } \\
\text { - Inherently biased. }\end{array}$ & $\begin{array}{l}\text { Fitzgerald } \\
\text { 2016; Lim et al. } \\
\text { 2015; }\end{array}$ \\
\hline $\begin{array}{l}\text { Surveys and } \\
\text { Questionnaires }\end{array}$ & $\begin{array}{l}\text { - More robust results do not } \\
\text { have consistency and } \\
\text { disagreement issues. } \\
\text { - Representative samples } \\
\text { create confidence. }\end{array}$ & $\begin{array}{l}\text { - Its value comes from well- } \\
\text { designed questions that capture } \\
\text { the attributes of the phenomenon, } \\
\text { which is not the case when there } \\
\text { is high uncertainty, or ambiguity, } \\
\text { like with emerging technologies. } \\
\text { - On emerging issues, finding a } \\
\text { representative sample is difficult. }\end{array}$ & $\begin{array}{l}\text { Bock et al. } \\
2017 ; \\
\text { NewVantage } \\
\text { Partners } 2017 ; \\
\text { Ransbotham } \\
\text { and Kiron } 2017\end{array}$ \\
\hline
\end{tabular}




\begin{tabular}{|c|c|c|c|}
\hline Name & Pros & Cons & Examples \\
\hline $\begin{array}{l}\text { Decision } \\
\text { Models Based } \\
\text { on Experts } \\
\text { Feedback }\end{array}$ & - Simple and Fast. & $\begin{array}{l}\text { - Lacks academic rigor. } \\
\text { - A simple listing of factors } \\
\text { without weights to reflect the } \\
\text { different impact/importance of } \\
\text { each factor. }\end{array}$ & $\begin{array}{l}\text { Bertino, Elisa, } \\
\text { and Elena } \\
\text { Ferrari. 2018; } \\
\text { Klievink et al. } \\
\text { 2017; Al } \\
\text { Nuaimi et al. } \\
2015\end{array}$ \\
\hline $\begin{array}{l}\text { Technology } \\
\text { Acceptance } \\
\text { Model }\end{array}$ & $\begin{array}{l}\text { - Useful to predict/forecast } \\
\text { customers attitude towards a } \\
\text { future technology. }\end{array}$ & $\begin{array}{l}\text { - Focuses on customers' } \\
\text { perception only. } \\
\text { - Similar challenges to surveys. }\end{array}$ & $\begin{array}{l}\text { Wease et al. } \\
2018 ; \\
\text { Marangunić } \\
\text { and Granić } \\
2015\end{array}$ \\
\hline $\begin{array}{l}\text { Cognitive } \\
\text { Maps }\end{array}$ & $\begin{array}{l}\text { - Very useful in modeling } \\
\text { dynamic systems. } \\
\text { - Helps to understand cause- } \\
\text { effect relationships between } \\
\text { concepts within a system. } \\
\text { - Decision making with } \\
\text { estimated values under } \\
\text { incomplete or uncertain } \\
\text { information. }\end{array}$ & $\begin{array}{l}\text { - More helpful for making } \\
\text { decisions around future } \\
\text { technologies where there is a high } \\
\text { amount of incomplete } \\
\text { information. } \\
\text { - The graphical representation is } \\
\text { not easy to read, making the final } \\
\text { product of this approach less } \\
\text { usable by non-academic industry } \\
\text { practitioners. } \\
\text { - No explicit methods to judge } \\
\text { experts' inconsistency and } \\
\text { disagreement. }\end{array}$ & $\begin{array}{l}\text { Jetter and } \\
\text { Sperry 2013; } \\
\text { Iakovidis and } \\
\text { Papageorgiou } \\
\text { 2011; Siraj et } \\
\text { al. 2001 }\end{array}$ \\
\hline
\end{tabular}

For the model proposed in this research to be able to fulfill the research goal and answer the research questions adequately, it should include several attributes. Hence, the methodology that will be used to build the model should be able to accommodate those attributes into the generated model of the research. Following are those attributes:

First, the research is about conducting readiness assessment of a city's ability to implement smart-city-related big data project, which is a complex topic, as shown by the literature review (See section 2). It requires considering several criteria under different 
perspectives related to the project requirements and the city's abilities against those requirements. So, the model should be a multi-criteria decision model.

Furthermore, for a city to decide how to focus their efforts, and decide which of the weak areas (in the form of readiness factors), revealed by the model, should be addressed entirely and which weak areas need less thorough preventive/corrective actions, the model should: First, have weights showing clearly the impact/importance of each criterion. Second, show the areas (in the form of criteria) where the city capabilities are weak. Finally, the model should clearly indicate why the city underperformed (or has weak capabilities) against the said criteria and what is the desirable capabilities they should acquire to perform well against it.

Moreover, such a model should be easy to use by project managers, who do not necessarily have a post-graduate-level-academic background. The model should also be reusable, as the city will seek to use it to evaluate their readiness against each big data project they are implementing as part of a smart-city initiative.

Finally, the model should reflect the judgment of experts from various related backgrounds to make sure the "weights" of criteria and the desirable capabilities of cities are reflective of real-life needs of cities since the goal of the model is to increase the chances of a successful project after all.

By referring to the benefits and limitations of HDM methodology and the discussion of the pros and cons of other methods above, it can be inferred that HDM is one of the most appropriate methodologies that can generate a model that have all the 
attributes needed to fulfill the research goal and answer the research questions since $\mathrm{HDM}$ is:

- A multi-criteria decision making (MCDM) method.

- Includes a hierarchy decision tree, allowing for more complex analysis and realization of complex and competing factors.

- Captures experts' judgment and transform it to numeric values using pairwise comparisons, which can be done anonymously and individually, that helps to address several concerns related to experts judgment. Furthermore, it allows analyzing experts' judgment using mathematical techniques for inconsistency and disagreement, hence, allowing proper handling of the reliability challenges associated with experts' judgment, to achieve a satisfactory degree of robustness in the model.

- Have weights for factors in each level of the hierarchy, allowing for proper modeling and analysis of the priority/impact of each factor (perspectives and criteria in my case).

- Desirability curves allow for clearly identifying the desired outcome for each criterion, as well as, the current level, the city has, against that criterion, for the project being considered.

- While building a model using HDM and desirability curves requires a strong academic background, the resulting model is intuitive and easy to use by users who do not need to have the same level of academic knowledge.

- Desirability curves allow for reusability of the model, which is important in this research case, as cities typically conduct a series of big data projects to implement its smart-city initiatives.

- Furthermore, sensitivity analysis allows for a better understanding of the flexibility of the model, and when it will require an update. 
Researchers had used HDM methodology before as a way to identify weak areas that need attention, related to the subject of their research. For instance, Dr. Estep researched technology transfer potential of research proposals. She developed an HDM model that can be used to rank research proposals based on which research proposals outcomes are more likely to move into real application. The HDM model developed by Dr. Estep can show, for proposals with poor ranking, what are the reasons for that, hence allowing for proposal enhancements (Estep 2017). Moreover, Dr. Gibson researched the performance of research centers within an organization. She developed an HDM model to compare the effectiveness of the cooperative research centers within an organization. The model highlights which research centers are the best performers, and which are the low performers. For low-performing centers, the model highlights, which factors are causing low performance. Therefore, those centers can focus on addressing those issues (Gibson 2016). 


\section{CHAPTER 4: RESEARCH DESIGN}

The research design is based on previous work that used HDM methodology (Estep 2017; Gibson 2016; Abotah 2014; Iskin 2014; Phan 2013). The research was conducted in four phases. Section 4.1 offers a summary of those phases, and Section 4.2 offers details of the research was carried out.

\subsection{High-Level Research Review}

On a high-level, the research can be divided into four phases (see Figure 14) including, Literature review, HDM model development, model validation and quantification, and Results analysis, discussion, and conclusions.

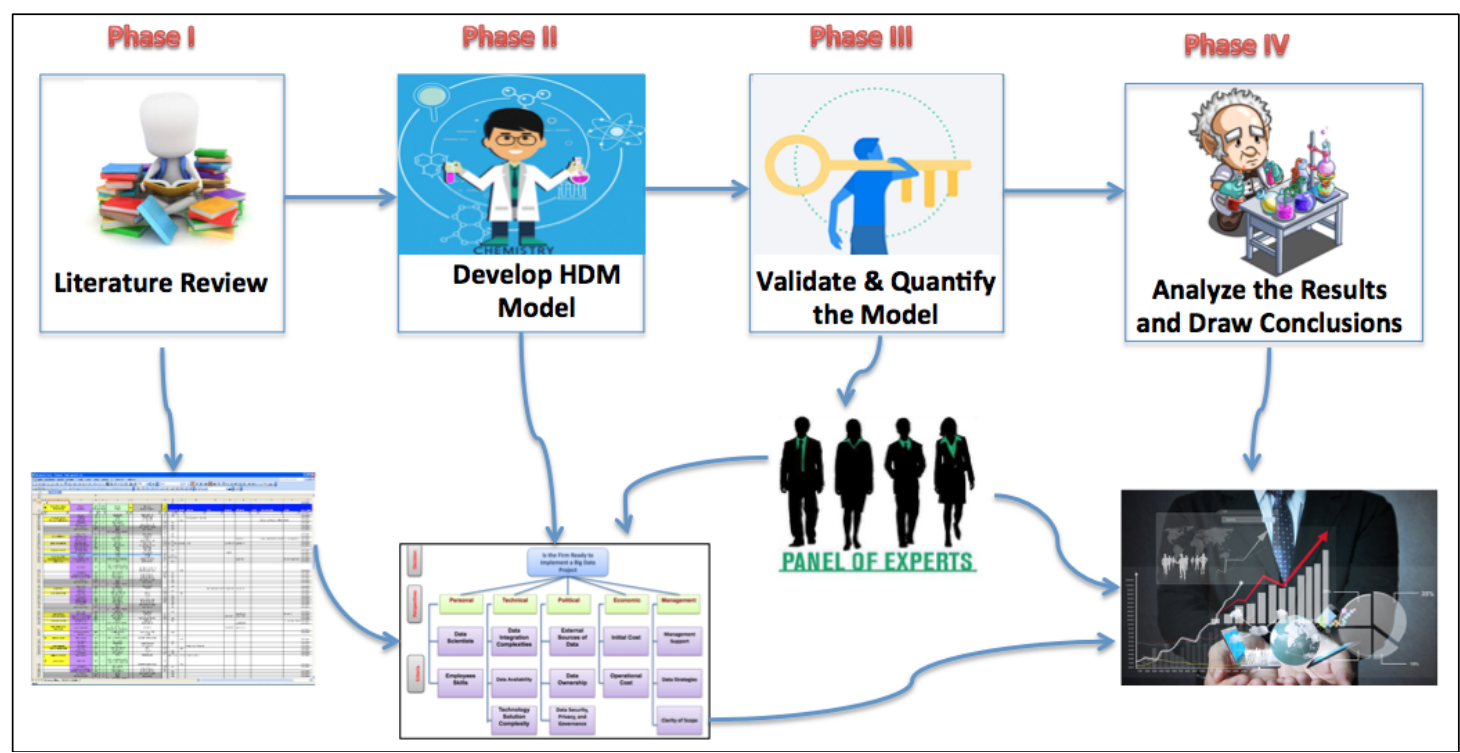

Figure 14. Research Phases

- Literature review: Covers the background information around big data, smart cities, big data projects challenges, and smart cities. The findings of the research will be used as the basis to develop the HDM model. 
- HDM model development: Based on the findings of the literature review, the initial HDM model and desirability curves will be developed. This phase will overlap with the next phase, were experts' feedback will be used to finalize the HDM model.

- Model validation and quantification: Several panels of experts will be formed to validate and quantify the model. Each panel will represent specific expertise that will be used to evaluate related parts of the model. The experts will be first asked to evaluate the criteria and desirability curves values. Then, they will be asked to conduct a pairwise comparison based on the HDM approach to quantify the model. Finally, the case study's city will be evaluated against the desirability curves.

- Results analysis, discussion, and conclusions: The pairwise comparisons by experts will be first validated using sensitivity and disagreement analysis. Then, projects conducted by a city will be analyzed and compared with the HDM model results. Finally, the business impact of the results and their meaning and implication will be discussed. Leading to the final conclusions of the research.

\subsection{Research Design Details}

Figure 15 illustrates the research design details. This design is following the same approach by previous research that used HDM and value curves (Estep 2017; Gibson 2016; Abotah 2014; Iskin 2014; Phan 2013). The research consisted of 15 steps as follow: 


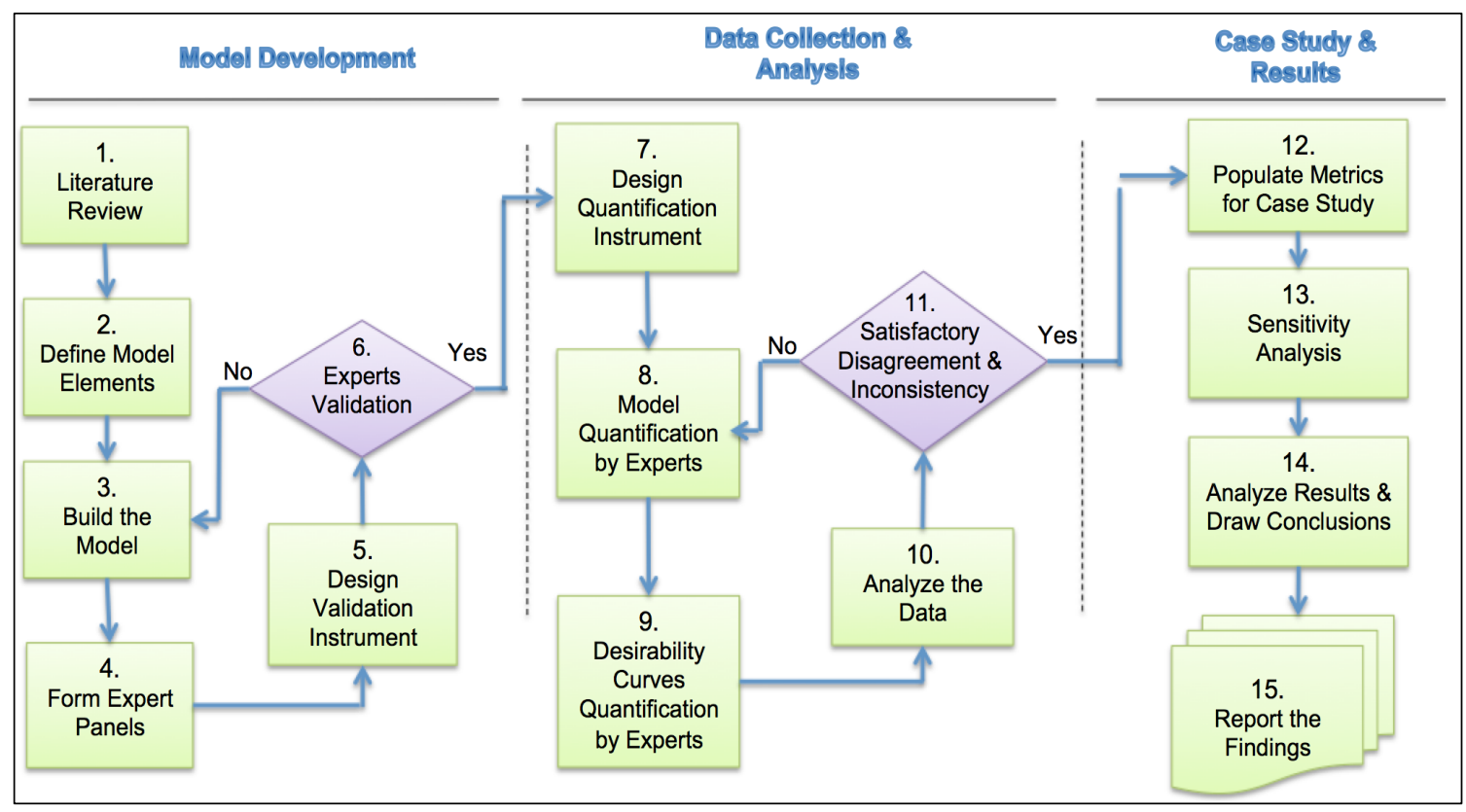

Figure 15. Research Approach Design

1. Conducting Literature Review: The primary goal of this phase was to identify the research gaps, objective, and questions. Detailed literature review and gap analysis can be found in Chapters 2 and 3.

2. Defining Model Elements: This step is also done based on literature review, the model initial elements were identified in Section 2.6. The main factors/criteria, affecting smartcity-related big data projects chances of success, where listed under four perspectives, along with a detailed discussion.

3. Building the Initial Model: This step is also done based on the findings from the literature review and gap analysis. Figure 16 illustrates the initial model. 


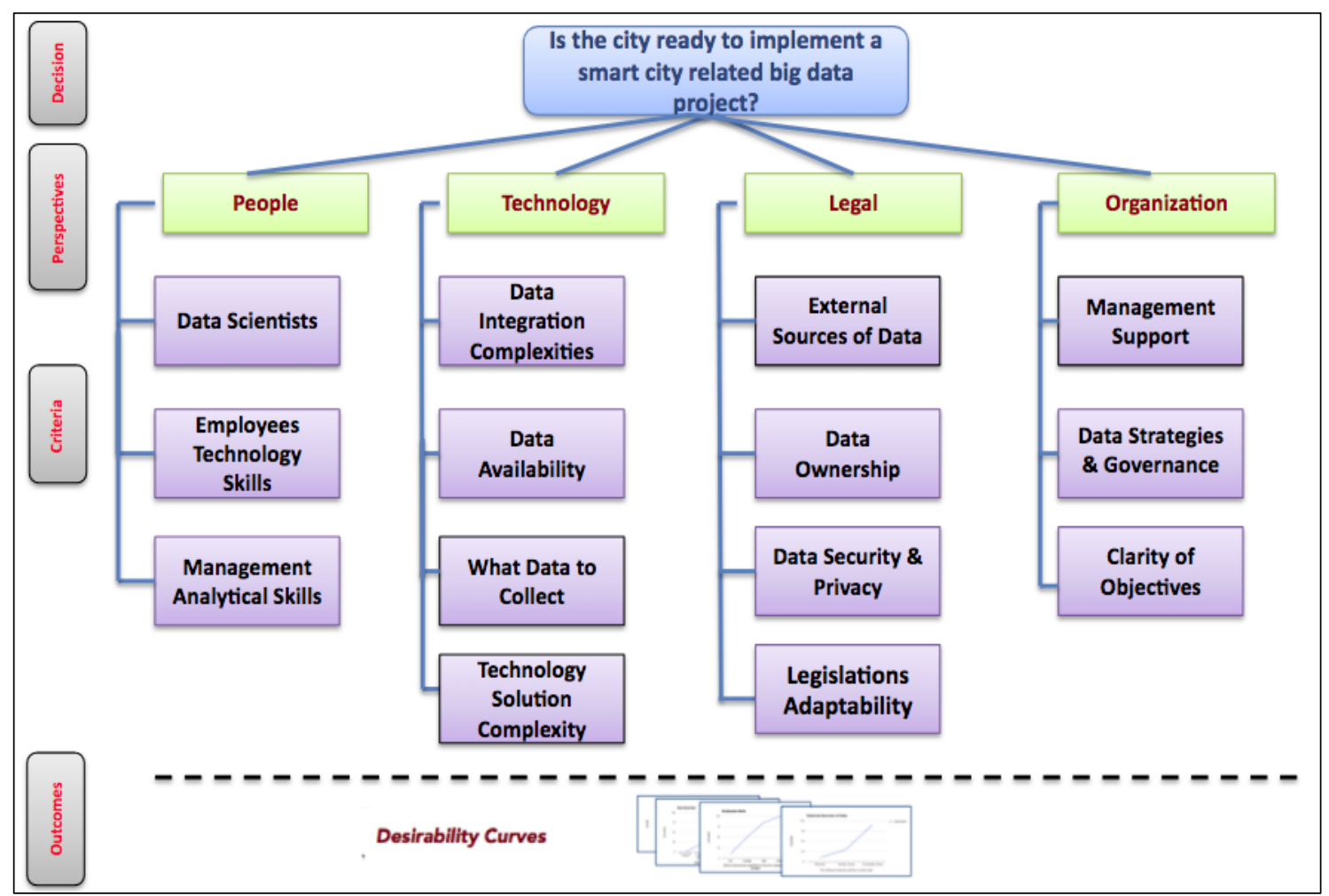

Figure 16. HDM Model for City's Readiness Assessment for a Smart-city-related Big Data Project

4. Forming Expert Panels: As part of this step, experts were invited to join expert panels.

More details about expert panels formation can be found in Section 4.3.

5. Designing Validation Instrument: Using Qualtrics software, a validation survey was developed and sent to experts to ask them to validate the model (as illustrated in Figure 17). Experts were also allowed to suggest new elements in each survey as well.

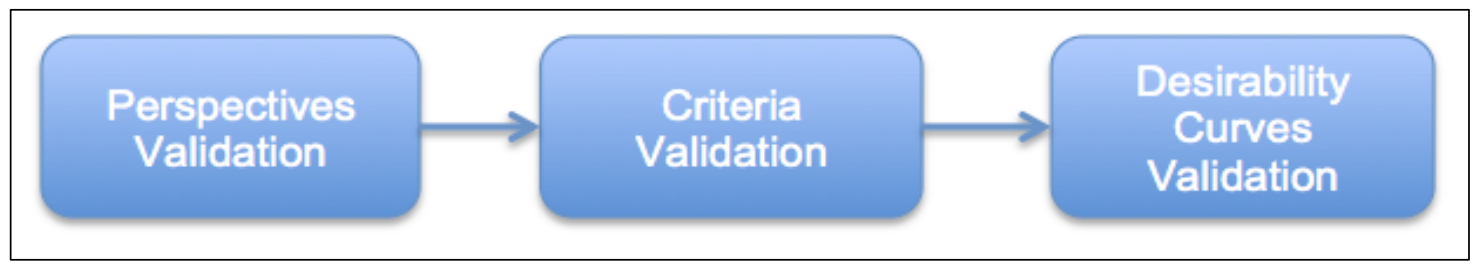

Figure 17. Model Validation

6. Experts Validation: Each element in the model was considered validated if a majority of three-quarter of the experts approve it. If a particular element failed to achieve this 
threshold, it will be removed. If a new element is suggested at any level by more than three experts, it will be added to the model, then steps 3,5 and 6 will be repeated. If a new element at any level is suggested by three or fewer experts only, it will be investigated using literature review, if there is support for that element, it will be added to the model, then steps 3,5, and 6 will be repeated (Section 5.2 includes the results of the validation).

7. Designing Quantification Instrument: Qualtrics survey software and The ETM HDMC software were used to collect experts' judgments of the model, in the form of pairwise comparisons, and then feedback was transformed into weights for perspectives and criteria.

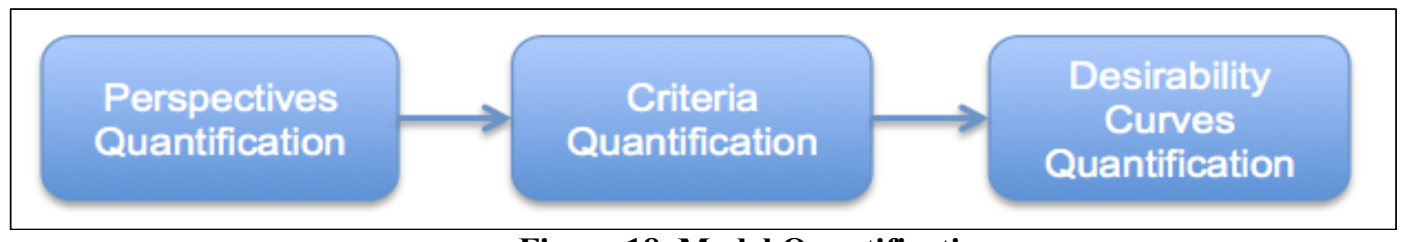

Figure 18. Model Quantification

8. Model Quantification by Experts: A survey was sent (as illustrated in Figure 18). Weights were calculated based on the constant-sum approach, as explained in Chapter 3. 9. Desirability/Value Curves Quantification by Experts: One-on-one meetings with experts were conducted, where experts were asked to identify possible statuses a city might have against each factor, based on their experience, and what score could be assigned with that status.

10. Analyzing the Data: Disagreement and inconsistency analysis were conducted to find out how reliable experts individual and collective judgment is as follow (see also Figure 19): 


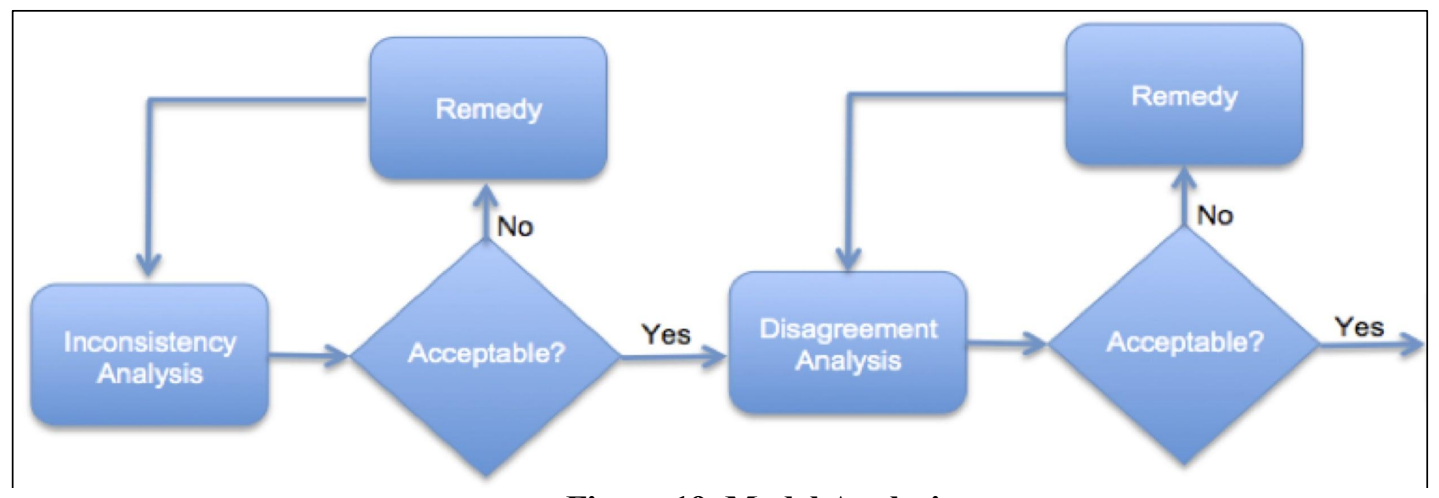

Figure 19. Model Analysis

Inconsistency: Using the inconsistency equation, as explained in Section 3.4.2.2.

For each expert with high inconsistency $(>0.1)$ :

- A discussion with each expert with high inconsistency will be conducted to make sure he/she clearly understand what is required.

- Then they will be asked to redo their quantification.

- If the inconsistency continues, the expert will be removed, and his/her judgment will be canceled.

Disagreement: Using the disagreement equations, as explained in Section 3.4.2.3.

For each element with high disagreement $(>0.1)$ :

- First, experts causing the disagreement will be identified, using standard deviation.

- If one or a few experts cause the disagreement:

○ Experts will be interviewed to find out why they gave the judgment they did, and it will result in one of three outcomes:

- Expert(s) are not really experts in the subject, and they will be removed 
- Expert(s) misunderstood the questions, and it will be clarified to them, then they will be asked to do the pairwise comparisons again

- Expert(s) have a valid point, which was not considered by the researcher (myself). In this case, the same point will be relayed to the other experts, and they (the other experts) will be asked to redo their pairwise comparisons.

- If the disagreement is caused by a relatively large group within the panel (more than 30\%), then cluster analysis will be conducted in Section 3.4.2.3. Each group of experts will be analyzed for similarities, if groups with distinct backgrounds have similar opinions, then the overall disagreement should be fine, as it represents a variety of opinions, and the final weights are representatives of real-life weights.

- If there are no clear background similarities between experts with similar opinions, then a Delphi approach will be used to have experts approach a concise judgment

11. Satisfactory Disagreement \& Inconsistency: In this phase, after experts' feedback was validated for inconsistency and disagreement, the model was finalized (see Chapter 5.3 for details). Weights were assigned to the model and value curves, and the model is ready to be used to assess a city's readiness to implement a big data project.

12. Populate Metrics for a Case Study: In this step, the model was applied to real projects to validate its practicality and ability to assess a city's readiness for a big data project. Four smart-city-related projects, including three being done by the City of Portland and one by the Transportation Research and Education Center (TREC) of Portland State University, were evaluated (see Chapter 6 and 7 for details). The researcher investigated 
the City of Portland status against the first three projects, at the time of selecting those projects, as well as, the status of TREC for the fourth project at the time of selecting the fourth project. Then, the researcher used the value curves to score the City of Portland and TREC readiness for those projects, as explained in section 3.4.4.

Moreover, the researcher used the value curves to identify a series of improvements that can enhance readiness for each of the projects.

Finally, the model and the evolutions were shared with the City of Portland smartcity officials and with the TREC project manager (Panel P12), and they were interviewed about the results.

13. Conducting Sensitivity Analysis: Sensitivity analysis was conducted, as explained in Section 3.4.2.4. Using the approach of extreme scenario analysis, where each perspective is boosted separately, to find out the effect on the scores (see Chapter 7 for more details). 14. Analyzing Results \& Drawing Conclusions: The final model and the application of the model for real projects used by the City of Portland and the TREC were analyzed leading to a discussion about the findings and implications.

15. Reporting the Findings: Finally, the results are reported in this dissertation. 


\subsection{Expert Panels Design}

\subsubsection{Expert Panels Format}

In reference to the discussion about experts' selection in section 5.3 and previous similar research, in term of using the HDM methodology (Estep 2017; Gibson 2016;

Abotah 2015; Iskin 2014; Phan 2013, Sheikh 2013), my research will include 12 panels to validate and quantifying my model, as explained in Table 6:

Table 6. Expert Panels

\begin{tabular}{|c|c|c|}
\hline Panel & Role & Tool \\
\hline $\mathrm{P} 1$ & Validate the perspectives & Qualtrics survey \\
\hline $\mathrm{P} 2$ & Validate the factors under the people perspective & Qualtrics survey \\
\hline P3 & Validate the factors under the technology perspective & Qualtrics survey \\
\hline P4 & Validate the factors under the legal perspective & Qualtrics survey \\
\hline P5 & Validate the factors under the organization perspective & Qualtrics survey \\
\hline P6 & Validate any changes due to the results of the validation phase & Qualtrics survey \\
\hline P7 & Quantify the perspectives & $\begin{array}{l}\text { ETM HDMC software } \\
+ \text { Qualtrics survey }\end{array}$ \\
\hline P8 & $\begin{array}{l}\text { Quantify the people perspective factors and related desirability } \\
\text { curves }\end{array}$ & $\begin{array}{l}\text { ETM HDMC software } \\
+ \text { Qualtrics survey }\end{array}$ \\
\hline P9 & $\begin{array}{l}\text { Quantify the technology perspective factors and related desirability } \\
\text { curves }\end{array}$ & $\begin{array}{l}\text { ETM HDMC software } \\
+ \text { Qualtrics survey }\end{array}$ \\
\hline $\mathrm{P} 10$ & Quantify the legal perspective factors and related desirability curves & $\begin{array}{l}\text { ETM HDMC software } \\
+ \text { Qualtrics survey }\end{array}$ \\
\hline P11 & $\begin{array}{l}\text { Quantify the organization perspective factors and related desirability } \\
\text { curves }\end{array}$ & $\begin{array}{l}\text { ETM HDMC software } \\
+ \text { Qualtrics survey }\end{array}$ \\
\hline $\mathrm{P} 12$ & $\begin{array}{l}\text { Assess Portland City's smart-city-related big data projects against } \\
\text { desirability curves }\end{array}$ & Interviews \\
\hline
\end{tabular}


P1: This panel will be asked to validate the perspectives. They will be asked through the Qualtrics survey tool, to approve the current perspectives, as well as, to suggest other perspectives for each level. Experts should be coming from a management background or academic background.

P2: This panel will be asked to validate the factors under the people perspective. They will be asked through the Qualtrics survey tool, to judge the suitability of the factors and to identify factors that might have gone undetected during the literature review. Experts should be coming from project management, data science, academic-related research, and business analysis/consulting background.

P3: This panel will be asked to validate the factors under the technology perspective. They will be asked through the Qualtrics survey tool, to judge the suitability of the factors and to identify factors that might have gone undetected during the literature review. Experts should be coming from project management, software engineering, academic-related research, and business analysis/consulting background.

P4: This panel will be asked to validate the factors under the legal perspective. They will be asked through the Qualtrics survey tool, to judge the suitability of the factors and to identify factors that might have gone undetected during the literature review. Experts should be coming from project management, academic-related research, Managementlevel Public Employees, and business analysis/consulting background.

P5: This panel will be asked to validate the factors under the organization perspective. They will be asked through the Qualtrics survey tool, to judge the suitability of the factors and to identify factors that might have gone undetected during the literature 
review. Experts should be coming from project management, public and private sector management, academic-related research, and business analysis/consulting background. P6: This panel will be asked to validate the perspectives and factors changes that might result from validating the model by panels 1 to 5 . This is a special panel that will include experts based on how their expertise is related to the changes. Experts in this panel will be asked through the Qualtrics survey tool, to judge the suitability of the changes. Experts should be coming from all the seven backgrounds identified in this research.

P7: This panel will be asked to quantify the perspectives by conducting pairwise comparisons between every two perspectives, using the Qualtrics survey tool and the ETM HDMC software. In addition, some of the experts in this panel will be asked to quantify the related desirability curves using one-on-one interviews. Experts should be coming from management (public and private sectors) background and academic background.

P8: This panel will be asked to quantify the factors under the people perspective by conducting pairwise comparisons between every two perspectives, using the Qualtrics survey tool and the ETM HDMC software. In addition, some of the experts in this panel will be asked to quantify the related desirability curves using one-on-one interviews. Experts should be coming from project management, data science, academic-related research, and business analysis/consulting background.

P9: This panel will be asked to quantify the factors under the technology perspective by conducting pairwise comparisons between every two perspectives, using the Qualtrics survey tool and the ETM HDMC software. In addition, some of the experts in this panel 
will be asked to quantify the related desirability curves using one-on-one interviews. Experts should be coming from project management, software engineering, academicrelated research, and business analysis/consulting background.

P10: This panel will be asked to quantify the factors under the legal perspective by conducting pairwise comparisons between every two perspectives, using the Qualtrics survey tool and the ETM HDMC software. In addition, some of the experts in this panel will be asked to quantify the related desirability curves using one-on-one interviews. Experts should be coming from project management, academic-related research, Management-level Public Employees, and business analysis/consulting background. P11: This panel will be asked to quantify the factors under the organization perspective by conducting pairwise comparisons between every two perspectives, using the Qualtrics survey tool and the ETM HDMC software. In addition, some of the experts in this panel will be asked to quantify the related desirability curves using one-on-one interviews. Experts should be coming from project management, public and private sector management, academic-related research, and business analysis/consulting background. P12: This panel will be asked to provide details about big data projects under the City of Portland smart-city initiative, throw one-on-one interviews. The details will be used by the researcher along with desirability curves to evaluate the big data projects using the model. Experts should be people related to the projects being evaluated, mainly project managers and city officials.

The general selection criteria for experts regarding smart-city-related big data projects readiness assessment include: 
- Expertise in the topic.

- Balance biases.

- Diversity in term of background, details of exposure to the research topic, and coming, as much as possible, from different organizations, to avoid bias by influence.

Furthermore, the research instruments would be email, online chat software (Hangout and Whatsapp) and online software tools (HDM@ and Qualtrics), so panelists will not meet physically, hence, bias by influence and silent bystanders issues will not affect research quality.

In term of background, the following is sought:

1. Project managers who managed projects related to big data, analytics, business intelligence reporting, data warehouse, smart cities, and data-driven software integrations. These technology areas were selected as they are related to big data projects to various degrees and project managers exposed to such projects can offer relevant and valuable judgment.

2. Software engineers who worked on projects related to big data, analytics, business intelligence reporting, data warehouse, smart cities, and data-driven software integrations. These technology areas were selected as they are related to big data projects to various degrees and project managers exposed to such projects can offer relevant and valuable judgment.

3. Business consultants/ analysts who offer big data and smart-city-related consulting and business analysis.

4. Data scientists with a focus on individuals who did smart-city related work. 
5. Academic researchers who are doing research related to big data, analytics, business intelligence reporting, data warehouse, and data-driven software integrations. As well as, research related to project management, with a particular focus on readiness assessment, pre-project risk mitigation, big-data-related project management challenges, and smart-cities-related challenges.

6. Business Leaders (IT): in companies that offer big data and smart-city-related solutions.

7. Management-level public employees: mainly city officials that are either making the strategic decisions within the city or supervising smart city initiatives.

For backgrounds from 1 until 4, the priority will be given for people who were exposed to public software projects.

Table 7 shows the roles/backgrounds that will be considered for each panel; the roles should be related to what is expected of the panel. For example, P1 panel will evaluate the model and how accurately it represents the main challenges facing smartcity-related big data projects, so, experts with an overview of the big picture of big data projects will be asked to evaluate the model. Another example is the P4 panel, where experts will be asked to quantify technical-related challenges, so experts with the bigdata-technical-related background will be asked to do the quantification judgment. 
Table 7. Experts Backgrounds for Each Panel

\begin{tabular}{|l|c|c|c|c|c|c|c|c|c|c|c|c|}
\hline Role / Background & P1 & P2 & P3 & P4 & P5 & P6 & P7 & P8 & P9 & P10 & P11 & P12 \\
\hline Project Managers & $\mathrm{X}$ & $\mathrm{X}$ & $\mathrm{X}$ & $\mathrm{X}$ & $\mathrm{X}$ & $\mathrm{X}$ & $\mathrm{X}$ & $\mathrm{X}$ & $\mathrm{X}$ & $\mathrm{X}$ & $\mathrm{X}$ & \\
\hline Software Engineers & & & $\mathrm{X}$ & & & $\mathrm{O}$ & & & $\mathrm{X}$ & & & \\
\hline $\begin{array}{l}\text { Business } \\
\text { Consultants/ Analysts }\end{array}$ & $\mathrm{X}$ & $\mathrm{X}$ & $\mathrm{X}$ & $\mathrm{X}$ & $\mathrm{X}$ & $\mathrm{O}$ & $\mathrm{X}$ & $\mathrm{X}$ & $\mathrm{X}$ & $\mathrm{X}$ & $\mathrm{X}$ & \\
\hline $\begin{array}{l}\text { Data Scientists } \\
\text { Academic } \\
\text { Researchers }\end{array}$ & $\mathrm{O}$ & $\mathrm{O}$ & $\mathrm{O}$ & $\mathrm{O}$ & $\mathrm{O}$ & $\mathrm{O}$ & $\mathrm{O}$ & $\mathrm{O}$ & $\mathrm{O}$ & $\mathrm{O}$ & $\mathrm{O}$ & \\
\hline $\begin{array}{l}\text { Business Leaders } \\
\text { (IT) }\end{array}$ & $\mathrm{X}$ & & & & & $\mathrm{O}$ & $\mathrm{X}$ & & & & & \\
\hline $\begin{array}{l}\text { Management-level } \\
\text { Public Employees }\end{array}$ & $\mathrm{X}$ & $\mathrm{O}$ & $\mathrm{O}$ & $\mathrm{O}$ & $\mathrm{O}$ & $\mathrm{X}$ & $\mathrm{X}$ & $\mathrm{O}$ & $\mathrm{O}$ & $\mathrm{O}$ & $\mathrm{O}$ & $\mathrm{X}$ \\
\hline
\end{tabular}

$\mathrm{X}$ : Will be included in a panel with no extra criteria

$\mathrm{O}$ : Will be included in panel only if experience/research is relevant to the particular area covered by the panel.

\subsubsection{Potential Experts}

Experts will be identified using two approaches, snowball, and bibliometric analysis.

Snowball approach: Experts identified by this approach come from three sources:

- Contacts established by the researcher in the last few years, as a student in PSU, mainly from group work in classes, internships, and local community social interactions.

- Contacts from the "Transportation Supercluster" and "Smart Cities Infrastructure Team" under "TAO Smart City Committee," which are several non-profit initiatives in Portland area around smart cities by the Technology Association of Oregon (http://www.techoregon.org/get-involved/communities-labs/smart-cities). 
- Contacts from the researcher previous work period in the United Arab Emirates (UAE). The researcher worked in UAE for 13 years before coming to the US to do his $\mathrm{Ph} . \mathrm{D}$. In that period, he was part of several big data analytics, BI, and datadriven projects, and he is in contact with many experts that would make a valuable addition to the expert panels.

Bibliometric analysis approach: Furthermore, Bibliometrics and Social Networking Analysis were used to expand the number of experts. According to Diodato and Gellatly (2013), "Bibliometric is a field that uses mathematical and statistical techniques, from counting to calculus, to study publishing and communication patterns in the distribution of information." Furthermore, Daim et al. (2006) indicated that bibliometric methods goal is to identify hidden patterns by exploring, organize and analyze large amounts of historical data (mainly academia literature). Bibliometrics methods have been used originally to track citations and collaboration in research. However, its utility has expanded over the years to other areas like understanding the past and forecasting the future, as well as, to identify scientific influence.

This approach includes analysis of information like authors, affiliations, conceptual maps, cluster and factor analysis, citation and co-citation analysis (Diodato and Gellatly 2013; Daim et al. 2006; Ramos-Rodríguez, Antonio-Rafael, and RuízNavarro. 2004; Van Raan 2003; Norton 2001; Subramanyam 1983).

According to Otte and Rousseau (2002), social network analysis (SNA) "is not a formal theory, but rather a broad strategy for investigating social structures." SNA leverages network and graph theories to view social structure as a network of members 
(people, groups, entities, or things in general) and channeling resources connected with ties (edges/links). The characteristics of the ties are being investigated by SNA rather than the members themselves. Therefore, SNA focuses on individuals' relations rather than on individuals themselves. There are different kinds of analysis under SNA like the ego network analysis and the global network analysis.

SNA origin and roots are in sociology. However, it expanded to other disciplines. For instance, SNA can be used to investigate relationships among people in organizations, or any other kind of groups, as well as, between people and documents. SNA investigates document mediums like publications, emails, social media and other types of documents to identify relations among people. In this context, SNA can be used to select experts by identifying individuals who have high influence or high connectivity in regards to a particular subject, making them relevant experts in that subject. To do so, SNA can be utilized to find "centrality degree" by analyzing networks to determine the number of connections for each expert related to a particular subject, as well as, the "centrality betweenness" by determining the number of shortest paths between two experts that a specific expert resides on (Baker 2018; Scott 2017; Garces et al. 2017; Daim et al. 2014; Fu et al. 2007; Otte and Rousseau 2002; Wetherell et al. 1994; Scott 1988)

For this research, experts can be identified as suggested by (Garces et al. 2017; Daim et al. 2014). By identifying keywords, related to the research and then use bibliometric and SNA analysis to identify potential experts (see Figure 20). 


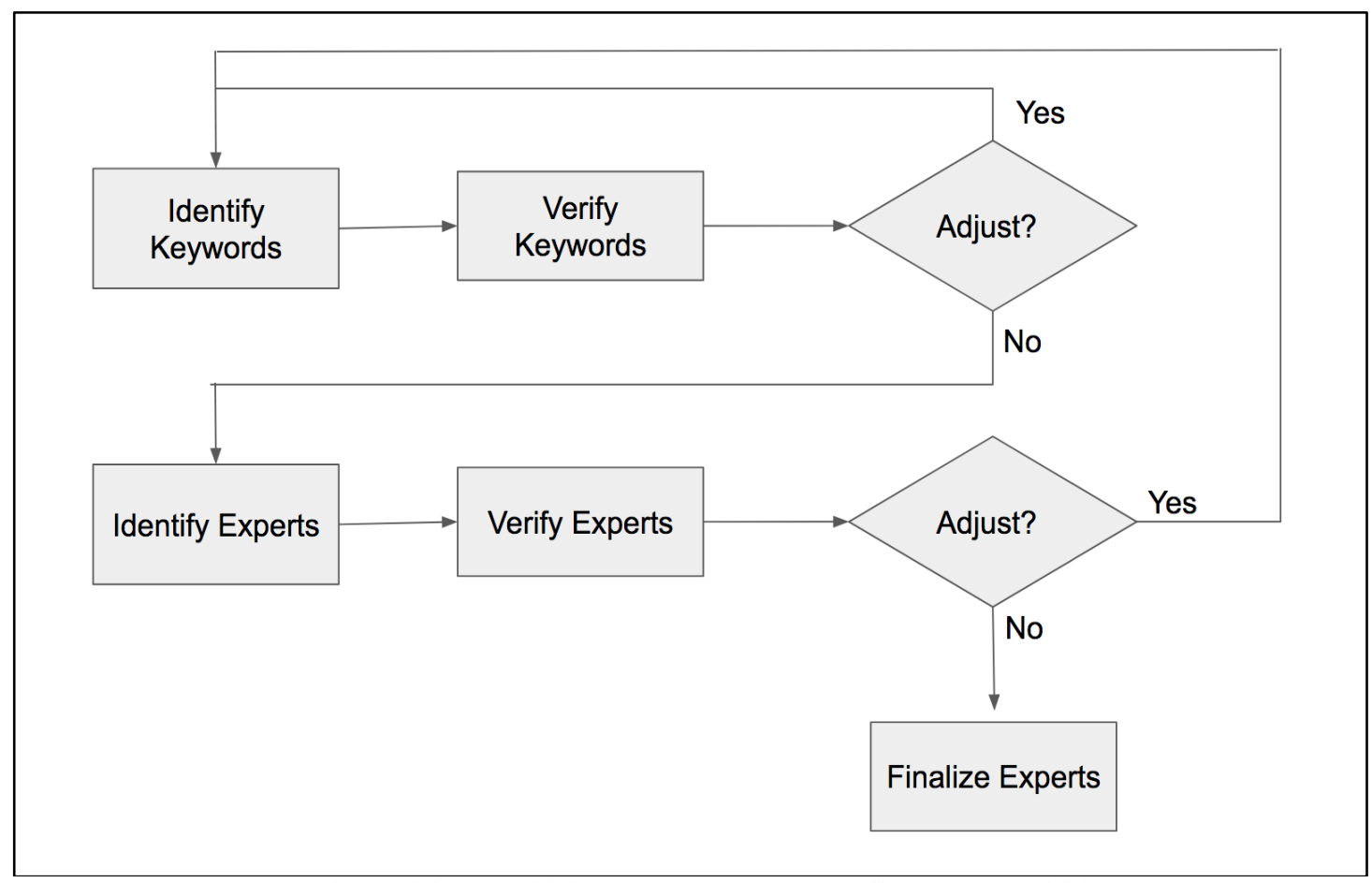

Figure 20. Identifying Experts Process (Garces et al. 2017)

Experts can be selected based on any of the following metrics related to experts' publications:

CIT: Expert's citations count (of published academic research).

PUB: Expert's publication count.

DEG: Degree of Centrality.

BET: Betweenness Centrality.

\section{COUNT: Patent Count}

Data sources, to be investigated, should cover basic research, applied research, and development (patents). Experts with great publications count are active in the field, experts with high betweenness are important for linking different groups of experts 
together, and experts with a high number of citations have potentially high impact research (Daim et al. 2014; Martino 2003).

The bibliometric analysis and SNA were conducted using an R package developed by ETM dept. Students, that utilizes the shiny package (Appendix D has more details about the software) and by leveraging on Web of Science engine for basic research, Compendex for applied research, and SumoBrain for patent analysis.

Finally, potential experts, are mapped based on their expertise and background, with the panels used in the research. 


\section{CHAPTER 5: RESULTS OF MODEL VALIDATION AND QUANTIFICATION}

This chapter presents the results of conducting the research steps 1 to 11 of the research design as explained in Section 4.2. For step 1 to 3 of the research design, the initial model was developed based on literature review findings. Tables 8 and 9 provide details for the initial list of perspectives and factors that have a critical impact on smartcity-related big data projects.

Table 8. Perspectives of Factors Affecting Smart-city-related Big Data Projects

\begin{tabular}{|l|l|}
\hline \multicolumn{1}{|c|}{ Perspective } & \multicolumn{1}{c|}{ Details } \\
\hline People Perspective & Factors related to people, including skills and perception. \\
\hline Technology Perspective & $\begin{array}{l}\text { Technical factors that are unique to big data projects due to the nature of big } \\
\text { data itself, and its characteristics (volume, velocity, variety, value, and so on.) }\end{array}$ \\
\hline Legal Perspective & $\begin{array}{l}\text { External environment factors, mainly due to data being owned and managed by } \\
\text { external entities, as well as, affecting external entities }\end{array}$ \\
\hline Organization Perspective & $\begin{array}{l}\text { What needs to be considered by management to enable successful and } \\
\text { sustainable big data adoption within the organization and to overcome barriers } \\
\text { to this adoption. }\end{array}$ \\
\hline
\end{tabular}


Table 9. Critical Factors Affecting Smart-city-related Big Data Projects

\begin{tabular}{|c|c|c|}
\hline Criteria & Details & References \\
\hline \multicolumn{3}{|c|}{ People Perspective } \\
\hline Data Scientists & $\begin{array}{l}\text { Data scientists are the minds that can realize what type, size, } \\
\text { and frequency of data need to be captured; they device the } \\
\text { predictive analysis algorithms that maximize data value, } \\
\text { with realization of organizational goals, as well as, internal } \\
\text { and external factors around the organization. } \\
\text { This criterion evaluates the city's data scientists and their } \\
\text { level of experience. }\end{array}$ & $\begin{array}{l}\text { Ransbotham and } \\
\text { Kiron 2018; Carillo } \\
\text { 2017; } \\
\text { Strawn 2016; } \\
\text { Davenport and Patil } \\
\text { 2012; } \\
\text { McGuire 2012; } \\
\text { Manyika et al. 2011; }\end{array}$ \\
\hline $\begin{array}{l}\text { Employees' } \\
\text { Technological } \\
\text { Skills }\end{array}$ & $\begin{array}{l}\text { This criterion evaluates employees information technology } \\
\text { skills and their ability to operate complex software systems. }\end{array}$ & $\begin{array}{l}\text { Carillo 2017; } \\
\text { Lam et al. 2017; } \\
\text { Stubbs 2014; } \\
\text { Kwon et al. 2014; } \\
\text { Brown et al. 2013; } \\
\text { McAfee et al. 2012; } \\
\text { LaValle et al. 2011; } \\
\text { LaValle et al. 2010; }\end{array}$ \\
\hline $\begin{array}{l}\text { Public } \\
\text { Acceptance }\end{array}$ & $\begin{array}{l}\text { This factor considers whether the public will perceive the } \\
\text { upcoming project as a "good" project. And would } \\
\text { the project be negatively or positively impacted by the } \\
\text { potential public perception. }\end{array}$ & $\begin{array}{l}\text { Dabab et al. 2018; } \\
\text { Roh 2017; } \\
\text { Van Staa et al. 2016; } \\
\text { Bright and Margetts } \\
\text { 2016; } \\
\text { Van Dijck 2014; }\end{array}$ \\
\hline $\begin{array}{l}\text { Management's } \\
\text { Analytical } \\
\text { Skills }\end{array}$ & $\begin{array}{l}\text { This criterion evaluates management analytical skills and } \\
\text { their ability to leverage big data analytics to support decision } \\
\text { making. }\end{array}$ & $\begin{array}{l}\text { Carillo 2017; } \\
\text { Lam et al. 2017; } \\
\text { Stubbs 2014; } \\
\text { Kwon et al. 2014; } \\
\text { Brown et al. 2013; } \\
\text { McAfee et al. 2012; } \\
\text { LaValle et al. 2011; } \\
\text { LaValle et al. 2010; }\end{array}$ \\
\hline \multicolumn{3}{|c|}{ Technology Perspective } \\
\hline $\begin{array}{l}\text { Data } \\
\text { Integration } \\
\text { Complexities }\end{array}$ & $\begin{array}{l}\text { One factor for big data to offer real value, is its ability to } \\
\text { aggregate and analyze data from various sources. } \\
\text { This criterion evaluates the challenges in integrating the data } \\
\text { from the various data sources that will be used in the project. }\end{array}$ & $\begin{array}{l}\text { Lim et al. 2018; } \\
\text { Ransbotham and } \\
\text { Kiron 2018; } \\
\text { Ransbotham 2016; } \\
\text { Chen and Zhang } \\
\text { 2014; } \\
\text { Kadadi et al. 2014; } \\
\text { Jagadish et al. 2014; } \\
\text { Mayer-Schönberger } \\
\text { and Cukier 2013; }\end{array}$ \\
\hline
\end{tabular}




\begin{tabular}{|c|c|c|}
\hline Criteria & Details & References \\
\hline $\begin{array}{l}\text { Data } \\
\text { Availability }\end{array}$ & $\begin{array}{l}\text { This criterion evaluates whether the data coming from } \\
\text { various sources can be accessed in a timely manner to make } \\
\text { meaningful results. From a technical perspective, the data } \\
\text { volume and velocity, for each source of data can affect its } \\
\text { timely accessibility. }\end{array}$ & $\begin{array}{l}\text { Jernigan et al. 2016; } \\
\text { Chen et al. 2014; } \\
\text { Jagadish et al. 2014; } \\
\text { Laurila et al. 2012; } \\
\text { Zikopoulos and } \\
\text { Eaton 2012; }\end{array}$ \\
\hline $\begin{array}{l}\text { What Data to } \\
\text { Collect }\end{array}$ & $\begin{array}{l}\text { This criterion evaluates whether the kind of data needs to be } \\
\text { collected is clear or not. Without this clarity, either more } \\
\text { data than needed could be captured, which will waste } \\
\text { resources, or less data than needed will be captured, } \\
\text { resulting in value loss. }\end{array}$ & $\begin{array}{l}\text { Ebner et al. 2014; } \\
\text { Walker 2014; } \\
\text { Adrian 2013; } \\
\text { Mayer-Schönberger } \\
\text { and Cukier 2013; }\end{array}$ \\
\hline $\begin{array}{l}\text { Technology } \\
\text { Solutions } \\
\text { Complexities }\end{array}$ & $\begin{array}{l}\text { In big data projects, several software tools are used together } \\
\text { to achieve the project goals } \\
\text { This criterion evaluates how complex is the mix of tools to } \\
\text { be used in the project. }\end{array}$ & $\begin{array}{l}\text { Lim et al. 2018; } \\
\text { Jernigan et al. 2016; } \\
\text { Jagadish et al. 2014; } \\
\text { Berman 2013; } \\
\text { Kaisler et al. 2013; }\end{array}$ \\
\hline \multicolumn{3}{|c|}{ Legal Perspective } \\
\hline $\begin{array}{l}\text { External } \\
\text { Sources of } \\
\text { Data }\end{array}$ & $\begin{array}{l}\text { This criterion evaluates accessibility to external sources of } \\
\text { data needed for the project, such data is available at clients, } \\
\text { suppliers, and other stakeholders end, are they willing to } \\
\text { share it or not? }\end{array}$ & $\begin{array}{l}\text { Ransbotham and } \\
\text { Kiron 2018; } \\
\text { Jernigan et al. 2016; } \\
\text { Mathieu 2015; } \\
\text { Jagadish et al. 2014; } \\
\text { Kwon et al. 2014; } \\
\text { McAfee et al. 2012; }\end{array}$ \\
\hline $\begin{array}{l}\text { Data } \\
\text { Ownership }\end{array}$ & $\begin{array}{l}\text { This criterion evaluates how much freedom the organization } \\
\text { has in disseminating analysis generated by big data system } \\
\text { based on data coming from external resources. }\end{array}$ & $\begin{array}{l}\text { Bertino and Ferrari } \\
\text { 2018; } \\
\text { Nunan and } \\
\text { Domenico 2017; } \\
\text { Harris 2015; } \\
\text { Andrejevic 2014; } \\
\text { Jagadish et al. 2014; } \\
\text { Kaisler et al. 2013; }\end{array}$ \\
\hline $\begin{array}{l}\text { Data security } \\
\text { and privacy }\end{array}$ & $\begin{array}{l}\text { This criterion evaluates the level of security and privacy the } \\
\text { system must have, versus the value it can generate. }\end{array}$ & $\begin{array}{l}\text { Bertino and Ferrari } \\
2018 ; \\
\text { Lim et al. 2018; } \\
\text { Nunan and } \\
\text { Domenico 2017; } \\
\text { Etzion and Aragon- } \\
\text { Correa 2016; } \\
\text { Andrejevic 2014; }\end{array}$ \\
\hline
\end{tabular}




\begin{tabular}{|c|c|c|}
\hline Criteria & Details & References \\
\hline & & $\begin{array}{l}\text { Jagadish et al. 2014; } \\
\text { Tallon 2013; }\end{array}$ \\
\hline $\begin{array}{l}\text { Legislations } \\
\text { Adaptability }\end{array}$ & $\begin{array}{l}\text { This criterion evaluates the city's ability to introduce new } \\
\text { legislation in a timely manner to keep up with the upcoming } \\
\text { project. }\end{array}$ & $\begin{array}{l}\text { Castelnovo et al. } \\
\text { 2016; Al Nuaimi et } \\
\text { al. 2015; Kramers et } \\
\text { al. 2015; Neirotti } \\
\text { 2014; }\end{array}$ \\
\hline \multicolumn{3}{|c|}{ Organization Perspective } \\
\hline $\begin{array}{l}\text { Management } \\
\text { Support }\end{array}$ & $\begin{array}{l}\text { Leadership and support for any project play a significant role } \\
\text { in the success chances of implementing the project. This is } \\
\text { even more true in the case of big data projects that requires a } \\
\text { lot of changes within the organization. } \\
\text { This criterion evaluates the management level of support for } \\
\text { the big data project. }\end{array}$ & $\begin{array}{l}\text { Ransbotham and } \\
\text { Kiron 2018; } \\
\text { Klievink et al. 2017; } \\
\text { Lam et al. 2017; } \\
\text { Etzion and Aragon- } \\
\text { Correa 2016; } \\
\text { Burcharth et al. } \\
\text { 2014; } \\
\text { McAfee et al. 2012; } \\
\text { LaValle et al. 2010; } \\
\text { Young and Jordan } \\
\text { 2008; } \\
\text { Schneider et al. } \\
\text { 1996; } \\
\text { Katz and Allen } \\
\text { 1982; }\end{array}$ \\
\hline $\begin{array}{l}\text { Data } \\
\text { Strategies and } \\
\text { Governance }\end{array}$ & $\begin{array}{l}\text { This criterion evaluates the maturity of strategies and } \\
\text { governance regarding data within the organization. }\end{array}$ & $\begin{array}{l}\text { DalleMule and } \\
\text { Davenport 2017; } \\
\text { Short and Todd } \\
\text { 2017; } \\
\text { Ebner et al. 2014; } \\
\text { McAfee et al. 2012; } \\
\text { Parise et al. 2012; }\end{array}$ \\
\hline $\begin{array}{l}\text { Clarity of } \\
\text { Objectives }\end{array}$ & $\begin{array}{l}\text { This criterion evaluates the clarity of the project objectives } \\
\text { and how it is related to organizational mission and vision } \\
\text { and how the project outcome is facilitating the achievement } \\
\text { of organizational strategic goals. }\end{array}$ & $\begin{array}{l}\text { Daim 2017; } \\
\text { Klievink et al. 2017; } \\
\text { Meredith 2017; } \\
\text { Etzion and Aragon- } \\
\text { Correa 2016; } \\
\text { Marr 2015b; } \\
\text { McAfee et al. 2012; } \\
\text { Fenwick et al. 2009; } \\
\text { Khan 2006; } \\
\text { Thiry 2002; }\end{array}$ \\
\hline
\end{tabular}


As explained in the research design chapter (Chapter 4), to finalize the model two things need to be done. First, asking subject-matter experts to validate the findings of the literature review, and identify any missing factors, that have a critical impact on smartcity-related big data projects, but not covered by literature adequately. Second, asking subject-matter experts to quantify the model; by identifying the relative importance of each factor within the model.

Steps 2 to 11 in the research design (see Chapter 4) explains how to capture subject-matter experts judgment for validation and quantification of the model, and how to analyze the robustness of the experts' judgments through the use of inconsistency and disagreement analysis. Following subsections represents the results of conducting those steps.

\subsection{Expert Panels Formation}

Expert panels were formed as explained in step 4 of the research design (see Section 4.2). Experts were identified and invited using the approaches discussed in Section 4.3.

\subsubsection{Overview of Experts}

A total of 48 Experts responded to the invitation and participated in the research expert panels. Appendix A includes a sample of the invitation letter sent to experts. The 48 experts represented all the backgrounds identified in Section 4.3 and came from various sectors related to smart-city and big data. Table 10 shows a list of the experts along with their sectors and backgrounds. Figure 21 represents the experts' sectors, and 
Figure 22 represents the experts' types (background). As illustrated by Table 10 and

Figure 22, many experts fall under two or more types based on their experience.

It can be seen from Table 10 and Figure 22 that the experts make a balanced group with all the experience types related to big data and smart cities represented. This is important, as having a balanced group increase minimize the bias and increase the reliability of the results. Moreover, experts were assigned to the 12 panels based on the type of their experience as illustrated in Section 4.3 and Table 7. Furthermore, Section 5.2 and 5.3 shows details about the panels and the experts assigned to each of them.

Table 10. List of Experts

\begin{tabular}{|c|c|c|c|c|c|c|c|c|c|}
\hline Expert & Title & $\begin{array}{l}\text { Sector } \\
\text { Type }\end{array}$ & $\begin{array}{c}\text { Project } \\
\text { Managers }\end{array}$ & $\begin{array}{c}\text { Business } \\
\text { Consultants/ } \\
\text { Analysts }\end{array}$ & $\begin{array}{l}\text { Software } \\
\text { Engineers }\end{array}$ & $\begin{array}{l}\text { Management } \\
\text {-level Public } \\
\text { Employees }\end{array}$ & $\begin{array}{c}\text { Academic } \\
\text { Researchers }\end{array}$ & $\begin{array}{c}\text { Data } \\
\text { Scientists }\end{array}$ & $\begin{array}{c}\text { Business } \\
\text { Leaders } \\
\text { (IT) }\end{array}$ \\
\hline Expert 1 & $\begin{array}{l}\text { IT Project } \\
\text { Manager }\end{array}$ & $\begin{array}{l}\text { Software } \\
\text { Industry }\end{array}$ & Y & Y & Y & & & & \\
\hline Expert 2 & $\begin{array}{l}\text { Senior } \\
\text { Project } \\
\text { Manager }\end{array}$ & $\begin{array}{l}\text { Software } \\
\text { Industry }\end{array}$ & Y & & Y & & & & \\
\hline Expert 3 & $\begin{array}{l}\text { Head of E- } \\
\text { Services dept. }\end{array}$ & $\begin{array}{l}\text { Public } \\
\text { Sector }\end{array}$ & Y & & & $\mathrm{Y}$ & & & \\
\hline Expert 4 & $\begin{array}{l}\text { Software } \\
\text { Engineer }\end{array}$ & $\begin{array}{l}\text { Software } \\
\text { Industry }\end{array}$ & & Y & Y & & & & \\
\hline Expert 5 & $\begin{array}{l}\text { Solutions } \\
\text { Architect }\end{array}$ & $\begin{array}{l}\text { Public } \\
\text { Sector }\end{array}$ & & Y & Y & $\mathrm{Y}$ & & & \\
\hline Expert 6 & $\begin{array}{l}\text { Technical } \\
\text { Services } \\
\text { Manager, } \\
\text { Project } \\
\text { Manager }\end{array}$ & $\begin{array}{l}\text { Software } \\
\text { Industry }\end{array}$ & Y & Y & Y & & & & \\
\hline Expert 7 & $\begin{array}{l}\text { Ph.D. and } \\
\text { Researcher }\end{array}$ & Academia & & & & & Y & Y & \\
\hline Expert 8 & $\begin{array}{l}\text { Senior } \\
\text { Software } \\
\text { Engineer }\end{array}$ & $\begin{array}{l}\text { Software } \\
\text { Industry }\end{array}$ & & Y & Y & & & & \\
\hline Expert 9 & $\begin{array}{l}\text { Senior } \\
\text { Software } \\
\text { Engineer }\end{array}$ & $\begin{array}{l}\text { Software } \\
\text { Industry }\end{array}$ & & & & & & & \\
\hline
\end{tabular}




\begin{tabular}{|c|c|c|c|c|c|c|c|c|c|}
\hline Expert & Title & $\begin{array}{c}\text { Sector } \\
\text { Type }\end{array}$ & $\begin{array}{c}\text { Project } \\
\text { Managers }\end{array}$ & $\begin{array}{c}\text { Business } \\
\text { Consultants/ } \\
\text { Analysts }\end{array}$ & $\begin{array}{l}\text { Software } \\
\text { Engineers }\end{array}$ & $\begin{array}{c}\text { Management } \\
\text {-level Public } \\
\text { Employees }\end{array}$ & $\begin{array}{c}\text { Academic } \\
\text { Researchers }\end{array}$ & $\begin{array}{c}\text { Data } \\
\text { Scientists }\end{array}$ & $\begin{array}{c}\text { Business } \\
\text { Leaders } \\
\text { (IT) }\end{array}$ \\
\hline Expert 10 & \begin{tabular}{|l} 
Vice \\
President \& \\
Chief \\
Information \\
Officer
\end{tabular} & $\begin{array}{l}\text { Other } \\
\text { (Healthcar } \\
\text { e) }\end{array}$ & & & Y & Y & & & $\mathrm{Y}$ \\
\hline Expert 11 & CEO, Ph.D. & $\begin{array}{l}\text { Others } \\
\text { (Consultin } \\
\text { g) }\end{array}$ & & $\mathrm{Y}$ & & & $\mathrm{Y}$ & & $\mathrm{Y}$ \\
\hline Expert 12 & $\begin{array}{l}\text { Sustainable } \\
\text { Transportatio } \\
\text { n Program } \\
\text { Manager }\end{array}$ & Academia & & Y & & & Y & & \\
\hline Expert 13 & SD Manager & $\begin{array}{l}\text { Software } \\
\text { Industry }\end{array}$ & & $\mathrm{Y}$ & $\mathrm{Y}$ & & & & \\
\hline Expert 14 & Data Scientist & $\begin{array}{l}\text { Software } \\
\text { Industry }\end{array}$ & & $\mathrm{Y}$ & & & & Y & \\
\hline Expert 15 & $\begin{array}{l}\text { Director of } \\
\text { intelligent } \\
\text { transportation } \\
\text { systems }\end{array}$ & $\begin{array}{l}\text { Public } \\
\text { Sector }\end{array}$ & & & & $\mathrm{Y}$ & & & Y \\
\hline Expert 16 & $\begin{array}{l}\text { Adjunct } \\
\text { Professor/ } \\
\text { Consultant }\end{array}$ & $\begin{array}{l}\text { Others } \\
\text { (Consultin } \\
\text { g) }\end{array}$ & $\mathrm{Y}$ & & & & $\mathrm{Y}$ & & \\
\hline Expert 17 & CEO, Ph.D. & $\begin{array}{l}\text { Software } \\
\text { Industry }\end{array}$ & $Y$ & Y & Y & & & & Y \\
\hline Expert 18 & $\begin{array}{l}\text { Faculty and } \\
\text { researcher }\end{array}$ & Academia & & & & & Y & & \\
\hline Expert 19 & $\begin{array}{l}\text { Assistant } \\
\text { Professor- } \\
\text { Research }\end{array}$ & Academia & & & & & $\mathrm{Y}$ & & \\
\hline Expert 20 & $\begin{array}{l}\text { Director and } \\
\text { Research } \\
\text { Professor }\end{array}$ & $\begin{array}{l}\text { Public } \\
\text { Sector }\end{array}$ & & & & $\mathrm{Y}$ & Y & & \\
\hline Expert 21 & $\begin{array}{l}\text { Associate } \\
\text { Director }\end{array}$ & $\begin{array}{l}\text { Public } \\
\text { Sector }\end{array}$ & & & & $\mathrm{Y}$ & $\mathrm{Y}$ & & \\
\hline Expert 22 & $\begin{array}{l}\text { Data } \\
\text { Warehouse \& } \\
\text { Business } \\
\text { Intelligence } \\
\text { Lead }\end{array}$ & $\begin{array}{l}\text { Others } \\
\text { (Banking) }\end{array}$ & & Y & & & & Y & \\
\hline Expert 23 & $\begin{array}{l}\text { Financial } \\
\text { Analyst }\end{array}$ & $\begin{array}{l}\text { Public } \\
\text { Sector }\end{array}$ & & & & Y & & & \\
\hline
\end{tabular}




\begin{tabular}{|c|c|c|c|c|c|c|c|c|c|}
\hline Expert & Title & $\begin{array}{l}\text { Sector } \\
\text { Type }\end{array}$ & $\begin{array}{c}\text { Project } \\
\text { Managers }\end{array}$ & $\begin{array}{c}\text { Business } \\
\text { Consultants/ } \\
\text { Analysts }\end{array}$ & $\begin{array}{c}\text { Software } \\
\text { Engineers }\end{array}$ & $\begin{array}{c}\text { Management } \\
\text {-level Public } \\
\text { Employees }\end{array}$ & $\begin{array}{c}\text { Academic } \\
\text { Researchers }\end{array}$ & $\begin{array}{c}\text { Data } \\
\text { Scientists }\end{array}$ & $\begin{array}{c}\text { Business } \\
\text { Leaders } \\
\text { (IT) }\end{array}$ \\
\hline Expert 24 & $\begin{array}{l}\text { Head of Big } \\
\text { Data Dept. }\end{array}$ & $\begin{array}{l}\text { Software } \\
\text { Industry }\end{array}$ & $\mathrm{Y}$ & & & & & & $\mathrm{Y}$ \\
\hline Expert 25 & $\begin{array}{l}\text { Senior } \\
\text { Researcher }\end{array}$ & Academia & & & & & Y & & \\
\hline Expert 26 & $\begin{array}{l}\text { Open Data } \\
\text { Coordinator }\end{array}$ & $\begin{array}{l}\text { Public } \\
\text { Sector }\end{array}$ & & & & $\mathrm{Y}$ & & & \\
\hline Expert 27 & CAE & $\begin{array}{l}\text { Software } \\
\text { Industry }\end{array}$ & & $Y$ & Y & & & & \\
\hline Expert 28 & $\begin{array}{l}\text { Program } \\
\text { Manager }\end{array}$ & $\begin{array}{l}\text { Software } \\
\text { Industry }\end{array}$ & Y & Y & & & & & Y \\
\hline Expert 29 & \begin{tabular}{|l} 
Director of \\
Project \\
Development
\end{tabular} & $\begin{array}{l}\text { Software } \\
\text { Industry }\end{array}$ & & & & & & & Y \\
\hline Expert 30 & $\begin{array}{l}\text { Machine } \\
\text { Learning } \\
\text { Engineer, } \\
\text { Ph.D. }\end{array}$ & $\begin{array}{l}\text { Software } \\
\text { Industry }\end{array}$ & & Y & & & Y & Y & \\
\hline Expert 31 & $\begin{array}{l}\text { Adjunct } \\
\text { Professor }\end{array}$ & Academia & & & & & Y & & \\
\hline Expert 32 & Ph.D. Student & Academia & & & & & Y & & \\
\hline Expert 33 & $\begin{array}{l}\text { Senior } \\
\text { Engineer }\end{array}$ & $\begin{array}{l}\text { Software } \\
\text { Industry }\end{array}$ & & Y & Y & & & & Y \\
\hline Expert 34 & $\begin{array}{l}\text { Business } \\
\text { Analyst }\end{array}$ & $\begin{array}{l}\text { Public } \\
\text { Sector }\end{array}$ & & $Y$ & & & & & \\
\hline Expert 35 & $\begin{array}{l}\text { Associate } \\
\text { Professor of } \\
\text { Software } \\
\text { Engineering }\end{array}$ & Academia & & & & & Y & & \\
\hline Expert 36 & Ph.D. Student & Academia & & & & & Y & & \\
\hline Expert 37 & Ph.D. Student & Academia & & & & & Y & & \\
\hline Expert 38 & $\begin{array}{l}\text { Founder, } \\
\text { Data Scientist }\end{array}$ & $\begin{array}{l}\text { Software } \\
\text { Industry }\end{array}$ & & Y & & & & Y & Y \\
\hline Expert 39 & President & $\begin{array}{l}\text { Others } \\
\text { (Consultin } \\
\mathrm{g} \text { ) }\end{array}$ & & & & & & & Y \\
\hline Expert 40 & $\begin{array}{l}\text { Program } \\
\text { Manager }\end{array}$ & $\begin{array}{l}\text { Public } \\
\text { Sector }\end{array}$ & & & & Y & & & Y \\
\hline
\end{tabular}




\begin{tabular}{|c|c|c|c|c|c|c|c|c|c|}
\hline Expert & Title & $\begin{array}{l}\text { Sector } \\
\text { Type }\end{array}$ & $\begin{array}{c}\text { Project } \\
\text { Managers }\end{array}$ & $\begin{array}{c}\text { Business } \\
\text { Consultants/ } \\
\text { Analysts }\end{array}$ & $\begin{array}{c}\text { Software } \\
\text { Engineers }\end{array}$ & $\begin{array}{c}\text { Management } \\
\text {-level Public } \\
\text { Employees }\end{array}$ & $\begin{array}{l}\text { Academic } \\
\text { Researchers }\end{array}$ & $\begin{array}{c}\text { Data } \\
\text { Scientists }\end{array}$ & $\begin{array}{c}\text { Business } \\
\text { Leaders } \\
\text { (IT) }\end{array}$ \\
\hline Expert 41 & $\begin{array}{l}\text { Executive } \\
\text { Director }\end{array}$ & Academia & & & & & Y & & Y \\
\hline Expert 42 & $\begin{array}{l}\text { Product } \\
\text { Manager }\end{array}$ & $\begin{array}{l}\text { Software } \\
\text { Industry }\end{array}$ & Y & & & & & & \\
\hline Expert 43 & $\begin{array}{l}\text { Principal } \\
\text { Engineer }\end{array}$ & $\begin{array}{l}\text { Software } \\
\text { Industry }\end{array}$ & & & Y & & & & \\
\hline Expert 44 & $\begin{array}{l}\text { Business } \\
\text { Intelligence } \\
\text { Manager }\end{array}$ & $\begin{array}{l}\text { Software } \\
\text { Industry }\end{array}$ & Y & & & & & & \\
\hline Expert 45 & $\begin{array}{l}\text { Adjunct } \\
\text { Professor }\end{array}$ & Academia & & & & & Y & Y & \\
\hline Expert 46 & $\begin{array}{l}\text { Co-Founder, } \\
\text { Phd }\end{array}$ & $\begin{array}{l}\text { Others } \\
\text { (Consultin } \\
\text { g) }\end{array}$ & & Y & & & & & Y \\
\hline Expert 47 & $\begin{array}{l}\text { Smart City } \\
\text { PDX/Tech } \\
\text { Services } \\
\text { Manager }\end{array}$ & $\begin{array}{l}\text { Public } \\
\text { Sector }\end{array}$ & & & & Y & & & Y \\
\hline Expert 48 & $\begin{array}{l}\text { Professor of } \\
\text { Big Data } \\
\text { Systems \& } \\
\text { Director for } \\
\text { Research, } \\
\text { Training and } \\
\text { Consultancy }\end{array}$ & Academia & & $\mathrm{Y}$ & & & $\mathrm{Y}$ & $\mathrm{Y}$ & \\
\hline
\end{tabular}




\section{Experts by Sector}

20

19

15
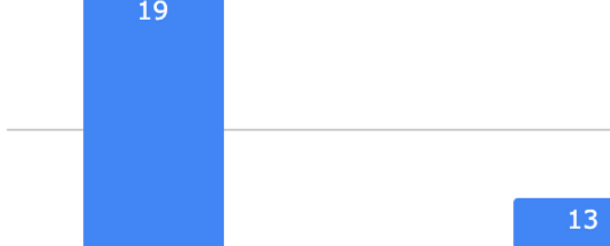

10

10

5

0

Software

Industry

Public Sector

Academia

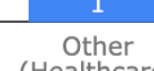

Healthcare)

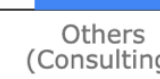

Others

(Banking)

Figure 21. Experts by Sector

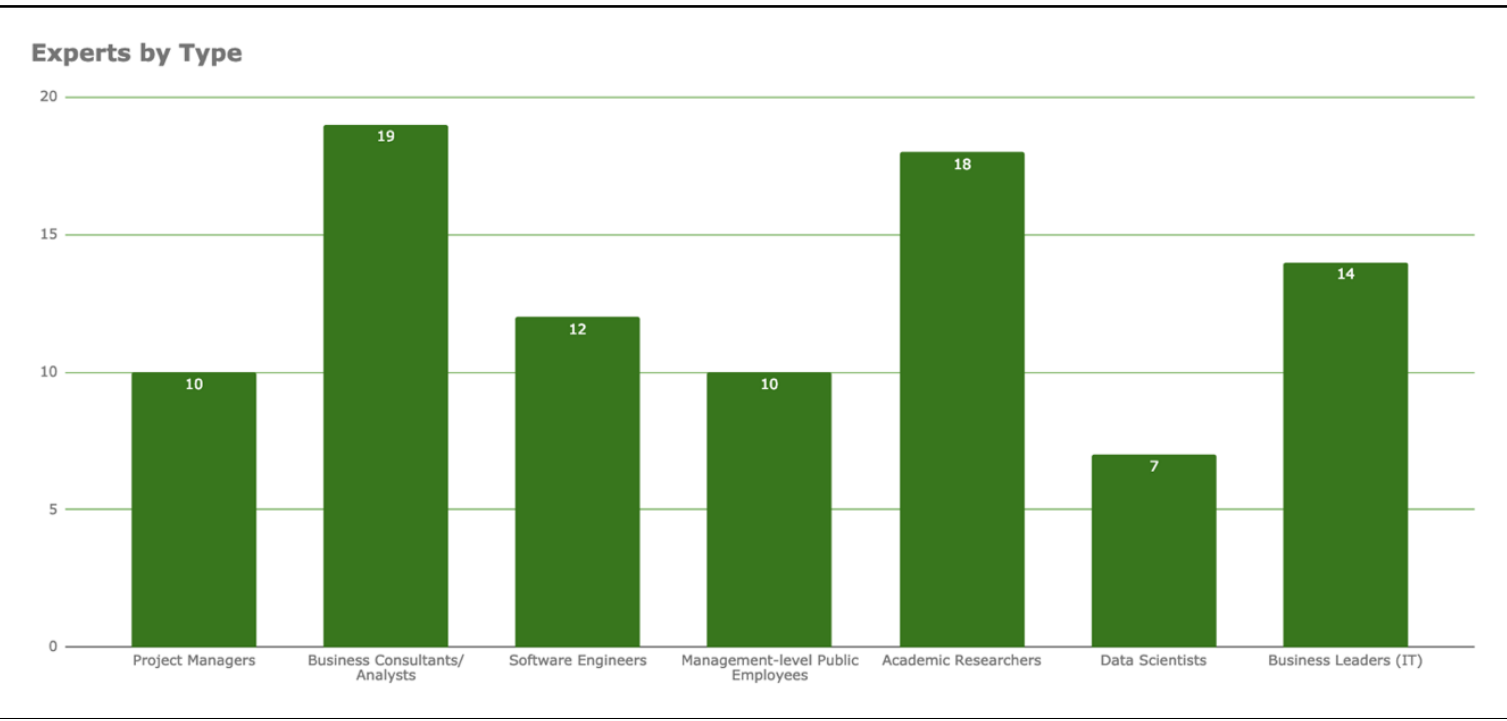

Figure 22. Experts by Type (The Same Expert Can Have Multiple Types) 


\subsubsection{Data Collection}

Experts were invited using email and Linkedin.com. Appendix A includes a sample of the invitation. In addition, email and Linkedin.com were used to send the details for participating in the model validation and the model quantification, Appendix A includes samples of the communications with experts.

As described in Section 4.3, Qualtrics surveys and one-on-one interviews were used to elicit experts' judgment and feedback for both the validation and quantification steps of the research model. Furthermore, results from quantification were re-entered by the researcher into HDM tool for further analysis. 


\subsection{HDM Model Validation}

The initial model was validated by the experts as explained in step 5 and 6 of the research design (see Section 4.2). Two rounds of validation took place using a Qualtrics survey (see Appendix B for the survey format).

In the first round, experts evaluated the factors identified by the research as the most critical factors affecting big data projects chances of success (with focus on smartcity-related projects). Experts also were given a chance to suggest other factors based on their experience.

Based on the results of this round, all factors were approved (by more than the threshold of $75 \%$ ) except for one factor that was removed, as it did not get enough approvals. Moreover, based on experts' feedback, three new factors were introduced, and two factors scope was expanded.

In the second round of validation, a special panel (P6) was formed of related experts to validate the changes. The experts approved all the changes. Following subsections show the validation details.

\subsubsection{Decision Level}

As part of one-on-one interviews with experts (representing all the panels) using email, face-to-face, and e-chat communication methods, experts were asked if they think the model decision and the goal of the research (assess a city's readiness to conduct a smart-city-related big data project) makes sense and is something that is needed and will add value. All interviewees (22 experts) agreed that the model decision and the goal of the research is proper and will add value to cities. 


\subsubsection{Perspective Level}

All perspectives were approved by more than $75 \%$ of experts from the P1 panel.

Table 11 is a summary of P1 panel judgment of the perspectives, and Table 12 includes details about the experts and their individual judgment.

Table 11. Perspectives Validation Summary by P1 Panel.

\begin{tabular}{|l|c|c|c|c|c|}
\hline \multicolumn{1}{|c|}{ Perspectives } & \# Experts & Answered? & Yes & No & Validation \% \\
\hline People & 18 & 18 & 16 & 2 & $89 \%$ \\
\hline Technology & 18 & 18 & 17 & 1 & $94 \%$ \\
\hline Legal & 18 & 18 & 17 & 1 & $94 \%$ \\
\hline Organization & 18 & 18 & 17 & 1 & $94 \%$ \\
\hline
\end{tabular}

Table 12. Perspectives Detailed Validation by P1 Panel.

\begin{tabular}{|l|c|c|c|c|}
\hline P1 Panel & People & Technology & Legal & Organization \\
\hline Expert 1 & $\mathrm{Y}$ & $\mathrm{Y}$ & $\mathrm{Y}$ & $\mathrm{Y}$ \\
\hline Expert 3 & $\mathrm{Y}$ & $\mathrm{Y}$ & $\mathrm{Y}$ & $\mathrm{Y}$ \\
\hline Expert 6 & $\mathrm{Y}$ & $\mathrm{Y}$ & $\mathrm{Y}$ & $\mathrm{Y}$ \\
\hline Expert 10 & $\mathrm{Y}$ & $\mathrm{Y}$ & $\mathrm{Y}$ & $\mathrm{Y}$ \\
\hline Expert 11 & $\mathrm{Y}$ & $\mathrm{Y}$ & $\mathrm{Y}$ & $\mathrm{Y}$ \\
\hline Expert 12 & $\mathrm{Y}$ & $\mathrm{Y}$ & $\mathrm{Y}$ & $\mathrm{Y}$ \\
\hline Expert 14 & $\mathrm{Y}$ & $\mathrm{N}$ & $\mathrm{Y}$ & $\mathrm{Y}$ \\
\hline Expert 15 & $\mathrm{Y}$ & $\mathrm{Y}$ & $\mathrm{Y}$ & $\mathrm{Y}$ \\
\hline Expert 16 & $\mathrm{Y}$ & $\mathrm{Y}$ & $\mathrm{Y}$ & $\mathrm{Y}$ \\
\hline Expert 17 & $\mathrm{Y}$ & $\mathrm{Y}$ & $\mathrm{Y}$ & $\mathrm{Y}$ \\
\hline Expert 18 & $\mathrm{~N}$ & $\mathrm{Y}$ & $\mathrm{Y}$ & $\mathrm{N}$ \\
\hline Expert 20 & $\mathrm{Y}$ & $\mathrm{Y}$ & $\mathrm{Y}$ & $\mathrm{Y}$ \\
\hline Expert 21 & $\mathrm{Y}$ & $\mathrm{Y}$ & $\mathrm{Y}$ & $\mathrm{Y}$ \\
\hline Expert 31 & $\mathrm{Y}$ & $\mathrm{Y}$ & $\mathrm{Y}$ & $\mathrm{Y}$ \\
\hline Expert 33 & $\mathrm{Y}$ & $\mathrm{Y}$ & $\mathrm{Y}$ & $\mathrm{Y}$ \\
\hline Expert 35 & $\mathrm{N}$ & $\mathrm{Y}$ & $\mathrm{N}$ & $\mathrm{Y}$ \\
\hline Expert 39 & $\mathrm{Y}$ & $\mathrm{Y}$ & $\mathrm{Y}$ & $\mathrm{Y}$ \\
\hline
\end{tabular}




\begin{tabular}{|c|c|c|c|c|}
\hline P1 Panel & People & Technology & Legal & Organization \\
\hline Expert 40 & $\mathrm{Y}$ & $\mathrm{Y}$ & $\mathrm{Y}$ & $\mathrm{Y}$ \\
\hline
\end{tabular}

\subsubsection{People Factors}

All factors under the people perspective were approved by more than $75 \%$ of experts from the P2 panel. Table 13 is a summary of P2 panel judgment of the peoplerelated factors, and Table 14 includes details about the experts and their individual judgment.

Table 13. People-related Factors Validation Summary by P2 Panel.

\begin{tabular}{|l|l|c|c|c|c|c|}
\hline Perspective & \multicolumn{1}{|c|}{ Criterion } & \# Experts & Answered? & Yes & No & Validation \% \\
\hline People & Data Scientists & 18 & 18 & 18 & 0 & $100 \%$ \\
\cline { 2 - 7 } & $\begin{array}{l}\text { Employees' } \\
\text { Technological Skills }\end{array}$ & 18 & 18 & 17 & 1 & $94 \%$ \\
\cline { 2 - 7 } & Public Perception & 18 & 18 & 17 & 1 & $94 \%$ \\
\cline { 2 - 7 } & $\begin{array}{l}\text { Management's } \\
\text { Analytical Skills }\end{array}$ & 18 & 18 & 18 & 0 & $100 \%$ \\
\hline
\end{tabular}

Table 14. People-related Factors Detailed Validation by P2 Panel.

\begin{tabular}{|l|c|c|c|c|}
\hline P2 Panel & $\begin{array}{c}\text { Data } \\
\text { Scientists }\end{array}$ & $\begin{array}{c}\text { Employees' } \\
\text { Technological Skills }\end{array}$ & Public Perception & $\begin{array}{c}\text { Management's Analytical } \\
\text { Skills }\end{array}$ \\
\hline Expert 1 & $\mathrm{Y}$ & $\mathrm{Y}$ & $\mathrm{Y}$ & $\mathrm{Y}$ \\
\hline Expert 2 & $\mathrm{Y}$ & $\mathrm{N}$ & $\mathrm{Y}$ & $\mathrm{Y}$ \\
\hline Expert 6 & $\mathrm{Y}$ & $\mathrm{Y}$ & $\mathrm{Y}$ & $\mathrm{Y}$ \\
\hline Expert 11 & $\mathrm{Y}$ & $\mathrm{Y}$ & $\mathrm{Y}$ & $\mathrm{Y}$ \\
\hline Expert 12 & $\mathrm{Y}$ & $\mathrm{Y}$ & $\mathrm{Y}$ & $\mathrm{Y}$ \\
\hline Expert 15 & $\mathrm{Y}$ & $\mathrm{Y}$ & $\mathrm{Y}$ & $\mathrm{Y}$ \\
\hline Expert 16 & $\mathrm{Y}$ & $\mathrm{Y}$ & $\mathrm{Y}$ & $\mathrm{Y}$ \\
\hline Expert 17 & $\mathrm{Y}$ & $\mathrm{Y}$ & $\mathrm{Y}$ & $\mathrm{Y}$ \\
\hline Expert 18 & $\mathrm{Y}$ & $\mathrm{Y}$ & $\mathrm{Y}$ & $\mathrm{Y}$ \\
\hline Expert 20 & $\mathrm{Y}$ & $\mathrm{Y}$ & $\mathrm{Y}$ & $\mathrm{Y}$ \\
\hline
\end{tabular}




\begin{tabular}{|l|c|c|c|c|}
\hline P2 Panel & $\begin{array}{c}\text { Data } \\
\text { Scientists }\end{array}$ & $\begin{array}{c}\text { Employees' } \\
\text { Technological Skills }\end{array}$ & Public Perception & $\begin{array}{c}\text { Management's Analytical } \\
\text { Skills }\end{array}$ \\
\hline Expert 21 & $\mathrm{Y}$ & $\mathrm{Y}$ & $\mathrm{Y}$ & $\mathrm{Y}$ \\
\hline Expert 23 & $\mathrm{Y}$ & $\mathrm{Y}$ & $\mathrm{Y}$ & $\mathrm{Y}$ \\
\hline Expert 25 & $\mathrm{Y}$ & $\mathrm{Y}$ & $\mathrm{N}$ & $\mathrm{Y}$ \\
\hline Expert 28 & $\mathrm{Y}$ & $\mathrm{Y}$ & $\mathrm{Y}$ & $\mathrm{Y}$ \\
\hline Expert 30 & $\mathrm{Y}$ & $\mathrm{Y}$ & $\mathrm{Y}$ & $\mathrm{Y}$ \\
\hline Expert 38 & $\mathrm{Y}$ & $\mathrm{Y}$ & $\mathrm{Y}$ & $\mathrm{Y}$ \\
\hline Expert 38 & $\mathrm{Y}$ & $\mathrm{Y}$ & $\mathrm{Y}$ & $\mathrm{Y}$ \\
\hline Expert 40 & $\mathrm{Y}$ & $\mathrm{Y}$ & $\mathrm{Y}$ & $\mathrm{Y}$ \\
\hline
\end{tabular}




\subsubsection{Technology Factors}

All factors under the technology perspective were approved by more than $75 \%$ of experts from the P3 panel. Table 15 is a summary of P3 panel judgment of the peoplerelated factors, and Table 16 includes details about the experts and their individual judgment.

Table 15. Technology-related Factors Validation Summary by P3 Panel.

\begin{tabular}{|l|l|c|c|c|c|c|}
\hline Perspective & \multicolumn{1}{|c|}{ Criterion } & \# Experts & Answered? & Yes & No & Validation \% \\
\hline Technology & $\begin{array}{l}\text { Data Integration } \\
\text { Complexities }\end{array}$ & 20 & 20 & 20 & 0 & $100 \%$ \\
\cline { 2 - 7 } & Data Availability & 20 & 20 & 20 & 0 & $100 \%$ \\
\cline { 2 - 7 } & What Data to Collect & 20 & 20 & 16 & 4 & $80 \%$ \\
\cline { 2 - 7 } & $\begin{array}{l}\text { Technology Solutions } \\
\text { Complexities }\end{array}$ & 20 & 20 & 16 & 4 & $80 \%$ \\
\hline
\end{tabular}

Table 16. Technology-related Factors Detailed Validation by P3 Panel.

\begin{tabular}{|c|c|c|c|c|}
\hline P3 Panel & $\begin{array}{l}\text { Data Integration } \\
\text { Complexities }\end{array}$ & $\begin{array}{c}\text { Data } \\
\text { Availability }\end{array}$ & $\begin{array}{c}\text { What Data to } \\
\text { Collect }\end{array}$ & $\begin{array}{c}\text { Technology Solutions } \\
\text { Complexities }\end{array}$ \\
\hline Expert 2 & $\mathrm{Y}$ & $\mathrm{Y}$ & $\mathrm{N}$ & $\mathrm{N}$ \\
\hline Expert 4 & $\mathrm{Y}$ & $\mathrm{Y}$ & $\mathrm{N}$ & $\mathrm{Y}$ \\
\hline Expert 5 & $\mathrm{Y}$ & $\mathrm{Y}$ & $\mathrm{N}$ & $\mathrm{Y}$ \\
\hline Expert 6 & $\mathrm{Y}$ & $\mathrm{Y}$ & $\mathrm{Y}$ & $\mathrm{Y}$ \\
\hline Expert 8 & $\mathrm{Y}$ & Y & $\mathrm{Y}$ & $\mathrm{N}$ \\
\hline Expert 9 & $\mathrm{Y}$ & Y & $\mathrm{Y}$ & $\mathrm{N}$ \\
\hline Expert 13 & $\mathrm{Y}$ & $\mathrm{Y}$ & $\mathrm{Y}$ & $\mathrm{Y}$ \\
\hline Expert 14 & $\mathrm{Y}$ & $\mathrm{Y}$ & $\mathrm{N}$ & $\mathrm{N}$ \\
\hline Expert 17 & $\mathrm{Y}$ & Y & $\mathrm{Y}$ & $\mathrm{Y}$ \\
\hline Expert 19 & $\mathrm{Y}$ & $\mathrm{Y}$ & Y & $\mathrm{Y}$ \\
\hline Expert 22 & $\mathrm{Y}$ & $\mathrm{Y}$ & $\mathrm{Y}$ & $\mathrm{Y}$ \\
\hline Expert 24 & $\mathrm{Y}$ & $\mathrm{Y}$ & Y & Y \\
\hline Expert 27 & $\mathrm{Y}$ & $\mathrm{Y}$ & $\mathrm{Y}$ & $\mathrm{Y}$ \\
\hline Expert 28 & $\mathrm{Y}$ & $\mathrm{Y}$ & $\mathrm{Y}$ & $\mathrm{Y}$ \\
\hline
\end{tabular}




\begin{tabular}{|l|c|c|c|c|}
\hline P3 Panel & $\begin{array}{c}\text { Data Integration } \\
\text { Complexities }\end{array}$ & $\begin{array}{c}\text { Data } \\
\text { Availability }\end{array}$ & $\begin{array}{c}\text { What Data to } \\
\text { Collect }\end{array}$ & $\begin{array}{c}\text { Technology Solutions } \\
\text { Complexities }\end{array}$ \\
\hline Expert 30 & $\mathrm{Y}$ & $\mathrm{Y}$ & $\mathrm{Y}$ & $\mathrm{Y}$ \\
\hline Expert 32 & $\mathrm{Y}$ & $\mathrm{Y}$ & $\mathrm{Y}$ & $\mathrm{Y}$ \\
\hline Expert 33 & $\mathrm{Y}$ & $\mathrm{Y}$ & $\mathrm{Y}$ & $\mathrm{Y}$ \\
\hline Expert 36 & $\mathrm{Y}$ & $\mathrm{Y}$ & $\mathrm{Y}$ & $\mathrm{Y}$ \\
\hline Expert 37 & $\mathrm{Y}$ & $\mathrm{Y}$ & $\mathrm{Y}$ & $\mathrm{Y}$ \\
\hline Expert 38 & $\mathrm{Y}$ & $\mathrm{Y}$ & $\mathrm{Y}$ & $\mathrm{Y}$ \\
\hline
\end{tabular}




\subsubsection{Legal Factors}

All factors under the legal perspective were approved by more than $75 \%$ of experts from the P4 panel except for "Legislations Adaptability" factor, which did not pass the threshold. Most of the rejects came from experts working in the public sector. One-on-one interviews revealed that in the United State, cities usually do not start projects before making sure that all needed legislations are created. Table 17 is a summary of P4 panel judgment of the legal-related factors, and Table 18 includes details about the experts and their individual judgment.

Table 17. Legal-related Factors Validation Summary by P4 Panel.

\begin{tabular}{|l|l|c|c|c|c|c|}
\hline Perspective & \multicolumn{1}{|c|}{ Criterion } & \# Experts & Answered? & Yes & No & Validation \% \\
\hline Legal & $\begin{array}{l}\text { External Sources } \\
\text { of Data }\end{array}$ & 18 & 18 & 18 & 0 & $100 \%$ \\
\cline { 2 - 7 } & Data Ownership & 18 & 18 & 17 & 1 & $94 \%$ \\
\cline { 2 - 7 } & $\begin{array}{l}\text { Data Security and } \\
\text { Privacy }\end{array}$ & 18 & 18 & 18 & 0 & $100 \%$ \\
\cline { 2 - 7 } & $\begin{array}{l}\text { Legislations } \\
\text { Adaptability }\end{array}$ & 18 & 18 & 13 & 5 & $72 \%$ \\
\hline
\end{tabular}

Table 18. Legal-related Factors Detailed Validation by P4 Panel.

\begin{tabular}{|l|c|c|c|c|}
\hline P4 Panel & $\begin{array}{c}\text { External Sources } \\
\text { of Data }\end{array}$ & $\begin{array}{c}\text { Data } \\
\text { Ownership }\end{array}$ & $\begin{array}{c}\text { Data Security and } \\
\text { Privacy }\end{array}$ & $\begin{array}{c}\text { Legislations } \\
\text { Adaptability }\end{array}$ \\
\hline Expert 1 & $\mathrm{Y}$ & $\mathrm{Y}$ & $\mathrm{Y}$ & $\mathrm{Y}$ \\
\hline Expert 2 & $\mathrm{Y}$ & $\mathrm{Y}$ & $\mathrm{Y}$ & $\mathrm{Y}$ \\
\hline Expert 3 & $\mathrm{Y}$ & $\mathrm{Y}$ & $\mathrm{Y}$ & $\mathrm{N}$ \\
\hline Expert 6 & $\mathrm{Y}$ & $\mathrm{Y}$ & $\mathrm{Y}$ & $\mathrm{Y}$ \\
\hline Expert 7 & $\mathrm{Y}$ & $\mathrm{Y}$ & $\mathrm{Y}$ & $\mathrm{Y}$ \\
\hline Expert 10 & $\mathrm{Y}$ & $\mathrm{Y}$ & $\mathrm{Y}$ & $\mathrm{Y}$ \\
\hline Expert 11 & $\mathrm{Y}$ & $\mathrm{Y}$ & $\mathrm{Y}$ & $\mathrm{Y}$ \\
\hline Expert 13 & $\mathrm{Y}$ & $\mathrm{Y}$ & $\mathrm{Y}$ & $\mathrm{Y}$ \\
\hline Expert 14 & $\mathrm{Y}$ & $\mathrm{N}$ & $\mathrm{Y}$ & $\mathrm{Y}$ \\
\hline
\end{tabular}




\begin{tabular}{|l|c|c|c|c|}
\hline P4 Panel & $\begin{array}{c}\text { External Sources } \\
\text { of Data }\end{array}$ & $\begin{array}{c}\text { Data } \\
\text { Ownership }\end{array}$ & $\begin{array}{c}\text { Data Security and } \\
\text { Privacy }\end{array}$ & $\begin{array}{c}\text { Legislations } \\
\text { Adaptability }\end{array}$ \\
\hline Expert 15 & $\mathrm{Y}$ & $\mathrm{Y}$ & $\mathrm{Y}$ & $\mathrm{Y}$ \\
\hline Expert 17 & $\mathrm{Y}$ & $\mathrm{Y}$ & $\mathrm{Y}$ & $\mathrm{Y}$ \\
\hline Expert 18 & $\mathrm{Y}$ & $\mathrm{Y}$ & $\mathrm{Y}$ & $\mathrm{Y}$ \\
\hline Expert 20 & $\mathrm{Y}$ & $\mathrm{Y}$ & $\mathrm{Y}$ & $\mathrm{Y}$ \\
\hline Expert 21 & $\mathrm{Y}$ & $\mathrm{Y}$ & $\mathrm{Y}$ & $\mathrm{Y}$ \\
\hline Expert 23 & $\mathrm{Y}$ & $\mathrm{Y}$ & $\mathrm{Y}$ & $\mathrm{N}$ \\
\hline Expert 25 & $\mathrm{Y}$ & $\mathrm{Y}$ & $\mathrm{Y}$ & $\mathrm{N}$ \\
\hline Expert 26 & $\mathrm{Y}$ & $\mathrm{Y}$ & $\mathrm{Y}$ & $\mathrm{N}$ \\
\hline Expert 31 & $\mathrm{Y}$ & $\mathrm{Y}$ & $\mathrm{Y}$ & $\mathrm{N}$ \\
\hline
\end{tabular}




\subsubsection{Organization Factors}

All factors under the organization perspective were approved by more than $75 \%$ of experts from the P5 panel. Table 19 is a summary of P5 panel judgment of the organization-related factors, and Table 20 includes details about the experts and their individual judgment.

Table 19. Organization-related Factors Validation Summary by P5 Panel.

\begin{tabular}{|c|l|c|c|c|c|c|}
\hline Perspective & \multicolumn{1}{|c|}{ Criterion } & \# Experts & Answered? & Yes & No & Validation \% \\
\hline Organization & Management Support & 21 & 21 & 20 & 1 & $95 \%$ \\
\cline { 2 - 7 } & $\begin{array}{l}\text { Data Strategies and } \\
\text { Governance }\end{array}$ & 21 & 21 & 20 & 1 & $95 \%$ \\
\cline { 2 - 7 } & Clarity of Objectives & 21 & 21 & 20 & 1 & $95 \%$ \\
\hline
\end{tabular}

Table 20. Organization-related Factors Detailed Validation by P5 Panel.

\begin{tabular}{|l|c|c|c|}
\hline \multicolumn{1}{|c|}{ P5 Panel } & $\begin{array}{c}\text { Management } \\
\text { Support }\end{array}$ & $\begin{array}{c}\text { Data Strategies and } \\
\text { Governance }\end{array}$ & Clarity of Objectives \\
\hline Expert 3 & $\mathrm{Y}$ & $\mathrm{Y}$ & $\mathrm{Y}$ \\
\hline Expert 4 & $\mathrm{Y}$ & $\mathrm{Y}$ & $\mathrm{Y}$ \\
\hline Expert 6 & $\mathrm{Y}$ & $\mathrm{Y}$ & $\mathrm{Y}$ \\
\hline Expert 10 & $\mathrm{Y}$ & $\mathrm{Y}$ & $\mathrm{Y}$ \\
\hline Expert 11 & $\mathrm{Y}$ & $\mathrm{Y}$ & $\mathrm{Y}$ \\
\hline Expert 12 & $\mathrm{Y}$ & $\mathrm{Y}$ & $\mathrm{Y}$ \\
\hline Expert 13 & $\mathrm{Y}$ & $\mathrm{Y}$ & $\mathrm{Y}$ \\
\hline Expert 15 & $\mathrm{Y}$ & $\mathrm{Y}$ & $\mathrm{Y}$ \\
\hline Expert 18 & $\mathrm{Y}$ & $\mathrm{Y}$ & $\mathrm{Y}$ \\
\hline Expert 19 & $\mathrm{Y}$ & $\mathrm{Y}$ & $\mathrm{Y}$ \\
\hline Expert 20 & $\mathrm{Y}$ & $\mathrm{Y}$ & $\mathrm{Y}$ \\
\hline Expert 23 & $\mathrm{Y}$ & $\mathrm{Y}$ & $\mathrm{N}$ \\
\hline Expert 26 & $\mathrm{Y}$ & $\mathrm{Y}$ & $\mathrm{Y}$ \\
\hline Expert 29 & $\mathrm{Y}$ & $\mathrm{Y}$ & $\mathrm{Y}$ \\
\hline Expert 31 & $\mathrm{Y}$ & $\mathrm{Y}$ & $\mathrm{Y}$ \\
\hline Expert 33 & $\mathrm{Y}$ & $\mathrm{Y}$ & $\mathrm{Y}$ \\
\hline Expert 34 & & $\mathrm{Y}$ & \\
\hline
\end{tabular}




\begin{tabular}{|l|c|c|c|}
\hline \multicolumn{1}{|c|}{ P5 Panel } & $\begin{array}{c}\text { Management } \\
\text { Support }\end{array}$ & $\begin{array}{c}\text { Data Strategies and } \\
\text { Governance }\end{array}$ & Clarity of Objectives \\
\hline Expert 35 & $\mathrm{Y}$ & $\mathrm{N}$ & $\mathrm{Y}$ \\
\hline Expert 38 & $\mathrm{N}$ & $\mathrm{Y}$ & $\mathrm{Y}$ \\
\hline Expert 39 & $\mathrm{Y}$ & $\mathrm{Y}$ & $\mathrm{Y}$ \\
\hline Expert 40 & $\mathrm{Y}$ & $\mathrm{Y}$ & $\mathrm{Y}$ \\
\hline
\end{tabular}




\subsubsection{Changes}

As part of the first round of validation, experts were asked to suggest factors based on their experience that are not covered in the initial list. Experts provided several suggestions. These suggestions were discussed with experts in one-on-one meetings for further elaborations. Then, the researcher aggregated those suggestions. Formed a new panel (P6) and asked the panel to validate the changes. Following are the changes:

\section{New Factors:}

Infrastructure Readiness (Technology Perspective): This factor considers a city's availability of/ability to acquire needed networks and IOT infrastructure to capture and transmit project related data. In addition, the availability/ability to procure needed software tools and technology frameworks that can scale with the exponential growth of data.

Policy and Regulatory Issues (Legal Perspective): This factor considers policy and regulatory issues that might have an impact on the project and the city's ability to address them including issues like privacy, open data, surveillance technology, AI, contracting methods, and so on. Such policies and regulations might be internal to the city or external (like GDPR).

Return on Investment (ROI) (Organization Perspective): This factor considers the ROI of the project. ROI is not financial as cities objective is not to make profit, but instead, it could be a service or image related. In other words, the focus is on costeffectiveness and whether the project realizes benefits that are important to related 
stakeholders and contribute to the smart-city aims of enhancing the quality of life in the city and improving operational efficiency.

Availability of Resources and Long-term Funding (Organization Perspective): Due to budget constraints, many cities follow an incremental approach with smaller delivery milestones and incremental/rapid improvement, instead of a big bang approach that includes a very long development duration to deliver one monolithic application. In addition, big data projects require costly operational management. So, this factor considers the city's ability to provide long-term funding and resources to support related future projects and provide sustainability to the current project's deliverables.

\section{Expanded factors:}

\section{Data Integration and Processing Complexities (Technology Perspective): "Data}

Processing" was added to the factor name and description. Data related complexities come from both the integration and the processing steps, and several experts pointed out that this should be mentioned explicitly.

\section{Clarity of Objective and Use Cases (Organization Perspective): "Use Cases" was} added to this factor to highlight that this is part of the clarity of what the project is trying to achieve. There should be clarity on the objectives in general and about the details of how to achieve them.

All changes were approved by more than $75 \%$ of experts from the P6 panel. Table 21 is a summary of P6 panel judgment of the changes, and Table 22 includes details about the experts and their individual judgment. 
Table 21. Changes Validation Summary by P6 Panel.

\begin{tabular}{|l|c|c|c|}
\hline \multicolumn{1}{|c|}{ New / Modified Criteria } & \# Experts & Yes & No \\
\hline Infrastructure Readiness & 16 & 16 & 0 \\
\hline Data Integration and Processing Complexities (Modified) & 16 & 16 & 0 \\
\hline Legislative \& Regulatory Issues & 14 & 14 & 0 \\
\hline ROI & 15 & 15 & 0 \\
\hline Availability of Resources and Long-term Funding & 15 & 15 & 0 \\
\hline Clarity of Objective and Use Cases (Modified) & 16 & 15 & 0 \\
\hline
\end{tabular}

Table 22. Changes Detailed Validation by P6 Panel.

\begin{tabular}{|c|c|c|c|c|c|}
\hline \multicolumn{2}{|c|}{ Technology } & \multirow{2}{*}{$\begin{array}{c}\text { Legal } \\
\text { Legislative } \\
\& \\
\text { Regulatory } \\
\text { Issues }\end{array}$} & \multicolumn{3}{|c|}{ Organization } \\
\hline $\begin{array}{l}\text { Infrastructure } \\
\text { Readiness }\end{array}$ & $\begin{array}{l}\text { Data Integration } \\
\text { \& Processing } \\
\text { Complexities }\end{array}$ & & ROI & $\begin{array}{l}\text { Availability of } \\
\text { Resources and Long- } \\
\text { term Funding }\end{array}$ & $\begin{array}{c}\text { Clarity of } \\
\text { Objective \& Use } \\
\text { Cases }\end{array}$ \\
\hline $\mathrm{Y}$ & $\mathrm{Y}$ & & $\mathrm{Y}$ & $\mathrm{Y}$ & $\mathrm{Y}$ \\
\hline $\mathrm{Y}$ & $\mathrm{Y}$ & $\mathrm{Y}$ & $\mathrm{Y}$ & $\mathrm{Y}$ & $\mathrm{Y}$ \\
\hline $\mathrm{Y}$ & $\mathrm{Y}$ & $\mathrm{Y}$ & $\mathrm{Y}$ & $\mathrm{Y}$ & $\mathrm{Y}$ \\
\hline $\mathrm{Y}$ & $\mathrm{Y}$ & $\mathrm{Y}$ & $\mathrm{Y}$ & $\mathrm{Y}$ & $\mathrm{Y}$ \\
\hline $\mathrm{Y}$ & $\mathrm{Y}$ & $\mathrm{Y}$ & $\mathrm{Y}$ & $\mathrm{Y}$ & $\mathrm{Y}$ \\
\hline $\mathrm{Y}$ & $\mathrm{Y}$ & $\mathrm{Y}$ & $\mathrm{Y}$ & $\mathrm{Y}$ & $\mathrm{Y}$ \\
\hline $\mathrm{Y}$ & $\mathrm{Y}$ & $\mathrm{Y}$ & $\mathrm{Y}$ & $\mathrm{Y}$ & $\mathrm{Y}$ \\
\hline $\mathrm{Y}$ & $\mathrm{Y}$ & $\mathrm{Y}$ & $\mathrm{Y}$ & $\mathrm{Y}$ & $\mathrm{Y}$ \\
\hline $\mathrm{Y}$ & $\mathrm{Y}$ & & & & \\
\hline $\mathrm{Y}$ & $\mathrm{Y}$ & $\mathrm{Y}$ & $\mathrm{Y}$ & $\mathrm{Y}$ & $\mathrm{Y}$ \\
\hline $\mathrm{Y}$ & $\mathrm{Y}$ & $\mathrm{Y}$ & $\mathrm{Y}$ & $\mathrm{Y}$ & $\mathrm{Y}$ \\
\hline $\mathrm{Y}$ & $\mathrm{Y}$ & $\mathrm{Y}$ & $\mathrm{Y}$ & $\mathrm{Y}$ & $\mathrm{Y}$ \\
\hline $\mathrm{Y}$ & $\mathrm{Y}$ & $\mathrm{Y}$ & $\mathrm{Y}$ & $\mathrm{Y}$ & $\mathrm{Y}$ \\
\hline $\mathrm{Y}$ & $\mathrm{Y}$ & $\mathrm{Y}$ & $\mathrm{Y}$ & $\mathrm{Y}$ & $\mathrm{Y}$ \\
\hline $\mathrm{Y}$ & $\mathrm{Y}$ & $\mathrm{Y}$ & $\mathrm{Y}$ & $\mathrm{Y}$ & $\mathrm{Y}$ \\
\hline $\mathrm{Y}$ & $\mathrm{Y}$ & $\mathrm{Y}$ & $\mathrm{Y}$ & $\mathrm{Y}$ & $\mathrm{Y}$ \\
\hline
\end{tabular}




\subsubsection{Final HDM Model}

Figure 23 represents the final HDM model that will be used to assess a city's readiness to implement a smart-city-related big data project.

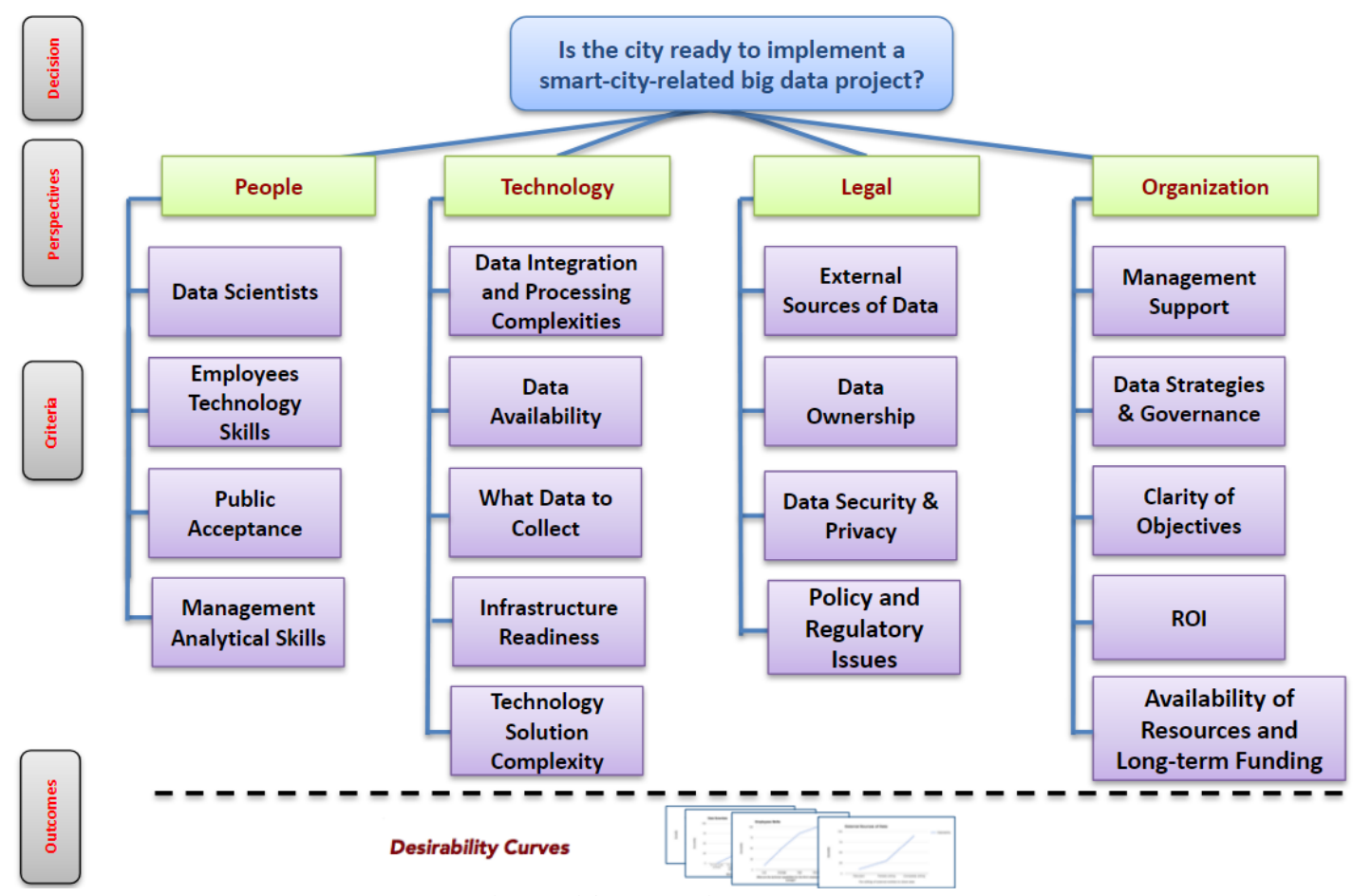

Figure 23. The Final HDM Model 


\subsection{HDM Model Quantification}

The next phase is to quantify the model by ranking the factors based on their relative importance, as explained in step 7 and 8 of the research design (see Section 4.2). Expert Panels 7 to 11 did the quantification, each panel consisting of subject-matter experts related to what the panel is asked to quantify, which is the perspectives and the factors under each perspective (see details about expert panels and subject-matter experts' types that joined each panel in Section 4.3). The experts were asked to rank the factors using the pairwise comparison approach, as explained in the methodology section (see Section 3.4). Experts conducted the comparisons using a Qualtrics survey (see Appendix B for the format of the survey). Then the researcher entered the results into the ETM HDM tool to analyze the results (see Appendix C for the format of the HDM Tool). Following subsections show the quantification details.

\subsubsection{Perspective Level}

Panel P7 experts, who are high-level executives, ranked the relative importance of each perspective in comparison with the other perspectives. Figure 24 is a graphical representation of the results of the pairwise comparisons, and Table 23 represents the details. 

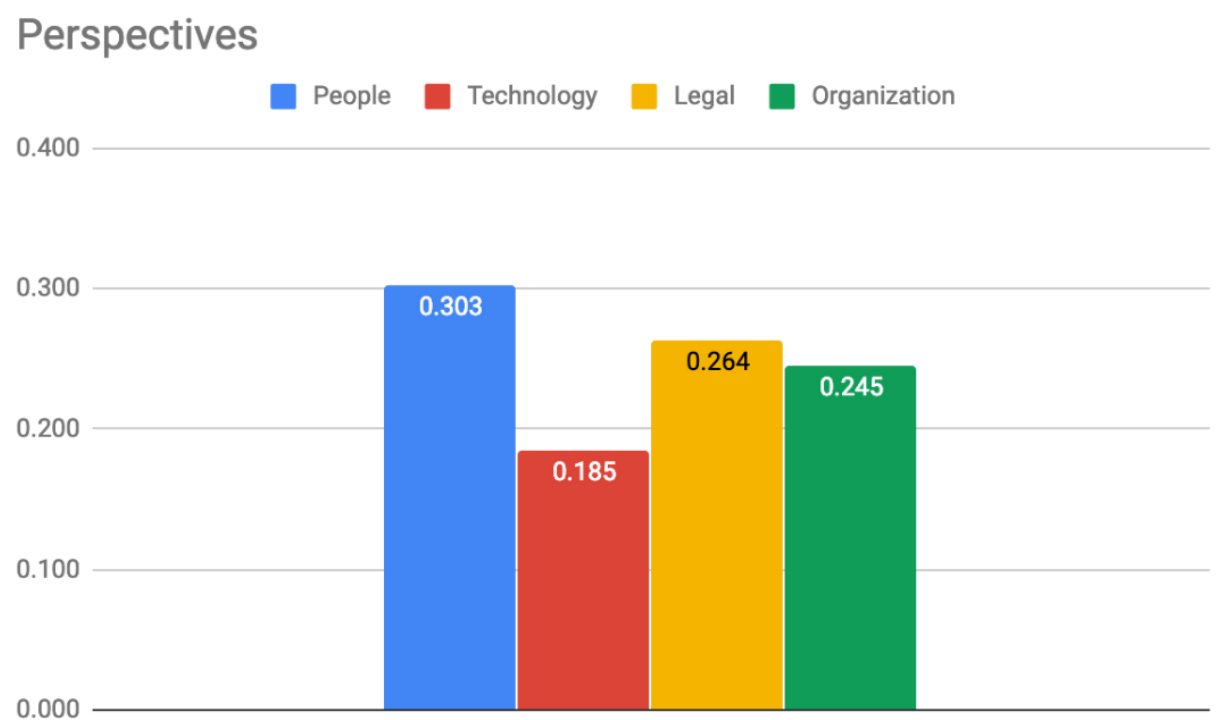

Figure 24. Perspectives Relative Weights

Table 23. Perspectives Relative Details

\begin{tabular}{|l|c|c|c|c|c|}
\hline \multicolumn{1}{|c|}{ Panel P7 } & People & Technology & Legal & Organization & Inconsistency \\
\hline Expert 15 & 0.14 & 0.25 & 0.34 & 0.26 & 0.01 \\
\hline Expert 1 & 0.27 & 0.20 & 0.33 & 0.20 & 0.00 \\
\hline Expert 10 & 0.35 & 0.24 & 0.14 & 0.26 & 0.03 \\
\hline Expert 7 & 0.23 & 0.18 & 0.38 & 0.21 & 0.00 \\
\hline Expert 17 & 0.43 & 0.18 & 0.13 & 0.25 & 0.04 \\
\hline Expert16 & 0.29 & 0.24 & 0.25 & 0.22 & 0.04 \\
\hline Expert 41 & 0.17 & 0.07 & 0.54 & 0.22 & 0.05 \\
\hline Expert 18 & 0.21 & 0.29 & 0.14 & 0.36 & 0.00 \\
\hline Expert 31 & 0.29 & 0.20 & 0.27 & 0.24 & 0.00 \\
\hline Expert 47 & 0.49 & 0.08 & 0.22 & 0.21 & 0.00 \\
\hline Expert 5 & 0.30 & 0.18 & 0.25 & 0.27 & 0.00 \\
\hline Expert 48 & 0.47 & 0.10 & 0.24 & 0.19 & 0.01 \\
\hline Expert 11 & 0.30 & 0.20 & 0.20 & 0.30 & 0.00 \\
\hline Mean & 0.303 & 0.185 & 0.264 & 0.245 & \\
\hline Minimum & 0.14 & 0.07 & 0.13 & 0.19 & \\
\hline Maximum & 0.49 & 0.29 & 0.54 & 0.36 & \\
\hline
\end{tabular}




\begin{tabular}{|l|c|c|c|c|c|}
\hline \multicolumn{1}{|c|}{ Panel P7 } & People & Technology & Legal & Organization & Inconsistency \\
\hline $\begin{array}{l}\text { Std. } \\
\text { Deviation }\end{array}$ & 0.10 & 0.06 & 0.11 & 0.04 & \\
\hline Disagreement & & & & & 0.074 \\
\hline
\end{tabular}

Note: three decimal digits were used for the final weights to break tie among factors, as ranking is one of the research questions. 


\subsubsection{People Factors}

Panel P8 experts ranked the relative importance of factors under the people perspective. Figure 25 is a graphical representation of the results of the pairwise comparisons, and Table 24 represents the details.

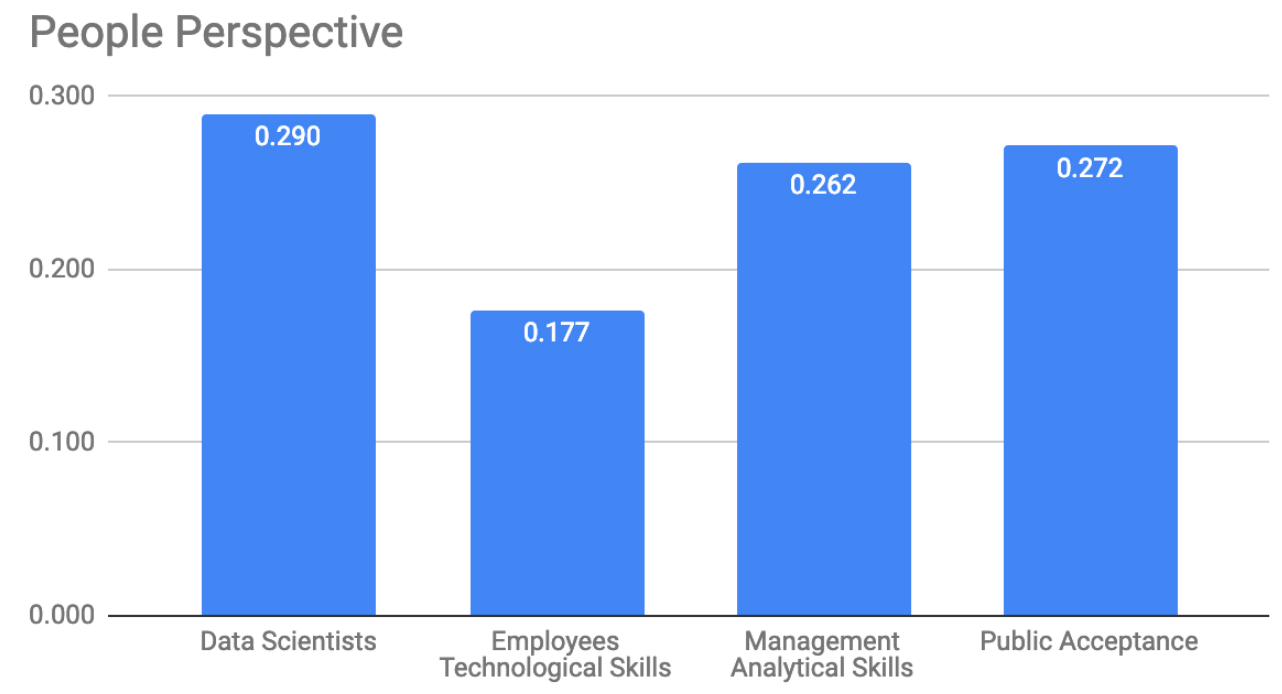

Figure 25. People Related Factors Weights

Table 24. People Related Factors Weights - Details

\begin{tabular}{|l|c|c|c|c|c|}
\hline Panel P8 & Data Scientists & $\begin{array}{c}\text { Employees } \\
\text { Technological } \\
\text { Skills }\end{array}$ & $\begin{array}{c}\text { Management } \\
\text { Analytical Skills }\end{array}$ & $\begin{array}{c}\text { Public } \\
\text { Acceptance }\end{array}$ & Inconsistency \\
\hline Expert 09 & 0.40 & 0.15 & 0.25 & 0.21 & 0.01 \\
\hline Expert 01 & 0.36 & 0.19 & 0.27 & 0.18 & 0.01 \\
\hline Expert 37 & 0.28 & 0.17 & 0.41 & 0.14 & 0.02 \\
\hline Expert 21 & 0.33 & 0.23 & 0.27 & 0.17 & 0.01 \\
\hline Expert 32 & 0.24 & 0.12 & 0.32 & 0.32 & 0.00 \\
\hline Expert 16 & 0.23 & 0.32 & 0.17 & 0.28 & 0.01 \\
\hline Expert 28 & 0.34 & 0.10 & 0.16 & 0.40 & 0.01 \\
\hline Expert 18 & 0.30 & 0.18 & 0.30 & 0.22 & 0.00 \\
\hline Expert 20 & 0.33 & 0.25 & 0.22 & 0.2 & 0.03 \\
\hline
\end{tabular}




\begin{tabular}{|l|c|c|c|c|c|}
\hline \multicolumn{1}{|c|}{ Panel P8 } & Data Scientists & $\begin{array}{c}\text { Employees } \\
\text { Technological } \\
\text { Skills }\end{array}$ & $\begin{array}{c}\text { Management } \\
\text { Analytical Skills }\end{array}$ & $\begin{array}{c}\text { Public } \\
\text { Acceptance }\end{array}$ & Inconsistency \\
\hline Expert 02 & 0.20 & 0.10 & 0.35 & 0.35 & 0.01 \\
\hline Expert 44 & 0.29 & 0.17 & 0.34 & 0.19 & 0.01 \\
\hline Expert 11 & 0.20 & 0.17 & 0.20 & 0.44 & 0.00 \\
\hline Expert 08 & 0.27 & 0.15 & 0.15 & 0.43 & 0.03 \\
\hline Mean & 0.290 & 0.177 & 0.262 & 0.272 & \\
\hline Minimum & 0.20 & 0.10 & 0.15 & 0.14 & \\
\hline Maximum & 0.40 & 0.32 & 0.41 & 0.44 & \\
\hline $\begin{array}{l}\text { Std. } \\
\text { Deviation }\end{array}$ & 0.06 & 0.06 & 0.08 & 0.10 & \\
\hline Disagreement & & & & & 0.073 \\
\hline
\end{tabular}

Note: three decimal digits were used for the final weights to break tie among factors, as ranking is one of the research questions. 


\subsubsection{Technology Factors}

Panel P9 experts ranked the relative importance of factors under the Technology perspective. Figure 26 is a graphical representation of the results of the pairwise comparisons, and Table 25 represents the details.

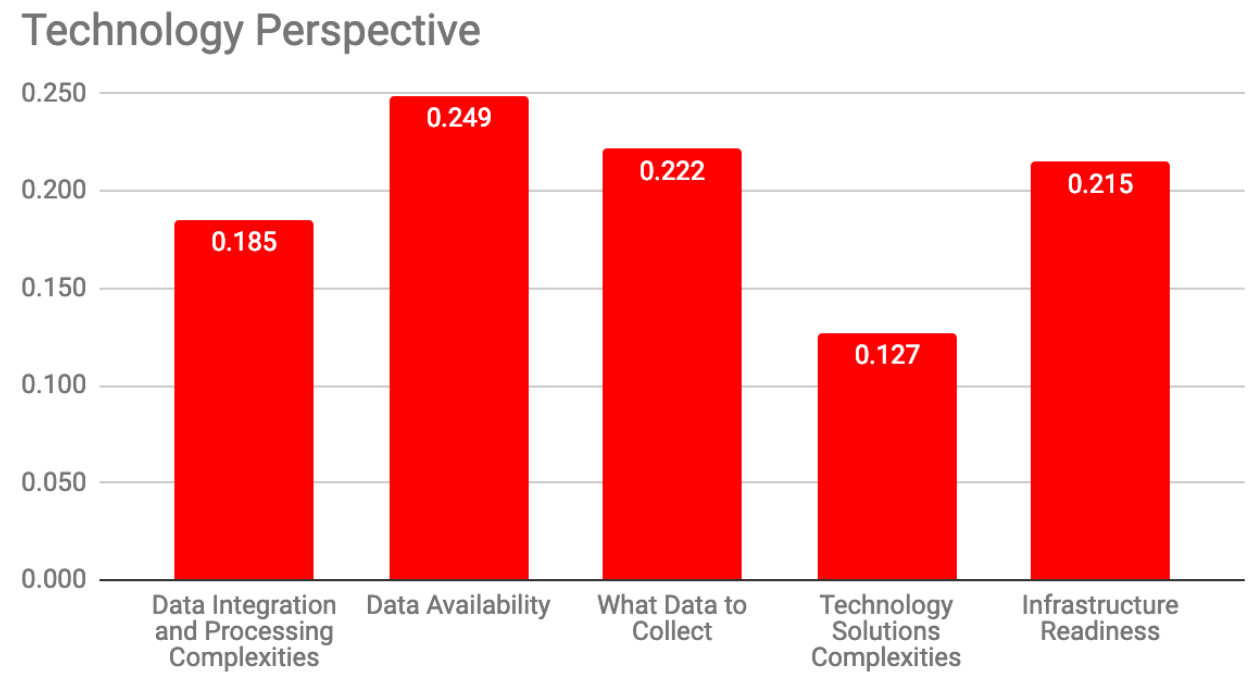

Figure 26. Technology Related Factors Weights

Table 25. Technology Related Factors Weights - Details

\begin{tabular}{|l|c|c|c|c|c|c|}
\hline Panel P9 & $\begin{array}{c}\text { Data } \\
\text { Integration } \\
\text { and Processing } \\
\text { Complexities }\end{array}$ & $\begin{array}{c}\text { Data } \\
\text { Availability }\end{array}$ & $\begin{array}{c}\text { What } \\
\text { Data to } \\
\text { Collect }\end{array}$ & $\begin{array}{c}\text { Technology } \\
\text { Solutions } \\
\text { Complexities }\end{array}$ & $\begin{array}{c}\text { Infrastructure } \\
\text { Readiness }\end{array}$ & Inconsistency \\
\hline Expert 09 & 0.21 & 0.23 & 0.32 & 0.10 & 0.14 & 0.00 \\
\hline Expert 27 & 0.24 & 0.27 & 0.17 & 0.19 & 0.13 & 0.04 \\
\hline Expert 01 & 0.23 & 0.19 & 0.16 & 0.15 & 0.27 & 0.01 \\
\hline Expert 36 & 0.16 & 0.25 & 0.27 & 0.15 & 0.17 & 0.01 \\
\hline Expert 45 & 0.17 & 0.31 & 0.23 & 0.12 & 0.16 & 0.01 \\
\hline Expert 43 & 0.32 & 0.25 & 0.18 & 0.11 & 0.14 & 0.01 \\
\hline Expert 28 & 0.16 & 0.14 & 0.20 & 0.19 & 0.31 & 0.05 \\
\hline Expert 19 & 0.20 & 0.23 & 0.20 & 0.09 & 0.28 & 0.03 \\
\hline Expert 02 & 0.14 & 0.22 & 0.3 & 0.15 & 0.19 & 0.01 \\
\hline
\end{tabular}




\begin{tabular}{|l|c|c|c|c|c|c|}
\hline Panel P9 & $\begin{array}{c}\text { Data } \\
\text { Integration } \\
\text { and Processing } \\
\text { Complexities }\end{array}$ & $\begin{array}{c}\text { Data } \\
\text { Availability }\end{array}$ & $\begin{array}{c}\text { What } \\
\text { Data to } \\
\text { Collect }\end{array}$ & $\begin{array}{c}\text { Technology } \\
\text { Solutions } \\
\text { Complexities }\end{array}$ & $\begin{array}{c}\text { Infrastructure } \\
\text { Readiness }\end{array}$ & Inconsistency \\
\hline Expert 42 & 0.24 & 0.32 & 0.19 & 0.10 & 0.14 & 0.02 \\
\hline Expert 05 & 0.14 & 0.25 & 0.25 & 0.10 & 0.26 & 0.05 \\
\hline Expert 44 & 0.13 & 0.34 & 0.20 & 0.10 & 0.23 & 0.01 \\
\hline Expert 06 & 0.16 & 0.25 & 0.34 & 0.12 & 0.14 & 0.01 \\
\hline Expert 33 & 0.14 & 0.24 & 0.16 & 0.130 & 0.33 & 0.04 \\
\hline Expert 08 & 0.14 & 0.25 & 0.16 & 0.11 & 0.34 & 0.02 \\
\hline Mean & 0.185 & 0.249 & 0.222 & 0.127 & 0.215 & \\
\hline Minimum & 0.13 & 0.14 & 0.16 & 0.09 & 0.13 & \\
\hline Maximum & 0.32 & 0.34 & 0.34 & 0.19 & 0.34 & \\
\hline $\begin{array}{l}\text { Std. } \\
\text { Deviation }\end{array}$ & 0.05 & 0.05 & 0.06 & 0.03 & 0.07 & \\
\hline Disagreement & & & & & & 0.053 \\
\hline
\end{tabular}

Note: three decimal digits were used for the final weights to break tie among factors, as ranking is one of the research questions. 


\subsubsection{Legal Factors}

Panel P10 experts ranked the relative importance of factors under the Legal perspective. Figure 27 is a graphical representation of the results of the pairwise comparisons, and Table 26 represents the details.

\section{Legal Perspective}

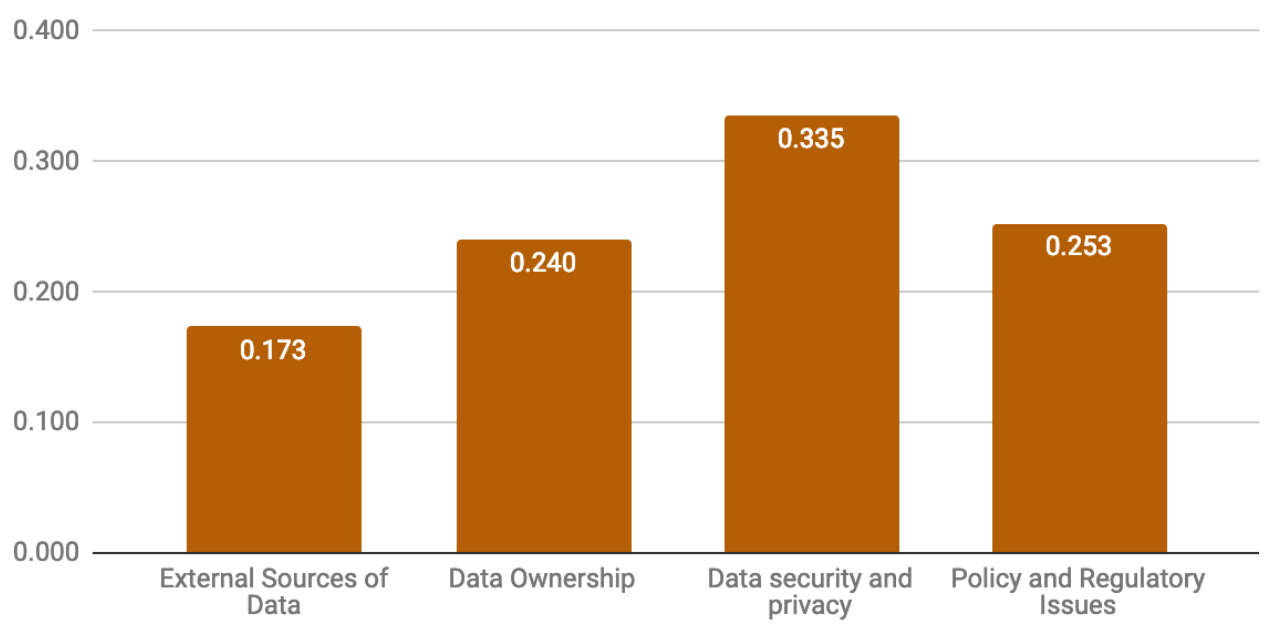

Figure 27. Legal Related Factors Weights

Table 26. Legal Related Factors Weights - Details

\begin{tabular}{|l|c|c|c|c|c|}
\hline Panel P10 & $\begin{array}{c}\text { External } \\
\text { Sources of } \\
\text { Data }\end{array}$ & $\begin{array}{c}\text { Data } \\
\text { Ownership }\end{array}$ & $\begin{array}{c}\text { Data security } \\
\text { and privacy }\end{array}$ & $\begin{array}{c}\text { Policy and } \\
\text { Regulatory } \\
\text { Issues }\end{array}$ & Inconsistency \\
\hline Expert 15 & 0.19 & 0.28 & 0.32 & 0.21 & 0.00 \\
\hline Expert 3 & 0.11 & 0.33 & 0.37 & 0.19 & 0.01 \\
\hline Expert 1 & 0.18 & 0.33 & 0.27 & 0.22 & 0.01 \\
\hline Expert 10 & 0.29 & 0.32 & 0.21 & 0.19 & 0.02 \\
\hline Expert 45 & 0.27 & 0.23 & 0.33 & 0.17 & 0.01 \\
\hline Expert 21 & 0.25 & 0.13 & 0.47 & 0.15 & 0.01 \\
\hline Expert 26 & 0.10 & 0.21 & 0.51 & 0.18 & 0.04 \\
\hline Expert 17 & 0.17 & 0.15 & 0.39 & 0.29 & 0.01 \\
\hline Expert 41 & 0.11 & 0.19 & 0.29 & 0.40 & 0.01 \\
\hline
\end{tabular}




\begin{tabular}{|c|c|c|c|c|c|}
\hline Panel P10 & $\begin{array}{c}\text { External } \\
\text { Sources of } \\
\text { Data }\end{array}$ & $\begin{array}{c}\text { Data } \\
\text { Ownership }\end{array}$ & $\begin{array}{l}\text { Data security } \\
\text { and privacy }\end{array}$ & $\begin{array}{l}\text { Policy and } \\
\text { Regulatory } \\
\text { Issues }\end{array}$ & Inconsistency \\
\hline Expert 20 & 0.18 & 0.30 & 0.33 & 0.20 & 0.00 \\
\hline Expert 31 & 0.15 & 0.25 & 0.30 & 0.30 & 0.00 \\
\hline Expert 47 & 0.08 & 0.29 & 0.34 & 0.29 & 0.00 \\
\hline Expert 23 & 0.16 & 0.21 & 0.33 & 0.31 & 0.01 \\
\hline Expert 2 & 0.20 & 0.16 & 0.26 & 0.38 & 0.00 \\
\hline Expert 48 & 0.16 & 0.22 & 0.31 & 0.31 & 0.01 \\
\hline Mean & 0.173 & 0.240 & 0.335 & 0.253 & \\
\hline Minimum & 0.08 & 0.13 & 0.21 & 0.15 & \\
\hline Maximum & 0.29 & 0.33 & 0.51 & 0.40 & \\
\hline $\begin{array}{l}\text { Std. } \\
\text { Deviation }\end{array}$ & 0.06 & 0.06 & 0.07 & 0.08 & \\
\hline Disagreement & & & & & 0.063 \\
\hline
\end{tabular}

Note: three decimal digits were used for the final weights to break tie among factors, as ranking is one of the research questions. 


\subsubsection{Organization Factors}

Panel P11 experts ranked the relative importance of factors under the Organization perspective. Figure 28 is a graphical representation of the results of the pairwise comparisons, and Table 27 represents the details.

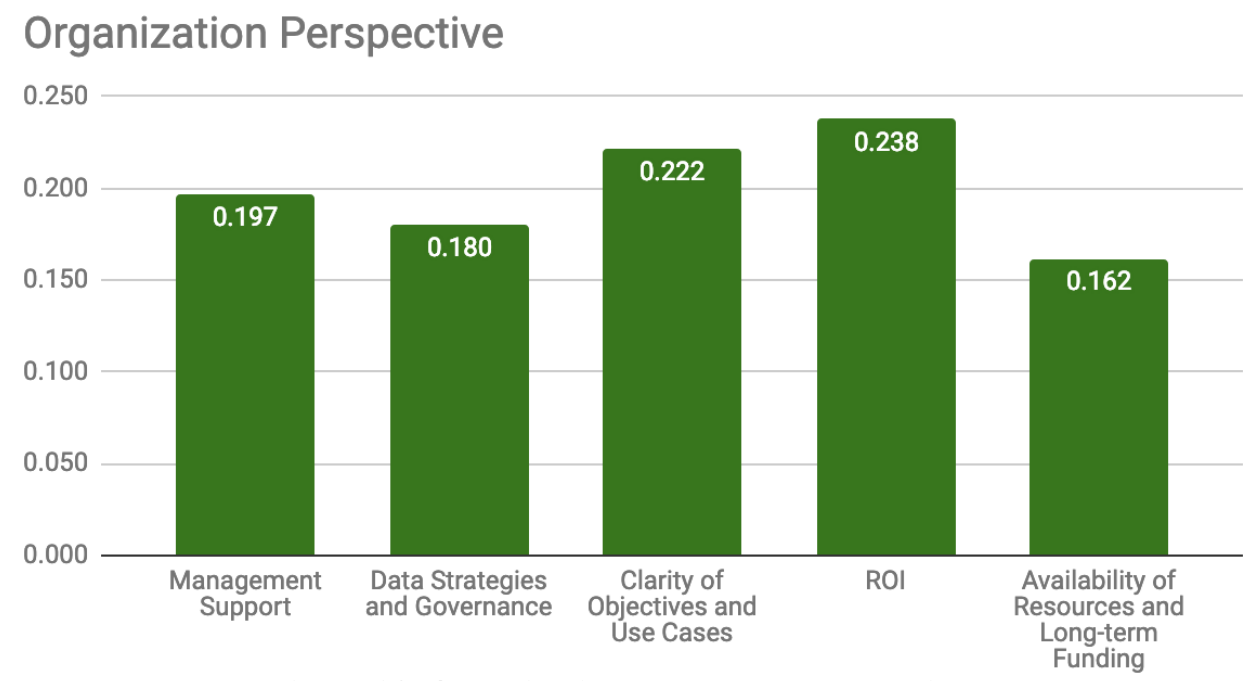

Figure 28. Organization Related Factors Weights

Table 27. Organization Related Factors Weights - Details

\begin{tabular}{|l|c|c|c|c|c|c|}
\hline Panel P11 & $\begin{array}{c}\text { Management } \\
\text { Support }\end{array}$ & $\begin{array}{c}\text { Data } \\
\text { Strategies and } \\
\text { Governance }\end{array}$ & $\begin{array}{c}\text { Clarity of } \\
\text { Objectives and } \\
\text { Use Cases }\end{array}$ & ROI & $\begin{array}{c}\text { Availability of } \\
\text { Resources and } \\
\text { Long-term } \\
\text { Funding }\end{array}$ & Inconsistency \\
\hline Expert 15 & 0.29 & 0.23 & 0.15 & 0.17 & 0.16 & 0.01 \\
\hline Expert 7 & 0.26 & 0.18 & 0.14 & 0.23 & 0.19 & 0.02 \\
\hline Expert 26 & 0.16 & 0.23 & 0.27 & 0.20 & 0.13 & 0.00 \\
\hline Expert 32 & 0.18 & 0.10 & 0.26 & 0.24 & 0.22 & 0.00 \\
\hline Expert 34 & 0.17 & 0.26 & 0.15 & 0.19 & 0.22 & 0.03 \\
\hline Expert 17 & 0.20 & 0.10 & 0.24 & 0.26 & 0.20 & 0.05 \\
\hline Expert 41 & 0.33 & 0.24 & 0.20 & 0.13 & 0.10 & 0.02 \\
\hline Expert 19 & 0.16 & 0.23 & 0.30 & 0.10 & 0.21 & 0.02 \\
\hline Expert 23 & 0.23 & 0.16 & 0.19 & 0.32 & 0.10 & 0.00 \\
\hline
\end{tabular}




\begin{tabular}{|l|c|c|c|c|c|c|}
\hline Panel P11 & $\begin{array}{c}\text { Management } \\
\text { Support }\end{array}$ & $\begin{array}{c}\text { Data } \\
\text { Strategies and } \\
\text { Governance }\end{array}$ & $\begin{array}{c}\text { Clarity of } \\
\text { Objectives and } \\
\text { Use Cases }\end{array}$ & ROI & $\begin{array}{c}\text { Availability of } \\
\text { Resources and } \\
\text { Long-term } \\
\text { Funding }\end{array}$ & Inconsistency \\
\hline Expert 46 & 0.18 & 0.16 & 0.24 & 0.29 & 0.13 & 0.01 \\
\hline Expert 33 & 0.05 & 0.12 & 0.29 & 0.47 & 0.07 & 0.05 \\
\hline Expert 11 & 0.15 & 0.15 & 0.23 & 0.25 & 0.21 & 0.00 \\
\hline Mean & 0.197 & 0.180 & 0.222 & 0.238 & 0.162 & 0.998 \\
\hline Minimum & 0.05 & 0.10 & 0.14 & 0.10 & 0.07 & \\
\hline Maximum & 0.33 & 0.26 & 0.3 & 0.47 & 0.22 & \\
\hline $\begin{array}{l}\text { Std. } \\
\text { Deviation }\end{array}$ & 0.07 & 0.05 & 0.05 & 0.09 & 0.05 & \\
\hline Disagreement & & & & & & 0.06 \\
\hline
\end{tabular}

Note: three decimal digits were used for the final weights to break tie among factors, as ranking is one of the research questions. 


\subsubsection{Final Model Weights}

The following table shows the final weighted model (the weights are calculated based the discussion in Sections 3.4.1, 3.4.3, and 3.4.6).

Table 28. HDM Model Final Weights

\begin{tabular}{|c|c|c|c|}
\hline Perspectives & Factors & $\begin{array}{c}\text { Local } \\
\text { Weight }\end{array}$ & $\begin{array}{c}\text { Global Weight } \\
\text { Local Weight * Perspective } \\
\text { Weight }\end{array}$ \\
\hline \multirow[t]{4}{*}{ People $(30.3 \%)$} & Data Scientists & $29.0 \%$ & $08.8 \%$ \\
\hline & Employees Technological Skills & $17.7 \%$ & $05.4 \%$ \\
\hline & Public Acceptance & $27.2 \%$ & $08.2 \%$ \\
\hline & Management Analytical Skills & $26.2 \%$ & $07.9 \%$ \\
\hline \multirow[t]{5}{*}{$\begin{array}{l}\text { Technology } \\
(18.5 \%)\end{array}$} & $\begin{array}{l}\text { Data Integration \& Processing } \\
\text { Complexities }\end{array}$ & $18.5 \%$ & $03.4 \%$ \\
\hline & Data Availability & $24.9 \%$ & $04.6 \%$ \\
\hline & What Data to Collect & $22.2 \%$ & $04.1 \%$ \\
\hline & Infrastructure Readiness & $21.5 \%$ & $04.0 \%$ \\
\hline & Technology Solutions Complexities & $12.7 \%$ & $02.3 \%$ \\
\hline \multirow[t]{4}{*}{ Legal (26.4\%) } & External Sources of Data & $17.3 \%$ & $04.6 \%$ \\
\hline & Data Ownership & $24.0 \%$ & $06.3 \%$ \\
\hline & Data security and privacy & $33.5 \%$ & $08.8 \%$ \\
\hline & Policy and Regulatory Issues & $25.3 \%$ & $06.7 \%$ \\
\hline \multirow{5}{*}{$\begin{array}{l}\text { Organization } \\
(24.5 \%)\end{array}$} & Management Support & $19.7 \%$ & $04.8 \%$ \\
\hline & Data Strategies and Governance & $18.0 \%$ & $04.4 \%$ \\
\hline & Clarity of Objectives and Use Cases & $22.2 \%$ & $05.4 \%$ \\
\hline & ROI & $23.8 \%$ & $05.8 \%$ \\
\hline & $\begin{array}{l}\text { Availability of Resources and long-term } \\
\text { Funding }\end{array}$ & $16.2 \%$ & $04.0 \%$ \\
\hline
\end{tabular}




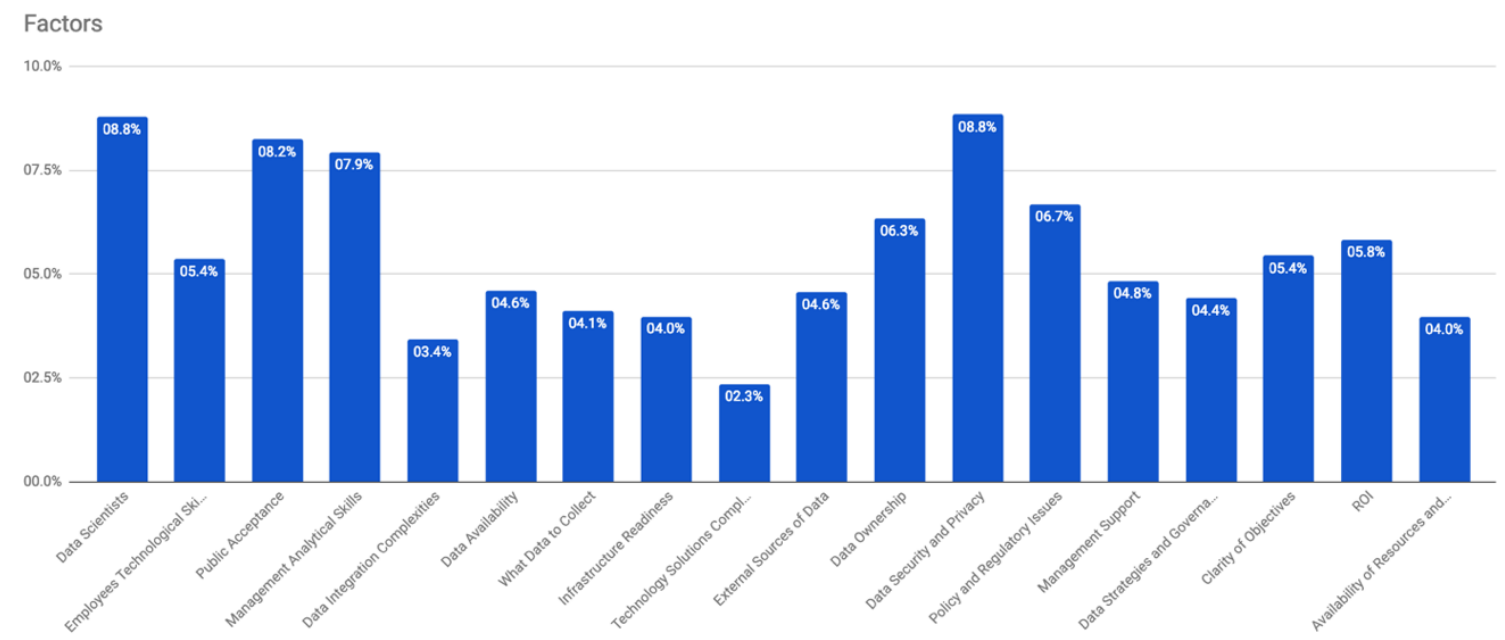

Figure 29. Factors that have Critical Impact on Smart-city-related Big Data Projects 


\subsection{Inconsistency and Disagreement Analysis}

HDM methodology is based on eliciting subject-matter experts' judgment; as such, the trustworthiness of the model depends directly on the experts being real experts in their field and able to provide sound judgment. Therefore, it is imperative to analyze experts' judgment and make sure their feedback is as reliable as possible. Section 3.4.2 discuss various issues related to experts' judgment. Furthermore, Section 3.4.5 discusses HDM methodology limitations including issues related to experts and how countermeasure them.

Following the discussion from Section 3.4.5, in this research, experts were asked to give their judgment using electronic Qualtrics surveys. Also, follow up with experts was done using one-on-one meetings. Therefore, experts never met each other or had the chance to discuss the surveys between themselves. This approach eliminates the "loud voice" and "bystander" problems associated with eliciting experts' judgment using panels or workshops. Furthermore, experts invited to this research represents 7 different backgrounds and 40 different organizations (as explained in Section 5.1), which minimize the bias that might result from experts representing a single industry or background.

Finally, as explained in step 10 of the research design (see Section 4.2), experts' judgment was analyzed mathematically for inconsistency and disagreement (more details about inconsistency and disagreement analysis can be found in Sections 3.4.2.2 and 3.4.2.3). The threshold for inconsistency is $10 \%$. If an expert judgment is inconsistent beyond $10 \%$, this means he or she might not be experts after all, and the actions 
explained in step 10 of the research design (see Section 4.2) must be taken to decide if the expert inconsistency is due to not being an expert, which might result in eliminating that experts judgment, or can be explained and approved and hence keeping the judgment. As illustrated by tables 23 to 27 , none of the experts in panels P7 to P11 have major inconsistency $(>10 \%)$. Moreover, the threshold for disagreement is $10 \%$, if a panel disagreement goes beyond $10 \%$, this means there is high disagreement that might bring the reliability of the aggregated weights of the model to question. The actions explained in step 10 of the research design (see Section 4.2) must be taken to decide on the source of the disagreement and how to handle it. As illustrated by tables 23 to 27 , none of the panels P7 to P11 have a major disagreement ( $>10 \%)$. 


\subsection{Value Curves}

One-on-one meetings with some experts from panels P7 to P11 were conducted, to create the value curves as explained in step 9 of the research design (see Section 4.2) and explained in Section 3.4.3 and Section 3.4.6. In the meetings, a discussion was conducted about each factor in the model and what are typical situations that cities usually have for each factor. The discussion was based on the factors' unit of measurement as shown in Table 29.

Table 29. Desirability Curve Matrix

\begin{tabular}{|c|c|c|}
\hline Perspective & Factors & Unit of Measurements \\
\hline \multirow{4}{*}{$\begin{array}{l}\text { Personal } \\
\text { Perspective }\end{array}$} & Data scientists & What data analytic skills available for this project? \\
\hline & $\begin{array}{l}\text { Employees' Technological } \\
\text { Skills }\end{array}$ & $\begin{array}{l}\text { What are the IT and data-entry capabilities for the city's } \\
\text { employees on average? }\end{array}$ \\
\hline & Public Acceptance & How would the public perceive this project? \\
\hline & $\begin{array}{l}\text { Management's Analytical } \\
\text { Skills }\end{array}$ & $\begin{array}{l}\text { What are the analytical skills for the city's management } \\
\text { on average? }\end{array}$ \\
\hline \multirow[t]{5}{*}{$\begin{array}{l}\text { Technical } \\
\text { Perspective }\end{array}$} & $\begin{array}{l}\text { Data Integration \& Processing } \\
\text { Complexities }\end{array}$ & How integrable are the data sources? \\
\hline & Data Availability & $\begin{array}{l}\text { Can the data, coming from various sources, be accessed } \\
\text { in a timely manner to make meaningful results? }\end{array}$ \\
\hline & What Data to Collect & Are we aware of what data we need? \\
\hline & Infrastructure Readiness & $\begin{array}{l}\text { What is the readiness status of the infrastructure needed } \\
\text { for this project? }\end{array}$ \\
\hline & $\begin{array}{l}\text { Technology Solutions } \\
\text { Complexities }\end{array}$ & $\begin{array}{l}\text { Does the mix of software tools and technologies needed } \\
\text { to achieve the project goals have any compatibility } \\
\text { issues? }\end{array}$ \\
\hline \multirow[t]{2}{*}{$\begin{array}{l}\text { Political } \\
\text { Perspective }\end{array}$} & External Sources of Data & $\begin{array}{l}\text { Are external entities willing to share data that is } \\
\text { important for the city to get benefits from big data } \\
\text { analytics? }\end{array}$ \\
\hline & Data Ownership & $\begin{array}{l}\text { Does the city have enough ownership and control over } \\
\text { the data to get benefits from big data analytics? }\end{array}$ \\
\hline
\end{tabular}




\begin{tabular}{|c|c|c|}
\hline Perspective & Factors & Unit of Measurements \\
\hline & Data Security and Privacy & $\begin{array}{l}\text { Does the level of data security and privacy needed affect } \\
\text { the city's ability to get benefits from big data analytics? }\end{array}$ \\
\hline & Policy and Regulatory Issues & $\begin{array}{l}\text { Do policy and regulatory issues have an impact on the } \\
\text { project? }\end{array}$ \\
\hline \multirow[t]{5}{*}{$\begin{array}{l}\text { Management } \\
\text { Perspective }\end{array}$} & Management Support & $\begin{array}{l}\text { What is the degree of top management support to the } \\
\text { project? }\end{array}$ \\
\hline & $\begin{array}{l}\text { Data Strategies and } \\
\text { Governance }\end{array}$ & Does the city have a clear data strategy and governance? \\
\hline & $\begin{array}{l}\text { Clarity of Objectives and Use } \\
\text { Cases }\end{array}$ & $\begin{array}{l}\text { Does the city have clear objectives to be achieved by this } \\
\text { project and clear use case with measurable goals? }\end{array}$ \\
\hline & Return on Investment (ROI) & Does the ROI of the project justify its cost? \\
\hline & $\begin{array}{l}\text { Availability of Resources and } \\
\text { Long-term Funding }\end{array}$ & $\begin{array}{l}\text { Are the resources and long-term fund available for the } \\
\text { project adequate? }\end{array}$ \\
\hline
\end{tabular}


Following subsections includes the value curves and their scores, based on the findings of the meetings.

\subsubsection{People Factors}

Table 30. People Related Factors Desirability Curves

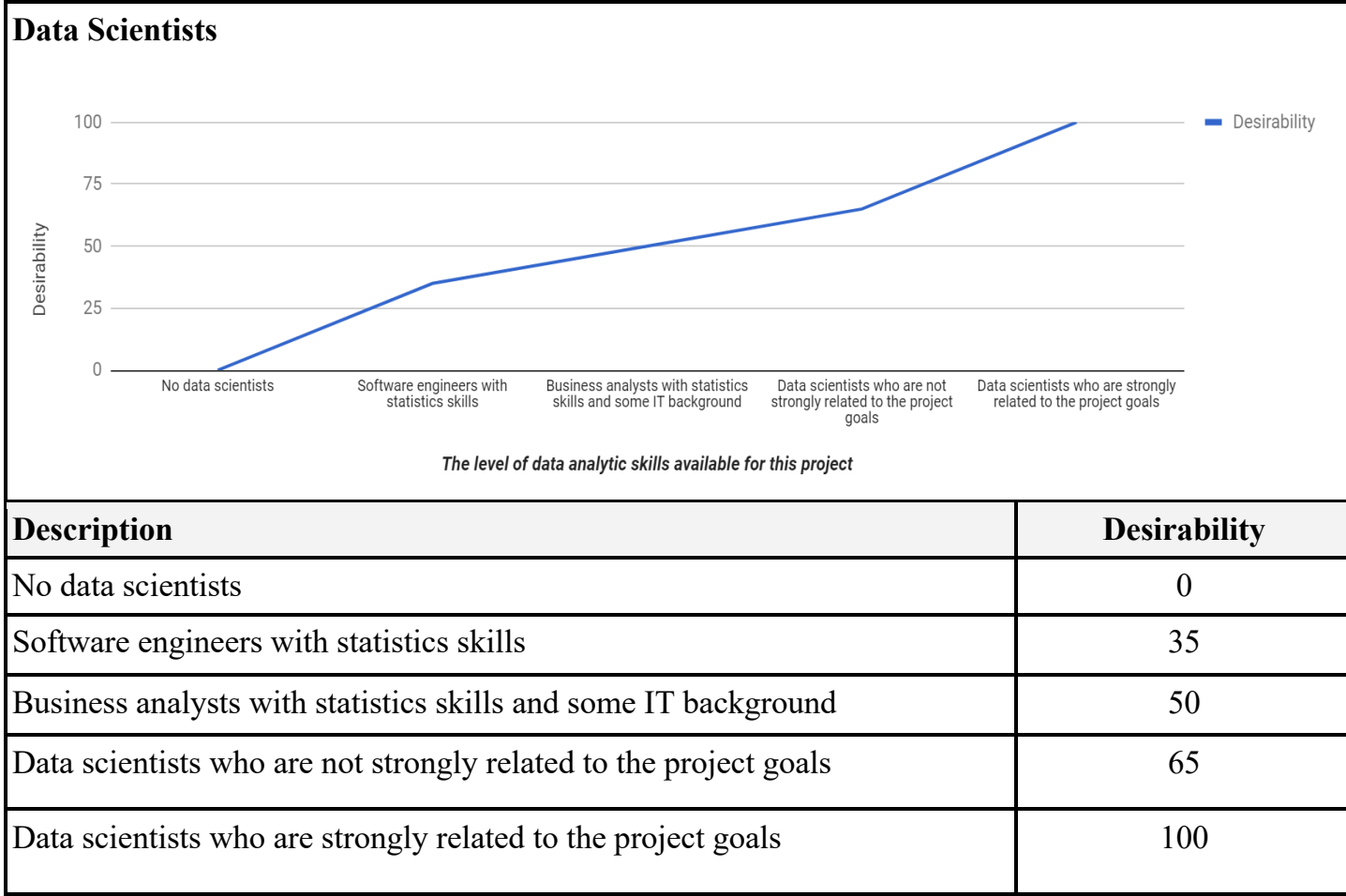

\section{Employees' Technological Skills}

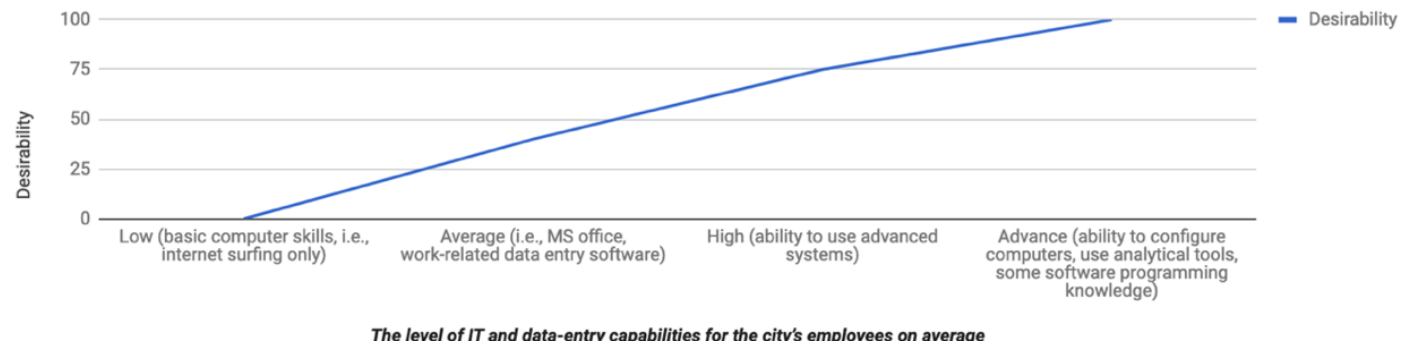

The level of IT and data-entry capabilities for the city's employees on average

\section{Description}

Desirability

Low (basic computer skills, i.e., internet surfing only)

Average (i.e., MS office, work-related data entry software)

High (ability to use advanced systems)

0

40

75 
Advance (ability to configure computers, use analytical tools, some software programming knowledge)

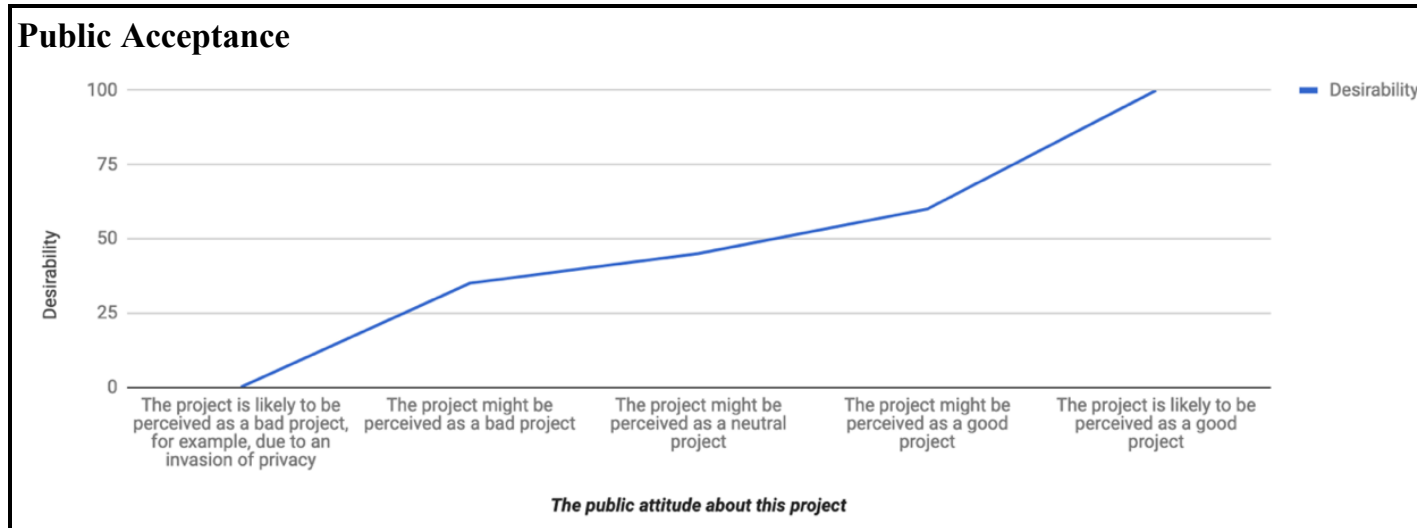

\section{Description}

Desirability

The project is likely to be perceived as a bad project, for example, due to an invasion of privacy

The project might be perceived as a bad project

The project might be perceived as a neutral project

The project might be perceived as a good project

The project is likely to be perceived as a good project

\section{Management's Analytical Skills}

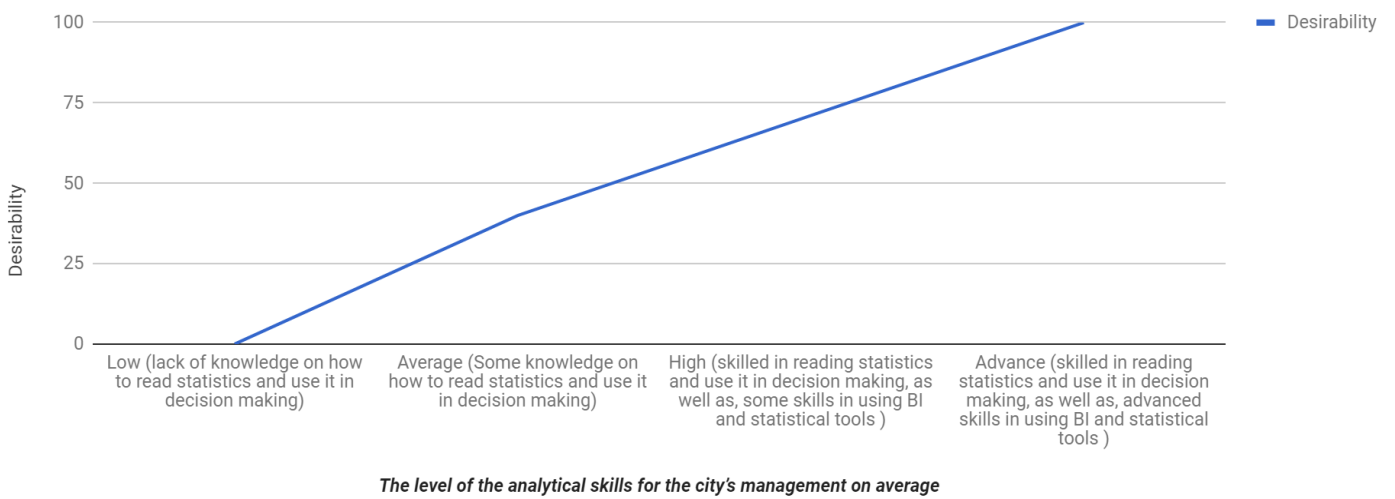

\section{Description}

Desirability

Low (lack of knowledge on how to read statistics and use it in decision making)

Average (Some knowledge on how to read statistics and use it in decision making)

40


High (skilled in reading statistics and use it in decision making, as well as, some skills in using BI and statistical tools)

Advance (skilled in reading statistics and use it in decision making, as well as, advanced skills in using BI and statistical tools) 


\subsubsection{Technology Factors}

Table 31. Technology Related Factors Desirability Curves

\section{Data Integration and Processing Complexities}

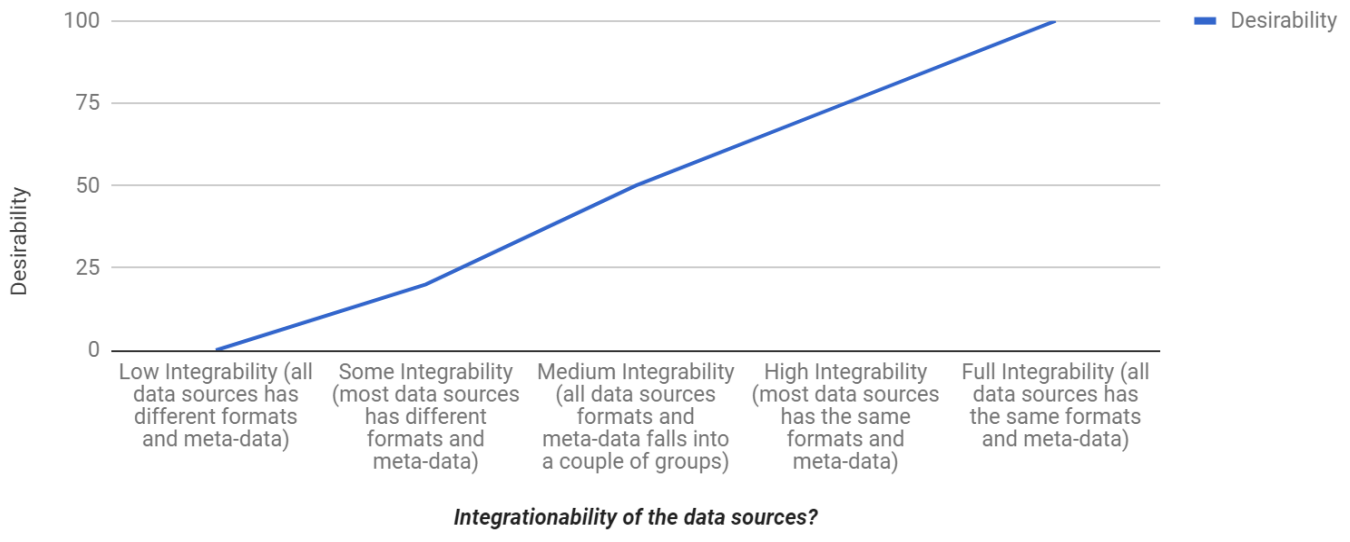

\section{Description}

Desirability

Low Integrability (all data sources have different formats and meta-data)

Some Integrability (most data sources have different formats and meta-data)

Medium Integrability (all data sources formats and meta-data falls into a couple of groups)

High Integrability (most data sources have the same formats and meta-data)

Full Integrability (all data sources have the same formats and meta-data)

20

\section{Data Availability}

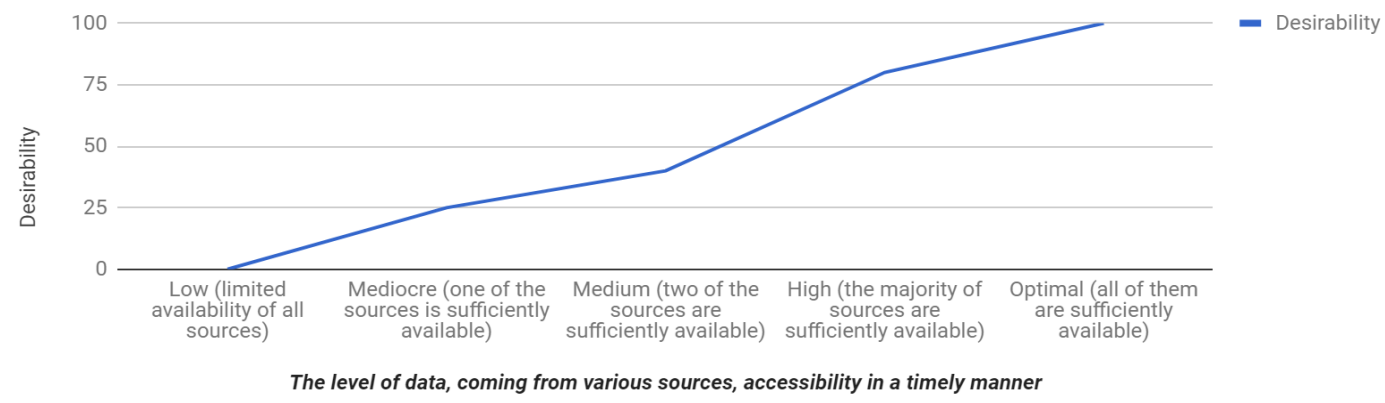

\section{Description}

Desirability

Low (limited availability of all sources)

Mediocre (one of the sources is sufficiently available)

Medium (two of the sources are sufficiently available) 


\begin{tabular}{|l|c|}
\hline High (the majority of sources are sufficiently available) & 80 \\
\hline Optimal (all of them are sufficiently available) & 100 \\
\hline
\end{tabular}

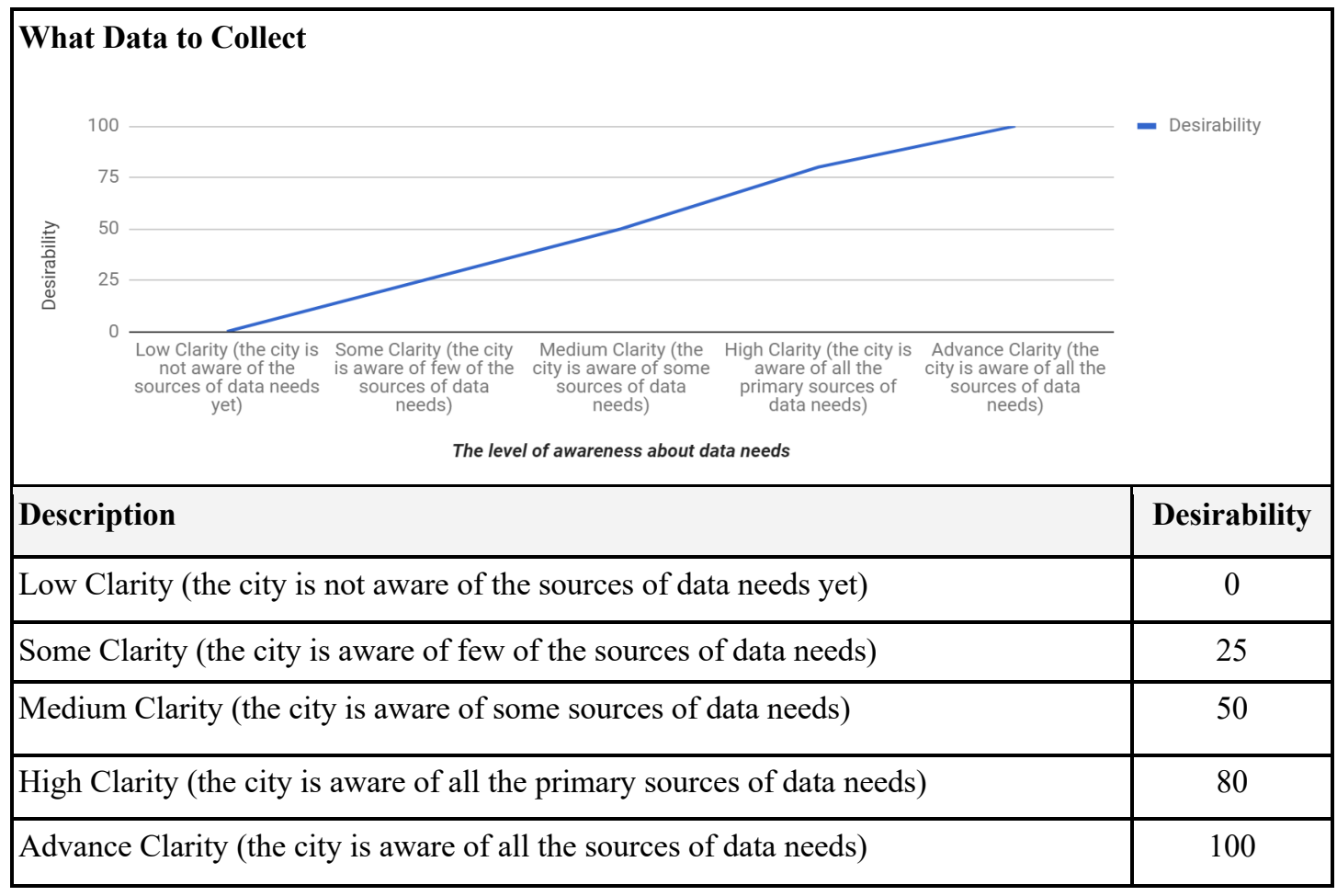

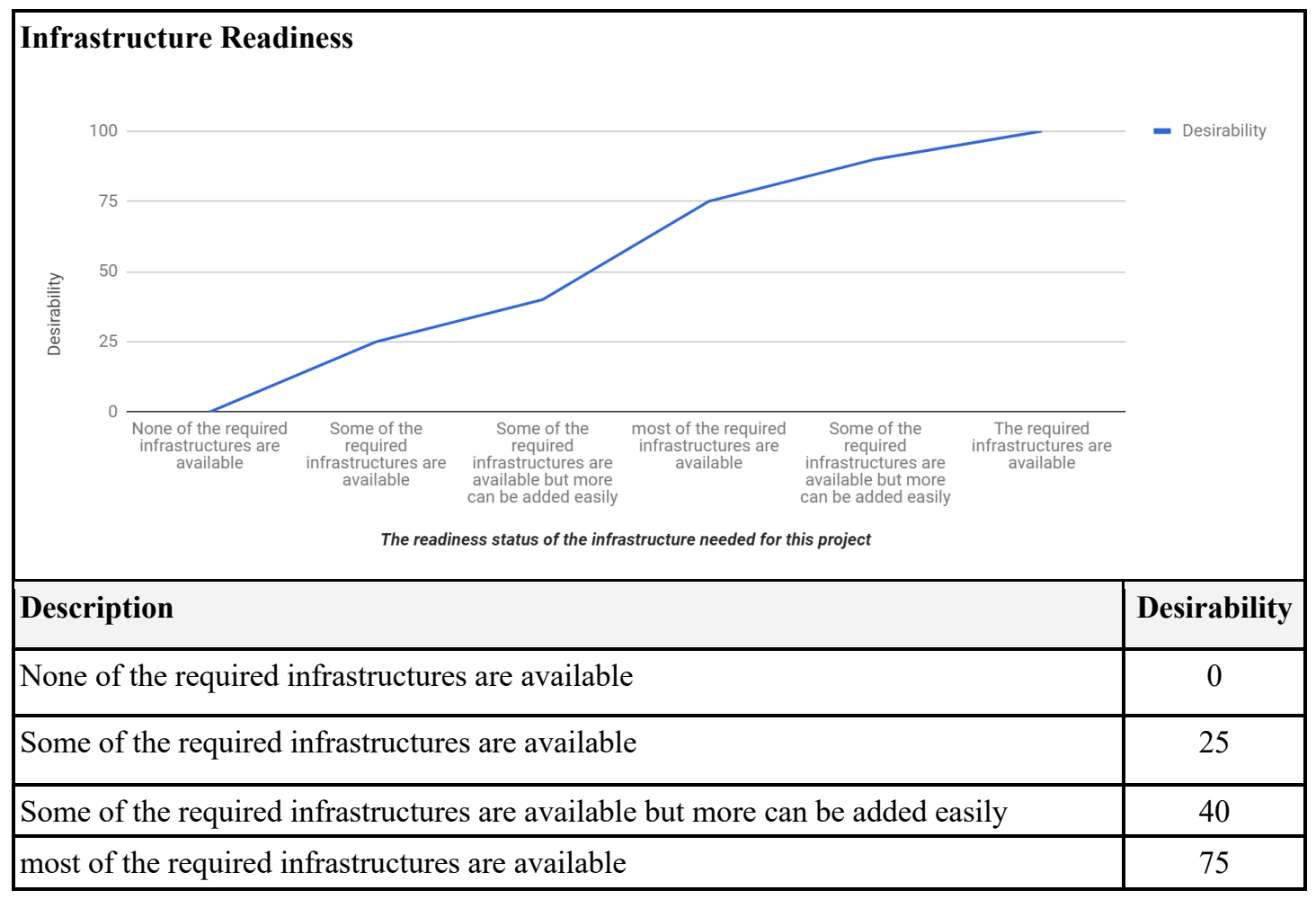




\begin{tabular}{|l|c|}
\hline Some of the required infrastructures are available but more can be added easily & 90 \\
\hline The required infrastructures are available & 100 \\
\hline
\end{tabular}

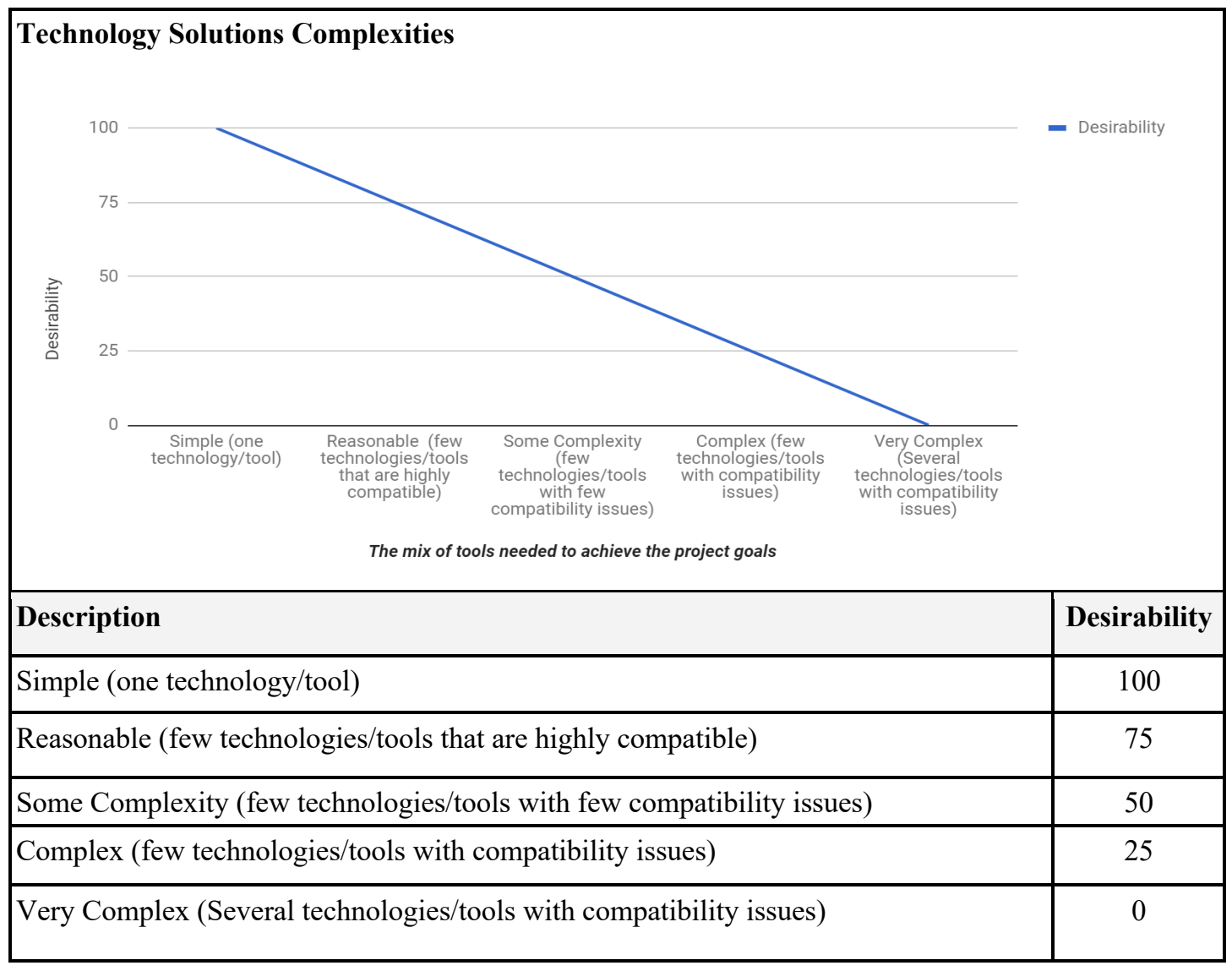




\subsubsection{Legal Factors}

Table 32. Legal Related Factors Desirability Curves

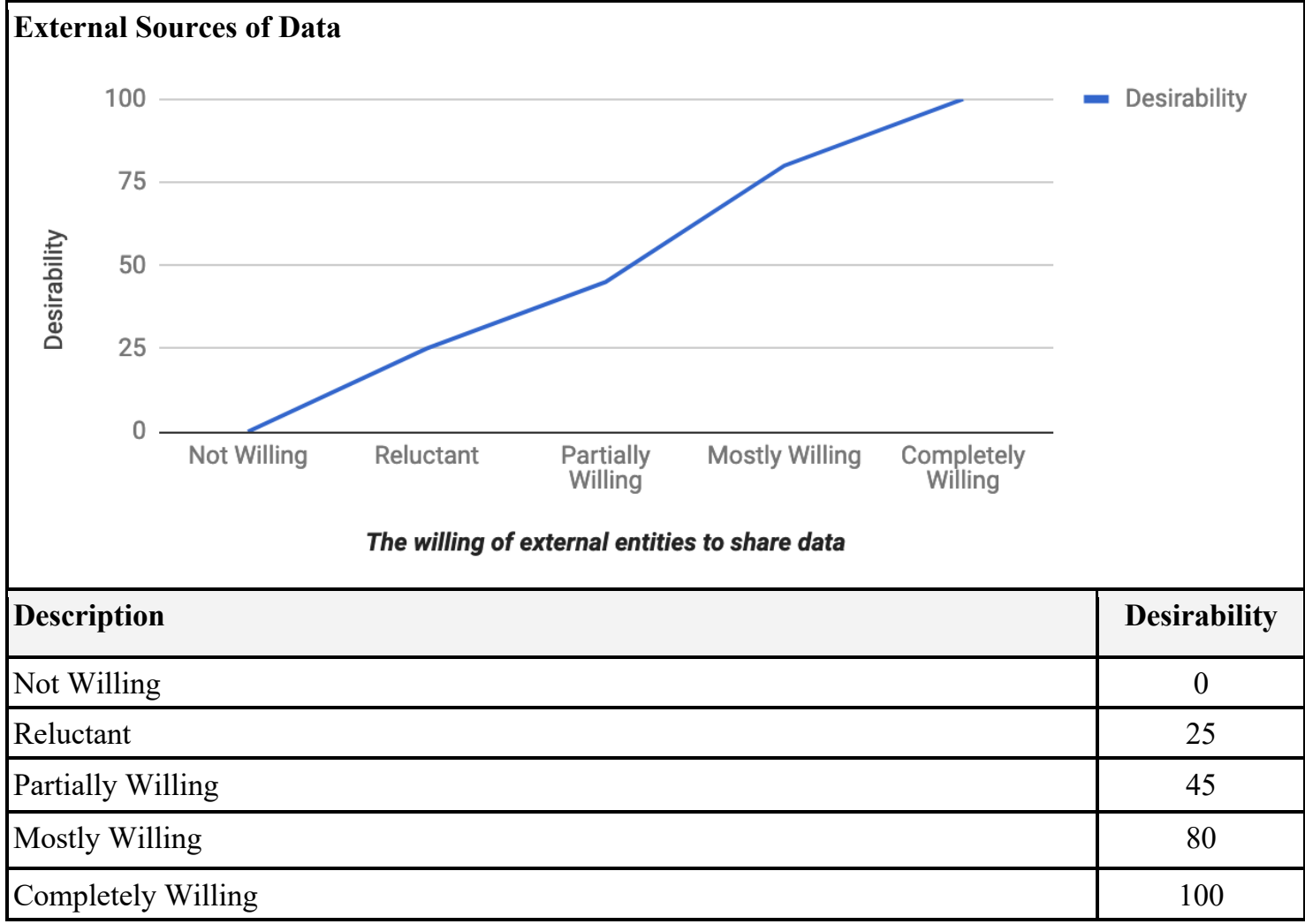

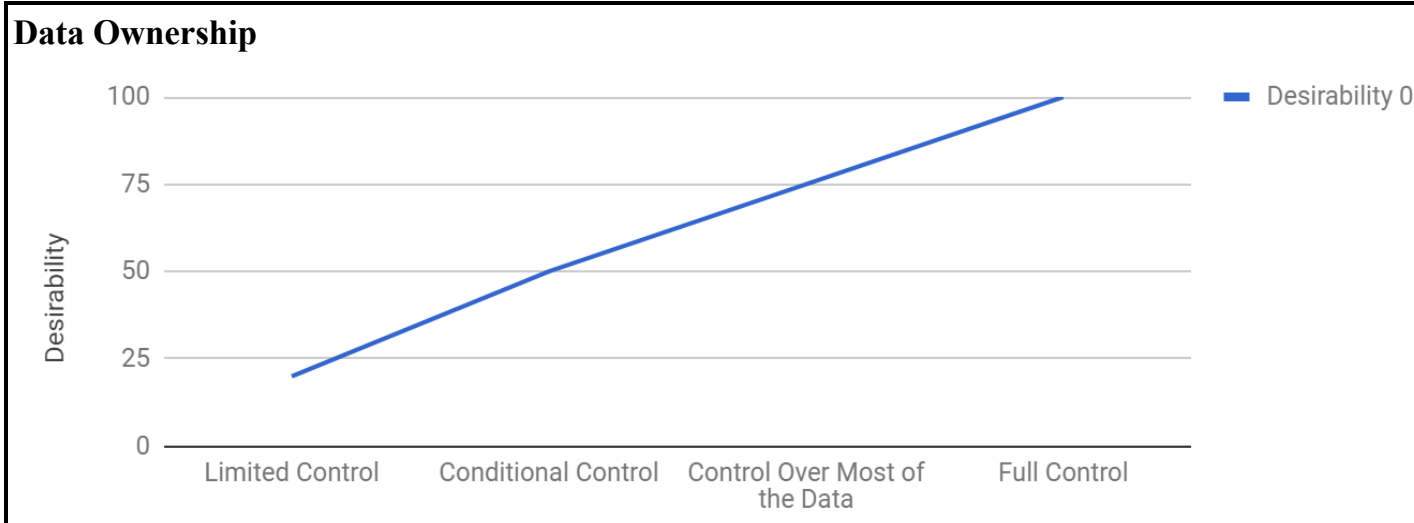

The level of ownership and control over the data?

\begin{tabular}{|l|c|}
\hline Description & Desirability \\
\hline No Control & 0 \\
\hline Limited Control & 20 \\
\hline Conditional Control & 50 \\
\hline
\end{tabular}




\begin{tabular}{|l|c|}
\hline Control Over Most of the Data & 75 \\
\hline Full Control & 100 \\
\hline
\end{tabular}

Data Security and Privacy

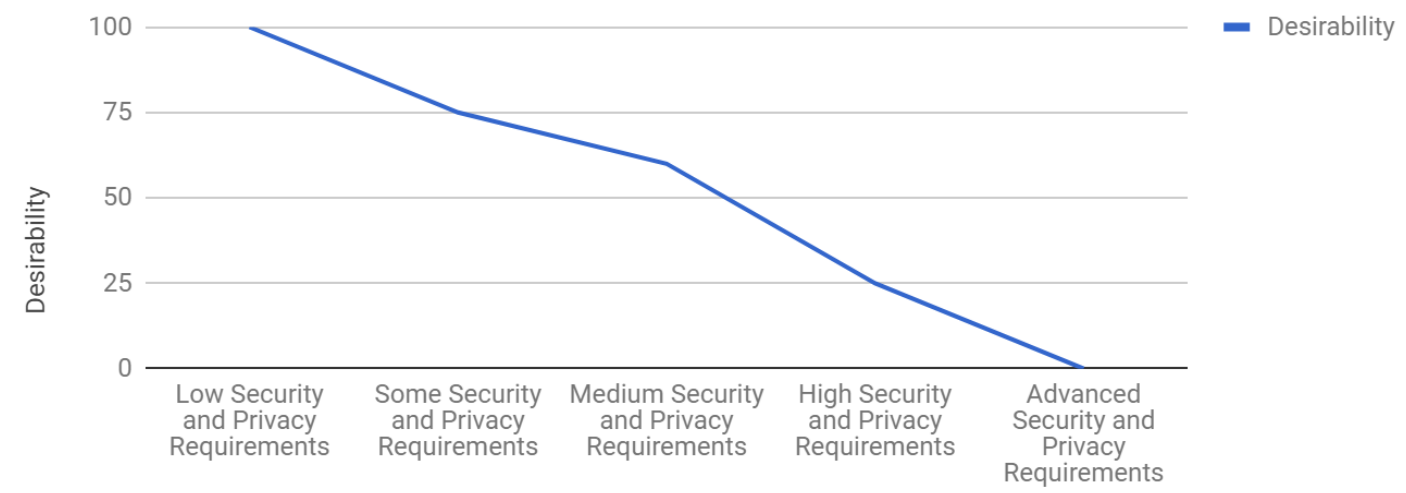

The level of data security and privacy needed

\begin{tabular}{|l|c|}
\hline Description & Desirability \\
\hline Low Security and Privacy Requirements & 100 \\
\hline Some Security and Privacy Requirements & 75 \\
\hline Medium Security and Privacy Requirements & 60 \\
\hline High Security and Privacy Requirements & 25 \\
\hline Advanced Security and Privacy Requirements & 0 \\
\hline
\end{tabular}

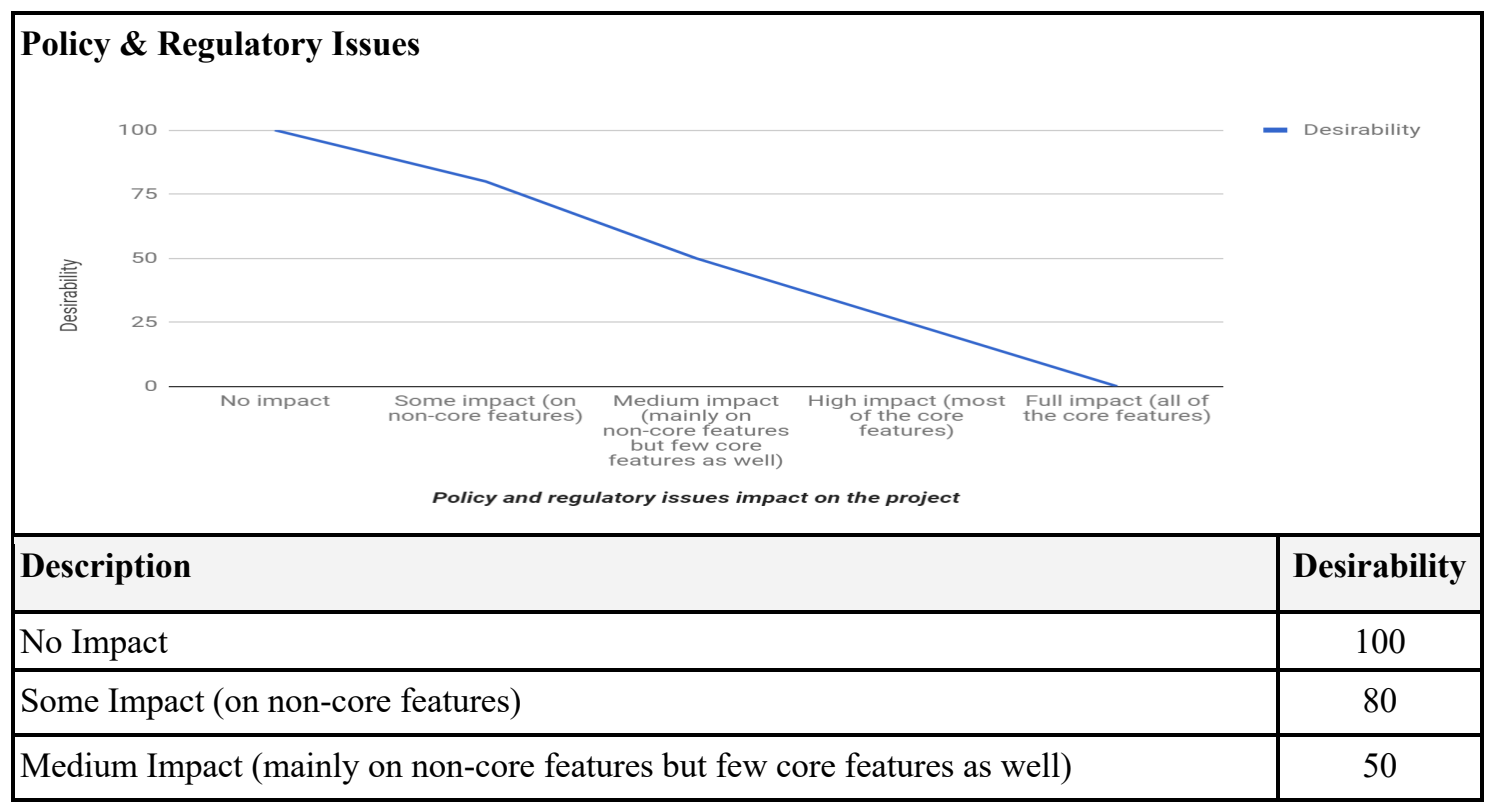


High Impact (most of the core features)

Full Impact (all of the core features) 


\subsubsection{Organization Factors}

Table 33. Organization Related Factors Desirability Curves

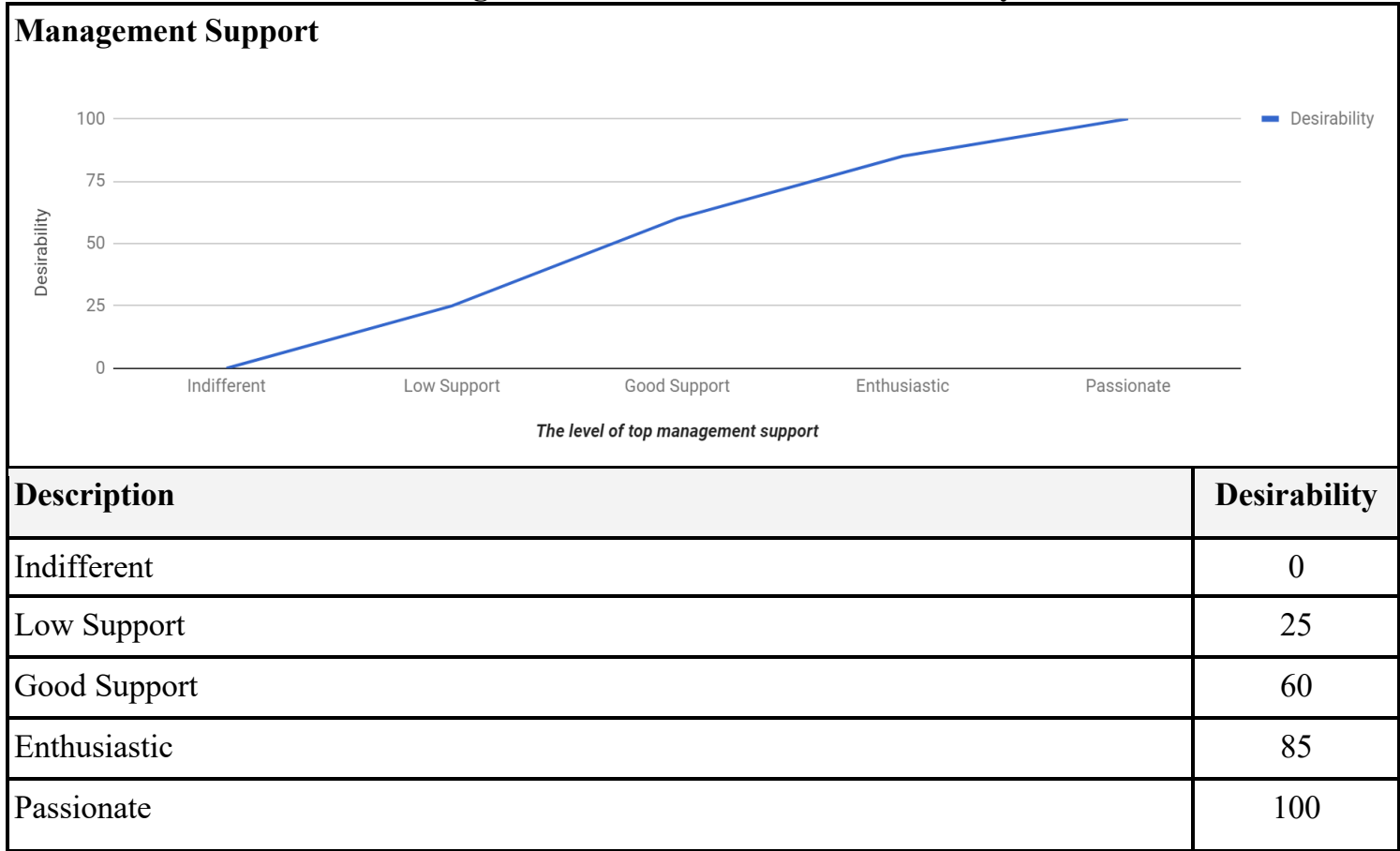

Data Strategies and Governance

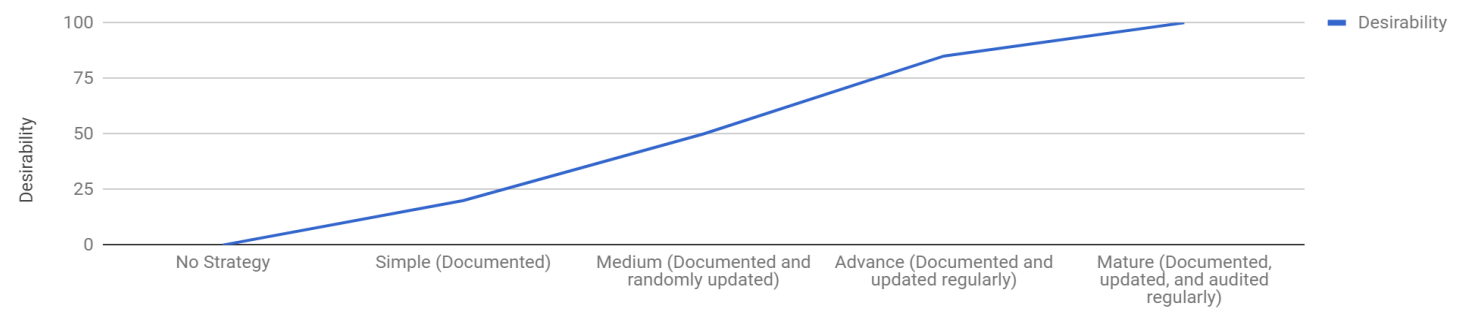

The maturity of data strategy and governance

\begin{tabular}{|l|c|}
\hline Description & Desirability \\
\hline No Strategy & 0 \\
\hline Simple (Documented) & 20 \\
\hline Medium (Documented and randomly updated) & 50 \\
\hline Advance (Documented and updated regularly) & 85 \\
\hline Mature (Documented, updated, and audited regularly) & 100 \\
\hline
\end{tabular}




\section{Clarity of Objectives and Use Cases}

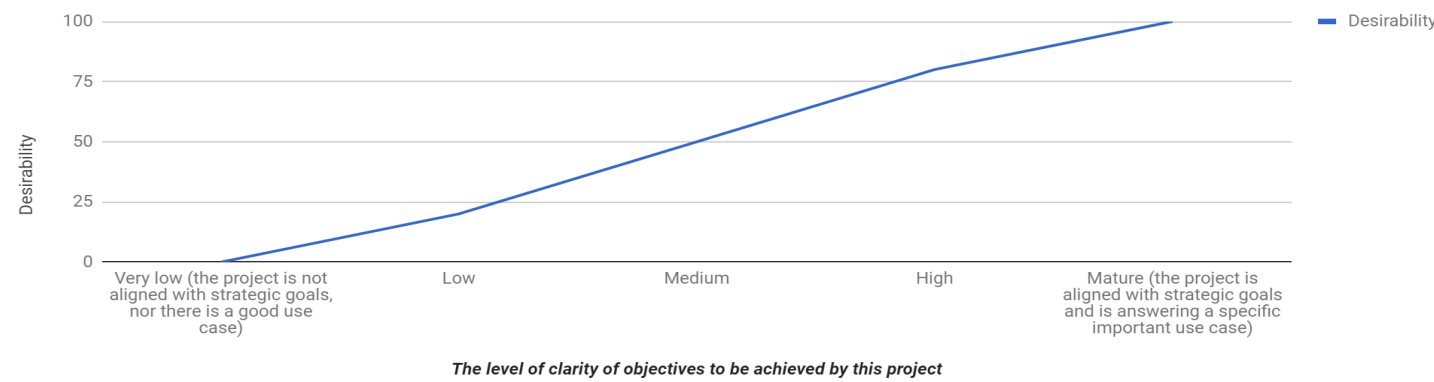

\begin{tabular}{|l|c|}
\hline Description & Desirability \\
\hline Very low (the project is not aligned with strategic goals, nor there is a good use case) & 0 \\
\hline Low & 20 \\
\hline Medium & 50 \\
\hline High & 80 \\
\hline $\begin{array}{l}\text { Mature (the project is aligned with strategic goals and is answering a specific important } \\
\text { use case) }\end{array}$ & 100 \\
\hline
\end{tabular}

\section{Return on Investment (ROI)}

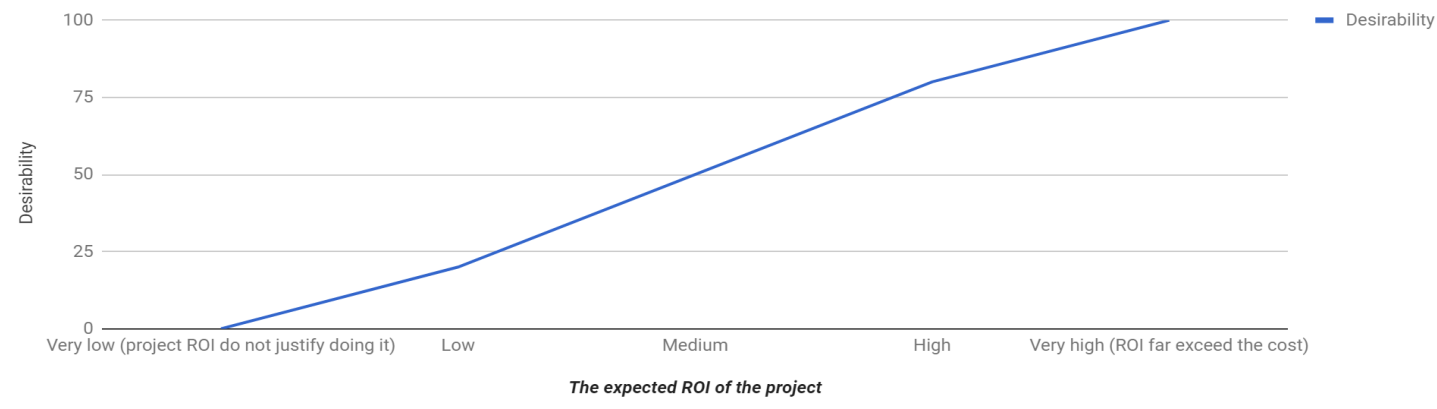

\begin{tabular}{|l|c|}
\hline Description & Desirability \\
\hline Very low (the project ROI do not justify doing it) & 0 \\
\hline Low & 20 \\
\hline Medium & 50 \\
\hline High & 80 \\
\hline Very high (ROI far exceed the cost) & 100 \\
\hline
\end{tabular}


Availability of Resources and Long-term Funding

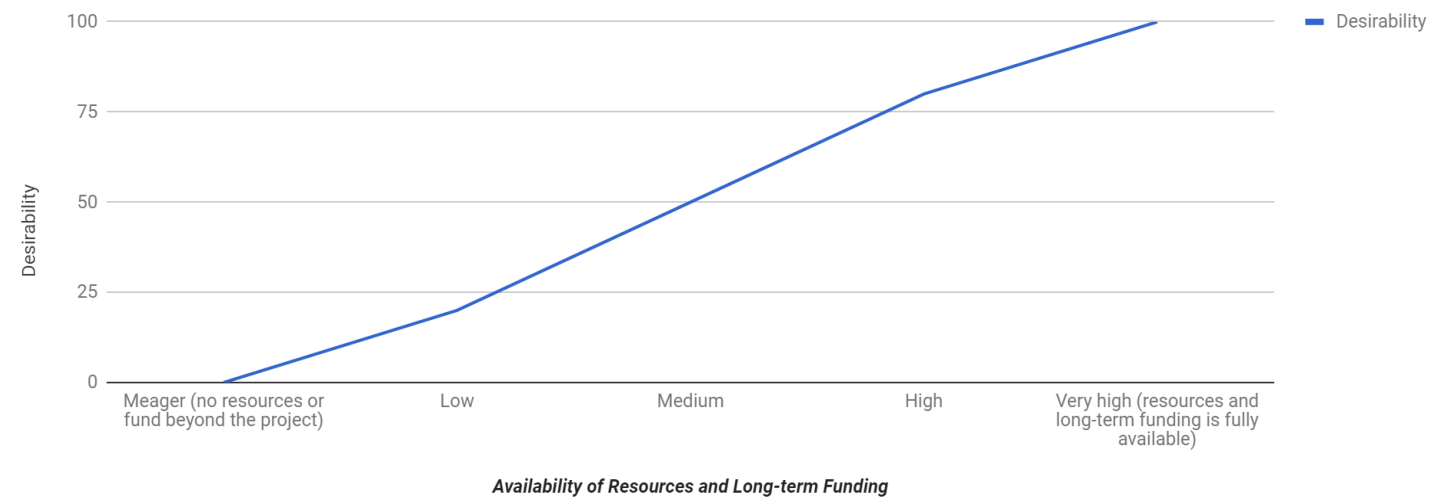

Description

Desirability

Meager (no resources or fund beyond the project)

Low

0

Medium

20

High

50

Very high (resources and long-term funding is fully available) 


\section{CHAPTER 6: CASE STUDY}

\subsection{Smart City PDX}

Portland, Oregon, is a thriving city. In the last few years, Portland has seen growth in economic and job rates that are among the highest in the United States (Badenhausen 2017; Oregon Employment Department 2016). As a result, the city population is also increasing at an unprecedented level, causing elevated pressure on the city's resources and infrastructure, and a hike in rental rates and property prices (PBOT 2019; Beebe 2016). In response to these changes and challenges, the city has recently initiated a smart city transformation initiative, called Smart City PDX, with the goals of achieving more efficient use of city resources and infrastructure, increasing the effectiveness of city decision making process, and get a better understanding and addressing of the local heterogeneous community dynamics and needs (Smart City PDX 2019a; PBOT 2019; Basalyga 2017).

As part of the Smart City PDX initiative, the City of Portland established a set of principles to guide how the city should approach its smart-city initiative. The guidelines stressed that the City of Portland would prioritize projects that reduce inequities for communities within the city. The guidelines focus on engaging community members while identifying needs and projects, and promoting projects that reduce disparities for certain underserved communities like communities of color and people with disabilities. Furthermore, the guidelines give priority to projects with measurable benefits, acknowledge that one size does not fit all, and seeks to advocate open data. The City of Portland seeks to achieve these goals by establishing partnerships with different 
stakeholders, like academia, the private sector, NGOs, and other government agencies (Smart City PDX 2019a).

\subsection{Case Study Smart-city Related Big Data Projects}

Under the Smart City PDX initiative, several projects were launched in the last couple of years (Smart City PDX 2019b). Following is a review of four smart-city-related big data projects that are related to the City of Portland and will be used as a case study for this research (each project is given a code for later reference in the format of Proj1, Proj2, and so on).

\subsubsection{Proj1: Traffic Safety Sensor Project (IQ Center)}

This is a pilot project that focuses on traffic safety. It will use sensor technology, installed into streetlights, to collect data about vehicles, cyclists, and pedestrian's behavior in several streets that are known for a high rate of traffic accidents in downtown Portland. The goal of the project is to use the captured traffic data to create insights about how people are using the streets. Then use the insights to make changes to traffic elements in these streets in a way that will reduce traffic accidents. This project includes attaching about 200 IoT sensors into streetlights, that will allow for real-time video analysis. The City of Portland is leading this project with direct sponsorship from the mayor. Furthermore, the City of Portland partnered with several private, public, and academic organizations for this project that include, AT\&T, GE, Intel, PGE, and Portland State University among other organizations (PBOT 2019b; PDX.edu 2019; Portlandiq.org 2019; Smart City PDX 2019c). 


\subsubsection{Proj2: Air Quality Sensor Testing \& Deployment}

This project is the first step in a program that aims to measure air quality and pollutants in the City of Portland. This project is unique in that its goal is to assess IoT devices itself. Under this project, The City of Portland is exploring several types of lowcost air quality sensors by installing them in certain areas in the I-5 corridor. The project will help the City of Portland to decide which low-cost sensor is more robust in the public right-of-way, it will also be used to demonstrate how to use the generated real-time data to better analyze air quality in Portland, and provide decision makers with insights to make proper planning to enhance the air quality in the city. This project is sponsored by the mayor. Moreover, the City of Portland partnered with several private, public, and academic organizations for this project that include, National Institute of Standards and Technology (NIST), Portland State University, Green Electric Council, Argonne National Laboratory, and University of Chicago among other organizations (Smart City PDX 2019d; Green Electric Council 2018; Levine 2018).

\subsubsection{Proj3: Connected Streetcar Project}

This is a pilot project that aims at laying the ground for future connected vehicles (CV) technologies in Portland, where cars can communicate with each other and with the infrastructure, to improve traffic safety and transportation efficiency. Under this project, the City of Portland and the National Institute for Transportation and Communities (NITC) are developing and testing a CV data collection platform, which will be implemented on the Portland Streetcar route. The goals of the project include enhancing the accuracy of streetcars schedule and provide data for researchers across cities working 
with NITC on CV technologies. Moreover, the City of Portland partnered with several public and academic organizations for this project that include, NITC, Portland State University - Transportation Research Education Center, University of Arizona, and Portland Streetcar (PBOT 2018; TREC 2018).

\subsubsection{Proj4: Pollution Prevention Technical Assistance for Idle Reduction and Electrification of Refrigerated Transport}

This project is different from the rest of the projects used for this research. It is led by the U.S. Environmental Protection Agency (EPA). The goal of the project is to understand and influence engine idling behavior by commercial fleets in distribution centers in the Pacific Northwest region. Specifically, when a truck is idling its engine in a distribution center to power the attached refrigerated unit (for trucks that move temperature-sensitive goods). Furthermore, the project goals include working with fleets to transform into electrification instead of the diesel engine idling. This project targeted 11 fleets that have regional headquarters in Portland. As part of the project, hundreds of IoT telematic devices that are attached to fleets' trucks were used to gather data about engine idling behavior by fleets and drivers. The insights from this project were used to show fleets' management the average time of idling by their fleet, as well as, the idling cost from financial, environmental, and noise perspectives. These findings were used in conjunction with "diesel vs. electricity" historical prices analysis to illuminate the benefits for fleets to move to electrification instead of engine idling to power the truck's refrigerated unit while in a distribution center. This project was done under the EPA P2 Program. Portland State University - Transportation Research Education Center, Drive 
Oregon, and CleanFuture Inc. partnered to implement this project (DOE 2018; Thornton et al. 2018). 


\section{CHAPTER 7: ANALYSIS OF CASE AND SENSITIVITY ANALYSIS}

In this chapter, the model will be demonstrated using the smart-city-related big data projects identified in the previous section, as described in steps 12 and 13 of the research design (see Section 4.2). First, the readiness score to implement each project will be calculated. Then scenario analysis will be used to assess the model sensitivity and the ramifications on each project under each scenario. Finally, a discussion on how the model can be used to enhance the readiness score for each project will be provided.

\subsection{City's Index of Readiness to Conduct a Smart-city-related Big Data Project Technology for Case Study}

Based on the researcher discussion with city officials, and close follow-up of the projects in the last two years, the readiness to do the projects by the City of Portland (for the first three projects), and PSU-TREC for the last project were assessed, and Table 34, Table 35, Table 36, and Table 37 show the results of the assessment.

The scoring was done as explained in Section 3.4.6. First, the researcher evaluated the City of Portland situation and capabilities when each of the first three projects (Proj1, Proj2, and Proj3), and the PSU TREC center situation and capabilities for the fourth project (Proj4). Then, for each project, the findings were compared for each factor in the HDM model with that factor's value curve, to identify the matching (or the most appropriate) level and give that project a score for that factor based on the value curve (please refer to Figure 12 in Section 3.4.6). Finally, the scores were calculated as shown in the following sections. 


\subsubsection{Readiness Score}

Table 34. Proj1 Readiness Assessment Score

\begin{tabular}{|c|c|c|c|c|}
\hline \multicolumn{5}{|c|}{ Proj1: Traffic Safety Sensor Project (IQ Center) Project } \\
\hline Perspectives & Factors & Weight & $\begin{array}{l}\text { Value Curve } \\
\text { Score }\end{array}$ & $\begin{array}{c}\text { Final Score } \\
\text { (Weight * VC Score) }\end{array}$ \\
\hline \multirow[t]{4}{*}{ People (30.3\%) } & Data Scientists & $08.8 \%$ & 50 & 4.4 \\
\hline & Employees Technological Skills & $05.4 \%$ & 40 & 2.1 \\
\hline & Public Acceptance & $08.2 \%$ & 35 & 2.9 \\
\hline & Management Analytical Skills & $07.9 \%$ & 70 & 5.6 \\
\hline \multirow[t]{5}{*}{ Technology (18.5\%) } & $\begin{array}{l}\text { Data Integration \& Processing } \\
\text { Complexities }\end{array}$ & $03.4 \%$ & 50 & 1.7 \\
\hline & Data Availability & $04.6 \%$ & 80 & 3.7 \\
\hline & What Data to Collect & $04.1 \%$ & 50 & 2.1 \\
\hline & Infrastructure Readiness & $04.0 \%$ & 40 & 1.6 \\
\hline & $\begin{array}{l}\text { Technology Solutions } \\
\text { Complexities }\end{array}$ & $02.3 \%$ & 25 & 0.6 \\
\hline \multirow[t]{4}{*}{ Legal (26.4\%) } & External Sources of Data & $04.6 \%$ & 80 & 3.7 \\
\hline & Data Ownership & $06.3 \%$ & 55 & 3.5 \\
\hline & Data Security and Privacy & $08.8 \%$ & 20 & 1.8 \\
\hline & Policy and Regulatory Issues & $06.7 \%$ & 55 & 3.7 \\
\hline \multirow{5}{*}{$\begin{array}{l}\text { Organization } \\
(24.5 \%)\end{array}$} & Management Support & $04.8 \%$ & 75 & 3.6 \\
\hline & Data Strategies and Governance & $04.4 \%$ & 30 & 1.3 \\
\hline & $\begin{array}{l}\text { Clarity of Objectives and Use } \\
\text { Cases }\end{array}$ & $05.4 \%$ & 75 & 4.1 \\
\hline & ROI & $05.8 \%$ & 60 & 3.5 \\
\hline & $\begin{array}{l}\text { Resources and long-term } \\
\text { Funding }\end{array}$ & $04.0 \%$ & 80 & 3.2 \\
\hline
\end{tabular}




\section{Proj1: Traffic Safety Sensor Project (IQ Center) Project}

\begin{tabular}{|c|c|c|c|c|}
\hline Perspectives & Factors & Weight & $\begin{array}{l}\text { Value Curve } \\
\text { Score }\end{array}$ & $\begin{array}{c}\text { Final Score } \\
\text { (Weight * VC Score) }\end{array}$ \\
\hline & Total & & & 52.9 \\
\hline
\end{tabular}

Table 35. Proj2 Readiness Assessment Score

\begin{tabular}{|c|c|c|c|c|}
\hline \multicolumn{5}{|c|}{ Proj2: Air Quality Sensor Testing \& Deployment } \\
\hline Perspectives & Factors & Weight & $\begin{array}{l}\text { Value Curve } \\
\text { Score }\end{array}$ & $\begin{array}{c}\text { Final Score } \\
\text { (Weight * VC Score) }\end{array}$ \\
\hline \multirow[t]{4}{*}{ People (30.3\%) } & Data Scientists & $08.8 \%$ & 90 & 7.9 \\
\hline & Employees Technological Skills & $05.4 \%$ & 40 & 2.1 \\
\hline & Public Acceptance & $08.2 \%$ & 55 & 4.5 \\
\hline & Management Analytical Skills & $07.9 \%$ & 90 & 7.1 \\
\hline \multirow[t]{5}{*}{ Technology $(18.5 \%)$} & $\begin{array}{l}\text { Data Integration \& Processing } \\
\text { Complexities }\end{array}$ & $03.4 \%$ & 20 & 0.7 \\
\hline & Data Availability & $04.6 \%$ & 85 & 3.9 \\
\hline & What Data to Collect & $04.1 \%$ & 75 & 3.1 \\
\hline & Infrastructure Readiness & $04.0 \%$ & 25 & 1.0 \\
\hline & $\begin{array}{l}\text { Technology Solutions } \\
\text { Complexities }\end{array}$ & $02.3 \%$ & 20 & 0.5 \\
\hline \multirow[t]{4}{*}{ Legal (26.4\%) } & External Sources of Data & $04.6 \%$ & 90 & 4.1 \\
\hline & Data Ownership & $06.3 \%$ & 70 & 4.4 \\
\hline & Data Security and Privacy & $08.8 \%$ & 50 & 4.4 \\
\hline & Policy and Regulatory Issues & $06.7 \%$ & 45 & 3.0 \\
\hline \multirow{4}{*}{$\begin{array}{l}\text { Organization } \\
(24.5 \%)\end{array}$} & Management Support & $04.8 \%$ & 50 & 2.4 \\
\hline & Data Strategies and Governance & $04.4 \%$ & 20 & 0.9 \\
\hline & $\begin{array}{l}\text { Clarity of Objectives and Use } \\
\text { Cases }\end{array}$ & $05.4 \%$ & 95 & 5.2 \\
\hline & ROI & $05.8 \%$ & 20 & 1.2 \\
\hline
\end{tabular}




\section{Proj2: Air Quality Sensor Testing \& Deployment}

\begin{tabular}{|c|c|c|c|c|}
\hline \multicolumn{1}{|c}{ Factors } & \multicolumn{2}{c|}{ Weight } & \multicolumn{1}{c|}{$\begin{array}{c}\text { Value Curve } \\
\text { Score }\end{array}$} & $\begin{array}{c}\text { Final Score } \\
\text { (Weight * VC Score) }\end{array}$ \\
& $\begin{array}{l}\text { Resources and long-term } \\
\text { Funding }\end{array}$ & $04.0 \%$ & 60 & 2.4 \\
\hline & Total & & & $\mathbf{5 8 . 9}$ \\
\hline
\end{tabular}

Table 36. Proj3 Readiness Assessment Score

\begin{tabular}{|c|c|c|c|c|}
\hline \multicolumn{5}{|c|}{ Proj3: Connected Streetcar Project } \\
\hline Perspectives & Factors & Weight & $\begin{array}{l}\text { Value Curve } \\
\text { Score }\end{array}$ & $\begin{array}{c}\text { Final Score } \\
\text { (Weight } * \text { VC Score) }\end{array}$ \\
\hline \multirow[t]{4}{*}{ People (30.3\%) } & Data Scientists & $08.8 \%$ & 55 & 4.8 \\
\hline & Employees Technological Skills & $05.4 \%$ & 40 & 2.1 \\
\hline & Public Acceptance & $08.2 \%$ & 65 & 5.4 \\
\hline & Management Analytical Skills & $07.9 \%$ & 80 & 6.4 \\
\hline \multirow[t]{5}{*}{ Technology (18.5\%) } & $\begin{array}{l}\text { Data Integration \& Processing } \\
\text { Complexities }\end{array}$ & $03.4 \%$ & 75 & 2.6 \\
\hline & Data Availability & $04.6 \%$ & 80 & 3.7 \\
\hline & What Data to Collect & $04.1 \%$ & 50 & 2.1 \\
\hline & Infrastructure Readiness & $04.0 \%$ & 30 & 1.2 \\
\hline & $\begin{array}{l}\text { Technology Solutions } \\
\text { Complexities }\end{array}$ & $02.3 \%$ & 80 & 1.9 \\
\hline \multirow[t]{4}{*}{ Legal (26.4\%) } & External Sources of Data & $04.6 \%$ & 90 & 4.1 \\
\hline & Data Ownership & $06.3 \%$ & 70 & 4.4 \\
\hline & Data Security and Privacy & $08.8 \%$ & 55 & 4.9 \\
\hline & Policy and Regulatory Issues & $06.7 \%$ & 50 & 3.3 \\
\hline
\end{tabular}




\begin{tabular}{|c|c|c|c|c|}
\hline \multicolumn{5}{|c|}{ Proj3: Connected Streetcar Project } \\
\hline Perspectives & Factors & Weight & $\begin{array}{l}\text { Value Curve } \\
\text { Score }\end{array}$ & $\begin{array}{c}\text { Final Score } \\
\text { (Weight * VC Score) }\end{array}$ \\
\hline \multirow{6}{*}{$\begin{array}{l}\text { Organization } \\
(24.5 \%)\end{array}$} & Management Support & $04.8 \%$ & 65 & 3.1 \\
\hline & Data Strategies and Governance & $04.4 \%$ & 55 & 2.4 \\
\hline & $\begin{array}{l}\text { Clarity of Objectives and Use } \\
\text { Cases }\end{array}$ & $05.4 \%$ & 45 & 2.4 \\
\hline & ROI & $05.8 \%$ & 30 & 1.7 \\
\hline & $\begin{array}{l}\text { Resources and long-term } \\
\text { Funding }\end{array}$ & $04.0 \%$ & 25 & 1.0 \\
\hline & Total & & & 57.6 \\
\hline
\end{tabular}

Table 37. Proj4 Readiness Assessment Score

\begin{tabular}{|l|l|c|c|c|}
\hline \multicolumn{2}{|c|}{ Proj4: Engine Idling (P2) Project } & Weight & $\begin{array}{c}\text { Value Curve } \\
\text { Score }\end{array}$ & $\begin{array}{c}\text { Final Score } \\
\text { (Weight * VC Score) }\end{array}$ \\
\hline \multirow{4}{*}{ People (30.3\%) } & Data Scientists & $08.8 \%$ & 60 & 5.3 \\
\cline { 2 - 5 } & Employees Technological Skills & $05.4 \%$ & 40 & 2.1 \\
\cline { 2 - 6 } & Public Acceptance & $08.2 \%$ & 100 & 8.2 \\
\cline { 2 - 6 } & Management Analytical Skills & $07.9 \%$ & 40 & 3.2 \\
\hline \multirow{5}{*}{ Technology (18.5\%) } & $\begin{array}{l}\text { Data Integration \& Processing } \\
\text { Complexities }\end{array}$ & $03.4 \%$ & 20 & 0.7 \\
\cline { 2 - 6 } & Data Availability & $04.6 \%$ & 80 & 3.7 \\
\cline { 2 - 6 } & What Data to Collect & $04.1 \%$ & 80 & 3.3 \\
\cline { 2 - 6 } & Infrastructure Readiness & $04.0 \%$ & 50 & 2.0 \\
\cline { 2 - 6 } & Technology Solutions Complexities & $02.3 \%$ & 25 & 0.6 \\
\hline
\end{tabular}




\begin{tabular}{|l|l|c|c|c|}
\hline \multicolumn{2}{|c|}{ Proj4: Engine Idling (P2) Project } & Weight & $\begin{array}{c}\text { Value Curve } \\
\text { Score }\end{array}$ & $\begin{array}{c}\text { Final Score } \\
\text { (Weight * VC Score) }\end{array}$ \\
\hline \multirow{4}{*}{ Perspectives } & External Sources of Data & $04.6 \%$ & 45 & 2.1 \\
\cline { 2 - 5 } & Data Ownership & $06.3 \%$ & 50 & 3.2 \\
\cline { 2 - 6 } & Data Security and Privacy & $08.8 \%$ & 60 & 5.3 \\
\cline { 2 - 6 } & Policy and Regulatory Issues & $06.7 \%$ & 50 & 3.3 \\
\hline \multirow{5}{*}{ Organization (24.5\%) } & Management Support & $04.8 \%$ & 60 & 2.9 \\
\cline { 2 - 6 } & Data Strategies and Governance & $04.4 \%$ & 20 & 0.9 \\
\cline { 2 - 6 } & $\begin{array}{l}\text { Clarity of Objectives and Use } \\
\text { Cases }\end{array}$ & $05.4 \%$ & 100 & 5.4 \\
\cline { 2 - 6 } & ROI & $05.8 \%$ & 80 & 4.7 \\
\cline { 2 - 6 } & Resources and long-term Funding & $04.0 \%$ & 25 & 1.0 \\
\hline & Total & & & $\mathbf{5 7 . 8}$ \\
\hline
\end{tabular}

\subsubsection{Strengths and Weaknesses}

Table 38 highlights the strengths and weaknesses of each project. This

comparison shows how the model was able to capture different attributes that contribute to each project. Following is a discussion about those points.

Table 38. Strengths and Weaknesses for each Scenario

\begin{tabular}{|c|c|c|c|}
\hline Proj1 & Factor & Factor Score & Value \\
\hline \multirow{3}{*}{ Strengths } & Data Availability & $\begin{array}{l}\text { High (the majority of sources are } \\
\text { sufficiently available) }\end{array}$ & 80 \\
\hline & External Sources of Data & Mostly Willing & 80 \\
\hline & $\begin{array}{l}\text { Resources and long-term } \\
\text { Funding }\end{array}$ & $\begin{array}{l}\text { High (resources and long-term funding } \\
\text { is available for the most part) }\end{array}$ & 80 \\
\hline Weaknesses & Public Acceptance & $\begin{array}{l}\text { The project might be perceived as } \\
\text { "invitation to privacy" }\end{array}$ & 35 \\
\hline
\end{tabular}




\begin{tabular}{|c|c|c|c|}
\hline & $\begin{array}{l}\text { Technology Solutions } \\
\text { Complexities }\end{array}$ & $\begin{array}{l}\text { Complex (few technologies/tools with } \\
\text { compatibility issues) }\end{array}$ & 25 \\
\hline & Data Security and Privacy & $\begin{array}{l}\text { High Security and Privacy } \\
\text { Requirements }\end{array}$ & 20 \\
\hline & Data Strategies and Governance & Simple (Documented) & 30 \\
\hline Proj2 & Factor & Factor Score & Value \\
\hline \multirow{4}{*}{ Strengths } & Data Scientists & $\begin{array}{l}\text { Data scientists who are strongly related } \\
\text { to the project goals }\end{array}$ & 90 \\
\hline & Management Analytical Skills & $\begin{array}{l}\text { Advance (ability to configure } \\
\text { computers, use analytical tools, some } \\
\text { software programming knowledge) }\end{array}$ & 90 \\
\hline & External Sources of Data & Mostly Willing & 90 \\
\hline & $\begin{array}{l}\text { Clarity of Objectives and Use } \\
\text { Cases }\end{array}$ & $\begin{array}{l}\text { Mature (the project is aligned with } \\
\text { strategic goals and is answering a } \\
\text { specific important use case) }\end{array}$ & 95 \\
\hline \multirow{4}{*}{ Weaknesses } & Data Integration Complexities & $\begin{array}{l}\text { Some Integrability (most data sources } \\
\text { has different formats and meta-data) }\end{array}$ & 20 \\
\hline & $\begin{array}{l}\text { Technology Solutions } \\
\text { Complexities }\end{array}$ & $\begin{array}{l}\text { Complex (few technologies/tools with } \\
\text { compatibility issues) }\end{array}$ & 20 \\
\hline & Data Strategies and Governance & Simple (Documented) & 20 \\
\hline & ROI & $\begin{array}{l}\text { Low (project ROI do not justify doing } \\
\text { it) }\end{array}$ & 20 \\
\hline Proj3 & Factor & Factor Score & Value \\
\hline \multirow{4}{*}{ Strengths } & Management Analytical Skills & $\begin{array}{l}\text { High (skilled in reading statistics and } \\
\text { use it in decision making, as well as, } \\
\text { some skills in using BI and statistical } \\
\text { tools) }\end{array}$ & 80 \\
\hline & Data Availability & $\begin{array}{l}\text { High (the majority of sources are } \\
\text { sufficiently available) }\end{array}$ & 80 \\
\hline & $\begin{array}{l}\text { Technology Solutions } \\
\text { Complexities }\end{array}$ & $\begin{array}{l}\text { Reasonable (few technologies/tools that } \\
\text { are highly compatible) }\end{array}$ & 80 \\
\hline & External Sources of Data & Mostly Willing & 90 \\
\hline
\end{tabular}




\begin{tabular}{|c|c|c|c|}
\hline \multirow{3}{*}{ Weaknesses } & Infrastructure Readiness & $\begin{array}{l}\text { Some of the required infrastructures are } \\
\text { available }\end{array}$ & 30 \\
\hline & ROI & $\begin{array}{l}\text { Low (project ROI do not justify doing } \\
\text { it) }\end{array}$ & 30 \\
\hline & $\begin{array}{l}\text { Resources and long-term } \\
\text { Funding }\end{array}$ & $\begin{array}{l}\text { Low (limited resources or fund beyond } \\
\text { the project) }\end{array}$ & 25 \\
\hline Proj4 & Factor & Factor Score & Value \\
\hline \multirow{3}{*}{ Strengths } & Public Acceptance & $\begin{array}{l}\text { The project likely be perceived as a } \\
\text { "good" project }\end{array}$ & 100 \\
\hline & $\begin{array}{l}\text { Clarity of Objectives and Use } \\
\text { Cases }\end{array}$ & $\begin{array}{l}\text { Mature (the project is aligned with } \\
\text { strategic goals and is answering a } \\
\text { specific important use case) }\end{array}$ & 100 \\
\hline & ROI & High (ROI far exceed the cost) & 80 \\
\hline \multirow{3}{*}{ Weaknesses } & Data Integration Complexities & $\begin{array}{l}\text { Some Integrability (most data sources } \\
\text { have different formats and meta-data) }\end{array}$ & 20 \\
\hline & $\begin{array}{l}\text { Technology Solutions } \\
\text { Complexities }\end{array}$ & $\begin{array}{l}\text { Complex (few technologies/tools with } \\
\text { compatibility issues) }\end{array}$ & 25 \\
\hline & $\begin{array}{l}\text { Resources and long-term } \\
\text { Funding }\end{array}$ & $\begin{array}{l}\text { Low (limited resources or fund beyond } \\
\text { the project) }\end{array}$ & 25 \\
\hline
\end{tabular}

For the Proj1 project, there are plenty of chances to enhance readiness, as there are no factors where the City of Portland scored above 90. Never the less, there are factors where the City of Portland is doing well, including the availability of data, as the data (video stream) is being captured and analyzed in real-time. Also, External sources of data, mainly private sector companies working with the City of Portland on the project, are willing to share the data. Moreover, those companies are willing to fund future expansions and operational costs of the project to a certain degree. 
On the other hand, as the nature of the project includes using advanced technologies that depend on image recognition, this project might face criticism from the public, and the City of Portland need to take multiple measures to maintain the privacy of pedestrians. Another issue is related to how several companies are participating in this project, which requires a complex integration of technologies. Lastly, the City of Portland is still working on its data strategy and governance, so the guidelines are not clear for this project.

For the Proj2 project, there are several factors where the City of Portland is performing well, and this includes having data scientists who are closely related to the subject of the project. In addition, the management of the department that supervises this project within the City of Portland has quite good analytical skills and the ability to use analytics in making a decision. Moreover, external sources of data owners are willing to share it, and the goals of the project are really clear, as NITC supports this project and the goals are well defined based on NITC guidelines.

On the other hand, the City of Portland scored low on several factors for this project, including the complexity of data integration and technology integration as this project is using sensors from different vendors. Also, the City of Portland is still working on its data strategy and governance, so the guidelines are not clear for this project. Lastly, there is no clear direct ROI, and this project is phase one of a larger program, the goal is to identify low-cost air-quality sensors that can be used for the coming stages of the program. 
For the Proj3 project, similar to the Proj1 project, there are plenty of chances to enhance readiness, as there are no factors where the City of Portland scored above 90. Never the less, the City of Portland doing well in the following factors, the management of the department that supervises this project within the City of Portland has quite good analytical skills and the ability to use analytics in making a decision. In addition, the majority of data sources are available when needed. Furthermore, since the technology solution being used is coming from one place, this makes compatibility issues less concerning. Moreover, the data sources owners are mainly willing to share their data.

On the other hand, the City of Portland scored low on several factors for this project, including the lack of infrastructure; for this project, infrastructure should be built from scratch, but the required types of equipment are available by partners. Also, ROI is low as this is a pilot project that aims at testing $\mathrm{CV}$ technologies more than fixing real problems. Lastly, while this project has a fund from NITC, there is no clear path for a further fund from the City of Portland or NITC.

For the Proj4 project, there are several factors where the PSU-TREC and partners are performing well, including public acceptance; as this project does not include any individual identification requirements, and it targets commercial fleets, so the public is more likely to perceive the project as a "good" project. Also, the objectives are clear and detailed based on EPA guidelines. Moreover, the ROI of the project is evident as it reduces the cost for fleets, reduces pollution, and reduce noise for neighborhoods that are closed to distribution centers. 
On the other hand, the PSU-TREC and partners scored low on several factors for this project, including data and technology complexities, as the data is being collected from different fleets that use different types and models of IoT telematics devices, therefore, the data structure and definition are not unified and the technologies to pull the data are different. Moreover, this project funding came from EPA with matching fund from partners, and there is no guarantee that the fund will be provided for future extensions or operational needs. 


\subsection{Scenario Analysis}

To better understand the dynamics of the model and the influence of each perspective as discussed in step 13 of the research design (see Section 4.2), extreme scenario analysis is conducted based on how this was conducted in previous HDM research work (see Section 3.4.2.4). In this analysis, four scenarios are suggested, in each scenario, one of the perspectives is boosted with the assumption that it might turn out in reality that this is the most critical perspective (see Table 39). In this analysis, a comparison was conducted between the original readiness scores and the new scores under each scenario, to find out how the project score is affected if any of those scenarios materialized in reality. The results suggested that there will be change, but it is not significant, and since those are extreme scenarios, and in practice most likely any change would be much less extreme, thus the model is reliable enough.

Table 39. Future Scenarios

\begin{tabular}{|l|c|c|c|c|}
\hline Base & $30.3 \%$ & $18.5 \%$ & $26.4 \%$ & $24.5 \%$ \\
\hline Scenario I: People Emphasis & $\mathbf{9 7 . 0 \%}$ & $1.0 \%$ & $1.0 \%$ & $1.0 \%$ \\
\hline $\begin{array}{l}\text { Scenario II: Technology } \\
\text { Emphasis }\end{array}$ & $1.0 \%$ & $\mathbf{9 7 . 0} \%$ & $1.0 \%$ & $1.0 \%$ \\
\hline Scenario III: Legal Emphasis & $1.0 \%$ & $1.0 \%$ & $\mathbf{9 7 . 0 \%}$ & $1.0 \%$ \\
\hline $\begin{array}{l}\text { Scenario IV: Organization } \\
\text { Emphasis }\end{array}$ & $1.0 \%$ & $1.0 \%$ & $1.0 \%$ & $\mathbf{9 7 . 0 \%}$ \\
\hline
\end{tabular}

Table 40 shows the results if Scenario I materialized, with people perspective factors being the most important for the project in reality. The results show that no 
changes are in projects ranking. However, each project score changed differently. The Proj2, Proj3, and Proj4 projects scores changed favorably, while the Proj1 project score was affected negatively. Among the projects, the Proj2 project changed the most with an extra 12.3 points, which suggests that if there are indications that people factors are the most critical factors in reality, then the Proj2 project can be done with more confidence in compare with other projects.

Table 40. Scenario I: People Emphasis

\begin{tabular}{|c|c|c|c|c|c|c|c|}
\hline \multicolumn{8}{|c|}{ Scenario I: People Emphasis } \\
\hline Perspectives & Factors & $\begin{array}{c}\text { Local } \\
\text { Weight }\end{array}$ & \begin{tabular}{|c|} 
Global \\
Weight
\end{tabular} & Proj1 & Proj2 & Proj3 & Proj4 \\
\hline \multirow{4}{*}{$\begin{array}{l}\text { People } \\
(97.0 \%)\end{array}$} & Data Scientists & $29.0 \%$ & $28.1 \%$ & 14.07 & 25.32 & 15.47 & 16.88 \\
\hline & $\begin{array}{l}\text { Employees } \\
\text { Technological } \\
\text { Skills }\end{array}$ & $17.7 \%$ & $17.2 \%$ & 6.87 & 6.87 & 6.87 & 6.87 \\
\hline & Public Acceptance & $27.2 \%$ & $26.4 \%$ & 9.23 & 14.51 & 17.15 & 26.38 \\
\hline & $\begin{array}{l}\text { Management } \\
\text { Analytical Skills }\end{array}$ & $26.2 \%$ & $25.4 \%$ & 17.79 & 22.87 & 20.33 & 10.17 \\
\hline \multirow[t]{5}{*}{$\begin{array}{l}\text { Technology } \\
(1.0 \%)\end{array}$} & $\begin{array}{l}\text { Data Integration \& } \\
\text { Processing } \\
\text { Complexities }\end{array}$ & $18.5 \%$ & $0.2 \%$ & 0.09 & 0.04 & 0.14 & 0.04 \\
\hline & Data Availability & $24.9 \%$ & $0.2 \%$ & 0.20 & 0.21 & 0.20 & 0.20 \\
\hline & $\begin{array}{l}\text { What Data to } \\
\text { Collect }\end{array}$ & $22.2 \%$ & $0.2 \%$ & 0.11 & 0.17 & 0.11 & 0.18 \\
\hline & $\begin{array}{l}\text { Infrastructure } \\
\text { Readiness }\end{array}$ & $21.5 \%$ & $0.2 \%$ & 0.09 & 0.05 & 0.06 & 0.11 \\
\hline & $\begin{array}{l}\text { Technology } \\
\text { Solutions } \\
\text { Complexities }\end{array}$ & $12.7 \%$ & $0.1 \%$ & 0.03 & 0.03 & 0.10 & 0.03 \\
\hline Legal (1.0\%) & $\begin{array}{l}\text { External Sources } \\
\text { of Data }\end{array}$ & $17.3 \%$ & $0.2 \%$ & 0.14 & 0.16 & 0.16 & 0.08 \\
\hline
\end{tabular}




\begin{tabular}{|c|c|c|c|c|c|c|c|}
\hline \multicolumn{8}{|c|}{ Scenario I: People Emphasis } \\
\hline \multirow[t]{4}{*}{ Perspectives } & Factors & \begin{tabular}{|c|} 
Local \\
Weight
\end{tabular} & \begin{tabular}{|l|} 
Global \\
Weight
\end{tabular} & Proj1 & Proj2 & Proj3 & Proj4 \\
\hline & Data Ownership & $24.0 \%$ & $0.2 \%$ & 0.13 & 0.17 & 0.17 & 0.12 \\
\hline & $\begin{array}{l}\text { Data Security \& } \\
\text { Privacy }\end{array}$ & $33.5 \%$ & $0.3 \%$ & 0.07 & 0.17 & 0.18 & 0.20 \\
\hline & $\begin{array}{l}\text { Policy and } \\
\text { Regulatory Issues }\end{array}$ & $25.3 \%$ & $0.3 \%$ & 0.14 & 0.11 & 0.13 & 0.13 \\
\hline \multirow[t]{6}{*}{$\begin{array}{l}\text { Organization } \\
(\mathbf{1 . 0 \% )}\end{array}$} & $\begin{array}{l}\text { Management } \\
\text { Support }\end{array}$ & $19.7 \%$ & $0.2 \%$ & 0.15 & 0.10 & 0.13 & 0.12 \\
\hline & $\begin{array}{l}\text { Data Strategies } \\
\text { and Governance }\end{array}$ & $18.0 \%$ & $0.2 \%$ & 0.05 & 0.04 & 0.10 & 0.04 \\
\hline & $\begin{array}{l}\text { Clarity of } \\
\text { Objectives and } \\
\text { Use Cases }\end{array}$ & $22.2 \%$ & $0.2 \%$ & 0.17 & 0.21 & 0.10 & 0.22 \\
\hline & ROI & $23.8 \%$ & $0.2 \%$ & 0.14 & 0.05 & 0.07 & 0.19 \\
\hline & $\begin{array}{l}\text { Resources and } \\
\text { Funding }\end{array}$ & $16.2 \%$ & $0.2 \%$ & 0.13 & 0.10 & 0.04 & 0.04 \\
\hline & & & Score & 49.59 & 71.16 & 61.51 & 61.98 \\
\hline
\end{tabular}

\begin{tabular}{|l|c|c|c|c|}
\hline \multicolumn{5}{|c|}{ Scenario I Analysis } \\
\hline \multicolumn{1}{|c|}{ Project } & Proj1 & Proj2 & Proj3 & Proj4 \\
\hline \multicolumn{5}{|c|}{ Score Changes } \\
\hline Original & 52.89 & 58.86 & 57.57 & 57.81 \\
\hline Scenario & 49.59 & 71.16 & 61.51 & 61.98 \\
\hline Change & $\mathbf{- 3 . 2 9}$ & $\mathbf{1 2 . 3}$ & $\mathbf{3 . 9 4}$ & $\mathbf{4 . 1 7}$ \\
\hline & & Rank Changes & 2 \\
\hline Original & 4 & 1 & 3 & 2 \\
\hline Scenario & 4 & 1 & 3 & \\
\hline
\end{tabular}


Table 41 shows the results if Scenario II materialized, with technology perspective factors being the most important for the project in reality. The results show that the Proj1, Proj2, and Proj3 projects ranking changed. Moreover, each project score changed differently. Only the Proj3 project score changed favorably, while the rest of the projects' scores was affected negatively. Furthermore, the Proj1 project is barely changed with -0.79 point change in score. While the Proj2 project was the most to change under this scenario with 9.1 points less than the original score. This scenario is generally bad and suggests that if there are indications that technology factors are the most critical factors in reality, more cautious and preparations must be considered.

Table 41. Scenario II: Technology Emphasis

\begin{tabular}{|c|c|c|c|c|c|c|c|}
\hline \multicolumn{8}{|c|}{ Scenario II: Technology Emphasis } \\
\hline Perspectives & Factors & $\begin{array}{c}\text { Local } \\
\text { Weight }\end{array}$ & $\begin{array}{l}\text { Global } \\
\text { Weight }\end{array}$ & Proj1 & Proj2 & Proj3 & Proj4 \\
\hline \multirow{4}{*}{$\begin{array}{l}\text { People } \\
(1.0 \%)\end{array}$} & Data Scientists & $29.0 \%$ & $0.3 \%$ & 0.15 & 0.26 & 0.16 & 0.17 \\
\hline & $\begin{array}{l}\text { Employees } \\
\text { Technological Skills }\end{array}$ & $17.7 \%$ & $0.2 \%$ & 0.07 & 0.07 & 0.07 & 0.07 \\
\hline & Public Acceptance & $27.2 \%$ & $0.3 \%$ & 0.10 & 0.15 & 0.18 & 0.27 \\
\hline & $\begin{array}{l}\text { Management } \\
\text { Analytical Skills }\end{array}$ & $26.2 \%$ & $0.3 \%$ & 0.18 & 0.24 & 0.21 & 0.10 \\
\hline \multirow[t]{5}{*}{$\begin{array}{l}\text { Technology } \\
(97.0 \%)\end{array}$} & $\begin{array}{l}\text { Data Integration \& } \\
\text { Processing } \\
\text { Complexities }\end{array}$ & $18.5 \%$ & $17.9 \%$ & 8.97 & 3.59 & 13.46 & 3.59 \\
\hline & Data Availability & $24.9 \%$ & $24.2 \%$ & 19.32 & 20.53 & 19.32 & 19.32 \\
\hline & What Data to Collect & $22.2 \%$ & $21.5 \%$ & 10.77 & 16.15 & 10.77 & 17.23 \\
\hline & $\begin{array}{l}\text { Infrastructure } \\
\text { Readiness }\end{array}$ & $21.5 \%$ & $20.9 \%$ & 8.34 & 5.21 & 6.26 & 10.43 \\
\hline & $\begin{array}{l}\text { Technology } \\
\text { Solutions } \\
\text { Complexities }\end{array}$ & $12.7 \%$ & $12.3 \%$ & 3.08 & 2.46 & 9.86 & 3.08 \\
\hline
\end{tabular}




\begin{tabular}{|c|c|c|c|c|c|c|c|}
\hline \multirow[t]{4}{*}{ Legal (1\%) } & $\begin{array}{l}\text { External Sources of } \\
\text { Data }\end{array}$ & $17.3 \%$ & $0.2 \%$ & 0.14 & 0.16 & 0.16 & 0.08 \\
\hline & Data Ownership & $24.0 \%$ & $0.2 \%$ & 0.13 & 0.17 & 0.17 & 0.12 \\
\hline & $\begin{array}{l}\text { Data Security and } \\
\text { Privacy }\end{array}$ & $33.5 \%$ & $0.3 \%$ & 0.07 & 0.17 & 0.18 & 0.20 \\
\hline & $\begin{array}{l}\text { Policy and } \\
\text { Regulatory Issues }\end{array}$ & $25.3 \%$ & $0.3 \%$ & 0.14 & 0.11 & 0.13 & 0.13 \\
\hline \multirow[t]{6}{*}{$\begin{array}{l}\text { Organization } \\
(\mathbf{1 \%})\end{array}$} & $\begin{array}{l}\text { Management } \\
\text { Support }\end{array}$ & $19.7 \%$ & $0.2 \%$ & 0.15 & 0.10 & 0.13 & 0.12 \\
\hline & $\begin{array}{l}\text { Data Strategies \& } \\
\text { Governance }\end{array}$ & $18.0 \%$ & $0.2 \%$ & 0.05 & 0.04 & 0.10 & 0.04 \\
\hline & $\begin{array}{l}\text { Clarity of Objectives } \\
\text { and Use Cases }\end{array}$ & $22.2 \%$ & $0.2 \%$ & 0.17 & 0.21 & 0.10 & 0.22 \\
\hline & ROI & $23.8 \%$ & $0.2 \%$ & 0.14 & 0.05 & 0.07 & 0.19 \\
\hline & $\begin{array}{l}\text { Resources and } \\
\text { Funding }\end{array}$ & $16.2 \%$ & $0.2 \%$ & 0.13 & 0.10 & 0.04 & 0.04 \\
\hline & & & Score & 52.10 & 49.76 & 61.35 & 55.40 \\
\hline
\end{tabular}

\begin{tabular}{|c|c|c|c|c|}
\hline \multicolumn{5}{|c|}{ Scenario II Analysis } \\
\hline Project & Proj1 & Proj2 & Proj3 & Proj4 \\
\hline \multicolumn{5}{|c|}{ Score Changes } \\
\hline Original & 52.89 & 58.86 & 57.57 & 57.81 \\
\hline Scenario & 52.1 & 49.76 & 61.35 & 55.4 \\
\hline Change & -0.79 & -9.1 & 3.78 & -2.41 \\
\hline \multicolumn{5}{|c|}{ Rank Changes } \\
\hline Original & 4 & 1 & 3 & 2 \\
\hline Scenario & 3 & 4 & 1 & 2 \\
\hline
\end{tabular}

Table 42 shows the results if Scenario III materialized, with legal perspective factors being the most important for the project in reality. The results show that the Proj2, 
Proj3, and Proj4 projects ranking changed. Moreover, each project score changed differently. The Proj2 and Proj3 scores changed favorably, while the Proj1 and Proj4 projects scores were affected negatively. Furthermore, among the projects, the Proj3 project changed the most with an extra 5.65 points. However, the changes are not extreme for any of the projects.

Table 42. Scenario III: Legal Emphasis

\begin{tabular}{|c|c|c|c|c|c|c|c|}
\hline \multicolumn{8}{|c|}{ Scenario III: Legal Emphasis } \\
\hline Perspectives & Factors & $\begin{array}{c}\text { Local } \\
\text { Weight }\end{array}$ & $\begin{array}{l}\text { Global } \\
\text { Weight }\end{array}$ & Proj1 & Proj2 & Proj3 & Proj4 \\
\hline \multirow[t]{4}{*}{ People (1.0\%) } & Data Scientists & $29.0 \%$ & $0.3 \%$ & 0.15 & 0.26 & 0.16 & 0.17 \\
\hline & $\begin{array}{l}\text { Employees } \\
\text { Technological Skills }\end{array}$ & $17.7 \%$ & $0.2 \%$ & 0.07 & 0.07 & 0.07 & 0.07 \\
\hline & Public Acceptance & $27.2 \%$ & $0.3 \%$ & 0.10 & 0.15 & 0.18 & 0.27 \\
\hline & $\begin{array}{l}\text { Management } \\
\text { Analytical Skills }\end{array}$ & $26.2 \%$ & $0.3 \%$ & 0.18 & 0.24 & 0.21 & 0.11 \\
\hline \multirow[t]{5}{*}{$\begin{array}{l}\text { Technology } \\
\text { (1.0\%) }\end{array}$} & $\begin{array}{l}\text { Data Integration \& } \\
\text { Processing } \\
\text { Complexities }\end{array}$ & $18.5 \%$ & $0.2 \%$ & 0.09 & 0.04 & 0.14 & 0.04 \\
\hline & Data Availability & $24.9 \%$ & $0.2 \%$ & 0.20 & 0.21 & 0.20 & 0.20 \\
\hline & What Data to Collect & $22.2 \%$ & $0.2 \%$ & 0.11 & 0.17 & 0.11 & 0.18 \\
\hline & $\begin{array}{l}\text { Infrastructure } \\
\text { Readiness }\end{array}$ & $21.5 \%$ & $0.2 \%$ & 0.09 & 0.05 & 0.06 & 0.11 \\
\hline & $\begin{array}{l}\text { Technology Solutions } \\
\text { Complexities }\end{array}$ & $12.7 \%$ & $0.1 \%$ & 0.03 & 0.03 & 0.10 & 0.03 \\
\hline \multirow[t]{4}{*}{ Legal $(97.0 \%)$} & $\begin{array}{l}\text { External Sources of } \\
\text { Data }\end{array}$ & $17.3 \%$ & $16.8 \%$ & 13.42 & 15.10 & 15.10 & 7.55 \\
\hline & Data Ownership & $24.0 \%$ & $23.3 \%$ & 12.80 & 16.30 & 16.30 & 11.64 \\
\hline & $\begin{array}{l}\text { Data Security and } \\
\text { Privacy }\end{array}$ & $33.5 \%$ & $32.5 \%$ & 6.50 & 16.25 & 17.87 & 19.50 \\
\hline & $\begin{array}{l}\text { Policy and Regulatory } \\
\text { Issues }\end{array}$ & $25.3 \%$ & $24.5 \%$ & 13.50 & 11.04 & 12.27 & 12.27 \\
\hline
\end{tabular}




\begin{tabular}{|c|c|c|c|c|c|c|c|}
\hline \multicolumn{8}{|c|}{ Scenario III: Legal Emphasis } \\
\hline Perspectives & Factors & $\begin{array}{l}\text { Local } \\
\text { Weight }\end{array}$ & $\begin{array}{l}\text { Global } \\
\text { Weight }\end{array}$ & Proj1 & Proj2 & Proj3 & Proj4 \\
\hline \multirow[t]{6}{*}{$\begin{array}{l}\text { Organization } \\
(\mathbf{1 . 0 \% )}\end{array}$} & Management Support & $19.7 \%$ & $0.2 \%$ & 0.15 & 0.10 & 0.13 & 0.12 \\
\hline & $\begin{array}{l}\text { Data Strategies \& } \\
\text { Governance }\end{array}$ & $18.0 \%$ & $0.2 \%$ & 0.05 & 0.04 & 0.10 & 0.04 \\
\hline & $\begin{array}{l}\text { Clarity of Objectives } \\
\text { and Use Cases }\end{array}$ & $22.2 \%$ & $0.2 \%$ & 0.17 & 0.21 & 0.10 & 0.22 \\
\hline & ROI & $23.8 \%$ & $0.2 \%$ & 0.14 & 0.05 & 0.07 & 0.19 \\
\hline & $\begin{array}{l}\text { Resources and } \\
\text { Funding }\end{array}$ & $16.2 \%$ & $0.2 \%$ & 0.13 & 0.10 & 0.04 & 0.04 \\
\hline & & & Score & 47.88 & 60.39 & 63.21 & 52.74 \\
\hline
\end{tabular}

\begin{tabular}{|l|c|c|c|c|}
\hline \multicolumn{5}{|c|}{ Scenario III Analysis } \\
\hline \multicolumn{1}{|c|}{ Project } & Proj1 & Proj2 & Proj3 & Proj4 \\
\hline \multicolumn{5}{|c|}{ Score Changes } \\
\hline Original & 52.89 & 58.86 & 57.57 & 57.81 \\
\hline Scenario & 47.88 & 60.39 & 63.21 & 52.74 \\
\hline Change & $\mathbf{- 5}$ & $\mathbf{1 . 5 3}$ & $\mathbf{5 . 6 5}$ & $\mathbf{- 5 . 0 7}$ \\
\hline & & Rank Changes & \\
\hline Original & 4 & 1 & 3 & 2 \\
\hline Scenario & 4 & 2 & 1 & 3 \\
\hline
\end{tabular}

Table 43 shows the results if Scenario IV materialized, with organization perspective factors being the most important for the project in reality. The results show that the Proj1, Proj2, and Proj3 projects ranking changed. Moreover, each project score changed differently. The Proj1 and the Proj4 scores changed favorably, while the Proj2 and Proj3 projects scores were affected negatively. Furthermore, among the projects, the 
Proj3 project changed the most as its score lost 13.13 points. Moreover, three of the projects had a score change of more than 10 points, making this scenario a volatile one, and more cautious and preparations must be considered if this scenario materialized.

Table 43. Scenario IV: Organization Emphasis

\begin{tabular}{|c|c|c|c|c|c|c|c|}
\hline \multicolumn{8}{|c|}{ Scenario 4: Organization Emphasis } \\
\hline Perspectives & Factors & $\begin{array}{c}\text { Local } \\
\text { Weight }\end{array}$ & $\begin{array}{l}\text { Global } \\
\text { Weight }\end{array}$ & Proj1 & Proj2 & Proj3 & Proj4 \\
\hline \multirow{4}{*}{$\begin{array}{l}\text { People } \\
(1.0 \%)\end{array}$} & Data Scientists & $29.0 \%$ & $0.3 \%$ & 0.15 & 0.26 & 0.16 & 0.17 \\
\hline & $\begin{array}{l}\text { Employees } \\
\text { Technological Skills }\end{array}$ & $17.7 \%$ & $0.2 \%$ & 0.07 & 0.07 & 0.07 & 0.07 \\
\hline & Public Acceptance & $27.2 \%$ & $0.3 \%$ & 0.10 & 0.15 & 0.18 & 0.27 \\
\hline & $\begin{array}{l}\text { Management } \\
\text { Analytical Skills }\end{array}$ & $26.2 \%$ & $0.3 \%$ & 0.18 & 0.24 & 0.21 & 0.10 \\
\hline \multirow[t]{5}{*}{$\begin{array}{l}\text { Technology } \\
(1 \%)\end{array}$} & $\begin{array}{l}\text { Data Integration \& } \\
\text { Processing } \\
\text { Complexities }\end{array}$ & $18.5 \%$ & $0.2 \%$ & 0.09 & 0.04 & 0.14 & 0.04 \\
\hline & Data Availability & $24.9 \%$ & $0.2 \%$ & 0.20 & 0.21 & 0.20 & 0.20 \\
\hline & What Data to Collect & $22.2 \%$ & $0.2 \%$ & 0.11 & 0.17 & 0.11 & 0.18 \\
\hline & $\begin{array}{l}\text { Infrastructure } \\
\text { Readiness }\end{array}$ & $21.5 \%$ & $0.2 \%$ & 0.09 & 0.05 & 0.06 & 0.11 \\
\hline & $\begin{array}{l}\text { Technology Solutions } \\
\text { Complexities }\end{array}$ & $12.7 \%$ & $0.1 \%$ & 0.03 & 0.03 & 0.10 & 0.03 \\
\hline \multirow[t]{4}{*}{ Legal (1\%) } & $\begin{array}{l}\text { External Sources of } \\
\text { Data }\end{array}$ & $17.3 \%$ & $0.2 \%$ & 0.14 & 0.16 & 0.16 & 0.08 \\
\hline & Data Ownership & $24.0 \%$ & $0.2 \%$ & 0.13 & 0.17 & 0.17 & 0.12 \\
\hline & $\begin{array}{l}\text { Data Security and } \\
\text { Privacy }\end{array}$ & $33.5 \%$ & $0.3 \%$ & 0.07 & 0.17 & 0.18 & 0.20 \\
\hline & $\begin{array}{l}\text { Policy and Regulatory } \\
\text { Issues }\end{array}$ & $25.3 \%$ & $0.3 \%$ & 0.14 & 0.11 & 0.13 & 0.13 \\
\hline \multirow{2}{*}{$\begin{array}{l}\text { Organization } \\
(97.0 \%)\end{array}$} & Management Support & $19.7 \%$ & $19.1 \%$ & 14.33 & 9.55 & 12.42 & 11.47 \\
\hline & $\begin{array}{l}\text { Data Strategies \& } \\
\text { Governance }\end{array}$ & $18.0 \%$ & $17.5 \%$ & 5.24 & 3.49 & 9.60 & 3.49 \\
\hline
\end{tabular}




\begin{tabular}{|c|c|c|c|c|c|c|c|}
\hline \multicolumn{8}{|c|}{ Scenario 4: Organization Emphasis } \\
\hline Perspectives & Factors & $\begin{array}{l}\text { Local } \\
\text { Weight }\end{array}$ & $\begin{array}{l}\text { Global } \\
\text { Weight }\end{array}$ & Proj1 & Proj2 & Proj3 & Proj4 \\
\hline & $\begin{array}{l}\text { Clarity of Objectives } \\
\text { and Use Cases }\end{array}$ & $22.2 \%$ & $21.5 \%$ & 16.15 & 20.46 & 9.69 & 21.53 \\
\hline & ROI & $23.8 \%$ & $23.1 \%$ & 13.85 & 4.62 & 6.93 & 18.47 \\
\hline & $\begin{array}{l}\text { Resources and } \\
\text { Funding }\end{array}$ & $16.2 \%$ & $15.7 \%$ & 12.57 & 9.43 & 3.93 & 3.93 \\
\hline & & & Score & 63.63 & 49.37 & 44.43 & 60.59 \\
\hline \multicolumn{7}{|c|}{ Scenario IV Analysis } & \\
\hline Project & Proj1 & \multicolumn{2}{|l|}{ Proj2 } & Proj3 & \multicolumn{2}{|c|}{ Proj4 } & \\
\hline \multicolumn{7}{|c|}{ Score Changes } & \\
\hline Original & 52.89 & \multicolumn{2}{|l|}{58.86} & 57.57 & \multicolumn{2}{|c|}{57.81} & \\
\hline Scenario & 63.63 & \multicolumn{2}{|l|}{49.37} & 44.43 & \multicolumn{2}{|c|}{60.59} & \\
\hline Change & 10.75 & \multicolumn{2}{|l|}{-9.49} & -13.13 & \multicolumn{2}{|c|}{2.78} & \\
\hline \multicolumn{7}{|c|}{ Rank Changes } & \\
\hline Original & 4 & 1 & & 3 & & & \\
\hline Scenario & 1 & 3 & & 4 & & & \\
\hline
\end{tabular}




\subsection{What Can be Done to Improve Readiness Score (and increase the potential for successful big data project)?}

This research goal is to help cities assess their readiness for an upcoming smartcity-related big data project, and identify weaknesses that might hinder the upcoming project. Then make improvements and corrective measurements based on the identified weaknesses.

In this section, a discussion is made about what can be done for each of the four projects evaluated in Section 7.1 to enhance the readiness score index for each of them. The goal of this section is to demonstrate how this research model can add value, as the goal of the research is not only to identify weaknesses but also to offer guidelines on how to improve it as well.

The target of the improvements would be factors, where the score is low, regardless of the factor weight, or the score is medium, but the factor has high weight (i.e., high impact on the overall index).

Tables 44 to 47 shows actions suggested for each project, and how those actions will result in a higher score. The way the model is intended to work is by identifying the corrective actions, execute them, and then re-assess the status of the city against the project. Based on the new assessment, new corrective actions should be introduced. This cycle should keep going until the city has enough confidence that they have enough understanding of the upcoming-project dynamics and the chances of a successful implementation are high (see Figure 30). Furthermore, value curves play a crucial role in this process. The project manager will consult value curves to identify what is the next 
level for each factor and what is the optimal level for that factor as well. Then, use those

levels as goals to target as part of the improvement process (see Figure 31).

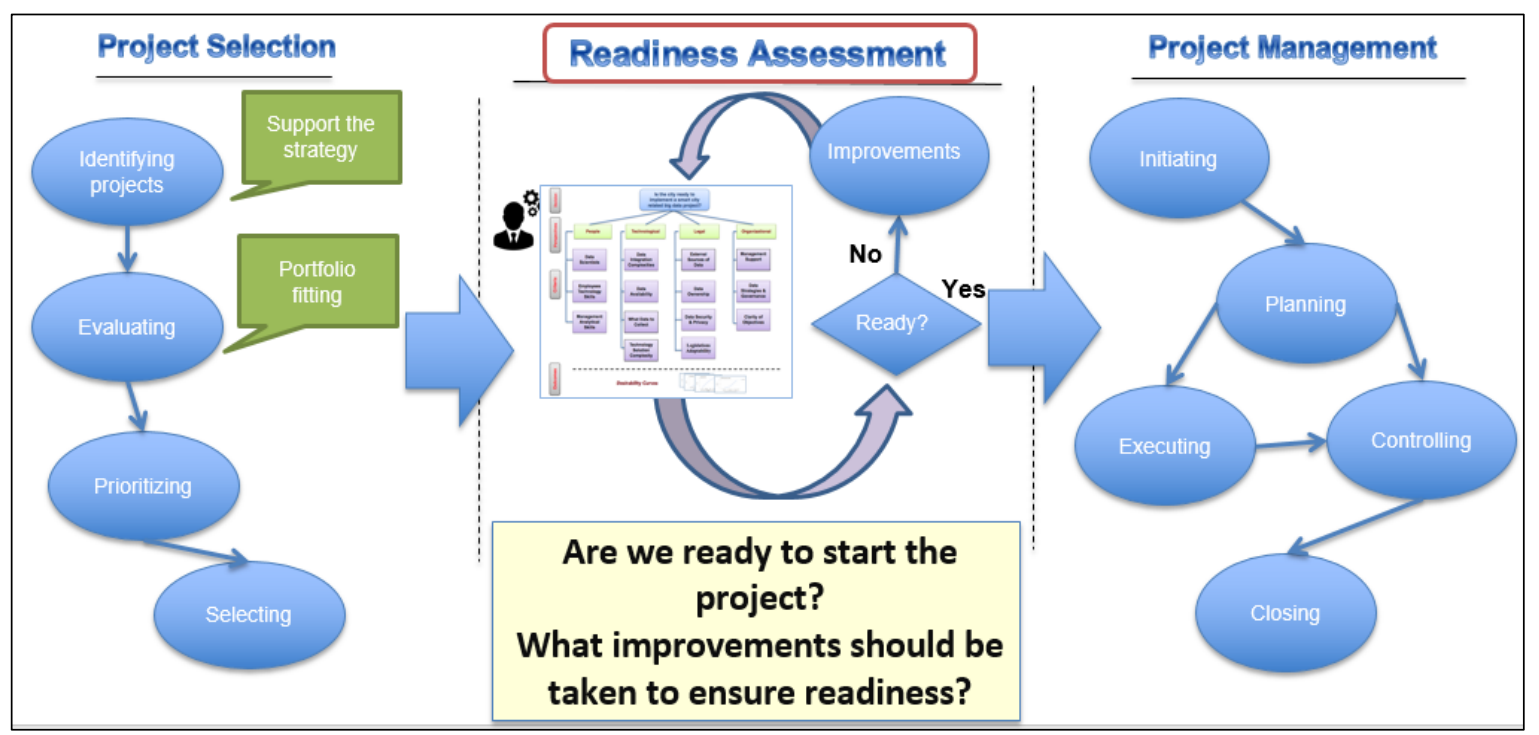

Figure 30. Continuous Readiness Assessment Approach

\section{Continuous Improvements}

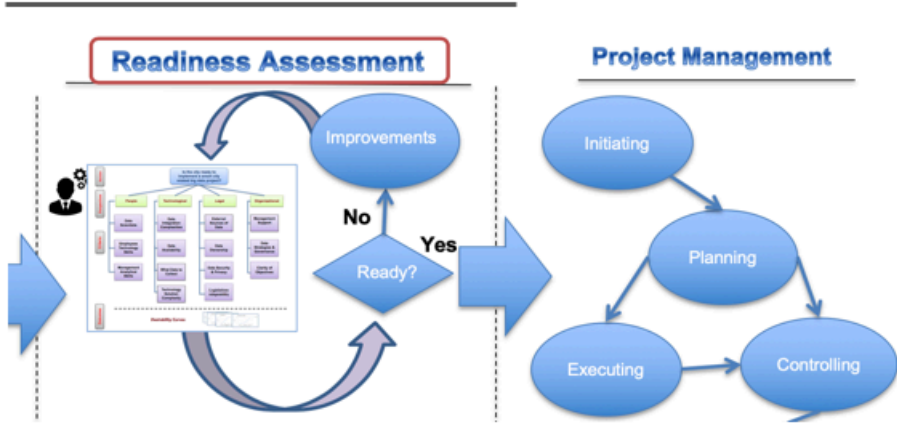

Project manager to use value curves to identify what is the next level and how to reach it.
Data Scientists: What analytical skills the city has?

\begin{tabular}{|l|l|}
\hline Description & Score \\
\hline
\end{tabular}

No analytics skills $\quad 0$

Software engineers with statistical skills $\quad 35$

Business analysts with statistics skills and some IT $\quad 50$

background

Data scientists who are not strongly related to the 65

project goals

Data scientists who are strongly related to the $\quad 100$

project goals

Management Support:

Description

Indifferent

Low Support

Good Support

Enthusiastic

Passionate

$=\begin{gathered}\text { And so on for } \\ \text { each factor }\end{gathered}$

Figure 31. Continuous Improvements Using VCs 
Table 44. Proj1 suggested enhancements

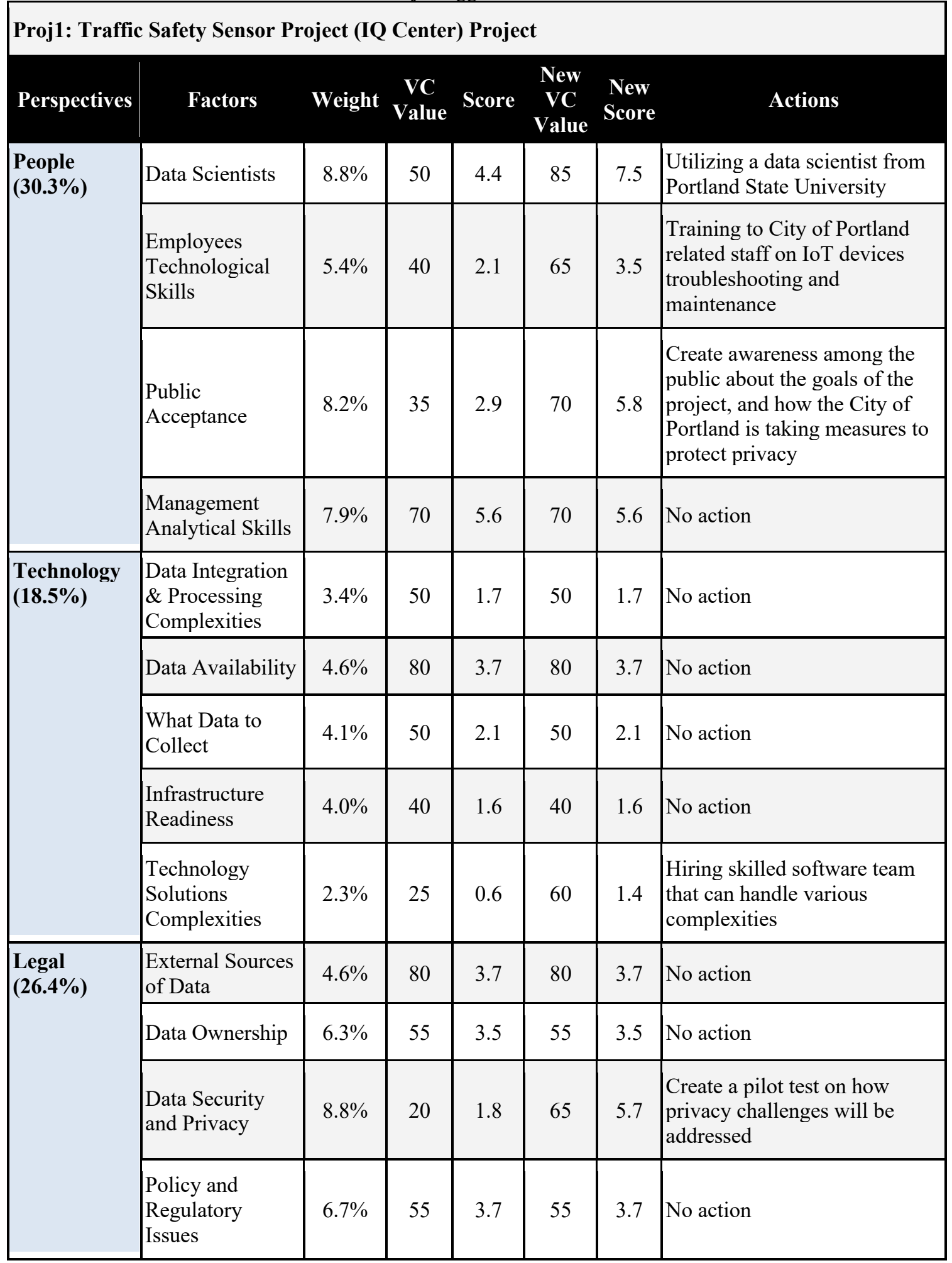




\begin{tabular}{|c|c|c|c|c|c|c|c|}
\hline \multicolumn{8}{|c|}{ Proj1: Traffic Safety Sensor Project (IQ Center) Project } \\
\hline Perspectives & Factors & Weight & $\begin{array}{c}\text { VC } \\
\text { Value }\end{array}$ & Score & $\begin{array}{l}\text { New } \\
\text { VC } \\
\text { Value }\end{array}$ & $\begin{array}{l}\text { New } \\
\text { Score }\end{array}$ & Actions \\
\hline \multirow[t]{6}{*}{$\begin{array}{l}\text { Organization } \\
(24.5 \%)\end{array}$} & $\begin{array}{l}\text { Management } \\
\text { Support }\end{array}$ & $4.8 \%$ & 75 & 3.6 & 75 & 3.6 & No action \\
\hline & $\begin{array}{l}\text { Data Strategies } \\
\text { and Governance }\end{array}$ & $4.4 \%$ & 30 & 1.3 & 70 & 3.1 & $\begin{array}{l}\text { Finalizing and implementing } \\
\text { the City of Portland data } \\
\text { strategy and governance } \\
\text { policies }\end{array}$ \\
\hline & $\begin{array}{l}\text { Clarity of } \\
\text { Objectives and } \\
\text { Use Cases }\end{array}$ & $5.4 \%$ & 75 & 4.1 & 75 & 4.1 & No action \\
\hline & ROI & $5.8 \%$ & 60 & 3.5 & 60 & 3.5 & No Action \\
\hline & $\begin{array}{l}\text { Resources and } \\
\text { long-term } \\
\text { Funding }\end{array}$ & $4.0 \%$ & 80 & 3.2 & 80 & 3.2 & No Action \\
\hline & Total & & & 52.9 & & 66.8 & \\
\hline
\end{tabular}

Table 45. Proj2 suggested enhancements

\section{Proj2: Air Quality Sensor Testing \& Deployment}

\begin{tabular}{|c|c|c|c|c|c|c|c|}
\hline Perspectives & Factors & Weight & $\begin{array}{c}\text { VC } \\
\text { Value }\end{array}$ & Score & $\begin{array}{c}\text { New VC } \\
\text { Value }\end{array}$ & $\begin{array}{l}\text { New } \\
\text { Score }\end{array}$ & Actions \\
\hline \multirow{4}{*}{$\begin{array}{l}\text { People } \\
(30.3 \%)\end{array}$} & Data Scientists & $8.8 \%$ & 90 & 7.9 & 90 & 7.9 & No action \\
\hline & $\begin{array}{l}\text { Employees } \\
\text { Technological } \\
\text { Skills }\end{array}$ & $5.4 \%$ & 40 & 2.1 & 65 & 3.5 & $\begin{array}{l}\text { Training to City of Portland } \\
\text { related staff on sensor devices } \\
\text { troubleshooting and } \\
\text { maintenance }\end{array}$ \\
\hline & $\begin{array}{l}\text { Public } \\
\text { Acceptance }\end{array}$ & $8.2 \%$ & 55 & 4.5 & 70 & 5.8 & $\begin{array}{l}\text { Create awareness among the } \\
\text { public about the goals of the } \\
\text { project, and listen to the } \\
\text { public concerns }\end{array}$ \\
\hline & $\begin{array}{l}\text { Management } \\
\text { Analytical } \\
\text { Skills }\end{array}$ & $7.9 \%$ & 90 & 7.1 & 90 & 7.1 & No action \\
\hline $\begin{array}{l}\text { Technology } \\
(18.5 \%)\end{array}$ & $\begin{array}{l}\text { Data Integration } \\
\& \text { Processing } \\
\text { Complexities }\end{array}$ & $3.4 \%$ & 20 & 0.7 & 50 & 1.7 & $\begin{array}{l}\text { Identifying and clearly } \\
\text { defining the needed data for } \\
\text { the project. Then working }\end{array}$ \\
\hline
\end{tabular}




\begin{tabular}{|c|c|c|c|c|c|c|c|}
\hline \multicolumn{8}{|c|}{ Proj2: Air Quality Sensor Testing \& Deployment } \\
\hline Perspectives & Factors & Weight & $\begin{array}{l}\text { VC } \\
\text { Value }\end{array}$ & Score & $\begin{array}{l}\text { New VC } \\
\text { Value }\end{array}$ & $\begin{array}{l}\text { New } \\
\text { Score }\end{array}$ & Actions \\
\hline & & & & & & & $\begin{array}{l}\text { with each IoT vendors on how } \\
\text { to transform the data supplied } \\
\text { by their telematic devices into } \\
\text { needed formats, before } \\
\text { starting the project. }\end{array}$ \\
\hline & $\begin{array}{l}\text { Data } \\
\text { Availability }\end{array}$ & $4.6 \%$ & 85 & 3.9 & 85 & 3.9 & No action \\
\hline & $\begin{array}{l}\text { What Data to } \\
\text { Collect }\end{array}$ & $4.1 \%$ & 75 & 3.1 & 75 & 3.1 & No action \\
\hline & $\begin{array}{l}\text { Infrastructure } \\
\text { Readiness }\end{array}$ & $4.0 \%$ & 25 & 1.0 & 25 & 1.0 & No action \\
\hline & $\begin{array}{l}\text { Technology } \\
\text { Solutions } \\
\text { Complexities }\end{array}$ & $2.3 \%$ & 20 & 0.5 & 60 & 1.4 & $\begin{array}{l}\text { Hiring skilled software team } \\
\text { that can handle various } \\
\text { complexities }\end{array}$ \\
\hline \multirow[t]{4}{*}{ Legal (26.4\%) } & \begin{tabular}{|l} 
External \\
Sources of Data
\end{tabular} & $4.6 \%$ & 90 & 4.1 & 90 & 4.1 & No action \\
\hline & Data Ownership & $6.3 \%$ & 70 & 4.4 & 70 & 4.4 & No action \\
\hline & $\begin{array}{l}\text { Data Security } \\
\text { and Privacy }\end{array}$ & $8.8 \%$ & 50 & 4.4 & 65 & 5.7 & $\begin{array}{l}\text { Create a pilot test on how } \\
\text { privacy challenges will be } \\
\text { addressed }\end{array}$ \\
\hline & $\begin{array}{l}\text { Policy and } \\
\text { Regulatory } \\
\text { Issues }\end{array}$ & $6.7 \%$ & 45 & 3.0 & 65 & 4.3 & $\begin{array}{l}\text { Studying related policies and } \\
\text { prepare proper plans } \\
\text { accordingly }\end{array}$ \\
\hline \multirow[t]{3}{*}{$\begin{array}{l}\text { Organization } \\
(\mathbf{2 4 . 5 \% )}\end{array}$} & $\begin{array}{l}\text { Management } \\
\text { Support }\end{array}$ & $4.8 \%$ & 50 & 2.4 & 70 & 3.4 & $\begin{array}{l}\text { Create awareness among the } \\
\text { City of Portland top } \\
\text { management about the long } \\
\text { term benefits of the project } \\
\text { results }\end{array}$ \\
\hline & $\begin{array}{l}\text { Data Strategies } \\
\text { and Governance }\end{array}$ & $4.4 \%$ & 20 & 0.9 & 70 & 3.1 & $\begin{array}{l}\text { Finalizing and implementing } \\
\text { the City of Portland data } \\
\text { strategy and governance } \\
\text { policies }\end{array}$ \\
\hline & $\begin{array}{l}\text { Clarity of } \\
\text { Objectives and } \\
\text { Use Cases }\end{array}$ & $5.4 \%$ & 95 & 5.2 & 95 & 5.2 & No action \\
\hline
\end{tabular}




\begin{tabular}{|c|c|c|c|c|c|c|c|}
\hline \multicolumn{8}{|c|}{ Proj2: Air Quality Sensor Testing \& Deployment } \\
\hline \multirow[t]{3}{*}{ Perspectives } & Factors & Weight & $\begin{array}{c}\text { VC } \\
\text { Value }\end{array}$ & Score & $\begin{array}{c}\text { New VC } \\
\text { Value }\end{array}$ & $\begin{array}{l}\text { New } \\
\text { Score }\end{array}$ & Actions \\
\hline & ROI & $5.8 \%$ & 20 & 1.2 & 50 & 2.9 & $\begin{array}{l}\text { Adding environment-related } \\
\text { goals to the project to make } \\
\text { its deliverables more tangible }\end{array}$ \\
\hline & $\begin{array}{l}\text { Resources and } \\
\text { long-term } \\
\text { Funding }\end{array}$ & $4.0 \%$ & 60 & 2.4 & 60 & 2.4 & No action \\
\hline & Total & & & 58.9 & & 71.0 & \\
\hline
\end{tabular}

Table 46. Proj3 suggested enhancements

\begin{tabular}{|c|c|c|c|c|c|c|c|}
\hline \multicolumn{8}{|c|}{ Proj3: Connected Streetcar Project } \\
\hline Perspectives & Factors & Weight & $\begin{array}{c}\text { VC } \\
\text { Value }\end{array}$ & Score & $\begin{array}{l}\text { New VC } \\
\text { Value }\end{array}$ & $\begin{array}{l}\text { New } \\
\text { Score }\end{array}$ & Actions \\
\hline \multirow[t]{4}{*}{$\begin{array}{l}\text { People } \\
(\mathbf{3 0 . 3 \% )}\end{array}$} & Data Scientists & $8.8 \%$ & 55 & 4.8 & 85 & 7.5 & $\begin{array}{l}\text { Utilizing a data scientist from } \\
\text { Portland State University }\end{array}$ \\
\hline & $\begin{array}{l}\text { Employees } \\
\text { Technological } \\
\text { Skills }\end{array}$ & $5.4 \%$ & 40 & 2.1 & 65 & 3.5 & $\begin{array}{l}\text { Training to City of Portland } \\
\text { related staff on sensor devices } \\
\text { troubleshooting and } \\
\text { maintenance }\end{array}$ \\
\hline & $\begin{array}{l}\text { Public } \\
\text { Acceptance }\end{array}$ & $8.2 \%$ & 65 & 5.4 & 65 & 5.4 & No action \\
\hline & $\begin{array}{l}\text { Management } \\
\text { Analytical } \\
\text { Skills }\end{array}$ & $7.9 \%$ & 80 & 6.4 & 80 & 6.4 & No action \\
\hline \multirow[t]{4}{*}{$\begin{array}{l}\text { Technology } \\
(\mathbf{1 8 . 5 \% )}\end{array}$} & $\begin{array}{l}\text { Data } \\
\text { Integration \& } \\
\text { Processing } \\
\text { Complexities } \\
\end{array}$ & $3.4 \%$ & 75 & 2.6 & 75 & 2.6 & No action \\
\hline & $\begin{array}{l}\text { Data } \\
\text { Availability }\end{array}$ & $4.6 \%$ & 80 & 3.7 & 80 & 3.7 & No action \\
\hline & $\begin{array}{l}\text { What Data to } \\
\text { Collect }\end{array}$ & $4.1 \%$ & 50 & 2.1 & 50 & 2.1 & No action \\
\hline & $\begin{array}{l}\text { Infrastructure } \\
\text { Readiness }\end{array}$ & $4.0 \%$ & 30 & 1.2 & 60 & 2.4 & $\begin{array}{l}\text { Installing IoT devices prior to } \\
\text { the project to test their } \\
\text { effectiveness and to get }\end{array}$ \\
\hline
\end{tabular}




\begin{tabular}{|c|c|c|c|c|c|c|c|}
\hline & & & & & & & $\begin{array}{l}\text { experience on how to } \\
\text { implement them }\end{array}$ \\
\hline & $\begin{array}{l}\text { Technology } \\
\text { Solutions } \\
\text { Complexities }\end{array}$ & $2.3 \%$ & 80 & 1.9 & 80 & 1.9 & No action \\
\hline \multirow[t]{4}{*}{ Legal (26.4\%) } & $\begin{array}{l}\text { External } \\
\text { Sources of } \\
\text { Data }\end{array}$ & $4.6 \%$ & 90 & 4.1 & 90 & 4.1 & No action \\
\hline & $\begin{array}{l}\text { Data } \\
\text { Ownership }\end{array}$ & $6.3 \%$ & 70 & 4.4 & 70 & 4.4 & No action \\
\hline & $\begin{array}{l}\text { Data Security } \\
\text { and Privacy }\end{array}$ & $8.8 \%$ & 55 & 4.9 & 65 & 5.7 & $\begin{array}{l}\text { Create a pilot test on how } \\
\text { privacy challenges will be } \\
\text { addressed }\end{array}$ \\
\hline & $\begin{array}{l}\text { Policy and } \\
\text { Regulatory } \\
\text { Issues }\end{array}$ & $6.7 \%$ & 50 & 3.3 & 50 & 3.3 & No action \\
\hline \multirow[t]{6}{*}{$\begin{array}{l}\text { Organization } \\
(24.5 \%)\end{array}$} & $\begin{array}{l}\text { Management } \\
\text { Support }\end{array}$ & $4.8 \%$ & 65 & 3.1 & 65 & 3.1 & No action \\
\hline & $\begin{array}{l}\text { Data Strategies } \\
\text { and } \\
\text { Governance }\end{array}$ & $4.4 \%$ & 55 & 2.4 & 55 & 2.4 & No action \\
\hline & $\begin{array}{l}\text { Clarity of } \\
\text { Objectives and } \\
\text { Use Cases }\end{array}$ & $5.4 \%$ & 45 & 2.4 & 45 & 2.4 & No action \\
\hline & ROI & $5.8 \%$ & 30 & 1.7 & 60 & 3.5 & $\begin{array}{l}\text { Expand immediate benefits. } \\
\text { e.g., working with } \\
\text { autonomous car makers to } \\
\text { share data with them }\end{array}$ \\
\hline & $\begin{array}{l}\text { Resources and } \\
\text { long-term } \\
\text { Funding }\end{array}$ & $4.0 \%$ & 25 & 1.0 & 60 & 2.4 & $\begin{array}{l}\text { Working with NITC, } \\
\text { automakers, and with the City } \\
\text { of Portland to get funding for } \\
\text { future expansions of the } \\
\text { project }\end{array}$ \\
\hline & Total & & & 57.6 & & 66.8 & \\
\hline
\end{tabular}


Table 47. Proj4 suggested enhancements

Proj4: Engine Idling (P2) Project

\begin{tabular}{|c|c|c|c|c|c|c|c|}
\hline Perspectives & Factors & Weight & $\begin{array}{c}\text { VC } \\
\text { Value }\end{array}$ & $\begin{array}{l}\text { Old } \\
\text { Score }\end{array}$ & $\begin{array}{c}\text { New VC } \\
\text { Value }\end{array}$ & $\begin{array}{l}\text { New } \\
\text { Score }\end{array}$ & Actions \\
\hline \multirow[t]{4}{*}{$\begin{array}{l}\text { People } \\
(30.3 \%)\end{array}$} & $\begin{array}{l}\text { Data } \\
\text { Scientists }\end{array}$ & $8.8 \%$ & 60 & 5.3 & 85 & 7.5 & $\begin{array}{l}\text { Utilizing a data scientist } \\
\text { from Portland State } \\
\text { University }\end{array}$ \\
\hline & $\begin{array}{l}\text { Employees } \\
\text { Technological } \\
\text { Skills }\end{array}$ & $5.4 \%$ & 40 & 2.1 & 65 & 3.5 & $\begin{array}{l}\text { Training to drivers on IoT } \\
\text { telematics devices } \\
\text { troubleshooting and } \\
\text { maintenance }\end{array}$ \\
\hline & $\begin{array}{l}\text { Public } \\
\text { Acceptance }\end{array}$ & $8.2 \%$ & 100 & 8.2 & 100 & 8.2 & No action \\
\hline & $\begin{array}{l}\text { Management } \\
\text { Analytical } \\
\text { Skills }\end{array}$ & $7.9 \%$ & 40 & 3.2 & 60 & 4.8 & $\begin{array}{l}\text { Commercial fleets } \\
\text { management to get training } \\
\text { on using analytics as part of } \\
\text { decision making }\end{array}$ \\
\hline \multirow[t]{5}{*}{$\begin{array}{l}\text { Technology } \\
\text { (18.5\%) }\end{array}$} & $\begin{array}{l}\text { Data } \\
\text { Integration \& } \\
\text { Processing } \\
\text { Complexities }\end{array}$ & $3.4 \%$ & 20 & 0.7 & 50 & 1.7 & $\begin{array}{l}\text { Identifying and clearly } \\
\text { defining the needed data for } \\
\text { the project. Then working } \\
\text { with each IoT vendors on } \\
\text { how to transform the data } \\
\text { supplied by their telematics } \\
\text { devices into needed formats, } \\
\text { before starting the project. }\end{array}$ \\
\hline & $\begin{array}{l}\text { Data } \\
\text { Availability }\end{array}$ & $4.6 \%$ & 80 & 3.7 & 80 & 3.7 & No action \\
\hline & $\begin{array}{l}\text { What Data to } \\
\text { Collect }\end{array}$ & $4.1 \%$ & 80 & 3.3 & 80 & 3.3 & No action \\
\hline & $\begin{array}{l}\text { Infrastructure } \\
\text { Readiness }\end{array}$ & $4.0 \%$ & 50 & 2.0 & 50 & 2.0 & No action \\
\hline & $\begin{array}{l}\text { Technology } \\
\text { Solutions } \\
\text { Complexities }\end{array}$ & $2.3 \%$ & 25 & 0.6 & 60 & 1.4 & $\begin{array}{l}\text { Hiring skilled software team } \\
\text { that can handle various } \\
\text { complexities }\end{array}$ \\
\hline Legal (26.4\%) & $\begin{array}{l}\text { External } \\
\text { Sources of } \\
\text { Data }\end{array}$ & $4.6 \%$ & 45 & 2.1 & 65 & 3.0 & $\begin{array}{l}\text { Explaining to fleets about } \\
\text { future tax credits that they } \\
\text { might be eligible to, based } \\
\text { on complying with the } \\
\text { project goals, as well as, } \\
\text { offering free consulting on } \\
\text { how to switch to } \\
\text { electrification }\end{array}$ \\
\hline
\end{tabular}




\begin{tabular}{|c|c|c|c|c|c|c|c|}
\hline & $\begin{array}{l}\text { Data } \\
\text { Ownership }\end{array}$ & $6.3 \%$ & 50 & 3.2 & 50 & 3.2 & No action \\
\hline & $\begin{array}{l}\text { Data Security } \\
\text { and Privacy }\end{array}$ & $8.8 \%$ & 60 & 5.3 & 70 & 6.2 & $\begin{array}{l}\text { Analyzing data to identify } \\
\text { security and privacy } \\
\text { challenges and how to } \\
\text { counter them }\end{array}$ \\
\hline & $\begin{array}{l}\text { Policy and } \\
\text { Regulatory } \\
\text { Issues }\end{array}$ & $6.7 \%$ & 50 & 3.3 & 50 & 3.3 & No Action \\
\hline \multirow[t]{6}{*}{$\begin{array}{l}\text { Organization } \\
(\mathbf{2 4 . 5 \% )}\end{array}$} & $\begin{array}{l}\text { Management } \\
\text { Support }\end{array}$ & $4.8 \%$ & 60 & 2.9 & 80 & 3.9 & $\begin{array}{l}\text { Creating awareness among } \\
\text { fleet management and } \\
\text { highlighting the financial } \\
\text { benefits of electrification to } \\
\text { get more support }\end{array}$ \\
\hline & $\begin{array}{l}\text { Data } \\
\text { Strategies and } \\
\text { Governance }\end{array}$ & $4.4 \%$ & 20 & 0.9 & 60 & 2.6 & $\begin{array}{l}\text { Establishing data strategies } \\
\text { and guidelines for this } \\
\text { project }\end{array}$ \\
\hline & $\begin{array}{l}\text { Clarity of } \\
\text { Objectives } \\
\text { and Use Cases }\end{array}$ & $5.4 \%$ & 100 & 5.4 & 100 & 5.4 & No action \\
\hline & ROI & $5.8 \%$ & 80 & 4.7 & 80 & 4.7 & No action \\
\hline & $\begin{array}{l}\text { Resources and } \\
\text { long-term } \\
\text { Funding }\end{array}$ & $4.0 \%$ & 25 & 1.0 & 60 & 2.4 & $\begin{array}{l}\text { Working with EPA, fleets, } \\
\text { and with the City of Portland } \\
\text { to get funding for future } \\
\text { expansions of the project }\end{array}$ \\
\hline & Total & & & 57.8 & & 70.7 & \\
\hline
\end{tabular}




\section{CHAPTER 8: RESEARCH VALIDITY}

Kelly stated that a test is valid if it measures what it claims to measure (Kelly 1927, p.14). Research validity should be tested to make sure that the research findings are sound and reliable. Moreover, there are two types of validations, external and internal. External validity is mainly about the generalizability of the findings, while internal validity is about determining if the research was done in a scientific manner and the results can be trusted (Schmidt 2012; Nevo 1985).

While conducting this research, and based on previous HDM-based research approach to measuring research validity (Estep 2017; Gibson 2016; Abotah 2014; Iskin 2014; Phan 2013), four types of research validity were used to make sure that the academic rigor was maintained,. Hence, it can be judged with confidence that the research outcome (the readiness assessment model) addressed the research gaps, objective, and questions in a proper scientific way. The four validity tests used are: construct validity, content validity, criterion validity, and generalizability validity. Following is a discussion of those validations.

\subsection{Construct Validity}

This validation focuses on whether the research design is suitable to achieve the required outcome (Schmidt 2012; Sireci 1998; Nevo 1985).

The initial model was constructed as a hierarchical decision tree, using the HDM methodology. Furthermore, the model was built based on an extensive literature review of previous research work that used the HDM methodology, and Chapter 3 includes details about the methodology based on this literature review. 
Furthermore, Section 3.4.7, included justification for using the HDM

methodology. In this section, a list of requirements for what a methodology should have to be able to address the research questions were offered, and then a discussion of how the HDM methodology is able to address those points was provided.

In addition, faculty and Ph.D. students familiar with the HDM methodology, from the Engineering and Technology Department at Portland State University, were asked to validate the clarity and proper use of the methodology, which they confirmed.

\subsection{Content Validity}

This validation focuses on whether the components of the model are relevant and can be used to measure/ answer the research questions (Healy and Perry 2000; Sireci 1998; Fitzpatrick 1983).

Content validation was done in four phases. First, validation of the suitability of the perspectives and the factors under each perspective were conducted by subject-matter experts. As explained in Section 5.2, two rounds of perspectives and factors suitability validation were carried out. In the first round, expert panels P1 to P5 were asked using Qualtrics survey tool, to judge the suitability of the perspectives and the criteria under each perspective, and to identify those that might have gone undetected during the literature review. Each panel was asked to validate a part of the model that is related to their expertise. This validation resulted in approving all the perspectives and the factors, except for one factor that was removed, the addition of new four factors, and the expanding of two factors' scope. In the second round, panel P6 validated and confirmed the changes. 
Then, subject-matter experts were asked to rank the factors and identify the relative factors' weight. As explained in Section 5.4, panels P7 to P11 quantified the model. Each panel was asked to quantify a part of the model that is related to their expertise.

After that, inconsistency and disagreement analysis were applied to validate the experts' quantification itself to make sure that their judgment is reliable and trustworthy, and the analysis showed that the level of inconsistency for each expert and the level of disagreement among experts in each panel is within the acceptable ranges (see Section $5.4)$.

Finally, the model reliability was tested using extreme scenario analysis as explained in Section 7.2.

\subsection{Criterion Validity}

This validation focuses on whether the research model is adding value. In other words, can the research model correctly predicts the outcome (Schmidt 2012; Dulewicz et al. 2003).

To conduct this validation and as explained in Chapter 6, the City of Portland was selected as a case study. Moreover, four smart-city-related big data projects that are currently being carried out/ already done in the City of Portland were chosen to be assessed for readiness by the research model to show how the model can be used and what value it can offer.

The results of conducting the case study, which can be found in Chapter 7, were shared with city officials, who found it to be very helpful and realistic. In addition, the 
CEO of a company that provides smart city-related consulting found this model to be very helpful for his company's business.

\subsection{Generalizability}

This external validation focuses on whether the research model can be used beyond the initial data, test, or use case, and is the model practical. For example, in this research case, can cities use the proposed model to assess their readiness to conduct a smart-city-related big data project or not (Steckler and McLeroy 2008; Calder et al. 1982).

Generalizability was addressed by first, asking subject-matter experts to validate the model components (see Chapter 5), and by adding value curves that allow the model to be used without the need to call the subject-matter experts again for each project.

Furthermore, officials from the City of Portland (smart city management) were asked about whether the model can be used for any smart-city-related big data projects, and they confirmed that. 


\section{CHAPTER 9: DISCUSSION}

In this section, a discussion is offered about the key findings from the results of the model validation and quantification, as well as, about the case study.

\subsection{Practical Application: General}

The problem statement section in Chapter 1 discussed the phenomenon of high percentage failure of big data projects. Readiness assessment before starting a project is one effective approach to reduce the possibility of failure. However, the gap analysis in Chapter 3 revealed that there is not enough research on how to assess readiness for a big data project. Moreover, the literature review showed that this is even more evident in smart-city-related big data projects.

Discussion with experts from each of the panels that validated the model confirmed these findings. Experts from different backgrounds related to big data and smart cities, including project managers, software engineers, data scientists, academic researchers, business analysts, business leaders, and public sectors leaders, all affirmed the value and the need for readiness assessment prior to starting a smart-city-related big data project or any project for that matter.

The experts validated 18 factors as being among the most critical issues that might affect a smart-city-related big data project, and a city, that is about to implement a big data project, should assess its current status against each of those factors as part of preparing for the upcoming project.

Experts' quantification of the model yielded notable results. First, the technology perspective received the lowest relative weight $(18.5 \%)$, as experts indicated that while 
this is a technology project, technological factors are not the main reasons of failure of this kind of projects. In practice, people perspective came first (relative weight of 30.3\%), then legal perspective (relative weight of 26.4\%), and organization perspective came third (relative weight of 24.5\%). All of those perspectives and the factors under each of them are higher in importance than technology perspective and its factors. This outcome indicates that big data projects are complicated and include engagement from several stakeholders within and outside the organization. In this context, this research model helps cities make sure they are assessing their readiness for a big data project in a way that is comprehensive and structured, and not limited to technology factors only. Therefore, help assess their status against each of those factors and what can be done to enhance the chances of a successful project before starting the project.

Second, people perspective has the highest weight as judged by the experts. This perspective has a focus on the skills needed from various actors related to big data projects, as well as, the public perception of big data projects. The demand for skilled people in the modern age is continuously increasing, and any city that is considering the transition into smart-city era, must consider related skills in its hiring process and its employees training programs. On the other hand, the public perception of a project is a crucial issue and cities must consider project marketing and community engagement as an integral part of doing this kind of projects.

Furthermore, the legal perspective has the second highest weight as judged by the experts, which show how the issues related to privacy and security, who own the data, 
and related regulations are among the important concerns and risks facing big data projects.

Finally, all the factors under the legal perspective, and the "public perception" factor under the people factor are external factors. They are beyond the direct control of a city, so a city planning to implement a smart-city-related big data project should consider "soft power" and how to positively influence external actors as an essential part of conducting a smart-city initiative.

\subsection{Practical Application: People Perspective}

Under the people perspective, the "data scientists" factor is identified by the experts as the most important factor (relative weight of $29.0 \%$ ). In fact, it is the most important factor across the whole model (relative weight of $8.8 \%$ ), along with the "data security and privacy" factor. Data scientists are the brain behind big data analytics, and they direct how to collect and process the data, how to analyze it, and how to make sense of the analytics. A city that is about to implement a big data project should make sure they have the required data science skill within the project team.

The second most important factor under people perspective, as identified by the experts, is the "Public Perception" factor (relative weight of $27.2 \%$ ), and the third most important across the whole model (relative weight of $8.2 \%$ ). This factor importance is related to the growing concerns about privacy. Many smart-city-related projects (see examples in Sections 2.2.3 and 6.2) are based on using IoT sensors that include face and voice recognition abilities. If the public perceived a project as an invasion of their privacy, the project most likely will be disputed and could face legal challenges. It is the 
duty of the city to create awareness about the up-coming project, its goals, and what privacy protection measurements are considered for the project. Marketing and community engagement are identified by the experts as powerful tools to create awareness and gain public acceptance.

\subsection{Practical Application: Technology Perspective}

Under the people perspective, the "data availability" factor is identified by the experts as the most important factor (relative weight of $24.9 \%$ ). This result is logical, as the primary goal of big data systems is to provide analytics and insights that allows decision makers to make the right decision at the right time (see Section 2.1). In order to do so, the data should be available at the right time, which is a two-fold challenge, getting the data from the sources in a timely manner, and process it in a timely manner as well.

Another interesting finding from the results of quantifying the technology perspective is that both "data integration complexities" and "technology solutions complexities" got the lowest relative weights of $18.5 \%$ and $12.7 \%$ respectively. Although, literature review indicated that they are important factors (see Section 2.6). Discussions with experts revealed a general view that big data technologies and data management processes are getting more mature and hence reducing challenges posed by both those factors.

\subsection{Practical Application: Legal Perspective}

Under the legal perspective, the "data security and privacy" factor is identified by the experts as the most important factor (relative weight of $33.5 \%$ ). In fact, it is the most important factor across the whole model (relative weight of $8.8 \%$ ), along with the "data 
scientists" factor. Discussion with several experts revealed that generating meaningful analytics that has value while maintaining the privacy of data subjects is one of the most crucial challenges facing big data projects. In fact, in some cases, were the only way to generate value from big data analytics is by breaching the privacy of data subjects, then the project should not be done at all. Data scientists have an important role here, to identify ways to create insights while protecting privacy. Furthermore, security is as important as maintaining privacy, even if the big data analytics are not breaching privacy, failing to protect data from unauthorized access will have the same results.

Moreover, the experts identified the "policy and regulatory issues" factor as the second most important under the legal perspective (relative weight of 25.3\%). As GDPR (EU GDPR 2019), the Freedom of Information Act (FOIA 2019), and other similar regulations have a significant effect on how to acquire, process, and store data.

Furthermore, a main challenge related to legal factors, as discussed by the experts, is that a city needs to own the data to make sure proper measures are taken to protect the privacy and security of the data. However, under freedom of information acts (federal and local), if the city owned the data, they are obliged to make it accessible to entities and individuals who want to access it, thus; breaching the privacy of the data subjects.

\subsection{Practical Application: Organization Perspective}

Under the organization perspective, the "return on investment (ROI)" and the "clarity of objectives and use cases" factors are identified by the experts as the most important factors (relative weight of $23.8 \%$ and $22.2 \%$ respectively). This result is interesting, as the literature review pointed out that the "Management Support" factor 
should be the most important factor under the organization perspective (see Section 2.6). However, it came third based on experts' judgment (relative weight of 19.7\%). On further discussion, experts indicated that if the project has high ROI (in the form of services and better quality of life to citizens), as well as, clear objectives and use cases, it will most likely result in gaining management support on all management levels to the project, thus they are more important. Therefore, cities need to consider those factors when preparing the project. General and vague goals, as well as use cases that do not address various stakeholders' needs, should be avoided.

\subsection{Can the Model be used for Other Sectors?}

The focus of this research is smart-city-related big data projects. Never the less, this model can be used to assess an organization's readiness to do a big data project in other sectors as well. The factors defined in this research as the most critical factors that can have an impact on big data projects are general enough to fit any sector. Those factors have initially been identified by literature review about big data in general. However, what might be different is the relative weight and importance of each factor from one sector to another. Since, the relative weights were calculated based on experts' judgment, in which experts were told that this model is meant for smart-city-related big data projects. This assumption, that weights might be different by sectors, can be verified by further research where experts from other sectors are asked to quantify the model for their sectors.

On a larger scheme, this model can be used as the base to build models to assess other kinds of large-scale IT projects. Chapter 2 includes a comparison between big data 
and large-scale IT projects that show similarities and differences between big data and other types of large-scale IT projects. Therefore, the same concept of readiness assessment can be utilized for other large-scale IT projects, but more research should be conducted to finalize the list of factors, and then experts related to that particular type of large-scale IT projects should be called to quantify the relative weights and importance of the factors. 


\section{CHAPTER 10: CONCLUSIONS}

Following are the conclusions of this research, with a discussion of how the research gap was addressed, and how this research helps increase the chances of a successful big data implementation. In addition, the limitations of this research are addressed, as well as, how those limitations could be potential opportunities for future research.

\subsection{Conclusions and Contributions}

Planning is at the core of project management, and without proper planning, the chances of achieving the project goals while realizing its constraints are dim, and if any, it would be more likely due to sheer luck. Besides, with the advanced understanding of project management practices today, sheer luck is not an acceptable option to implement any type of projects. It is no longer acceptable to start a project without proper preparations and understanding of the dynamics surrounding the project, and how to manage those dynamics. In this context, a valuable tool that project managers can use to effectively understand the internal and external dynamics surrounding a project is readiness assessment. As readiness assessment includes assessing the organization's status against factors that have a significant impact on the upcoming project, which will lead to adequate planning and risk management, if done correctly, and hence better chances of achieving a successful project, by taking control of the project environment instead of depending on sheer luck.

In this research, readiness assessment was explored as a vital tool that project managers and organizations can use to prepare to implement a big data project. Research 
indicates that big data projects tend to fail with an alarmingly high percentage. Research also indicates that the factor influencing big data projects are examined and studied to a great extent in the last decade.

However, there is not enough research on how to harness this knowledge to help upcoming projects from failing. Therefore, in this research, the goal was to bridge this gap and provide a model that can be used to conduct a readiness assessment for an upcoming big data project. This research considered smart city application of big data as a focus area since big data applications are vast with some differences across sectors.

\subsubsection{Research Gaps and Questions}

This research resulted in a model that can be used by cities to assess their readiness to conduct a smart-city-related big data project. The research leveraged the lessons learned from previous projects (from literature review, see Section 2.6), and experts' feedback (see Chapter 5) to address the gaps and answer the research questions. The HDM methodology was used to build a hierarchical presentation of those factors, and to elicit experts' judgment to identify the relative importance of each factor, as well as, the categories the factors fall under toward the assessment of a city's readiness for a big data project. Furthermore, a case study was conducted where four projects related to the City of Portland were assessed using the model to demonstrate its practicality and effectiveness in evaluating a city to prepare for a smart-city-related big data project. Table 46 is a summary of how the research addressed the gaps, and Table 47 is a summary of how research questions were answered. 
Table 48. How the Research Addressed the Gaps

\begin{tabular}{|l|l|}
\hline Research Gap & Addressed By \\
\hline $\begin{array}{l}\text { RG1: There is limited research about } \\
\text { structured approaches to evaluate big data } \\
\text { readiness. }\end{array}$ & $\begin{array}{l}\text { The HDM model proposed by this research is a } \\
\text { comprehensive and structured way to evaluate } \\
\text { readiness assessment for a big data project. }\end{array}$ \\
\hline $\begin{array}{l}\text { RG2: There is limited research about } \\
\text { evaluating big data project's challenges under } \\
\text { different perspectives. }\end{array}$ & $\begin{array}{l}\text { The research identified the most important factors } \\
\text { influencing big data projects and what are their } \\
\text { relative importance/priorities. Also, factors are } \\
\text { classified into perspectives. }\end{array}$ \\
\hline $\begin{array}{l}\text { RG3: There is limited research about the } \\
\text { dynamics of internal and external factors } \\
\text { surrounding big data projects. }\end{array}$ & $\begin{array}{l}\text { Relative weights identified by this research, the } \\
\text { use of value curves, and simulation conducted by } \\
\text { this research addressed this point. }\end{array}$ \\
\hline
\end{tabular}

Table 49. How the Research Addressed the Questions

\begin{tabular}{|l|l|}
\hline Research Question & Answered By \\
\hline $\begin{array}{l}\text { RQ1: What are the main factors influencing } \\
\text { smart-city-related big data projects? }\end{array}$ & $\begin{array}{l}\text { The HDM model components (perspectives and } \\
\text { factors) are the main factors influencing smart- } \\
\text { city-related big data projects, as identified by this } \\
\text { research. See Section 2.6 and Section 5.2.6. }\end{array}$ \\
\hline $\begin{array}{l}\text { RQ2: What are the weights (relative } \\
\text { importance) of the factors affecting the } \\
\text { successful implementation of smart-city- } \\
\text { related big data projects? }\end{array}$ & $\begin{array}{l}\text { The HDM model quantification answered this } \\
\text { question. See Chapter 5 (Results of Model } \\
\text { Validation and Quantification) in general and the } \\
\text { summary in Section 5.3.6. }\end{array}$ \\
\hline $\begin{array}{l}\text { RQ3: Does the proposed model offer an } \\
\text { effective and practical way to evaluate the } \\
\text { city's readiness to implement a big data } \\
\text { project? }\end{array}$ & $\begin{array}{l}\text { Section 3.4.6 (City's Index of Readiness to } \\
\text { Conduct a Smart-city-related Big Data Project), } \\
\text { Chapter 7 (Analysis of Case Study) and Chapter } \\
\text { 8 (Research Validity) answered this question. }\end{array}$ \\
\hline
\end{tabular}

\subsubsection{Research Implications}

The implications of this research are two-fold: First, on the big picture level, this research contributes to the technology management body of knowledge on big data project management. As the literature review and gap analysis parts of this research indicate, there is a lack of structured and comprehensive understanding of the managerial issues around big data projects and the dynamics surrounding big data projects. This 
research advanced our understanding of this discipline, as well as, highlighted the dynamics of the internal and external factors affecting big data projects and the need for organizational readiness assessment before conducting big data projects (see Chapter 9 for more details).

Second, on the application level, this research offers a framework that cities, in particular, and organizations in general, can use to prepare to conduct big data projects properly. The research introduced an effective mechanism to assess an organization readiness for big data projects, through the identifying of weak areas within the organization, which probably will undermine the upcoming project. Allowing for preventive measurements to be taken, before starting the project, to overcome those weaknesses and make sure the project will be successful.

\subsection{Limitations}

First research limitation is related to the generalizability of the model. The research model was developed with consideration for smart-city-related big data projects. Applications of big data in other sectors might benefit from this model with expected minor changes in relative weights of factors. However, the extent of this change and whether all the factors identified in this research apply to other sectors is something that cannot be determined with absolute confidence, based on this research only. Further research where experts from other sectors are asked to provide their judgment for both the validation and quantification phases on this research must be carried out, and then, an analysis of the resulted model changes can lead to better conclusions on how representable the model is for other sectors. 
Another limitation regarding the generalizability of the model is related to the case study; the case study included four smart-city-related big data projects wat are being conducted in Portland, OR. Each project represents a different focus, traffic safety, connected vehicles (CV) technology, pollution monitoring, and engine idling. However, they are still related to one city.

Another limitation is related to experts. The experts for this research were thoroughly vetted. Great care was taken in identifying experts to make sure that they have the right expertise, and that they represent different backgrounds related to the research subject. Furthermore, experts' feedback was analyzed for inconsistency and disagreement to validate their judgment. Moreover, the issues of "loud voice" and "bystanders" are removed by making sure the experts do not talk to each other (see Section 3.4.5 for more details). However, experts are humans and as such, their judgment could be affected by bias and subjectivity that cannot always be detected.

Finally, during the course of this research, experts provided valuable feedback related to the research, some of this feedback could be considered as limitations including the following two points: IT technologies maturity continue to change and as such the challenges facing any IT project in general, therefore, the model should be "refreshed" frequently to maintain its relevance. Another point is related to the relative importance; some experts suggested that the relative importance of each factor might change during each phase of the project, while the model captures general relative importance of how each factor is expected to affect the project. 


\subsection{Future Work}

The limitations of this research can be addressed through future work. The following are suggested as future work based on the limitation's discussion:

- Conducting the same research for other sectors where big data applications are prominent, and then analyzing the model changes that resulted from the new research.

- Using the model to evaluate smart-city-related big data projects in other cities in the USA to judge its practicality beyond the City of Portland.

- Refreshing the model periodically to maintain its relevance.

- Researching the possibility to create a model that can assess factors that have dynamic relative importance that changes based on the phase of the project.

Furthermore, based on the discussion findings here are more suggested future work:

- Researching the challenge of maintaining data privacy while complying with regulations regarding access to public records.

- Researching the importance of marketing and community engagement to create awareness and gain public acceptance.

- Researching the value of clear objectives, use cases, and ROI on gaining management support for a project. 


\section{REFERENCES}

Abbas, Mustafa Sulaiman. 2016. "Consistency Analysis for Judgment Quantification in Hierarchical Decision Model”. Dissertations and Theses, Portland State University.

Abotah, Remal. 2014. "Evaluation of Energy Policy Instruments for the Adoption of Renewable Energy: Case of Wind Energy in the Pacific Northwest U.S." Dissertations and Theses, Portland State University.

Abotah, Remal, and Tugrul U. Daim. 2017. "Towards Building a Multi Perspective Policy Development Framework for Transition into Renewable Energy." Sustainable Energy Technologies and Assessments 21 (June): 67-88. https://doi.org/10.1016/j.seta.2017.04.004.

Adler-Milstein, Julia, Catherine M DesRoches, Peter Kralovec, Gregory Foster, Chantal Worzala, Dustin Charles, Talisha Searcy, and Ashish K Jha. 2015. "Electronic Health Record Adoption in US Hospitals: Progress Continues, but Challenges Persist." Health Affairs 34 (12): 2174-80.

Adrian, Alexandru. 2013. "Big Data Challenges." Database Systems Journal IV (3).

Adrian, Cecilia, Rusli Abdullah, Rodziah Atan, and Yusmadi Yah Jusoh. 2017. "Factors Influencing to the Implementation Success of Big Data Analytics: A Systematic Literature Review." In 2017 International Conference on Research and Innovation in Information Systems (ICRIIS), pp. 1-6. IEEE, 2017.

Aguarón, Juan, and José María Moreno-Jiménez. 2003. "The Geometric Consistency Index: Approximated Thresholds." European Journal of Operational Research 147 (1): 137-45. https://doi.org/10.1016/S0377-2217(02)00255-2.

Ahmadi, Hossein, Maryam Salahshour Rad, Alireza Almaee, Mehrbakhsh Nilashi, Othman Ibrahim, HM Dahlan, and Rozana Zakaria. 2014. "Ranking the MacroLevel Critical Success Factors of Electronic Medical Record Adoption Using Fuzzy AHP Method." International Journal of Innovation and Scientific Research $8(1): 35-42$.

Al Nuaimi, Eiman, Hind Al Neyadi, Nader Mohamed, and Jameela Al-Jaroodi. 2015. "Applications of Big Data to Smart Cities." Journal of Internet Services and Applications 6 (1). https://doi.org/10.1186/s13174-015-0041-5.

Al-Omari, Ahmed, and Hussein Al-Omari. 2006. "E-Government Readiness Assessment Model." Journal of Computer Science 2 (11): 841-45.

Ahmadi, Hossein, Othman Ibrahim, and Mehrbakhsh Nilashi. 2015. "Investigating a New Framework for Hospital Information System Adoption: A Case on Malaysia." Journal of Soft Computing and Decision Support Systems 2 (2): 26-33.

Alam, Muhammad, Joaquim Ferreira, and José Fonseca. 2016. "Introduction to Intelligent Transportation Systems." In Intelligent Transportation Systems: Dependable Vehicular Communications for Improved Road Safety, edited by Muhammad Alam, Joaquim Ferreira, and José Fonseca, 1-17. Cham: Springer International Publishing. https://doi.org/10.1007/978-3-319-28183-4_1. 
Aldhaban, Fahad, Tugrul U. Daim, and Robert Harmon. 2016. "Exploring the Adoption and Use of the Smartphone Technology in Emerging Regions: Case of Saudi Arabia." In 2015 Portland International Conference on Management of Engineering and Technology (PICMET), pp. 2355-2370. IEEE, 2015.. https://doi.org/10.1109/PICMET.2016.7806623.

Alonso, José Antonio, and M. Teresa Lamata. 2006. "Consistency in the Analytic Hierarchy Process: A New Approach.” International Journal of Uncertainty, Fuzziness and Knowledge-Based Systems 14 (04): 445-59. https://doi.org/10.1142/S0218488506004114.

Amer, Muhammad, and Tugrul Daim. 2013. "Expert Judgment Quantification.” In Research and Technology Management in the Electricity Industry, edited by Tugrul Daim, Terry Oliver, and Jisun Kim, 31-65. London: Springer London. https://doi.org/10.1007/978-1-4471-5097-8_3.

Andrejevic, Mark. 2014. "Big Data, Big Questions| The Big Data Divide." International Journal of Communication 8:17.

Angrave, David, Andy Charlwood, Ian Kirkpatrick, Mark Lawrence, and Mark Stuart. 2016. "HR and Analytics: Why HR Is Set to Fail the Big Data Challenge: Why HR Is Set to Fail the Big Data Challenge." Human Resource Management Journal 26 (1):1-11. https://doi.org/10.1111/1748-8583.12090.

Arthur, Lisa. 2013. "What Is Big Data?” Forbes. August 15, 2013. https://www.forbes.com/sites/lisaarthur/2013/08/15/what-is-big-data/.

Ashtiani, Behzad, Farzad Haghighirad, Ahmad Makui, and Golam ali Montazer. 2009. "Extension of Fuzzy TOPSIS Method Based on Interval-Valued Fuzzy Sets." Applied Soft Computing 9 (2): 457-61. https://doi.org/10.1016/j.asoc.2008.05.005.

Asselin-Miller, Nick, Marius Biedka, Gena Gibson, and Sujith Kollamthodi. 2017. "The Costs and Benefits of Deploying Cooperative Intelligent Transportation Systems in Europe out to 2030."

Atkinson, Roger. 1999. "Project Management: Cost, Time and Quality, Two Best Guesses and a Phenomenon, Its Time to Accept Other Success Criteria." International Journal of Project Management 17 (6):337-42. https://doi.org/10.1016/S0263-7863(98)00069-6.

Barham, Husam. 2017. "Achieving Competitive Advantage Through Big Data: A Literature Review." In 2017 Portland International Conference on Management of Engineering and Technology (PICMET), pp. 1-7. IEEE, 2017. https://doi.org/10.23919/PICMET.2017.8125459

Badenhausen, Kurt. 2017. "Portland, Ore., Leads the Best Places for Business and Careers 2017." Forbes. October 24, 2017.

https://www.forbes.com/sites/kurtbadenhausen/2017/10/24/portland-ore-rates-asthe-best-place-for-business-and-careers-2017/.

Baker, John, Karina Lovell, and Neil Harris. 2006. "How Expert Are the Experts? An Exploration of the Concept of 'Expert' within Delphi Panel Techniques." Nurse Researcher (through 2013) 14 (1): 59. 
Baker, Kenneth R. 2016. Optimization Modeling with Spreadsheets. Third Edition. Hoboken: Wiley.

Baker, Rachel. 2018. “Understanding College Students' Major Choices Using Social Network Analysis." Research in Higher Education 59 (2): 198-225. https://doi.org/10.1007/s11162-017-9463-1.

Balali, Vahid, Banafsheh Zahraie, and Abbas Roozbahani. 2014. “A Comparison of AHP and PROMETHEE Family Decision Making Methods for Selection of Building Structural System." American Journal of Civil Engineering and Architecture 2 (5): 149-59.

Bartlett, Randy. 2013. A Practitioner's Guide to Business Analytics: Using Data Analysis Tools to Improve Your Organization's Decision Making and Strategy. New York: McGraw-Hill.

Bartko, John J. 1976. “On Various Intraclass Correlation Reliability Coefficients.” Psychological Bulletin 83 (5): 762.

Basalyga, Stephanie. 2017. "Portland Making the Most of 'Smart City' Momentum." Daily Journal of Commerce. February 24, 2017. http://djcoregon.com/news/2017/02/23/portland-making-the-most-of-smart-citymomentum/.

Batty, Michael. 2013. "Big Data, Smart Cities and City Planning." Dialogues in Human Geography 3 (3):274-79. https://doi.org/10.1177/2043820613513390.

Batty, M., K. W. Axhausen, F. Giannotti, A. Pozdnoukhov, A. Bazzani, M. Wachowicz, G. Ouzounis, and Y. Portugali. 2012. "Smart Cities of the Future." The European Physical Journal Special Topics 214 (1):481-518. https://doi.org/10.1140/epjst/e2012-01703-3.

Bean, Randy. 2016. “Just Using Big Data Isn't Enough Anymore.” Harvard Business Review, February. https://hbr.org/2016/02/just-using-big-data-isnt-enoughanymore.

Beebe, Craig. 2016. "Portland Region Nears 2.4 Million Residents, Growing by 41,000 Last Year.” Metro. March 23, 2016. https:/www.oregonmetro.gov/news/portlandregion-nears-24-million-residents-growing-41000-last-year.

Beecham, Sarah, Tracy Hall, Carol Britton, Michaela Cottee, and Austen Rainer. 2005. "Using an Expert Panel to Validate a Requirements Process Improvement Model." Journal of Systems and Software 76 (3): 251-75. https://doi.org/10.1016/j.jss.2004.06.004.

Belanche, Daniel, Luis V. Casaló, and Carlos Orús. 2016. "City Attachment and Use of Urban Services: Benefits for Smart Cities.” Cities 50 (February):75-81. https://doi.org/10.1016/j.cities.2015.08.016.

Bell, Peter C., and Gregory Zaric. 2013. Analytics for Managers: With Excel. 1st ed. New York, NY: Routledge.

Berman, Jules J. 2013. Principles of Big Data: Preparing, Sharing, and Analyzing Complex Information. Amsterdam: Elsevier, Morgan Kaufmann.

Bertino, Elisa, and Elena Ferrari. 2018. "Big Data Security and Privacy." In $A$ Comprehensive Guide Through the Italian Database Research Over the Last 25 
Years, edited by Sergio Flesca, Sergio Greco, Elio Masciari, and Domenico Saccà, 31:425-39. Cham: Springer International Publishing. https://doi.org/10.1007/978-3-319-61893-7_25.

Bhutia, Pema Wangchen, and Ruben Phipon. 2012. "Application of AHP and TOPSIS Method for Supplier Selection Problem." IOSR Journal of Engineering 2 (10): 43-50.

Bloch, Michael, Sven Blumberg, and Jürgen Laartz. 2012. "Delivering Large-Scale IT Projects on Time, on Budget, and on Value." Harvard Business Review.

Bock, Robert, Marco Iansiti, and Karim R. Lakhani. 2017. "What the Companies on the Right Side of the Digital Business Divide Have in Common." Harvard Business Review. January 31, 2017. https://hbr.org/2017/01/what-the-companies-on-theright-side-of-the-digital-business-divide-have-in-common.

Boyd, Danah, and Kate Crawford. 2012. "Critical Questions for Big Data: Provocations for a Cultural, Technological, and Scholarly Phenomenon.” Information, Communication \& Society 15 (5):662-79. https://doi.org/10.1080/1369118X.2012.678878.

Brans, Jean-Pierre, Ph Vincke, and Bertrand Mareschal. 1986. "How to Select and How to Rank Projects: The PROMETHEE Method.” European Journal of Operational Research 24 (2): 228-38.

Brans, Jean-Pierre, and Yves De Smet. 2016. "PROMETHEE Methods." In Multiple Criteria Decision Analysis, 187-219. Springer.

Brehmer, Berndt. 1976. "Social Judgment Theory and the Analysis of Interpersonal Conflict." Psychological Bulletin 83 (6): 985.

Bright, Jonathan, and Helen Margetts. 2016. "Big Data and Public Policy: Can It Succeed Where E-Participation Has Failed?: Editorial: Big Data and Public Policy." Policy \& Internet 8 (3): 218-24.

Brown, Bernice B. 1968. Delphi Process: A Methodology Used for the Elicitation of Opinions of Experts. Rand Corp Santa Monica CA.

Brown, B, D Court, and P Willmott. 2013. "Mobilizing Your C-Suite for Big-Data Analytics." McKinsey Quarterly 4:76-87.

Buckley, Jonathan. 2015. "Why the Majority of Big Data Projects Fail." Qubole (blog). June 18, 2015. https://www.qubole.com/blog/big-data/big-data-projects-fail/.

Bughin, Jacques. 2016. "Reaping the Benefits of Big Data in Telecom.” Journal of Big Data 3 (1). https://doi.org/10.1186/s40537-016-0048-1.

Burcharth, Ana Luiza de Araújo, Mette Praest Knudsen, and Helle Alsted Søndergaard. 2014. "Neither Invented nor Shared Here: The Impact and Management of Attitudes for the Adoption of Open Innovation Practices." Technovation 34 (3):149-61. https://doi.org/10.1016/j.technovation.2013.11.007.

Burgman, Mark A, Marissa McBride, Raquel Ashton, Andrew Speirs-Bridge, Louisa Flander, Bonnie Wintle, Fiona Fidler, Libby Rumpff, and Charles Twardy. 2011. "Expert Status and Performance." PLoS One 6 (7): e22998. 
Burrows, Roger, and Mike Savage. 2014. "After the Crisis? Big Data and the Methodological Challenges of Empirical Sociology.” Big Data \& Society 1 (1):205395171454028. https://doi.org/10.1177/2053951714540280.

Cacuci, Dan G. 1981. "Sensitivity Theory for Nonlinear Systems. I. Nonlinear Functional Analysis Approach." Journal of Mathematical Physics 22 (12): 2794-2802.

Caragliu, Andrea, Chiara Del Bo, and Peter Nijkamp. 2011. "Smart Cities in Europe." Journal of Urban Technology 18 (2):65-82. https://doi.org/10.1080/10630732.2011.601117.

Calder, Bobby J., Lynn W. Phillips, and Alice M. Tybout. "The concept of external validity." Journal of Consumer Research 9, no. 3 (1982): 240-244.

Carillo, Kevin Daniel André. 2017. "Let's Stop Trying to Be 'Sexy'-Preparing Managers for the (Big) Data-Driven Business Era." Business Process Management Journal $23(3)$.

Carroll, Archie B. 1994. 'Social Issues in Management Research: Experts' Views, Analysis, and Commentary.” Business \& Society 33 (1): 5-29. https://doi.org/10.1177/000765039403300102.

Castelnovo, Walter, Gianluca Misuraca, and Alberto Savoldelli. 2016. "Smart Cities Governance: The Need for a Holistic Approach to Assessing Urban Participatory Policy Making." Social Science Computer Review 34 (6):724-39. https://doi.org/10.1177/0894439315611103.

Cats-Baril, William, and Ronald Thompson. 1995. "Managing Information Technology Projects in the Public Sector." Public Administration Review 55 (6): 559. https://doi.org/10.2307/3110347.

Cearley, David. 2016. “Gartner Inc.: Top 10 Technology Trends for 2016.” Forbes, January 15. http://www.forbes.com/sites/gartnergroup/2016/01/15/top-10technology-trends-for-2016/.

Chen, Shu-Jen, and Ching-Lai Hwang. 1992. "Fuzzy Multiple Attribute Decision Making Methods.” In Fuzzy Multiple Attribute Decision Making, 289-486. Springer.

Chen, Chen-Tung. 2000. "Extensions of the TOPSIS for Group Decision-Making Under Fuzzy Environment." Fuzzy Sets and Systems 114 (1): 1-9.

Chen, Hongyi, and Dundar F. Kocaoglu. 2008. "A Sensitivity Analysis Algorithm for Hierarchical Decision Models.” European Journal of Operational Research 185 (1):266-88. https://doi.org/10.1016/j.ejor.2006.12.029.

Chen, Hsinchun, Roger H. L. Chiang, and Veda C. Storey. 2012. "Business Intelligence and Analytics: From Big Data to Big Impact." MIS Quarterly: Management Information Systems 36 (4):1165-88.

Chan, Leong. 2013. "Developing a Strategic Policy Choice Framework for Technological Innovation: Case of Chinese Pharmaceuticals." Dissertations and Theses, Portland State University.

Chen, CL Philip, and Chun-Yang Zhang. 2014. "Data-Intensive Applications, Challenges, Techniques and Technologies: A Survey on Big Data." Information Sciences 275:314-47. 
Chen, Min, Shiwen Mao, and Yunhao Liu. 2014. "Big Data: A Survey." Mobile Networks and Applications 19 (2):171-209. https://doi.org/10.1007/s11036-0130489-0.

Cheng, Xiang, Liuqing Yang, and Xia Shen. 2015. "D2D for Intelligent Transportation Systems: A Feasibility Study." IEEE Transactions on Intelligent Transportation Systems 16 (4):1784-93. https://doi.org/10.1109/TITS.2014.2377074.

Chiolero, Arnaud. 2013. "Big Data in Epidemiology: Too Big to Fail?” Epidemiology 24 (6):938-39. https://doi.org/10.1097/EDE.0b013e31829e46dc.

Cho, Kwangsu, Christian D Schunn, and Davida Charney. 2006. "Commenting On Writing: Typology And Perceived Helpfulness Of Comments From Novice Peer Reviewers And Subject Matter Experts.” Written Communication 23 (3): 260-94. Chourabi, Hafedh, Taewoo Nam, Shawn Walker, J. Ramon Gil-Garcia, Sehl Mellouli, Karine Nahon, Theresa A. Pardo, and Hans Jochen Scholl. 2012. "Understanding Smart Cities: An Integrative Framework." In 2012 45th Hawaii international conference on system sciences, pp. 2289-2297. IEEE, 2012. https://doi.org/10.1109/HICSS.2012.615.

Chowdhury, Mashrur, and Kakan Dey. 2016. "Intelligent Transportation Systems-A Frontier for Breaking Boundaries of Traditional Academic Engineering Disciplines [Education]." IEEE Intelligent Transportation Systems Magazine 8 (1):4-8. https://doi.org/10.1109/MITS.2015.2503199.

Chuttur, Mohammad Y. 2009. "Overview of the Technology Acceptance Model: Origins, Developments and Future Directions." Working Papers on Information Systems 9 (37): 9-37.

Cleland, David I., and Dundar F. Kocaoglu. 1981. Engineering Management. McGrawHill Series in Industrial Engineering and Management Science. New York: McGraw-Hill.

Cobb, Charles G. 2011. Making Sense of Agile Project Management: Balancing Control and Agility. Hoboken, N.J: Wiley.

Coelho, Margarida C, and Nagui Rouphail. 2010. "Assessing the Impact of V2V/V2I Communication Systems on Traffic Congestion and Emissions." In Proceedings of the European Conference on Human Centred Design for Intelligent Transport Systems. 2010.

Columbus, Louis. 2014. "84\% Of Enterprises See Big Data Analytics Changing Their Industries' Competitive Landscapes In The Next Year." Forbes. October 19, 2014. http://www.forbes.com/sites/louiscolumbus/2014/10/19/84-of-enterprisessee-big-data-analytics-changing-their-industries-competitive-landscapes-in-thenext-year/.

Cooke, Roger. 1991. Experts in Uncertainty: Opinion and Subjective Probability in Science. Oxford University Press on Demand.

Cowan, Kelly. 2017. "Technology Planning for Aligning Emerging Business Models and Regulatory Structures: The Case of Electric Vehicle Charging and the Smart Grid." Dissertations and Theses, Portland State University. https://doi.org/10.15760/etd.5915. 
Guangting, Zhu, and Zhu Junxuan. 2014. "The Study of Impact of 'Big Data' to Purchasing Intention." International Journal of Business and Social Science 5 (10). http://search.proquest.com/openview/6f48d4281080a671eb4ec2dbc5974b32/1?pq -origsite $=$ gscholar.

Dabab, Maoloud, Rebecca Craven, Husam Barham, and Elizabeth Gibson. 2018. "Exploratory Strategic Roadmapping Framework for Big Data Privacy Issues." In 2018 Portland International Conference on Management of Engineering and Technology (PICMET), 1-9. Honolulu, HI: IEEE. https://doi.org/10.23919/PICMET.2018.8481834

Daim, Tugrul U, Guillermo Rueda, Hilary Martin, and Pisek Gerdsri. 2006. "Forecasting Emerging Technologies: Use of Bibliometrics and Patent Analysis." Technological Forecasting and Social Change 73 (8): 981-1012.

Daim, Tugrul U, Willy Schweinfort, Gulgun Kayakutlu, and Noah Third. 2010. "Identification of Energy Policy Priorities from Existing Energy Portfolios Using Hierarchical Decision Model and Goal Programming: Case of Germany and France." International Journal of Energy Sector Management 4 (1): 24-43.

Daim, Tugrul U, Kevin van Blommestein, Nazrul Islam, Sercan Ozcan, James Hillegas, and Judith Estep. 2014. "Integrating Data Mining into Technology Roadmapping." In Proceedings of PICMET'14 Conference: Portland International Center for Management of Engineering and Technology; Infrastructure and Service Integration, pp. 2972-2985. IEEE, 2014.

Daim, Tugrul U. ed. 2016. Hierarchical Decision Modeling: Essays in Honor of Dundar F. Kocaoglu. Innovation, Technology, and Knowledge Management. Cham: Springer.

Daim, Tugrul U., Monticha Khammuang, and Edwin Garces. 2016. "The Application of Social Network Analysis: Case of Smart Roofing." In Anticipating Future Innovation Pathways Through Large Data Analysis, edited by Tugrul U. Daim, Denise Chiavetta, Alan L. Porter, and Ozcan Saritas, 273-302. Cham: Springer International Publishing. https://doi.org/10.1007/978-3-319-39056-7_15.

Daim, Tugrul U. 2017. Managing Technological Innovation: Tools and Methods. Vol. 1. World Scientific.

Dalati, Serene, and Jorge Marx Gómez. 2018. "Surveys and Questionnaires." In Modernizing the Academic Teaching and Research Environment, 175-86. Springer.

Dalkey, Norman, and Olaf Helmer. 1963. "An Experimental Application of the Delphi Method to the Use of Experts." Management Science 9 (3): 458-67.

DalleMule, Leandro, and Thomas H Davenport. 2017. "What's Your Data Strategy?" Harvard Business Review 95 (3):112-21.

Dantzig, G.B., 1963. Linear Programming and Extensions. Princeton University Press, Princeton, NJ.

Dar, Kashif, Mohamed Bakhouya, Jaafar Gaber, Maxime Wack, and Pascal Lorenz. 2010. "Wireless Communication Technologies for ITS Applications [Topics in 
Automotive Networking." IEEE Communications Magazine 48 (5):156-62. https://doi.org/10.1109/MCOM.2010.5458377.

Davenport, Thomas H. 2006. "Competing on Analytics." Harvard Business Review, January. https://hbr.org/2006/01/competing-on-analytics.

Davenport, Thomas H, and DJ Patil. 2012. "Data Scientist." Harvard Business Review 90 (5):70-76.

Davenport, Thomas H., and Randy Bean. 2018. "Big Companies Are Embracing Analytics, But Most Still Don't Have a Data-Driven Culture.” Harvard Business Review, February 15, 2018. https://hbr.org/2018/02/big-companies-areembracing-analytics-but-most-still-dont-have-a-data-driven-culture.

Davis, Fred D. 1993. "User Acceptance of Information Technology: System Characteristics, User Perceptions and Behavioral Impacts." International Journal of Man-Machine Studies 38 (3): 475-87. https://doi.org/10.1006/imms.1993.1022.

Day, J. 2002. "What Is an Expert?” Radiography 8 (2): 63-70. https://doi.org/10.1053/radi.2002.0369.

Dillman, Don A. 1978. Mail and Telephone Surveys: The Total Design Method. Vol. 19. Wiley New York.

Dimitrakopoulos, George, and Panagiotis Demestichas. 2010. "Intelligent Transportation Systems.” IEEE Vehicular Technology Magazine 5 (1):77-84. https://doi.org/10.1109/MVT.2009.935537.

Diodato, Virgil P, and Peter Gellatly. 2013. Dictionary of Bibliometrics. Routledge.

DOE. 2018. "Alternative Fuels Data Center: Electric Refrigeration Translates Fuel Burn into Savings for Nonprofit.” May 29, 2018. https://afdc.energy.gov/case/3069.

DoD. 2011. “Technology Readiness Assessment Guidance.” May 13, 2011. https://www.dau.mil/acquipedia/Pages/ArticleDetails.aspx?aid=df418a39-2a574e69-987e-bb0796587089.

DOT. 2016. "Traffic Safety Facts 2015: Motor Vehicle Crash Data from the Fatality Analysis Reporting System (FARS) and the General Estimates System (GES) 812384." US Department of Transportation. https://crashstats.nhtsa.dot.gov/Api/Public/ViewPublication/812384.

DOT. 2017. "Intelligent Transportation Systems - About ITS." US Department of Transportation. 2017. https://www.its.dot.gov/about.htm.

Dreyfus, Hubert L., and Stuart E. Dreyfus. 2005. "Peripheral Vision: Expertise in Real World Contexts." Organization Studies 26 (5): 779-92. https://doi.org/10.1177/0170840605053102.

Duffield, Christine. 1993. "The Delphi Technique: A Comparison of Results Obtained Using Two Expert Panels." International Journal of Nursing Studies 30 (3): 22737.

Dulewicz, Victor, Malcolm Higgs, and Mark Slaski. 2003. "Measuring Emotional Intelligence: Content, Construct and Criterion-related Validity." Journal of Managerial Psychology 18 (5): 405-20. https://doi.org/10.1108/02683940310484017.

Dumbill, Edd. 2012. "What is big data." https:/www.oreilly.com/ideas/what-is-big-data. 
Ebner, Katharina, Thilo Buhnen, and Nils Urbach. 2014. "Think Big with Big Data: Identifying Suitable Big Data Strategies in Corporate Environments.” In 2014 47th Hawaii International Conference on System Sciences, pp. 3748-3757. IEEE, 2014. https://doi.org/10.1109/HICSS.2014.466.

Eisenhardt, Kathleen M. 1989. "Building Theories from Case Study Research." The Academy of Management Review 14 (4): 532-50. doi:10.2307/258557.

El-Gazzar, Rania, Eli Hustad, and Dag H. Olsen. 2016. "Understanding Cloud Computing Adoption Issues: A Delphi Study Approach.” Journal of Systems and Software 118 (August): 64-84. https://doi.org/10.1016/j.jss.2016.04.061.

Erevelles, Sunil, Nobuyuki Fukawa, and Linda Swayne. 2016. "Big Data Consumer Analytics and the Transformation of Marketing." Journal of Business Research 69 (2):897-904. https://doi.org/10.1016/j.jbusres.2015.07.001.

Estep, Judith, and Tugrul Daim. 2016. “A Framework for Technology Transfer Potential Assessment." In 2016 Portland International Conference on Management of Engineering and Technology (PICMET), pp. 2846-2852. IEEE, 2016. https://doi.org/10.1109/PICMET.2016.7806626.

Estep, Judith. 2017. "Development of a Technology Transfer Score for Evaluating Research Proposals: Case Study of Demand Response Technologies in the Pacific Northwest." Dissertations and Theses, Portland State University. http://archives.pdx.edu/ds/psu/19604.

Ethirajan, D, S Purushothaman, and S Prema. 2017. "Adoption of E-Governance Applications towards Big Data Approach.” International Journal of Applied Engineering Research 12 (21):11336-40.

Etzion, Dror, and J. Alberto Aragon-Correa. 2016. "Big Data, Management, and Sustainability: Strategic Opportunities Ahead.” Organization \& Environment 29 (2):147-55. https://doi.org/10.1177/1086026616650437.

EU GDPR. 2019. "EUGDPR - Information Portal.” 2019. https://eugdpr.org/.

Farid, Shahid, Rodina Ahmad, and Mujahid Alam. 2015. "A Hierarchical Model for ELearning Implementation Challenges Using AHP.” Malaysian Journal of Computer Science 28 (3): 166-88.

Fazey, Ioan, John A Fazey, and Della MA Fazey. 2005. "Learning More Effectively from Experience." Ecology and Society 10 (2).

Feigenbaum, Edward A, and Pamela McCorduck. 1984. The Fifth Generation: Artificial Intelligence and Japan's Computer Challenge to the World.

Fenwick, David, Tugrul U. Daim, and Nathasit Gerdsri. 2009. "Value Driven Technology Road Mapping (VTRM) Process Integrating Decision Making and Marketing Tools: Case of Internet Security Technologies." Technological Forecasting and Social Change 76 (8):1055-77. https://doi.org/10.1016/j.techfore.2009.04.005.

FHWA. 2017. "Traffic Congestion and Reliability: Trends and Advanced Strategies for Congestion Mitigation: Executive Summary." United States Department of Transportation - Federal Highway Administration. https://ops.fhwa.dot.gov/congestion_report/executive_summary.htm. 
Fink, Arlene, Jacqueline Kosecoff, Mark Chassin, and Robert H Brook. 1984.

"Consensus Methods: Characteristics and Guidelines for Use." American Journal of Public Health 74 (9): 979-83.

Fitzgerald, Michael. 2016. "Data-Driven City Management: A Close Look at Amsterdam's Smart City Initiative.” MIT Sloan Management Review 57 (4).

Fitzpatrick, Anne R. 1983. "The Meaning of Content Validity." Applied Psychological Measurement 7 (1): 3-13. https://doi.org/10.1177/014662168300700102.

Firican, George. 2017. “The 10 Vs of Big Data.” TDWI Upside. February 8, 2017. https://upside.tdwi.org/articles/2017/02/08/10-vs-of-big-data.aspx.

Fleiss, Joseph L, and Jacob Cohen. 1973. "The Equivalence of Weighted Kappa and the Intraclass Correlation Coefficient as Measures of Reliability." Educational and Psychological Measurement 33 (3): 613-19.

Flood, Mark D, HV Jagadish, and Louiqa Raschid. 2016. "Big Data Challenges and Opportunities in Financial Stability Monitoring." Banque de France, Financial Stability Review 20.

Floricel, Serghei, and Roger Miller. 2001. "Strategizing for Anticipated Risks and Turbulence in Large-Scale Engineering Projects." International Journal of Project Management 19 (8): 445-55.

Flyvbjerg, Bent, and Alexander Budzier. 2011. "Why Your IT Project May Be Riskier than You Think." Harvard Business Review, September. https://hbr.org/2011/09/why-your-it-project-may-be-riskier-than-you-think.

Fogue, Manuel, Piedad Garrido, Francisco Martinez, Juan-Carlos Cano, Carlos Calafate, and Pietro Manzoni. 2012. "Automatic Accident Detection: Assistance Through Communication Technologies and Vehicles." IEEE Vehicular Technology Magazine 7 (3):90-100. https://doi.org/10.1109/MVT.2012.2203877.

FOIA. 2019. "Freedom of Information Act Frequently Asked Questions." 2019. https://www.foia.gov/faq.html.

$\mathrm{Fu}$, Yupeng, Rongjing Xiang, Yiqun Liu, Min Zhang, and Shaoping Ma. 2007. "Finding Experts Using Social Network Analysis." In Proceedings of the IEEE/WIC/ACM International Conference on Web Intelligence, pp. 77-80. IEEE Computer Society, 2007.

Gaffney, Neil. 2017. "FHWA Announces Vehicle-to-Infrastructure Guidance.” Text. DOT. January 19, 2017. https://www.transportation.gov/briefing-room/fhwa0317. GAO. 2016. "Technology Readiness Assessment Guide.” 2016. https://www.gao.gov/assets/680/679006.pdf.

Garces, Edwin, Kevin van Blommestein, Jamie Anthony, James Hillegas-Elting, Tugrul Daim, and Byung-Sung Yoon. 2017. "Technology Domain Analysis: A Case of Energy-Efficient Advanced Commercial Refrigeration Technologies." Sustainable Production and Consumption 12: 221-33.

García, Salvador, Sergio Ramírez-Gallego, Julián Luengo, José Manuel Benítez, and Francisco Herrera. 2016. "Big Data Preprocessing: Methods and Prospects." Big Data Analytics 1 (1). https://doi.org/10.1186/s41044-016-0014-0. 
Gastel, Barbara, and Robert A Day. 2016. How to Write and Publish a Scientific Paper. ABC-CLIO

Gibson, Elizabeth. 2016. “A Measurement System for Science and Engineering Research Center Performance Evaluation." Dissertations and Theses, Portland State University. https://doi.org/10.15760/etd.3276.

Global Market Insights. 2016. "Intelligent Transportation Systems (ITS) Market Size Report, 2022.” March 2016. https:/www.gminsights.com/industryanalysis/intelligent-transportation-system-ITS-market.

Green Electric Council. 2018. “A Story of Sustainable Sensors.” June 2018. http://greenelectronicscouncil.org/wp-content/uploads/2018/06/GEC-PortlandSustainable-Sensors-Story-FINAL-4.pdf.

Greenhalgh, Trisha, Deborah Swinglehurst, and Rob Stones. 2014. "Rethinking Resistance to 'Big IT': A Sociological Study of Why and When Healthcare Staff Do Not Use Nationally Mandated Information and Communication Technologies." Health Services and Delivery Research 2 (39): 1-86. https://doi.org/10.3310/hsdr02390.

Groves, Peter, Basel Kayyali, David Knott, and Steve Van Kuiken. 2016. "The Big Data Revolution in Healthcare: Accelerating Value and Innovation.” Center for US Health System Reform: Business Technology Office.

Guilford, Joy Paul. 1954. Psychometric Methods (2nd ed.). New York, NY, US: Mcgraw Hill.

Gumus, Alev Taskin. 2009. "Evaluation of Hazardous Waste Transportation Firms by Using a Two Step Fuzzy-AHP and TOPSIS Methodology." Expert Systems with Applications 36 (2): 4067-74. https://doi.org/10.1016/j.eswa.2008.03.013.

Hammond, Kenneth R. 2000. Human Judgment and Social Policy: Irreducible Uncertainty, Inevitable Error, Unavoidable Injustice. Oxford University Press on Demand.

Harell, Georgina, and Tugrul U. Daim. 2010. "HDM Modeling as a Tool to Assist Management With Employee Motivation: The Case of Silicon Forest."

Engineering Management Journal 22 (1): 23-33. https://doi.org/10.1080/10429247.2010.11431850.

Harris, Jim. 2015. "Who Owns Big Data?” The Data Roundtable (blog). March 26, 2015. http://blogs.sas.com/content/datamanagement/2015/03/26/owns-big-data/.

Harrison, C., B. Eckman, R. Hamilton, P. Hartswick, J. Kalagnanam, J. Paraszczak, and P. Williams. 2010. "Foundations for Smarter Cities." IBM Journal of Research and Development 54 (4):1-16. https://doi.org/10.1147/JRD.2010.2048257.

Hashem, Ibrahim Abaker Targio, Victor Chang, Nor Badrul Anuar, Kayode Adewole, Ibrar Yaqoob, Abdullah Gani, Ejaz Ahmed, and Haruna Chiroma. 2016. "The Role of Big Data in Smart City." International Journal of Information Management 36 (5):748-58.

Healy, Marilyn, and Chad Perry. 2000. "Comprehensive Criteria to Judge Validity and Reliability of Qualitative Research within the Realism Paradigm.” Qualitative 
Market Research: An International Journal 3 (3): 118-26.

https://doi.org/10.1108/13522750010333861.

Hinz, Oliver, Christian Schulze, and Carsten Takac. 2014. "New Product Adoption in

Social Networks: Why Direction Matters.” Journal of Business Research 67 (1):

2836-44. https://doi.org/10.1016/j.jbusres.2012.07.005.

Hogaboam, Liliya, Brian Ragel, and Tugrul Daim. 2014. "Development of a Hierarchical

Decision Model (HDM) for Health Technology Assessment (HTA) to Design and Implement a New Patient Care Database for Low Back Pain.” In Proceedings of PICMET'14 Conference: Portland International Center for Management of Engineering and Technology; Infrastructure and Service Integration, pp. 35113517. IEEE, 2014.

HRSA 2018. "Readiness Assessment \& Developing Project Aims." 2018.

https://www.hrsa.gov/sites/default/files/quality/toolbox/508pdfs/readinessassessm ent.pdf.

Hwang, Ching-Lai, and Abu Syed Md. Masud. 1979. Multiple Objective Decision Making - Methods and Applications. Vol. 164. Lecture Notes in Economics and Mathematical Systems. Berlin, Heidelberg: Springer Berlin Heidelberg. https://doi.org/10.1007/978-3-642-45511-7.

IBM. 2017. “10 Key Marketing Trends for 2017.” July 19, 2017. https://www01.ibm.com/common/ssi/cgi-bin/ssialias?htmlfid=WRL12345USEN.

IBM. 2016. "IBM Big Data - What Is Big Data." 2016. http://www.ibm.com/bigdata/us/en/.

IBM. 2016b. "IBM - What Is a Data Scientist? - Bringing Big Data to the Enterprise." Accessed June 1, 2016. https:/www-01.ibm.com/software/data/infosphere/datascientist/.

Iakovidis, Dimitris K, and Elpiniki Papageorgiou. 2011. "Intuitionistic Fuzzy Cognitive Maps for Medical Decision Making.” IEEE Transactions on Information Technology in Biomedicine 15 (1): 100-107.

Iansiti, Marco, and Karim Lakhani. 2016. "The Digital Business Divide Analyzing the Operating Impact of Digital Transformation.” Keystone Strategy. http://download.microsoft.com/download/0/4/3/0430CF1B-0E7B-44E0-BAF423C03E12F065/The_Digital_Business_Divide_white_paper.pdf.

Idle-Free California. 2018. "Idle-Free California | Heavy-Duty Vehicle Idling." 2018. http://idlefreecalifornia.org/heavy-duty.html.

Imondi, Chris, Arundhati Shastri, Tom Shott, Jayanth Siddappa, and Tugrul U. Daim. 2018. "Technology Assessment: Nosocomial Infection Solutions." In Infrastructure and Technology Management, edited by Tugrul U. Daim, Leong Chan, and Judith Estep, 271-95. Cham: Springer International Publishing. https://doi.org/10.1007/978-3-319-68987-6_8.

Iooss, Bertrand, and Paul Lemaître. 2015. "A Review on Global Sensitivity Analysis Methods." In Uncertainty Management in Simulation-Optimization of Complex Systems, edited by Gabriella Dellino and Carlo Meloni, 59:101-22. Boston, MA: Springer US. https://doi.org/10.1007/978-1-4899-7547-8_5. 
Iron Mountain. 2015. "Seizing The Information Advantage - Executive Summary." Pricewaterhouse Coopers \& Iron Mountain. http://www.ironmountain.com/resources/whitepapers/s/seizing-the-informationadvantage-executive-summary.

Ishizaka, Alessio, and Ashraf Labib. 2009. "Analytic Hierarchy Process and Expert Choice: Benefits and Limitations." OR Insight 22 (4): 201-20. https://doi.org/10.1057/ori.2009.10.

Iskin, Ibrahim. 2014. "An Assessment Model for Energy Efficiency Program Planning in Electric Utilities: Case of the Pacific of Northwest U.S.A." Dissertations and Theses, Portland State University. https://doi.org/10.15760/etd.1850.

Jagadish, H. V., Johannes Gehrke, Alexandros Labrinidis, Yannis Papakonstantinou, Jignesh M. Patel, Raghu Ramakrishnan, and Cyrus Shahabi. 2014. "Big Data and Its Technical Challenges." Communications of the ACM 57 (7):86-94. https://doi.org/10.1145/2611567.

Jairath, N, and J Weinstein. 1994. "The Delphi Methodology (Part One): A Useful Administrative Approach." Canadian Journal of Nursing Administration 7 (3): $29-42$.

James, Josh. 2018. "Data Never Sleeps 6.0 | Domo Blog.” Domo Blog (blog). June 5, 2018. https://www.domo.com/blog/data-never-sleeps-6/.

Jernigan, Stephanie, Sam Ransbotham, and David Kiron. 2016. "Data Sharing and Analytics Drive Success With IoT." MIT Sloan Management Review, September 8, 2016. http://sloanreview.mit.edu/projects/data-sharing-and-analytics-drivesuccess-with-internet-of-things/.

Jetter, Antonie J., and Kasper Kok. 2014. "Fuzzy Cognitive Maps for Futures Studies-A Methodological Assessment of Concepts and Methods." Futures 61 (September): 45-57. https://doi.org/10.1016/j.futures.2014.05.002.

Jetter, Antonie J., and Richard C. Sperry. 2013. "Fuzzy Cognitive Maps for Product Planning: Using Stakeholder Knowledge to Achieve Corporate Responsibility." In 2013 46th Hawaii International Conference on System Sciences, pp. 925-934. IEEE, 2013. https://doi.org/10.1109/HICSS.2013.238.

John Walker, Saint. 2014. "Big Data: A Revolution That Will Transform How We Live, Work, and Think." International Journal of Advertising 33 (1):181-83. https://doi.org/10.2501/IJA-33-1-181-183.

Joseph, A.D., A.R. Beresford, J. Bacon, D.N. Cottingham, J.J. Davies, B.D. Jones, Haitao Guo, et al. 2006. "Intelligent Transportation Systems." IEEE Pervasive Computing 5 (4):63-67. https://doi.org/10.1109/MPRV.2006.77.

Junior, Francisco Rodrigues Lima, Lauro Osiro, and Luiz Cesar Ribeiro Carpinetti. 2014. "A Comparison Between Fuzzy AHP and Fuzzy TOPSIS Methods to Supplier Selection." Applied Soft Computing 21: 194-209.

Kache, Florian, and Stefan Seuring. 2017. "Challenges and Opportunities of Digital Information at the Intersection of Big Data Analytics and Supply Chain Management." International Journal of Operations \& Production Management 37 (1): 10-36. https://doi.org/10.1108/IJOPM-02-2015-0078. 
Kadadi, Anirudh, Rajeev Agrawal, Christopher Nyamful, and Rahman Atiq. 2014. "Challenges of Data Integration and Interoperability in Big Data." In 2014 IEEE international conference on big data (big data), pp. 38-40. IEEE, 2014.

Kaiser, Michael G., Fedi El Arbi, and Frederik Ahlemann. 2015. "Successful Project Portfolio Management beyond Project Selection Techniques: Understanding the Role of Structural Alignment." International Journal of Project Management 33 (1):126-39. https://doi.org/10.1016/j.ijproman.2014.03.002.

Kaisler, Stephen, Frank Armour, J. Alberto Espinosa, and William Money. 2013. "Big Data: Issues and Challenges Moving Forward." In 2013 46th Hawaii International Conference on System Sciences, pp. 995-1004. IEEE, 2013. https://doi.org/10.1109/HICSS.2013.645.

Katal, Avita, Mohammad Wazid, and R. H. Goudar. 2013. "Big Data: Issues, Challenges, Tools and Good Practices." In 2013 Sixth international conference on contemporary computing (IC3), pp. 404-409. IEEE, 2013. https://doi.org/10.1109/IC3.2013.6612229.

Katz, Ralph, and Thomas J. Allen. 1982. "Investigating the Not Invented Here (NIH) Syndrome: A Look at the Performance, Tenure, and Communication Patterns of 50 R \& D Project Groups.” R\&D Management 12 (1):7-20. https://doi.org/10.1111/j.1467-9310.1982.tb00478.x.

Kelley, Truman Lee. 1927. "Interpretation of Educational Measurements."

Kennedy, Elizabeth, and Tugrul U. Daim. 2010. "A Strategy to Assist Management in Workforce Engagement and Employee Retention in the High Tech Engineering Environment." Evaluation and Program Planning 33 (4): 468-76. https://doi.org/10.1016/j.evalprogplan.2009.12.001.

Kerkering, J. Charles. 2002. "Eliciting and Analyzing Expert Judgment, A Practical Guide." Technometrics 44 (2): 193-94. https://doi.org/10.1198/tech.2002.s716.

Kerzner, Harold. 2013. Project Management: A Systems Approach to Planning, Scheduling, and Controlling. Eleventh edition. Hoboken, New Jersey: John Wiley \& Sons, Inc.

Khan, Asadullah. 2006. "Project Scope Management." Cost Engineering 48 (6):12-16.

Khan, Zaheer, Ashiq Anjum, and Saad Liaquat Kiani. 2013. "Cloud Based Big Data Analytics for Smart Future Cities." In 2013 IEEE/ACM 6th International Conference on Utility and Cloud Computing, pp. 381-386. IEEE, 2013. https://doi.org/10.1109/UCC.2013.77.

Khanam, Momtaj, Husam Barham, Alaa Nour, Sallam Thabet, and Tugrul Daim. 2017. "Technology Assessment in the Energy Sector." In Research and Development Management, edited by Tugrul Daim, Jisun Kim, and Kenny Phan, 61-85. Cham: Springer International Publishing. https://doi.org/10.1007/978-3-319-54537-0_5.

Kilic, Huseyin Selcuk, Selim Zaim, and Dursun Delen. 2015. "Selecting 'The Best' ERP System for SMEs Using a Combination of ANP and PROMETHEE Methods." Expert Systems with Applications 42 (5): 2343-52. https://doi.org/10.1016/j.eswa.2014.10.034. 
Kim, Jooho, and Makarand Hastak. 2018. "Social Network Analysis: Characteristics of Online Social Networks after a Disaster.” International Journal of Information Management 38 (1): 86-96. https://doi.org/10.1016/j.ijinfomgt.2017.08.003.

Kitchenham, Barbara A, Shari Lawrence Pfleeger, Lesley M Pickard, Peter W Jones, David C. Hoaglin, Khaled El Emam, and Jarrett Rosenberg. 2002. "Preliminary Guidelines for Empirical Research in Software Engineering." IEEE Transactions on Software Engineering 28 (8): 721-34.

Kitchin, Rob. 2014. "The Real-Time City? Big Data and Smart Urbanism." GeoJournal 79 (1):1-14. https://doi.org/10.1007/s10708-013-9516-8.

Klievink, Bram, Bart-Jan Romijn, Scott Cunningham, and Hans de Bruijn. 2017. "Big Data in the Public Sector: Uncertainties and Readiness." Information Systems Frontiers 19 (2):267-83. https://doi.org/10.1007/s10796-016-9686-2.

Kocaoglu, Dundar F. 1983. “A Participative Approach to Program Evaluation.” IEEE Transactions on Engineering Management, no. 3:112-18.

Kocaoglu, Dundar F., Tugrul U. Daim, Ibrahim Iskin, and Yasser Alizadeh. 2016. "Technology Assessment: Criteria for Evaluating a Sustainable Energy Portfolio." In Hierarchical Decision Modeling, edited by Tugrul U. Daim, 3-34. Cham: Springer International Publishing. https://doi.org/10.1007/978-3-319-18558-3_1.

Koch, Gary G. 1982. "Intraclass Correlation Coefficient." Encyclopedia of Statistical Sciences.

Koczkodaj, Waldemar W. 1993. "A New Definition of Consistency of Pairwise Comparisons." Mathematical and Computer Modelling 18 (7): 79-84.

Kosko, Bart. 1986. "Fuzzy Cognitive Maps." International Journal of Man-Machine Studies 24 (1): 65-75.

Kramers, Anna, Mattias Höjer, Nina Lövehagen, and Josefin Wangel. 2014. "Smart Sustainable Cities - Exploring ICT Solutions for Reduced Energy Use in Cities." Environmental Modelling \& Software 56 (June):52-62. https://doi.org/10.1016/j.envsoft.2013.12.019.

Kwon, Ohbyung, Namyeon Lee, and Bongsik Shin. 2014. "Data Quality Management, Data Usage Experience and Acquisition Intention of Big Data Analytics." International Journal of Information Management 34 (3):387-94. https://doi.org/10.1016/j.ijinfomgt.2014.02.002.

Kuhnert, Petra M., Tara G. Martin, and Shane P. Griffiths. 2010. “A Guide to Eliciting and Using Expert Knowledge in Bayesian Ecological Models: Expert Elicitation and Use in Bayesian Models.” Ecology Letters 13 (7): 900-914. https://doi.org/10.1111/j.1461-0248.2010.01477.x.

Kynn, Mary. 2007. “The 'Heuristics and Biases' Bias in Expert Elicitation.” Journal of the Royal Statistical Society: Series A (Statistics in Society) https://doi.org/10.1111/j.1467-985X.2007.00499.x.

Labrinidis, Alexandros, and Hosagrahar V Jagadish. 2012. "Challenges and Opportunities with Big Data." Proceedings of the VLDB Endowment 5 (12):203233. 
Lai, Vincent S, Bo K Wong, and Waiman Cheung. 2002. "Group Decision Making in a Multiple Criteria Environment: A Case Using the AHP in Software Selection." European Journal of Operational Research 137 (1): 134-44.

Lam, Son K., Stefan Sleep, Thorsten Hennig-Thurau, Shrihari Sridhar, and Alok R. Saboo. 2017. "Leveraging Frontline Employees' Small Data and Firm-Level Big Data in Frontline Management: An Absorptive Capacity Perspective." Journal of Service Research 20 (1):12-28. https://doi.org/10.1177/1094670516679271.

Laney, Doug. 2001. "3D Data Management: Controlling Data Volume, Velocity and Variety." META Group Research Note 6:70.

Langfeldt, Liv. 2002. Decision-Making in Expert Panels Evaluating Research: Constraints, Processes and Bias. NIFU.

Lauesen, Soren, and Otto Vinter. 2001. "Preventing Requirement Defects: An Experiment in Process Improvement." Requirements Engineering 6 (1): 37-50.

Laurila, J. K., Daniel Gatica-Perez, I. Aad, Blom J., Olivier Bornet, Trinh-Minh-Tri Do, O. Dousse, J. Eberle, and M. Miettinen. 2012. "The Mobile Data Challenge: Big Data for Mobile Computing Research." presented at the Pervasive Computing.

LaValle, Steve, Michael S Hopkins, Eric Lesser, Rebecca Shockley, and Nina Kruschwitz. 2010. "Analytics: The New Path to Value." MIT Sloan Management Review 52 (1):1-25.

LaValle, Steve, Eric Lesser, Rebecca Shockley, Michael S Hopkins, and Nina Kruschwitz. 2011. "Big Data, Analytics and the Path from Insights to Value." MIT Sloan Management Review 52 (2):21.

Lavoie, Joao Ricardo, and Tugrul U. Daim. 2018. “Technology Readiness Levels Enhancing R\&D Management and Technology Transfer Capabilities: Insights from a Public Utility in Northwest USA." International Journal of Transitions and Innovation Systems 6 (1): 48. https://doi.org/10.1504/IJTIS.2018.090776.

Layne, Karen, and Jungwoo Lee. 2001. "Developing Fully Functional E-Government: A Four Stage Model." Government Information Quarterly 18 (2): 122-36.

Legris, Paul, John Ingham, and Pierre Collerette. 2003. "Why Do People Use Information Technology? A Critical Review of the Technology Acceptance Model." Information \& Management 40 (3): 191-204.

Levine, Ben. 2018. "Air Quality Sensor Pilot Offers Lessons for Other IoT Installations." April 3, 2018. http://www.govtech.com/fs/infrastructure/Air-Quality-SensorPilot-Offers-Lessons-for-Other-IoT-Installations.html.

Lim, Chie-Hyeon, Min-Jun Kim, Jun-Yeon Heo, and Kwang-Jae Kim. 2015. "Design of Informatics-Based Services in Manufacturing Industries: Case Studies Using Large Vehicle-Related Databases." Journal of Intelligent Manufacturing, July. https://doi.org/10.1007/s10845-015-1123-8.

Lim, Chiehyeon, Kwang-Jae Kim, and Paul P. Maglio. 2018. "Smart Cities with Big Data: Reference Models, Challenges, and Considerations." Cities 82 (December): 86-99. https://doi.org/10.1016/j.cities.2018.04.011.

Lima Junior, Francisco Rodrigues, Lauro Osiro, and Luiz Cesar Ribeiro Carpinetti. 2014. "A Comparison Between Fuzzy AHP and Fuzzy TOPSIS Methods to Supplier 
Selection." Applied Soft Computing 21 (August): 194-209.

https://doi.org/10.1016/j.asoc.2014.03.014.

Lingga, Marwan. 2016. "Developing a Hierarchical Decision Model to Evaluate Nuclear

Power Plant Alternative Siting Technologies.” Dissertations and Theses, Portland

State University. https://doi.org/10.15760/etd.2938.

Linkov, Jon. 2015. "Collision-Avoidance Systems Are Changing the Look of Car

Safety." Consumer Reports. December 17, 2015.

https://www.consumerreports.org/car-safety/collision-avoidance-systems-arechanging-the-look-of-car-safety/.

Linstone, Harold A, and Murray Turoff. 1975. The Delphi Method. Addison-Wesley Reading, MA.

Lukasová, Alena. 1979. "Hierarchical Agglomerative Clustering Procedure.” Pattern Recognition 11 (5-6): 365-81.

Lyles, Marjorie A. 1990. "A Research Agenda For Strategic Management In The 1990s." Journal of Management Studies 27 (4): 363-75.

Maglio, Paul P., and Chie-Hyeon Lim. 2016. "Innovation and Big Data in Smart Service Systems." Journal of Innovation Management 4 (1):11-21.

Mahmoodzadeh, S, J Shahrabi, M Pariazar, and MS Zaeri. 2007. "Project Selection by Using Fuzzy AHP and TOPSIS Technique." World Academy of Science, Engineering and Technology 30: 333-38.

Mahoney, Michael J. 1977. "Publication Prejudices: An Experimental Study of Confirmatory Bias in the Peer Review System." Cognitive Therapy and Research 1 (2): 161-75. https://doi.org/10.1007/BF01173636.

Majumdar, Ankush, Tumpa Hazra, and Amit Dutta. 2017. "Landfill Site Selection by AHP Based Multi-Criteria Decision Making Tool: A Case Study in Kolkata, India." Journal of The Institution of Engineers (India): Series A 98 (3): 277-83.

Mankins, John C. 1995. “Technology Readiness Levels.” White Paper, April 6: 1995. Mankins, John C. 2009. "Technology Readiness Assessments: A Retrospective." Acta Astronautica 65 (9-10): 1216-23. https://doi.org/10.1016/j.actaastro.2009.03.058.

Manyika, James, Michael Chui, Brad Brown, Jacques Bughin, Richard Dobbs, Charles Roxburgh, and Angela Hung Byers. 2011. "Big Data: The next Frontier for Innovation, Competition, and Productivity | McKinsey \& Company.” May 2011. http://www.mckinsey.com/business-functions/digital-mckinsey/our-insights/bigdata-the-next-frontier-for-innovation.

Marangunić, Nikola, and Andrina Granić. 2015. “Technology Acceptance Model: A Literature Review from 1986 to 2013." The Information Society 14 (1): 81-95. https://doi.org/10.1007/s10209-014-0348-1.

Marr, Bernard. 2015. "Why Only One of the 5 Vs of Big Data Really Matters." IBM Big Data \& Analytics Hub. Available Online at www.Ibmbigdatahub. Com/Blog/Whyonly-One-5-vs-Big-Data-Really-Matters (Last Accessed February 29, 2016). 
Marr, Bernard. 2015b. "Where Big Data Projects Fail.” Forbes. March 17, 2015. http://www.forbes.com/sites/bernardmarr/2015/03/17/where-big-data-projectsfail/.

Martin, Tara G., Mark A. Burgman, Fiona Fidler, Petra M. Kuhnert, Samantha LowChoy, Marissa Mcbride, and Kerrie Mengersen. 2012. "Eliciting Expert Knowledge in Conservation Science: Elicitation of Expert Knowledge." Conservation Biology 26 (1): 29-38. https://doi.org/10.1111/j.15231739.2011.01806.x.

Martinez, Erwin V. 1994. "Avoiding Large-Scale Information Systems Project Failure.” Project Management Journal 25 (2): 17-25.

Martino, Joseph P. 2003. "A Review of Selected Recent Advances in Technological Forecasting." Technological Forecasting and Social Change 70 (8): 719-33.

Mathers, Nigel, Nick Fox, and Amanda Hunn. 2007. "Surveys and Questionnaires." Trent: RDSU.

Mathieu, Blaine. 2015. "How to Use Big Data Analytics as a Competitive Advantage." GoodData. December 16, 2015.

Maxwell, Kelly L, and Richard M Clifford. 2004. "School Readiness Assessment." Young Children 59 (1): 42-46.

Mayer-Schönberger, Viktor, and Kenneth Cukier. 2014. Big Data: A Revolution That Will Transform How We Live, Work, and Think. First Mariner Books edition. Boston: Mariner Books, Houghton Mifflin Harcourt.

McAfee, Andrew, Erik Brynjolfsson, and Thomas H Davenport. 2012. "Big Data: The Management Revolution." Harvard Business Review 90 (10):60-68.

McGuire, Tim, James Manyika, Michael Chui, James Manyika, and Michael Chui. 2012. "Why Big Data Is the New Competitive Advantage | Ivey Business Journal." August 2012. http://iveybusinessjournal.com/publication/why-big-data-is-thenew-competitive-advantage/.

Meijer, Albert, and M Bolivar. 2013. "Governing the Smart City: Scaling-up the Search for Socio-Techno Synergy."

Meredith, Jack R. 2017. Project Management: A Strategic Managerial Approach. Tenth Edition. Hoboken: Wiley.

Merriam-Webster. 2018a. "Definition of Inconsistent.” 2018. https://www.merriamwebster.com/dictionary/inconsistent.

Merriam-Webster. 2018b. "Definition of Disagreement." 2018. https://www.merriamwebster.com/dictionary/inconsistent.

Meyer, Mary A., and Jane M. Booker. 2001. Eliciting and Analyzing Expert Judgment: A Practical Guide. ASA-SIAM Series on Statistics and Applied Probability. Philadelphia, Pa: Society for Industrial and Applied Mathematics and American Statistical Association.

Moral-Munoz, Jose A., Manuel J. Cobo, Francisco Chiclana, Andrew Collop, and Enrique Herrera-Viedma. 2016. "Analyzing Highly Cited Papers in Intelligent Transportation Systems.” IEEE Transactions on Intelligent Transportation Systems 17 (4):993-1001. https://doi.org/10.1109/TITS.2015.2494533. 
Mohammadi, Kaveh, Amir Khanlari, and Babak Sohrabi. 2009. "Organizational Readiness Assessment for Knowledge Management:" International Journal of Knowledge Management 5 (1): 29-45. https://doi.org/10.4018/jkm.2009010103.

Mudavadi, Caroline, Liliya Hogaboam, and Tugrul U. Daim. 2016. "A Hierarchical Decision Model (HDM) for Exploring the Adoption of Electronic Health Records." In 2016 Portland International Conference on Management of Engineering and Technology (PICMET), pp. 2770-2781. IEEE, 2016. https://doi.org/10.1109/PICMET.2016.7806627.

Mumpower, Jeryl L, and Thomas R Stewart. 1996. "Expert judgment and Expert Disagreement." Thinking \& Reasoning 2 (2-3): 191-212.

Narayanan, Venkatachalam. 2014. "Using Big-Data Analytics to Manage Data Deluge and Unlock Real-Time Business Insights." The Journal of Equipment Lease Financing 32 (2): 1-6.

Nasser, T, and RS Tariq. 2015. "Big Data Challenges." Journal of Computer Engineering \& Information Technology 4 (3).

Neirotti, Paolo, Alberto De Marco, Anna Corinna Cagliano, Giulio Mangano, and Francesco Scorrano. 2014. "Current Trends in Smart City Initiatives: Some Stylised Facts." Cities 38 (June):25-36. https://doi.org/10.1016/j.cities.2013.12.010.

Nevo, Baruch. "Face validity revisited." Journal of Educational Measurement 22, no. 4 (1985): 287-293.

NewVantage Partners. 2019. "Big Data and AI Executive Survey 2019." NewVantage Partners LLC. https://newvantage.com/wp-content/uploads/2018/12/Big-DataExecutive-Survey-2019-Findings-Updated-010219-1.pdf.

NewVantage Partners. 2017. "Big Data Executive Survey 2017: Executive Summary." NewVantage Partners LLC. http://newvantage.com/wpcontent/uploads/2017/01/Big-Data-Executive-Survey-2017-ExecutiveSummary.pdf.

Niemeijer, Karsten. 2014. "The ABC's of Big Data." Foresight Investor (blog). September 18, 2014. http://foresightinvestor.com/articles/411823-the-abc-s-ofbig-data.

Northrop, Linda, Peter Feiler, Richard P Gabriel, John Goodenough, Rick Linger, Tom Longstaff, Rick Kazman, Mark Klein, Douglas Schmidt, and Kevin Sullivan. 2006. "Ultra-Large-Scale Systems: The Software Challenge of the Future." Carnegie-Mellon Univ Pittsburgh Pa Software Engineering Inst.

Norton, Melanie. 2000. Introductory Concepts in Information Science. Information Today, Inc.

Nunan, Daniel, and Marialaura Di Domenico. 2017. "Big Data: A Normal Accident Waiting to Happen?" Journal of Business Ethics 145 (3):481-91.

O’Halloran, Kay L., Sabine Tan, Duc-Son Pham, John Bateman, and Andrew Vande Moere. 2018. “A Digital Mixed Methods Research Design: Integrating Multimodal Analysis With Data Mining and Information Visualization for Big 
Data Analytics." Journal of Mixed Methods Research 12 (1):11-30. https://doi.org/10.1177/1558689816651015.

Okoli, Chitu, and Suzanne D Pawlowski. 2004. "The Delphi Method as a Research Tool: An Example, Design Considerations and Applications." Information \& Management 42 (1): 15-29.

Olama, Mohammed M., Allen W. McNair, Sreenivas R. Sukumar, and James J. Nutaro. 2014. "A Qualitative Readiness-Requirements Assessment Model for Enterprise Big-Data Infrastructure Investment.” Next-Generation Analyst II, vol. 9122, p. 91220E. International Society for Optics and Photonics, 2014. https://doi.org/10.1117/12.2050605.

Olsen, Richard Paul. 1971. “Can Project Management Be Defined?” Project Management Quarterly 2 (1).

Olson, David L. 2001. "Comparison of Three Multicriteria Methods to Predict Known Outcomes.” European Journal of Operational Research 130 (3): 576-87.

Opricovic, Serafim, and Gwo-Hshiung Tzeng. 2004. "Compromise Solution by MCDM Methods: A Comparative Analysis of VIKOR and TOPSIS.” European Journal of Operational Research 156 (2): 445-55.

Oracle. 2016. "Big Data | What Is Big Data? | Oracle.” 2016. https://www.oracle.com/big-data/index.html.

Oregon Employment Department. 2016. "Portland GDP Growth Ranks 10th Fastest Among 100 Largest Metros.” QualityInfo. October 18, 2016. https://www.qualityinfo.org/-/portland-gdp-growth-ranks-10th-fastest-among100-largestmetros?redirect=https $\% 3 \mathrm{~A} \% 2 \mathrm{~F} \% 2 \mathrm{Fwww}$.qualityinfo.org $\% 2 \mathrm{Fhome} \% 3 \mathrm{Fp} \_\mathrm{p} \_\mathrm{id} \%$ 3D3\%26p_p_lifecycle $\% 3 \mathrm{D} 0 \% 26 \mathrm{p} \_\mathrm{p} \_$state $\% 3 \mathrm{Dmaximized} \% 26 \mathrm{p} \_\mathrm{p} \_$mode $\% 3 \mathrm{Dvi}$ ew\%26_3_groupId\%3D0\%26_3_keywords\%3Dportland-metro-job-growthamong-the-fastest-in-the-us\%26_3_struts_action\%3D\%252Fsearch\%252Fsearch\%26_3_redirect\%3D\%252 F\&inheritRedirect $=$ true.

Otte, Evelien, and Ronald Rousseau. 2002. "Social Network Analysis: A Powerful Strategy, Also for the Information Sciences." Journal of Information Science 28 (6): 441-53. https://doi.org/10.1177/016555150202800601.

Oztaysi, Basar. 2014. “A Decision Model for Information Technology Selection Using AHP Integrated TOPSIS-Grey: The Case of Content Management Systems." Knowledge-Based Systems 70 (November): 44-54. https://doi.org/10.1016/j.knosys.2014.02.010.

Papadimitratos, P., A. La Fortelle, K. Evenssen, R. Brignolo, and S. Cosenza. 2009. "Vehicular Communication Systems: Enabling Technologies, Applications, and Future Outlook on Intelligent Transportation." IEEE Communications Magazine 47 (11):84-95. https://doi.org/10.1109/MCOM.2009.5307471.

Parasuraman, A. 2000. “Technology Readiness Index (Tri): A Multiple-Item Scale to Measure Readiness to Embrace New Technologies." Journal of Service Research 2 (4): 307-20. https://doi.org/10.1177/109467050024001. 
Parise, Salvatore, Bala Iyer, and Dan Vesset. 2012. "Four Strategies to Capture and Create Value from Big Data." Ivey Business Journal 76 (4):1-5.

PBOT. 2019 "Smart City Challenge: Ubiquitous Mobility for Portland | The City of Portland, Oregon.” 2019. https://www.portlandoregon.gov/transportation/69999.

PBOT. 2019b. "Traffic Safety Sensor Project | The City of Portland, Oregon." 2019. https://www.portlandoregon.gov/transportation/76735.

PBOT. 2018. "Connected Streetcar Project | PBOT Smart Cities Pilots | The City of Portland, Oregon.” 2018. https://www.portlandoregon.gov/transportation/article/691671.

PDX.edu. 2019. "Using Big Data to Improve Cities.” 2019. https://www.pdx.edu/profile/using-big-data-improve-cities.

Phan, Kenny. 2013. "Innovation Measurement: A Decision Framework to Determine Innovativeness of a Company." Dissertations and Theses, Portland State University. https://doi.org/10.15760/etd.1017.

Philip Chen, C.L., and Chun-Yang Zhang. 2014. "Data-Intensive Applications, Challenges, Techniques and Technologies: A Survey on Big Data." Information Sciences 275 (August):314-47. https://doi.org/10.1016/j.ins.2014.01.015.

Pianosi, Francesca, Keith Beven, Jim Freer, Jim W. Hall, Jonathan Rougier, David B. Stephenson, and Thorsten Wagener. 2016. "Sensitivity Analysis of Environmental Models: A Systematic Review with Practical Workflow." Environmental Modelling \& Software 79 (May): 214-32. https://doi.org/10.1016/j.envsoft.2016.02.008.

PMI. 2017. "What Is Project Management?” 2017. https:/www.pmi.org/about/learnabout-pmi/what-is-project-management.

Portlandiq.org. 2019. "Portland IQ Programs." Portland Innovation Quadrant. 2019. https://www.portlandiq.org/programs.

Prescott, Michael E. 2014. "Big Data and Competitive Advantage at Nielsen." Management Decision 52 (3):573-601. https://doi.org/10.1108/MD-09-20130437.

Puiu, Dan, Payam Barnaghi, Ralf Tonjes, Daniel Kumper, Muhammad Intizar Ali, Alessandra Mileo, Josiane Xavier Parreira, et al. 2016. “CityPulse: Large Scale Data Analytics Framework for Smart Cities.” IEEE Access 4:1086-1108. https://doi.org/10.1109/ACCESS.2016.2541999.

Puthanpura, Aurobindh Kalathil, Rafaa Khalifa, Leong Chan, and Husam Barham. 2018. "Technology Assessment: Emerging Automotive Technologies for the Future." In Infrastructure and Technology Management, edited by Tugrul U. Daim, Leong Chan, and Judith Estep, 367-85. Cham: Springer International Publishing. https://doi.org/10.1007/978-3-319-68987-6_12.

Rajaraman, V. 2016. "Big Data Analytics.” Resonance 21 (8):695-716. https://doi.org/10.1007/s12045-016-0376-7.

Ramos-Rodríguez, Antonio-Rafael, and José Ruíz-Navarro. 2004. "Changes in the Intellectual Structure of Strategic Management Research: A Bibliometric Study of 
the Strategic Management Journal, 1980-2000." Strategic Management Journal 25 (10): 981-1004. https://doi.org/10.1002/smj.397.

Ransbotham, Sam. 2016. "The Smart Way to Deal with Messy Data.” MIT Sloan Management Review, December 20, 2016. http://sloanreview.mit.edu/article/thesmart-way-to-deal-with-messy-data/.

Ransbotham, Sam, and David Kiron. 2017. "Analytics as a Source of Business Innovation." MIT Sloan Management Review. http://sloanreview.mit.edu/projects/analytics-as-a-source-of-business-innovation/.

Ransbotham, Sam, and David Kiron. 2018. "Using Analytics to Improve Customer Engagement.” MIT Sloan Management Review. January 30, 2018.

https://sloanreview.mit.edu/projects/using-analytics-to-improve-customerengagement/.

Razmi, Jafar, Mohamad Sadegh Sangari, and Reza Ghodsi. 2009. "Developing a Practical Framework for ERP Readiness Assessment Using Fuzzy Analytic Network Process." Advances in Engineering Software 40 (11): 1168-78. https://doi.org/10.1016/j.advengsoft.2009.05.002.

Reddy, Trips. 2014. "7 Big Data Blunders You're Thankful Your Company Didn't Make." Umbel. October 22, 2014. https://www.umbel.com/blog/big-data/7-bigdata-blunders/.

Rizvi, Mohammad Raza. 2017. "7 Challenges and Solutions in Managing Large Scale IT Projects." Project-Management.Com (blog). November 2, 2017. https://projectmanagement.com/7-challenges-and-solutions-in-managing-large-scale-itprojects/.

Roh, Seungkook. 2017. "Big Data Analysis of Public Acceptance of Nuclear Power in Korea." Nuclear Engineering and Technology 49 (4): 850-54

Rosacker, Kirsten M., and David L. Olson. 2008. "An Empirical Assessment of IT Project Selection and Evaluation Methods in State Government." Project Management Journal 39 (1):49-58. https://doi.org/10.1002/pmj.20036.

Rosculet, N., R. Samata, A. Dixit, S. Harris, N. S. MacCallum, D. A. Brearley, P. J. Watkinson et al. "P143 Using Big Data to Investigate Physiology: Retention of Co2 does not Impact the Oxygen-Haemoglobin Dissociation Curve of Critically Ill Adults." (2017): A160-A161.

Rooyen, G.-J. van, S. Zeadally, and M.J. Booysen. 2011. "Survey of Media Access Control Protocols for Vehicular Ad Hoc Networks." IET Communications 5 (11):1619-31. https://doi.org/10.1049/iet-com.2011.0085.

Runge, Michael C., Sarah J. Converse, and James E. Lyons. 2011. "Which Uncertainty? Using Expert Elicitation and Expected Value of Information to Design an Adaptive Program." Biological Conservation 144 (4): 1214-23. https://doi.org/10.1016/j.biocon.2010.12.020.

Russom, Philip. 2011. "Big Data Analytics.” TDWI Best Practices Report, Fourth Quarter 19:40. 
Sagiroglu, Seref, and Duygu Sinanc. "Big data: A review." In 2013 International Conference on Collaboration Technologies and Systems (CTS), pp. 42-47. IEEE, 2013.

Saito, Masashi. 2016. "Editor's Message to Special Issue of Intelligent Transportation Systems and Mobile Communication toward Smart Communities." Journal of Information Processing 24 (1):29-30. https://doi.org/10.2197/ipsjjip.24.29.

Saltz, Jeffrey S. "The Need for New Processes, Methodologies and Tools to Support Big Data Teams and Improve Big Data Project Effectiveness." In 2015 IEEE International Conference on Big Data (Big Data), pp. 2066-2071. IEEE, 2015.

Saltz, Jeffrey S., and Ivan Shamshurin. "Big Data Team Process Methodologies: A Literature Review and the Identification of Key Factors for a Project's Success." In 2016 IEEE International Conference on Big Data (Big Data), pp. 2872-2879. IEEE, 2016.

Saaty, Thomas L. 1977. "A Scaling Method for Priorities in Hierarchical Structures." Journal of Mathematical Psychology 15 (3): 234-81. https://doi.org/10.1016/0022-2496(77)90033-5.

Saaty, Thomas L. 2008. "Decision Making with the Analytic Hierarchy Process." International Journal of Services Sciences 1 (1): 83-98.

Saaty, Thomas L. 2013. "Analytic Network Process.” Encyclopedia of Operations Research and Management Science, 64-72.

Saltelli, A., S. Tarantola, and K. P.-S. Chan. 1999. "A Quantitative Model-Independent Method for Global Sensitivity Analysis of Model Output.” Technometrics 41 (1): 39-56. https://doi.org/10.1080/00401706.1999.10485594.

Schneider, Benjamin, Arthur P. Brief, and Richard A. Guzzo. 1996. "Creating a Climate and Culture for Sustainable Organizational Change." Organizational Dynamics 24 (4):7-19. https://doi.org/10.1016/S0090-2616(96)90010-8.

Schmidt, Frank L. 2012. "Cognitive Tests Used in Selection Can Have Content Validity as Well as Criterion Validity: A Broader Research Review and Implications for Practice: Content Validity of Cognitive Tests." International Journal of Selection and Assessment 20 (1): 1-13. https://doi.org/10.1111/j.1468-2389.2012.00573.x.

Schuurman, Dimitri, Bastiaan Baccarne, and Lieven De Marez. 2012. "Smart Ideas for Smart Cities: Investigating Crowdsourcing for Generating and Selecting Ideas for ICT Innovation in a City Context." Journal of Theoretical and Applied Electronic Commerce Research 7 (3):11-12. https://doi.org/10.4067/S071818762012000300006.

Schwalbe, Kathy. 2015. Information Technology Project Management. Eighth edition. Australia; Brazil: Cengage Learning.

Scott, John. 1988. "Social Network Analysis." Sociology 22 (1): 109-27.

Scott, John. 2017. Social Network Analysis. Sage.

Shapiro, Joel. 2018. "Help Your Team Understand What Data Is and Isn't Good For." Harvard Business Review, October 12, 2018. https://hbr.org/2018/10/help-yourteam-understand-what-data-is-and-isnt-good-for. 
Sheikh, Nasir, Tugrul Daim, and Dundar F. Kocaoglu. "Use of Multiple Perspectives and Decision Modeling for PV Technology Assessment." In 2011 Proceedings of PICMET'1 1: Technology Management in the Energy Smart World (PICMET), pp. 1-21. IEEE, 2011.

Sheikh, Nasir Jamil. 2013. "Assessment of Solar Photovoltaic Technologies Using Multiple Perspectives and Hierarchical Decision Modeling." Dissertations and Theses, Portland State University.

Shieh, Lon-Fon, Ching-Chiang Yeh, and Ming-Cheng Lai. 2015. "Critical Success Factors in Digital Publishing Technology Using an ANP Approach." Technological and Economic Development of Economy 22 (5): 670-84. https://doi.org/10.3846/20294913.2015.1073640.

Shrout, Patrick E, and Joseph L Fleiss. 1979. "Intraclass Correlations: Uses in Assessing Rater Reliability." Psychological Bulletin 86 (2): 420.

Short, James, and Steve Todd. 2017. "What's Your Data Worth?” MIT Sloan Management Review 58 (3):17.

Shukla, Sandarbh, P.K. Mishra, Rajeev Jain, and H.C. Yadav. 2016. "An Integrated Decision Making Approach for ERP System Selection Using SWARA and PROMETHEE Method." International Journal of Intelligent Enterprise 3 (2): 120. https://doi.org/10.1504/IJIE.2016.076041.

Sill, S, B Christie, A Diephaus, D Garretson, K Sullivan, and S Sloan. 2011. "Intelligent Transportation Systems (ITS) Standards Program Strategic Plan for 2011-2014.” US. Department of Transportation (USDOT), Final Report. FHWA-JPO-11-052.

Siraj, Ambareen, Susan M Bridges, and Rayford B Vaughn. 2001. "Fuzzy Cognitive Maps for Decision Support in an Intelligent Intrusion Detection System." 4:216570.

Sireci, Stephen G. 1998. "The Construct of Content Validity." Social Indicators Research 45 (1/3): 83-117. https://doi.org/10.1023/A:1006985528729.

Sivarajah, Uthayasankar, Muhammad Mustafa Kamal, Zahir Irani, and Vishanth Weerakkody. 2017. "Critical Analysis of Big Data Challenges and Analytical Methods." Journal of Business Research 70 (January):263-86. https://doi.org/10.1016/j.jbusres.2016.08.001.

Smart City PDX. 2019a. "Smart City PDX: Guiding Principles and Priorities Framework" Smart City PDX. 2019. https://www.smartcitypdx.com/guidingprinciples.

Smart City PDX. 2019b. "Current Projects.” Smart City PDX. 2019. https://www.smartcitypdx.com/projects.

Smart City PDX. 2019c. "Traffic Safety Sensor Project.” Smart City PDX. 2019. https://www.smartcitypdx.com/traffic-safety-sensor-project.

Smart City PDX. 2019d. “Air Quality Sensor Testing \& Deployment." Smart City PDX. 2019. https://www.smartcitypdx.com/air-quality-sensor.

Smith, Richard. 2006. "Peer Review: A Flawed Process at the Heart of Science and Journals." Journal of the Royal Society of Medicine 99 (4): 178-82. 
Snyder-Halpern, R. 2001. "Indicators of Organizational Readiness for Clinical Information Technology/Systems Innovation: A Delphi Study.” International Journal of Medical Informatics 63 (3): 179-204.

Stach, Wojciech, Lukasz Kurgan, and Witold Pedrycz. 2010. "Expert-Based and Computational Methods for Developing Fuzzy Cognitive Maps.” In Fuzzy Cognitive Maps, 23-41. Springer.

Steckler, Allan, and Kenneth R. McLeroy. "The importance of external validity." (2008): 9-10.

Stoemmer, Peter. 2006. "How to Find the Right Projects." In The 20th IPMA World Congress on Project Management.

Strawn, George. 2016. "Data Scientist." IT Professional 18 (3):55-57. https://doi.org/10.1109/MITP.2016.41.

Stubbs, Evan. 2014. Big Data, Big Innovation: Enabling Competitive Differentiation through Business Analytics. Wiley \& SAS Business Series. Hoboken, NJ: Wiley.

Subramanyam, Krishnappa. 1983. "Bibliometric Studies of Research Collaboration: A Review." Information Scientist 6 (1): 33-38.

Sumner, Mary. 1999. "Critical Success Factors in Enterprise Wide Information Management Systems Projects.” In AMCIS 1999 Proceedings, 297-303. Acm.

Suthaharan, Shan. 2016. "Big Data Analytics." In Machine Learning Models and Algorithms for Big Data Classification, by Shan Suthaharan, 36:31-75. Boston, MA: Springer US. https://doi.org/10.1007/978-1-4899-7641-3_3.

Swanson, Ian. 2017. "Study: Data Science Platforms Help Insight Leaders Outperform Competition." January 17, 2017. https://www.linkedin.com/pulse/study-datascience-platforms-help-insight-leaders-ian-swanson.

Sweet, Stephen A., and Karen Grace-Martin. 2012. Data Analysis with SPSS: A First Course in Applied Statistics. 4th ed. Boston: Allyn \& Bacon.

Tallon, Paul P. 2013. "Corporate Governance of Big Data: Perspectives on Value, Risk, and Cost." Computer 46 (6):32-38. https://doi.org/10.1109/MC.2013.155.

Tan, Kim Hua, YuanZhu Zhan, Guojun Ji, Fei Ye, and Chingter Chang. 2015. "Harvesting Big Data to Enhance Supply Chain Innovation Capabilities: An Analytic Infrastructure Based on Deduction Graph.” International Journal of Production Economics 165 (July):223-33. https://doi.org/10.1016/j.ijpe.2014.12.034.

Thabet, Nasser, and Tariq Rahim Soomro. 2015. "Big Data Challenges." Journal of Computer Engineering \& Information Technology 4 (3). https://www.researchgate.net/publication/282281171_Big_Data_Challenges.

Thiry, Michel. 2002. "Combining Value and Project Management into an Effective Programme Management Model.” International Journal of Project Management 20 (3):221-27. https://doi.org/10.1016/S0263-7863(01)00072-2.

Thomopoulos, Nikolas, and Moshe Givoni. 2015. "The Autonomous Car-a Blessing or a Curse for the Future of Low Carbon Mobility? An Exploration of Likely vs. Desirable Outcomes." European Journal of Futures Research 3 (1). https://doi.org/10.1007/s40309-015-0071-z. 
Thornton, John, John MacArthur, and Husam Barham. 2018. "Electrification of Transport Refrigeration Units for Temperature-Sensitive Freight: US Environmental Protection Agency Region 10 Technical Assistance Case Study.” Transportation Research Record 2672 (24): 122-33.

Titler, Marita G., and Debra Matsen Pettit. 1995. "Discharge Readiness Assessment." The Journal of Cardiovascular Nursing 9 (4): 64-74. https://doi.org/10.1097/00005082-199507000-00007.

Tole, Alexandru Adrian. 2013. "Big Data Challenges.” Database Systems Journal 4 (3):31-40.

Toulminet, Gwenaelle, Jacques Boussuge, and Claude Laurgeau. 2008. "Comparative Synthesis of the 3 Main European Projects Dealing with Cooperative Systems (CVIS, SAFESPOT and COOPERS) and Description of Coopers Demonstration Site 4." In 2008 11th International IEEE Conference on Intelligent Transportation Systems, pp. 809-814. IEEE, 2008. https://doi.org/10.1109/ITSC.2008.4732652.

Tran, Thien A., and Tugrul Daim. 2008. "A Taxonomic Review of Methods and Tools Applied in Technology Assessment." Technological Forecasting and Social Change 75 (9): 1396-1405. https://doi.org/10.1016/j.techfore.2008.04.004.

Tranos, Emmanouil, and Drew Gertner. 2012. "Smart Networked Cities?" Innovation: The European Journal of Social Science Research 25 (2):175-90. https://doi.org/10.1080/13511610.2012.660327.

TREC. 2018. "Smart City PDX Pilot: NITC Researchers Take Connected Vehicle Technology for a Test Run on Portland Streetcar | Transportation Research and Education Center.” August 23, 2018. https://trec.pdx.edu/news/smart-city-pdxpilot-nitc-researchers-take-connected-vehicle-technology-test-run-portland.

Triantaphyllou, Evangelos. 2000. "Multi-Criteria Decision Making Methods." In MultiCriteria Decision Making Methods: A Comparative Study, 5-21. Springer.

Tsai, Chun-Wei, Chin-Feng Lai, Han-Chieh Chao, and Athanasios V. Vasilakos. 2016. "Big Data Analytics." In Big Data Technologies and Applications, by Borko Furht and Flavio Villanustre, 13-52. Cham: Springer International Publishing. https://doi.org/10.1007/978-3-319-44550-2_2.

Turányi, Tamás. 1990. "Sensitivity Analysis of Complex Kinetic Systems. Tools and Applications." Journal of Mathematical Chemistry 5 (3): 203-48.

US Census Bureau. 2017. "US Census Bureau Offical Web Site.” 2017. https://www.census.gov/en.html.

US Government Accountability Office. 2015. "Intelligent Transportation Systems: Vehicle-to-Infrastructure Technologies Expected to Offer Benefits, but Deployment Challenges Exist." September 2015. http://www.gao.gov/assets/680/672548.pdf.

Van Blommestein, Kevin C, and Tugrul U Daim. 2013. "Residential Energy Efficient Device Adoption in South Africa." Sustainable Energy Technologies and Assessments 1: 13-27. 
Van Dijck, Jose. 2014. "Datafication, Dataism and Dataveillance: Big Data Between Scientific Paradigm and Ideology." Surveillance \& Society 12 (2): 197-208.

Van Raan, Anthony FJ. 2003. "The Use of Bibliometric Analysis in Research Performance Assessment and Monitoring of Interdisciplinary Scientific

Developments." Technology Assessment-Theory and Practice 1 (12): 20-29.

Van Staa, Tjeerd-Pieter, Ben Goldacre, Iain Buchan, and Liam Smeeth. 2016. "Big Health Data: The Need to Earn Public Trust." BMJ, July, i3636.

Vann, James L. 2004. "Resistance to Change and the Language of Public Organizations: A Look at 'Clashing Grammars' in Large-Scale Information Technology Projects." Public Organization Review 4 (1): 47-73. https://doi.org/10.1023/B:PORJ.0000015651.06417.e1.

Walker, James. 2017. "Big Data Strategies Disappoint with 85 Percent Failure Rate." November 23, 2017. http://www.digitaljournal.com/tech-andscience/technology/big-data-strategies-disappoint-with-85-percent-failurerate/article/508325.

Walker, Saint John. 2014. "Big Data: A Revolution That Will Transform How We Live, Work, and Think." International Journal of Advertising 33 (1):181-83. https://doi.org/10.2501/IJA-33-1-181-183.

Wang, Bing, Dundar F Kocaoglu, Tugrul U Daim, and Jiting Yang. 2010. “A Decision Model for Energy Resource Selection in China." Energy Policy 38 (11): 7130-41.

Wang, Junbo, Yilang Wu, Hui-Huang Hsu, and Zixue Cheng. 2017. "Spatial Big Data Analytics for Cellular Communication Systems." In Big Data Analytics for Sensor-Network Collected Intelligence, 153-66. Elsevier. https://doi.org/10.1016/B978-0-12-809393-1.00007-6.

Wease, Greg, Kwasi Boateng, Chih-Jen Yu, Leong Chan, and Husam Barham. 2018. "Technology Assessment: Cloud Service Adoption Decision." In Infrastructure and Technology Management, edited by Tugrul U. Daim, Leong Chan, and Judith Estep, 447-71. Cham: Springer International Publishing. https://doi.org/10.1007/978-3-319-68987-6_16.

Weiland, R. J., and L. B. Purser. 2000. "Intelligent Transportation Systems." Transportation in the New Millennium. https://trid.trb.org/view.aspx?id=639268.

Weinstein, Bruce D. 1993. "What Is an Expert?" Theoretical Medicine 14 (1): 57-73. https://doi.org/10.1007/BF00993988.

Wetherell, Charles, Andrejs Plakans, and Barry Wellman. 1994. "Social Networks, Kinship, and Community in Eastern Europe." The Journal of Interdisciplinary History 24 (4): 639-63.

Willcocks, Leslie, and Catherine Griffiths. 1994. "Predicting Risk of Failure in LargeScale Information Technology Projects.” Technological Forecasting and Social Change 47 (2): 205-28. https://doi.org/10.1016/0040-1625(94)90029-9.

Winter, Richard, Rick Gilbert, and Judith Davis. 2013. "Special Report. Big Data. What Does It Really Cost?” Cambridge MA: Winter Corporation.

Yin, Robert K. 2009. Case Study Research: Design and Methods. 4th ed. Applied Social Research Methods, v. 5. Los Angeles, Calif: Sage Publications. 
Young, Raymond, and Ernest Jordan. 2008. "Top Management Support: Mantra or Necessity?" International Journal of Project Management 26 (7):713-25. https://doi.org/10.1016/j.ijproman.2008.06.001.

Youngmin Jeong, Jo Woon Chong, Hyundong Shin, and M. Z. Win. 2013. "Intervehicle Communication: Cox-Fox Modeling." IEEE Journal on Selected Areas in Communications 31 (9):418-33. https://doi.org/10.1109/JSAC.2013.SUP.0513038.

$\mathrm{Yu}, \mathrm{F}$. Richard. 2016. "Connected Vehicles for Intelligent Transportation Systems [Guest Editorial]." IEEE Transactions on Vehicular Technology 65 (6):3843-44. https://doi.org/10.1109/TVT.2016.2565738.

Zheng, Zibin, Jieming Zhu, and Michael R. Lyu. 2013. "Service-Generated Big Data and Big Data-as-a-Service: An Overview.” In 2013 IEEE international congress on Big Data, pp. 403-410. IEEE, 2013. https://doi.org/10.1109/BigData.Congress.2013.60.

Zikopoulos, Paul, and Chris Eaton. 2012. Understanding Big Data: Analytics for Enterprise Class Hadoop and Streaming Data. New York: McGraw-Hill. 


\section{APPENDIX A: Letters of Invitation to Experts}

Recruiting Letter:

Title: Invitation to Participate in my Ph.D. Research as a Subject Matter Expert Hi [First Name],

How are you?

I'm a Ph.D. student at Portland State University (the Engineering and Technology Management department) etm.pdx.edu.

I'm researching the project management challenges facing big data projects under smartcity initiatives.

As part of my research, I'm developing a model that can be used by cities to assess readiness to conduct a big data project, and I need subject-matter experts to validate and quantify my research model.

As an expert, your anonymous input is valuable for my research. I would be grateful if you can help me by participating in my research.

\section{Participation:}

Here is what is needed, should you accept to participate:

First round:

Survey - 10 minutes: Validating the most important factors affecting big data projects (under smart city initiatives).

Second round:

Survey - 10 minutes: Ranking the factors.

I appreciate your help and time.

Attached to this email you will find a summary of my research.

Also, please let me know if you are interested in the outcome of the research, I'll be glad to share research results with you upon the conclusion of my research.

\section{Consent}

Your participation in this study indicates that you have read the information provided on this link:

https://drive.google.com/file/d/14QffT1phv2H3U2fbZ7NNaltDBPMTuCPK/view?usp=s haring 
The consent form indicates that you are not waiving any of your legal rights as a research participant, your personal information will be confidential and will not be shared with any third party, and you can withdraw from participating at any time.

Thanks,

Husam Barham, PMP

Ph.D. Candidate

Engineering and Technology Management Department

Portland State University (pdx.edu)

$+1-971-280-9088$

https://www.researchgate.net/profile/Husam_Barham

https://www.linkedin.com/in/husam-barham-pmp-mib-847a1188 
Invitation to Validate the Model Letter:

Title: [Research Survey]: Validating the Model Survey

Hi [First Name],

Thanks for accepting my invitation to to participate in my research.

The first step is to evaluate the challenges affecting a successful big data project as part of a smart city initiative.

Attached to this email you will find a summary about my research, please go through it then do the survey on the below link:

Survey link:

https://portlandstate.qualtrics.com/jfe/form/SV_0cj9rJjlVkS8jBj

Deadline: I'll appreciate it if you can do the survey by December-20.

If you have any questions please don't hesitate to contact me.

\section{Consent:}

Your participation in this study indicates that you have read the information provided (or the information was read to you) on this link:

https://drive.google.com/file/d/14QffT1phv2H3U2fbZ7NNaltDBPMTuCPK/view?usp=s haring

The consent form indicates that you are not waiving any of your legal rights as a research participant, your personal information will be confidential and will not be shared with any third party, and you can withdraw from participating at any time.

Thanks,

Husam Barham, PMP

Ph.D. Candidate

Engineering and Technology Management Department

Portland State University

+1 (971) 280-9088

https://www.linkedin.com/in/husam-barham-pmp-mib-847a1188 
Invitation to Quantify the Model Letter:

Title: [Research Survey]: Step 2: Ranking the Factors Survey

Hi [First Name],

After a couple of rounds of data collection, the list of the most important factors when assessing a city's readiness to implement a big data project is finalized. Each factor was approved by at least $75 \%$ of the experts who participated in the validation survey.

I now ask you to rank the factors.

Please use the following link for the survey (It will take approximately 15 to 20 minutes to complete, thanks for your patience) :

\section{https://portlandstate.qualtrics.com/jfe/form/SV 6WfyOFahYG4ZXWR?sc p a=1}

\section{Notes:}

- You can do the survey in several sessions, just make sure to call the link from the same browser window when you come back.

- If you lost the session, please notify me, I can send you a special link that will allow you to continue from where you stopped

Deadline: I'll appreciate it if you can do the survey by January-15.

More details about my research on this link:

https://drive.google.com/file/d/1TSrnsY-s2V1C4mduVW2DJRj7ndWquG1W/view

Note: Starting on page 11, you can find details about next steps and how the model I'm building as part of my research will be used.

If you have questions at any time about the study or the procedures, you may contact me via email (hbarham@pdx.edu) or phone+1 (971) 280-9088.

I appreciate your help and time.

\section{Consent:}

Your participation in this study indicates that you have read the information provided (or the information was read to you) on this link:

https://drive.google.com/file/d/14QffT1phv2H3U2fbZ7NNaltDBPMTuCPK/view?usp=s haring

The consent form indicates that you are not waiving any of your legal rights as a research participant, your personal information will be confidential and will not be shared with any third party, and you can withdraw from participating at any time. 
Husam Barham, PMP

Ph.D. Candidate

Engineering and Technology Management Department

Portland State University etm.pdx.edu

+1 (971) 280-9088

https://www.linkedin.com/in/husam-barham-pmp-mib-847a1188

https://www.researchgate.net/profile/Husam_Barham 


\section{APPENDIX B: Qualtrics Surveys to Evaluate and Quantify the Model Qualtrics Validation Survey:}

Start of Block: Welcome message block

\section{P1 Husam Barham's Research Model Evaluation A Hierarchical Decision Model} to Evaluate Readiness to Execute a Smart City's Big Data Project My research goal is to develop a model that can be used by cities to improve chances of implementing a successful smart-city-related big data projects by:

- Assess their readiness to implement a big data project

- Pinpoint areas where improvements need to be done before initiating such a project.

P2

Thanks for participating as an expert in my research.

The first step is to evaluate the factors affecting a successful big data project as part of a smart city initiative.

Research focus: a big data project is already selected by a city under the umbrella of a smart-city initiative. Also, the fund is available.

Before starting the project, the city is to use the model I'm proposing to assess if they are ready to do the project, by comparing the city's current status against a set of critical factors that are known to affect this kind of projects.

Survey Objective: The objective of this survey is to validate the preliminary list of factors that were identified based on a comprehensive literature review. The following questions are intended to capture your judgment of the suitability of those factors and to identify those that might have gone undetected during my literature review. Your input will be used to help finalize my model.

Experts Validation: In the next pages, you will be asked, to evaluate the factors identified by the research as the most critical reasons for big data projects to fail/succeed (with focus on smart-city-related projects). You will also be able to suggest other factors based on your experience.

More details about my research on this link:

https://rive.google.com/file/d/1TSrnsY-s2V1C4mduVW2DJRj7ndWquG1W/view

Note: Starting on page 11, you can find details about next steps and how the model I'm building as part of my research will be used. 
Please click on the next button (-->) on the right bottom of the screen

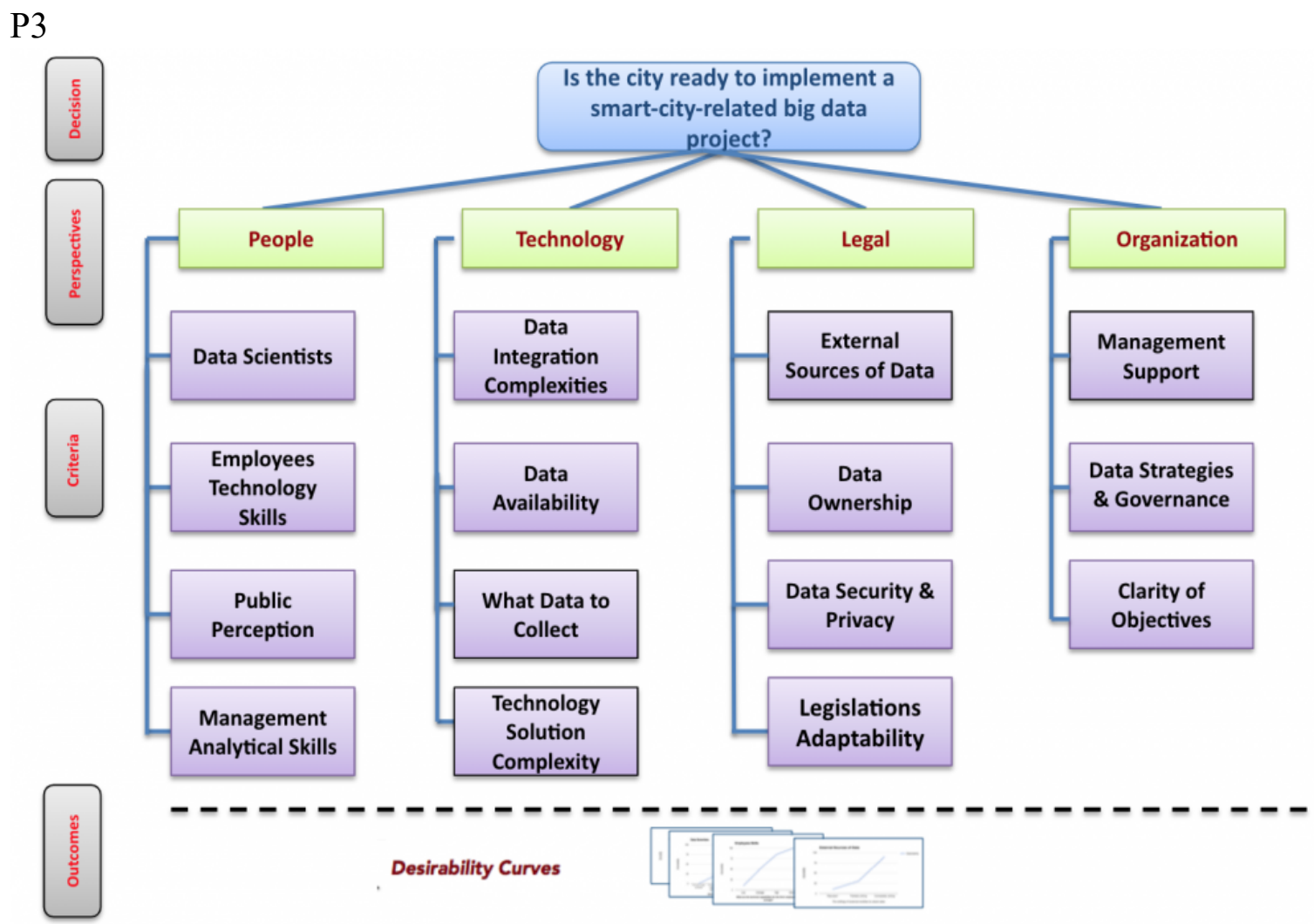

End of Block: Welcome message block

Start of Block: Questions

P4_1 Husam Barham Ph.D. research - Model Evaluation

P4 Please enter you name:

\section{Q_FirstName First Name}




\section{Q_LastName Last Name}

P6

\section{People Perspective}

Factors related to people, including skills and perception

\begin{tabular}{|l|l|}
\hline Factors & Details \\
\hline Data Scientists & $\begin{array}{l}\text { Data scientists are the minds that can realize what type, size, and frequency of data need to be captured; } \\
\text { they device the predictive analysis algorithms that maximize data value, with realization of organizational } \\
\text { goals, as well as, internal and external factors around the firm. } \\
\text { This factor considers city's data scientists and their level of experience in relation to the upcoming project. }\end{array}$ \\
\hline $\begin{array}{l}\text { Employees' } \\
\text { Technological Skills }\end{array}$ & $\begin{array}{l}\text { This factor considers employees information technology skills and their ability to operate complex software } \\
\text { systems. }\end{array}$ \\
\hline $\begin{array}{l}\text { Public Perspective } \\
\text { This factor considers whether the public will perceive the upcoming project as a "good" project or not. And } \\
\text { would the project be negatively or positively impacted by the potential public perception. }\end{array}$ \\
\hline Management's & $\begin{array}{l}\text { This factor considers management analytical skills and their ability to leverage big data analytics to support } \\
\text { decision making. }\end{array}$ \\
\hline Analytical Skills &
\end{tabular}

Q1_C Please indicate if the following are important factors to the success of big data projects (from the people perspective group):

Note: Please refer to the above table and the email attachments for details about the research and challenges

Data Scientists (1)
Yes (1)
No (2)

Employees' Technological

Skills (2)

Public Perception (3)

Management's Analytical

Skills (4) 
Q2_C If you think there are other factors related to people perspective, or if you have comments on the listed factors, please provide it here:

End of Block: Questions 
Start of Block: Block 2

P7_1 Husam Barham Ph.D. research - Model Evaluation

P7

\section{Technology Perspective}

Technical factors that are unique to big data projects due to the nature of big data itself, and its characteristics (volume, velocity, variety, value, and so on.)

\begin{tabular}{|l|l|}
\hline Factors & Details \\
\hline $\begin{array}{l}\text { Data Integration } \\
\text { Complexities }\end{array}$ & $\begin{array}{l}\text { One factor for big data to offer real value, is its ability to ingest, aggregate and analyze data from various } \\
\text { sources. } \\
\text { This factor considers the challenges in integrating the data from the various data sources that will be used } \\
\text { in the upcoming project. }\end{array}$ \\
\hline Data Availability & $\begin{array}{l}\text { This factor considers whether the data coming from various sources can be accessed in timely manner to } \\
\text { make meaningful results. From technical perspective, the data volume and velocity, for each source of data } \\
\text { can affect its accessibility. }\end{array}$ \\
\hline What Data to Collect & $\begin{array}{l}\text { This factor considers whether the kind of data that should be collected is clear or not. Without this clarity, } \\
\text { either more data (than needed) could be captured, which means resources waste, or less data (than } \\
\text { needed) will be captured, resulting in value loss. }\end{array}$ \\
\hline $\begin{array}{l}\text { Technology Solutions } \\
\text { Complexities }\end{array}$ & $\begin{array}{l}\text { In big data projects, several software tools are used together to achieve the project goals. } \\
\text { This factor considers how complex is the mix of tools to be used in the project. }\end{array}$ \\
\hline
\end{tabular}

Q3_C Please indicate if the following are important factors to the success of big data projects (from the technology perspective group):

Note: Please refer to the above table and the email attachments for details about the research and challenges
Data Integration Complexities
Yes (1)
No (2)
(1)

Data Availability (2)

What Data to Collect (3)

Technology Solutions

Complexities (4)

Q4_C If you think there are other factors related to technology perspective, or if you have comments on the listed factors, please provide it here: 
End of Block: Block 2 
Start of Block: Block 3

P8_1 Husam Barham Ph.D. research - Model Evaluation

P8

\section{Legal Perspective}

External environment factors, mainly due to data being owned and managed by external entities, as well as, affecting external entities

\begin{tabular}{|l|l|}
\hline Factors & Details \\
\hline $\begin{array}{l}\text { External Sources of } \\
\text { Data }\end{array}$ & $\begin{array}{l}\text { This factor considers accessibility to external sources of data needed for the project. Such data is available } \\
\text { at clients, suppliers, and other stakeholders ends. } \\
\text { Are they willing to share it or not? }\end{array}$ \\
\hline Data Ownership & $\begin{array}{l}\text { This factor considers how much freedom the city has in disseminating analytics generated by the big data } \\
\text { system based on data coming from external sources. }\end{array}$ \\
\hline $\begin{array}{l}\text { Data security and } \\
\text { privacy }\end{array}$ & $\begin{array}{l}\text { This factor considers the level of security and privacy the system must have, versus the value it can } \\
\text { generate. }\end{array}$ \\
\hline $\begin{array}{l}\text { Legislations } \\
\text { Adaptability }\end{array}$ & $\begin{array}{l}\text { This factor considers the city's ability to introduce new legislations in timely manner to keep up with the } \\
\text { upcoming project. }\end{array}$ \\
\hline
\end{tabular}

Q5_C Please indicate if the following are important factors to the success of big data projects (from the legal perspective group):

Note: Please refer to the above table and the email attachments for details about the research and challenges
External Sources of Data (1)
Yes (1)
No (2)

Data Ownership (2)

Data security and privacy (3)

Legislations Adaptability (4) 
Q6_C If you think there are other factors related to legal perspective, or if you have comments on the listed factors, please provide it here:

End of Block: Block 3 
Start of Block: Block 4

P9_1 Husam Barham Ph.D. research - Model Evaluation

P9

\section{Organization Perspective}

What need to be considered by management to enable successful and sustainable big data adoption within the organization and to overcome barriers to this adoption.

\begin{tabular}{|l|l|}
\hline Factors & Details \\
\hline Management Support & $\begin{array}{l}\text { Leadership support for any project plays significant role in whether the project will be successful. This is } \\
\text { even more true in the case of big data projects that requires a lot of changes within the organization. } \\
\text { This factor considers management level of support to the upcoming big data project. }\end{array}$ \\
\hline $\begin{array}{l}\text { Data Strategies and } \\
\text { Governance }\end{array}$ & $\begin{array}{l}\text { This factor considers the maturity of strategies and governance regarding how to handle data within the } \\
\text { organization. }\end{array}$ \\
\hline Clarity of Objectives & $\begin{array}{l}\text { This factor considers the clarity of the project objectives and how it is related to organizational mission and } \\
\text { vision and how the project outcome is facilitating the achievement of organizational strategic goals. }\end{array}$ \\
\hline
\end{tabular}

Q7_C Please indicate if the following are important factors to the success of big data projects (from the organizational perspective group):

Note: Please refer to the above table and the email attachments for details about the research and challenges

Management Support (1)

Data Strategies and

Governance (2)

Clarity of Objectives (3)

$$
\text { Yes (1) No (2) }
$$

Q8_C If you think there are other factors related to organizational perspective, or if you have comments on the listed challenges, please provide it here: 
End of Block: Block 4

Start of Block: Block 5

P10_1 Husam Barham Ph.D. research - Model Evaluation

P10

Second step is to evaluate the perspectives (classifications) of the factors affecting big data projects as part of a smart city initiative.

Please evaluate the perspectives considering the factors under each perspective you just evaluated.

Note: There is no financial perspective on purpose: the model assumes that there is already enough fund for the project; as usually cities don't select projects before confirming the funding first. The goal of my research is to assess and enhance the chances of success of big data projects that already have funded and are already selected.

P10
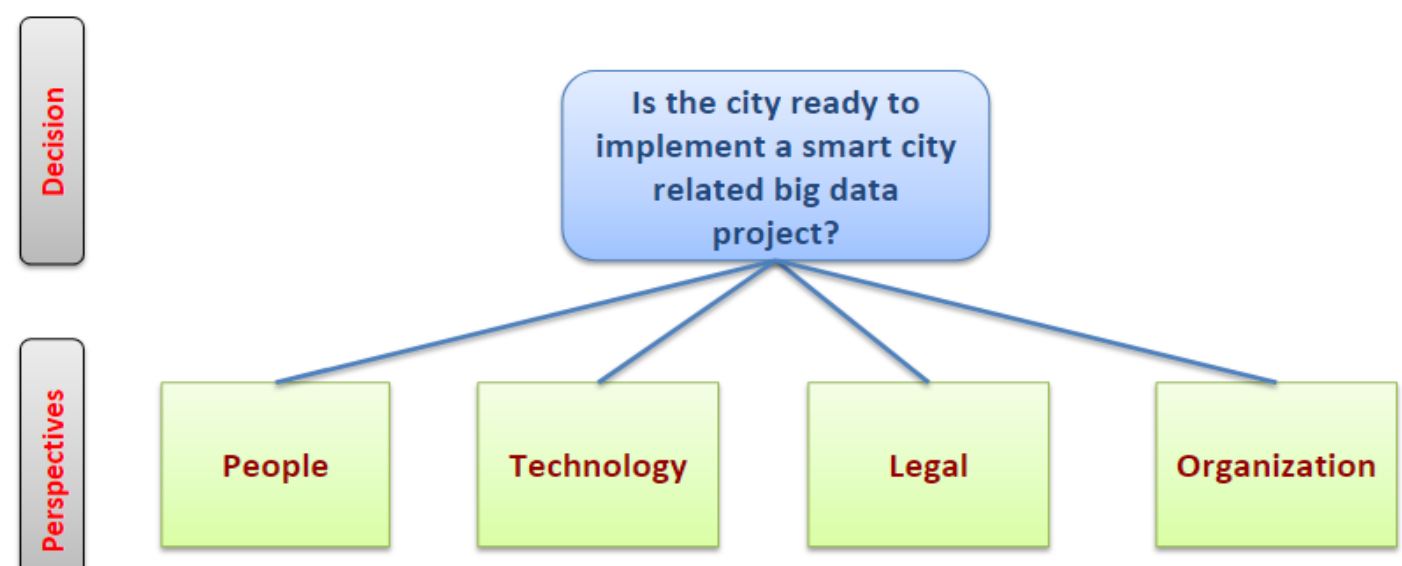


\section{P11}

\section{Perspectives}

\begin{tabular}{|l|l|}
\hline Perspective & Details \\
\hline People Perspective & Factors related to people, including skills and perception \\
\hline Technology Perspective & $\begin{array}{l}\text { Technical factors that are unique to big data projects due to the nature of } \\
\text { big data itself, and its characteristics (volume, velocity, variety, value, and so } \\
\text { on.) }\end{array}$ \\
\hline Legal Perspective & $\begin{array}{l}\text { External environment factors, mainly due to data being owned and managed } \\
\text { by different external entities, as well as, affecting external entities }\end{array}$ \\
\hline Organization Perspective & $\begin{array}{l}\text { What need to be considered by management to enable successful and } \\
\text { sustainable big data adoption within the organization and to overcome } \\
\text { barriers to this adoption. }\end{array}$ \\
\hline
\end{tabular}

\section{Q1_P Please indicate if the following perspectives are proper perspectives to classify} big data project's success factors under

Note: Please refer to the above table and the email attachments for details about the research and perspectives

People (1)
Yes (1)
No (2)

Technology (2)

Legal (3)

Organization (4)

Q2_P If you think that there are other perspectives or you have comments on the listed perspectives, please provide it here. 
End of Block: Block 5

Start of Block: Block 6

P12

Submission Confirmation

By clicking on the " -->" button, your answers will be submitted.

Thanks.

End of Block: Block 6 


\section{Qualtrics Quantification Survey:}

Start of Block: Welcome message block

P1 Husam Barham's Ph.D. Research Model Ranking A Hierarchical Decision Model to Evaluate Readiness to Execute a Smart City's Big Data Project

$\mathrm{P} 2$

Thanks for participating in my research.

\section{Survey Objective:}

The objective of this survey is to rank the factors that should be considered when assessing a city's readiness to implement a particular big data project.

The survey is designed to capture your assessment of the relative importance of each factor in comparison with the other factors, in order to rank and identify their relative weights.

Research goal: is to develop a model that can be used by cities to improve chances of implementing successful smart-city-related big data projects by helping cities:

- Assess their readiness to implement a big data project

- Pinpoint areas where improvements need to be done before initiating such a project.

Research focus: a big data project is already selected by a city under the umbrella of a smart-city initiative. Also, the fund is available. Before starting the project, the city is to use the model I am proposing to assess if they are ready to do the project, by comparing the city's current status against a set of critical factors that are known to affect this kind of project.

Methodology: my research is based on the Hierarchical Decision-Making methodology (a variation of the more known AHP methodology).

P4 Please enter you name:

\section{Q FirstName First Name}




\section{Q LastName Last Name}

Q67

Please click on the next button (-->) on the right bottom of the screen

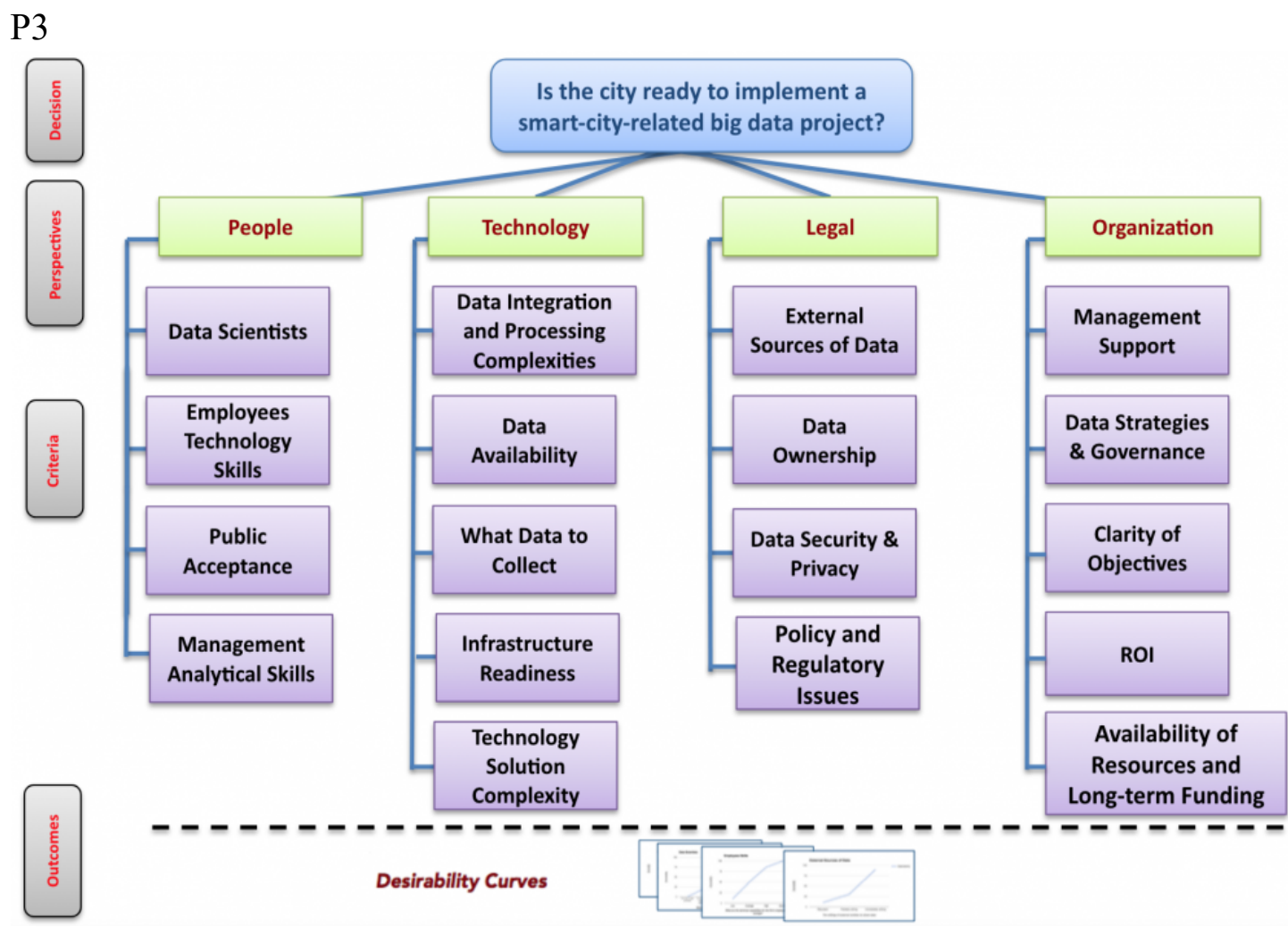

End of Block: Welcome message block

Start of Block: People

P4_1 Big Data and Smart Cities Research - Survey 
P6

\section{People Perspective}

Factors related to people, including skills and perception

\begin{tabular}{|l|l|}
\hline Factors & Details \\
\hline Data Scientists & $\begin{array}{l}\text { Data scientists are the minds that can realize what type, size, and frequency of data need to be captured; } \\
\text { they devise the predictive analysis algorithms that maximize data value, with realization of organizational } \\
\text { goals, as well as, internal and external factors around the firm. } \\
\text { This factor considers city's data scientists and their level of experience in relation to the upcoming project. }\end{array}$ \\
\hline $\begin{array}{l}\text { Employees' } \\
\text { Technological Skills }\end{array}$ & $\begin{array}{l}\text { This factor considers employees information technology skills and their ability to operate complex software } \\
\text { systems. }\end{array}$ \\
\hline Public Acceptance & $\begin{array}{l}\text { This factor considers whether the public will perceive the upcoming project as a "good" project. And would } \\
\text { the project be negatively or positively impacted by the potential public perception. }\end{array}$ \\
\hline $\begin{array}{l}\text { Management's } \\
\text { Analytical Skills }\end{array}$ & $\begin{array}{l}\text { This factor considers management ability/willingness to leverage big data analytics to support decision } \\
\text { making. }\end{array}$ \\
\hline
\end{tabular}

You will quantify the importance of each factor through pairwise comparisons. Please read the instructions below:

- $\quad$ Items will be compared against each other, in pairs. Assign the points according to your opinion.

- $\quad$ The assignment of points should reflect the importance of each item. Example: if $\mathrm{A}$ is $3 \mathrm{x}$ more important than $\mathrm{B}$, A should receive 75 points and $\mathrm{B}$ should receive 25 points.

- $\quad$ Note that for each pairwise comparison, the total of points assigned must be 100 .

- $\quad$ Please try to be logically consistent in your choices, i.e., if $\mathrm{A}$ is better than $\mathrm{B}$, and $\mathrm{B}$ is better than $\mathrm{C}$, A must be better than $\mathrm{C}$.

Note: Please refer to the above table for a summary about each factor

Q1_C Please judge the importance of the following factors dividing 100 points between them. Drag the bars below assigning more points to the one you deem more important. 


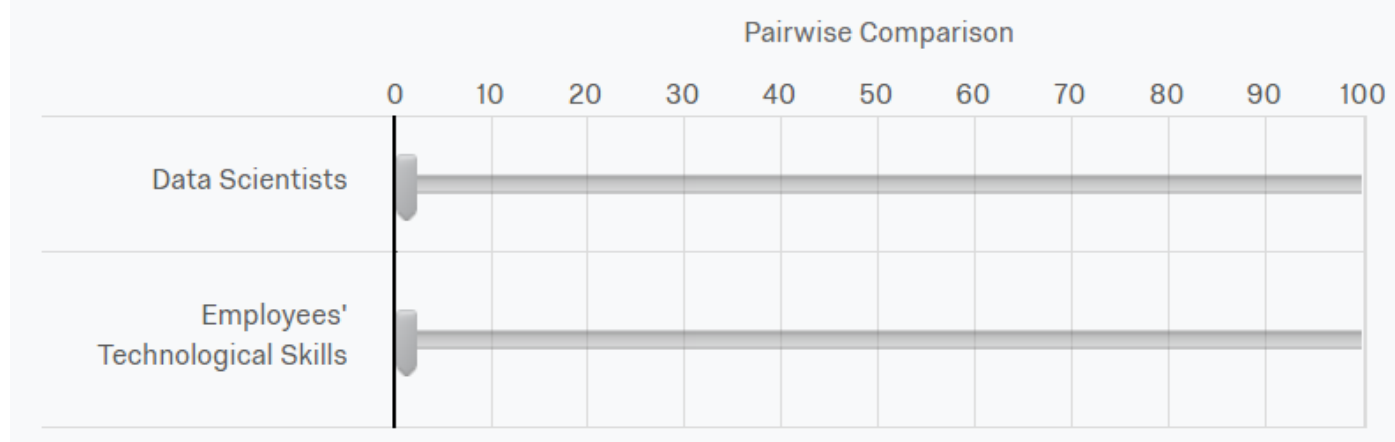

*

Q35

Pairwise Comparison

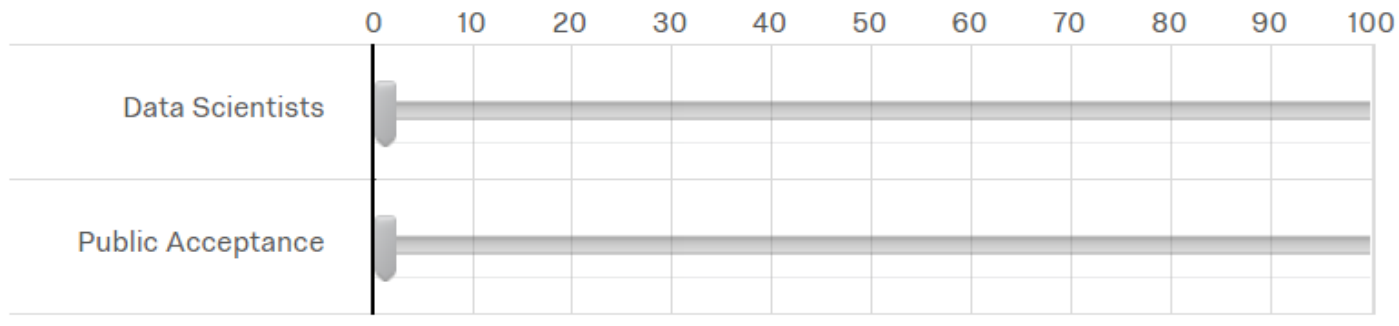

is

Q36

Pairwise Comparison

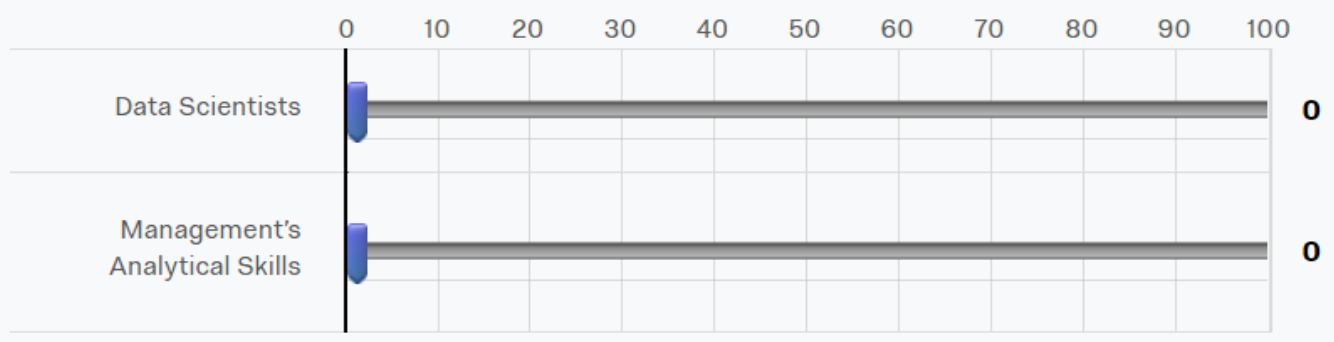


난

Q38

Pairwise Comparison

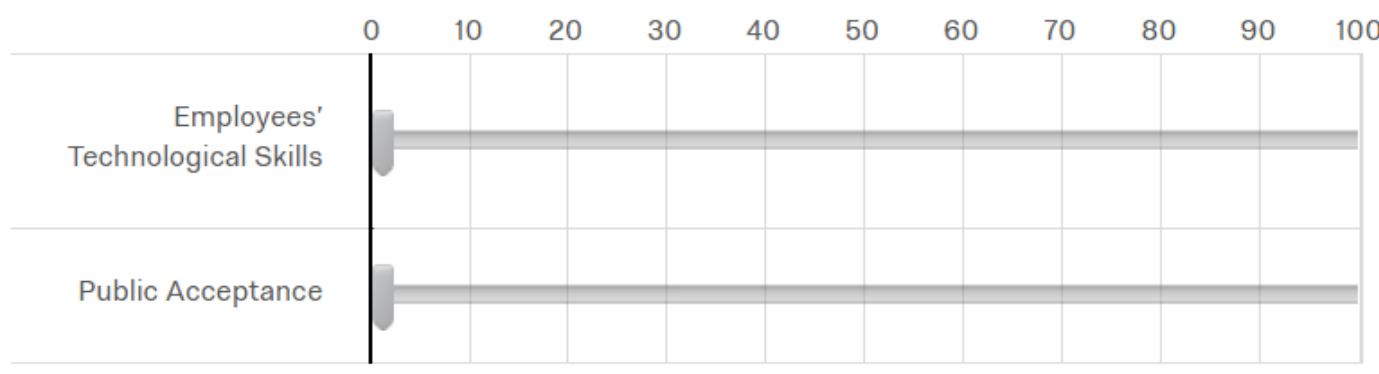

3

Q39

\begin{tabular}{|c|c|c|c|c|c|c|c|c|c|c|c|}
\hline & \multicolumn{11}{|c|}{ Pairwise Comparison } \\
\hline & 0 & 10 & 20 & 30 & 40 & 50 & 60 & 70 & 80 & 90 & 100 \\
\hline Employees' & & & & & & & & & & & \\
\hline Technological Skills & & & & & & & & & & & \\
\hline Management's & & & & & & & & & & & \\
\hline Analytical Skills & & & & & & & & & & & \\
\hline
\end{tabular}

is

Q40 


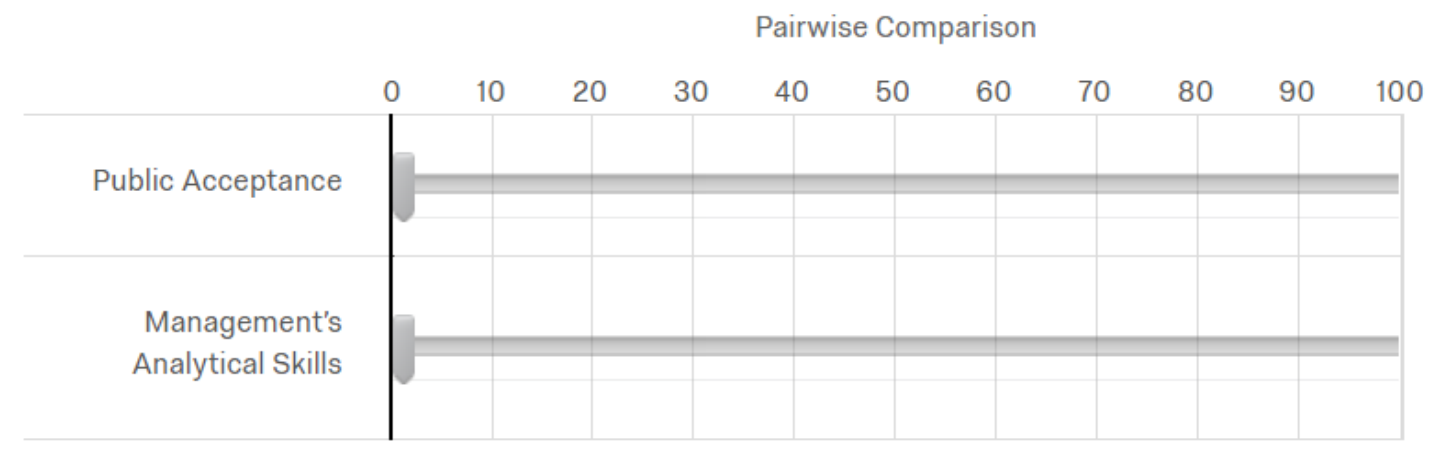

Q37 If you have comments, please provide it here:

End of Block: People 


\section{Start of Block: Technology}

\section{P7_1 Big Data and Smart Cities Research - Survey}

P7

\section{Technology Perspective}

Technical factors that are unique to big data projects due to the nature of big data itself, and its characteristics (volume, velocity, variety, value, and so on.)

\begin{tabular}{|l|l|}
\hline Factors & Details \\
\hline $\begin{array}{l}\text { Data Integration and } \\
\text { Processing Complexities }\end{array}$ & $\begin{array}{l}\text { Big data system's ability to ingest, cleanse, aggregate and analyze data from various sources is vital to } \\
\text { generate value. } \\
\text { This factor considers the challenges in integrating and processing the data from the various data sources that } \\
\text { will be used in the upcoming project. }\end{array}$ \\
\hline Data Availability & $\begin{array}{l}\text { This factor considers whether the data coming from various sources can be accessed in timely manner to } \\
\text { make meaningful results. From technical perspective, the data volume and velocity, for each source of data } \\
\text { can affect its accessibility. }\end{array}$ \\
\hline What Data to Collect & $\begin{array}{l}\text { This factor considers whether the types of data that should be collected is clear or not. Without this clarity, } \\
\text { either more data (than needed) could be captured, which means resources waste, or less data (than needed) } \\
\text { will be captured, resulting in value loss. }\end{array}$ \\
\hline Infrastructure Readiness & $\begin{array}{l}\text { This factor considers a city's availability-of/ability-to acquire needed networks and IOT infrastructure to } \\
\text { capture and transmit project related data. In addition, the availability/ability to procure needed software } \\
\text { tools and technology frameworks that can scale with the exponential growth of data. }\end{array}$ \\
\hline $\begin{array}{l}\text { Technology Solutions } \\
\text { Complexities }\end{array}$ & $\begin{array}{l}\text { In big data projects, several software tools are used together to achieve the project goals. } \\
\text { This factor considers how complex is the mix of tools to be used in the project and what skillset is needed. }\end{array}$
\end{tabular}

You will quantify the importance of each factor through pairwise comparisons. Please read the instructions below:

- $\quad$ Items will be compared against each other, in pairs. Assign the points according to your opinion.

- The assignment of points should reflect the importance of each item. Example: if $\mathrm{A}$ is $3 \mathrm{x}$ more important than $\mathrm{B}$, A should receive 75 points and $\mathrm{B}$ should receive 25 points.

- $\quad$ Note that for each pairwise comparison, the total of points assigned must be 100 .

- $\quad$ Please try to be logically consistent in your choices, i.e., if $\mathrm{A}$ is better than $\mathrm{B}$, and $\mathrm{B}$ is better than $\mathrm{C}, \mathrm{A}$ must be better than $\mathrm{C}$.

Note: Please refer to the above table for a summary about each factor 
Q42 Please judge the importance of the following factors dividing 100 points between them. Drag the bars below assigning more points to the one you deem more important.
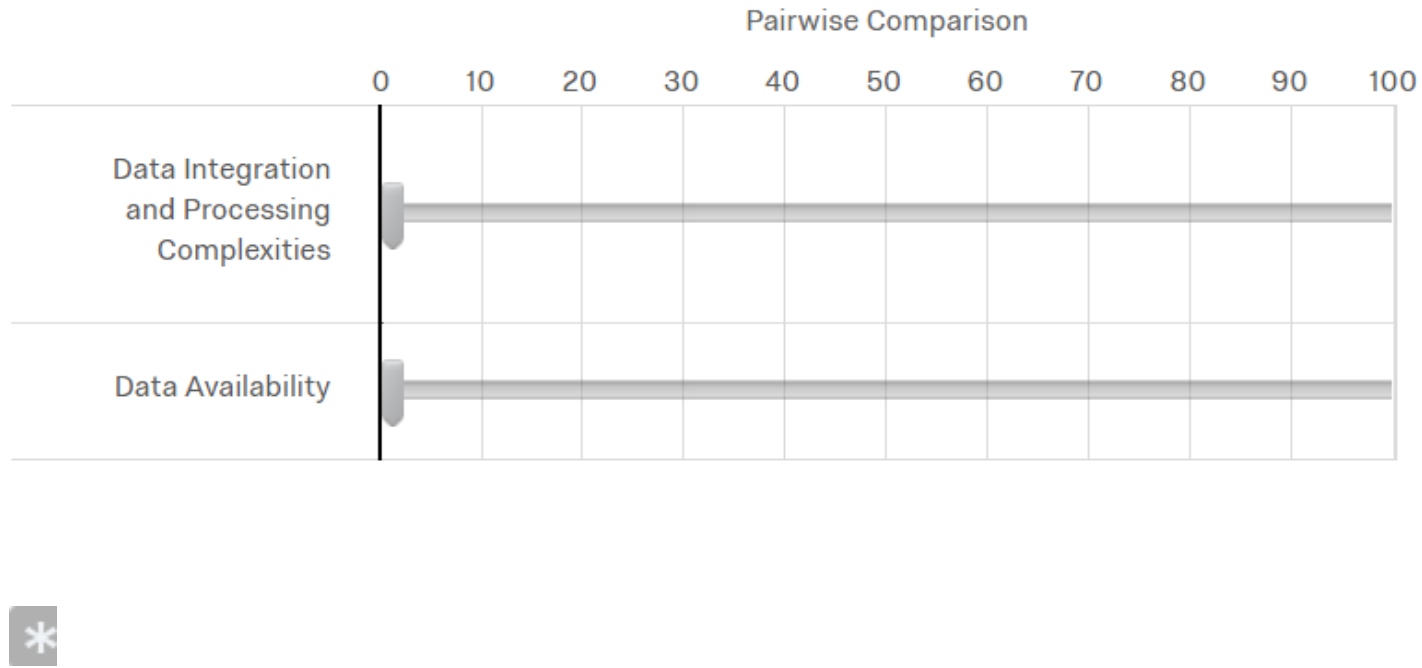

Q43

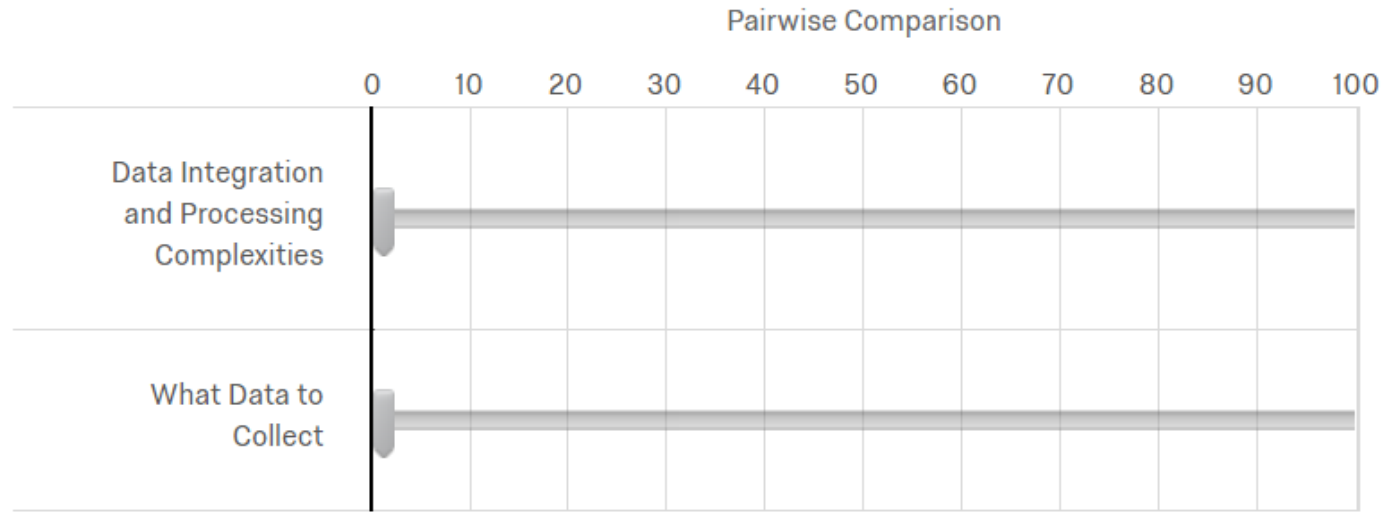

Q44 


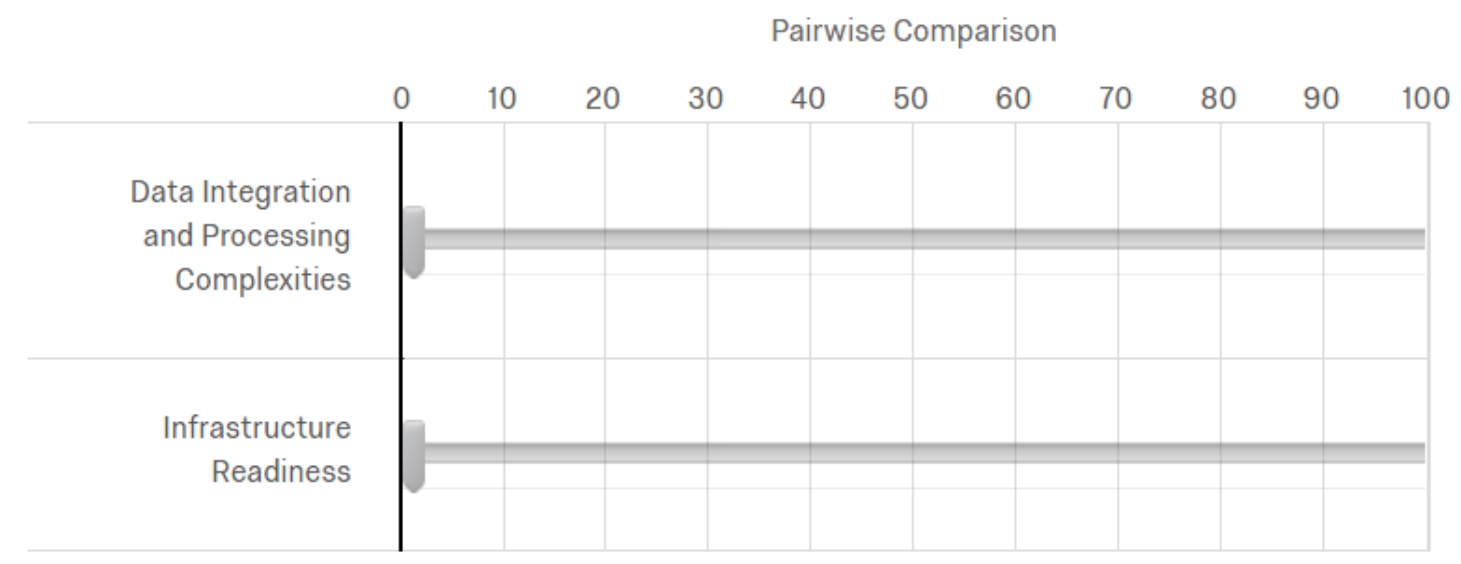

*

Q45

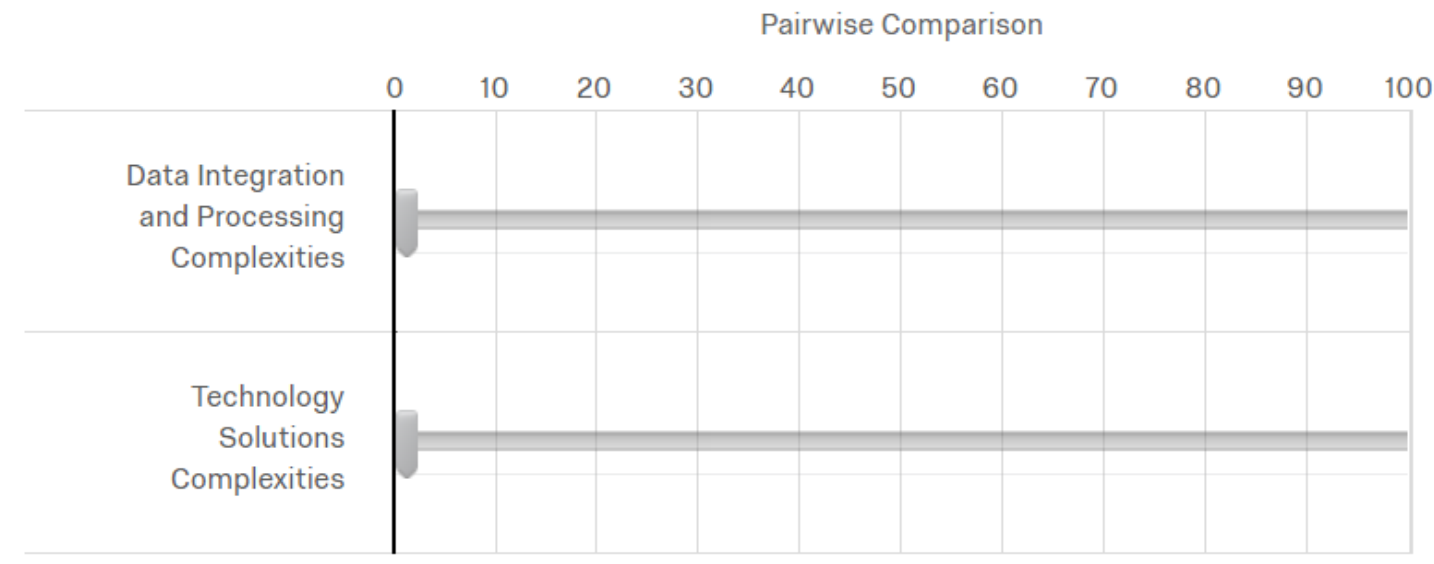

*

Q46 
Pairwise Comparison

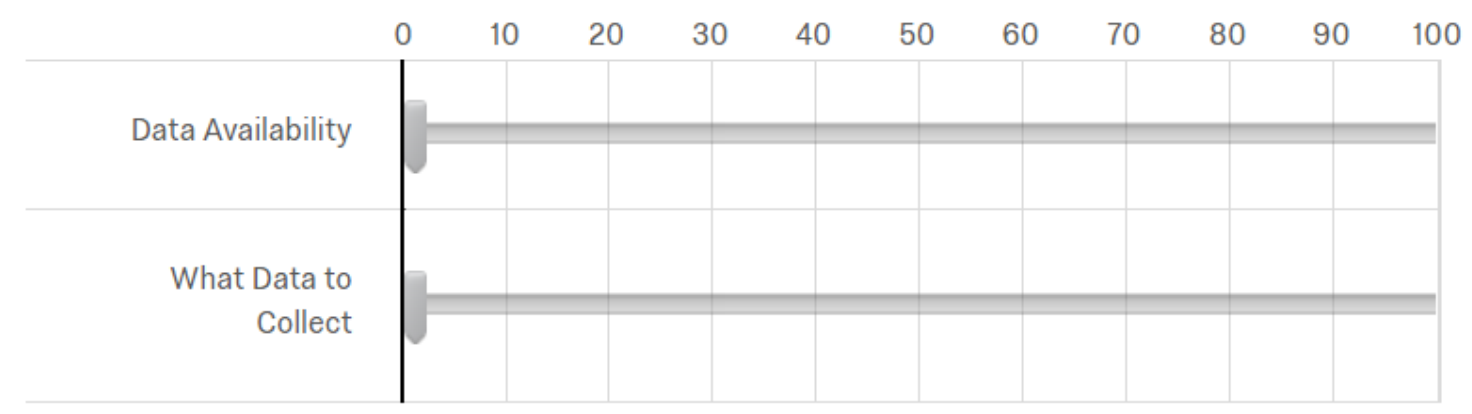

3

Q48

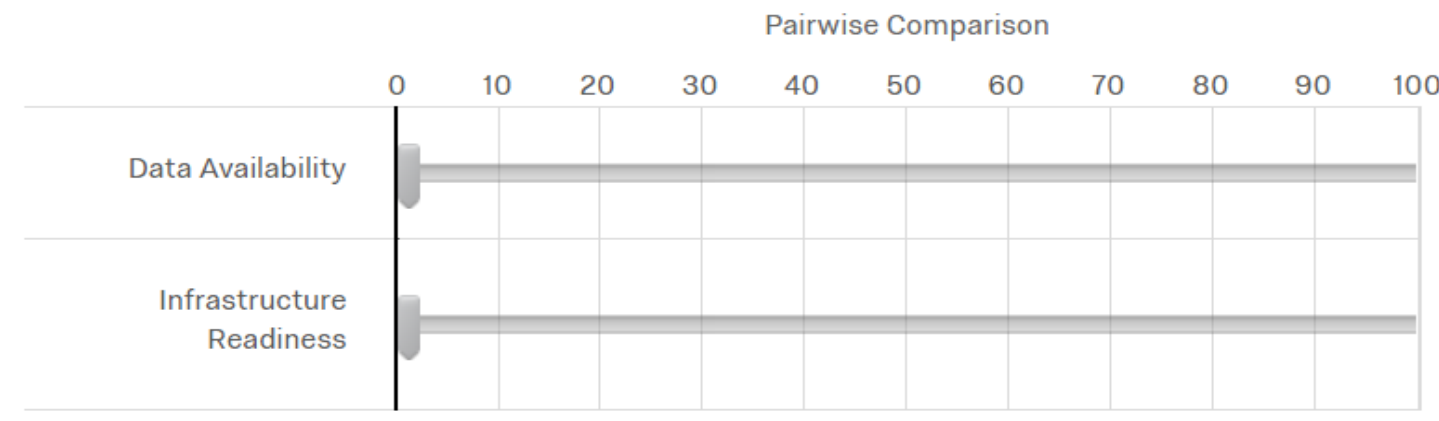

为 
Q47

Pairwise Comparison

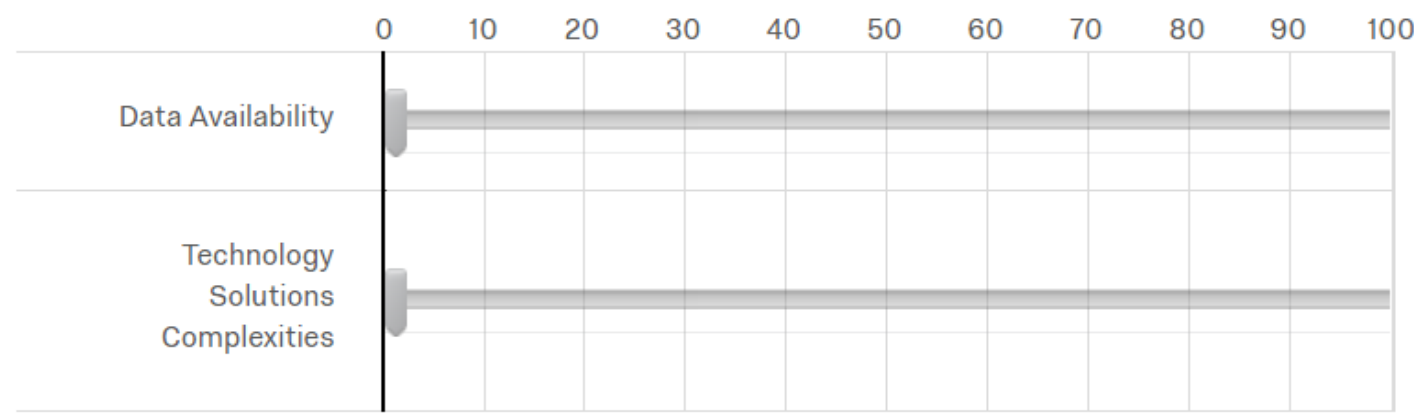

为

Q49

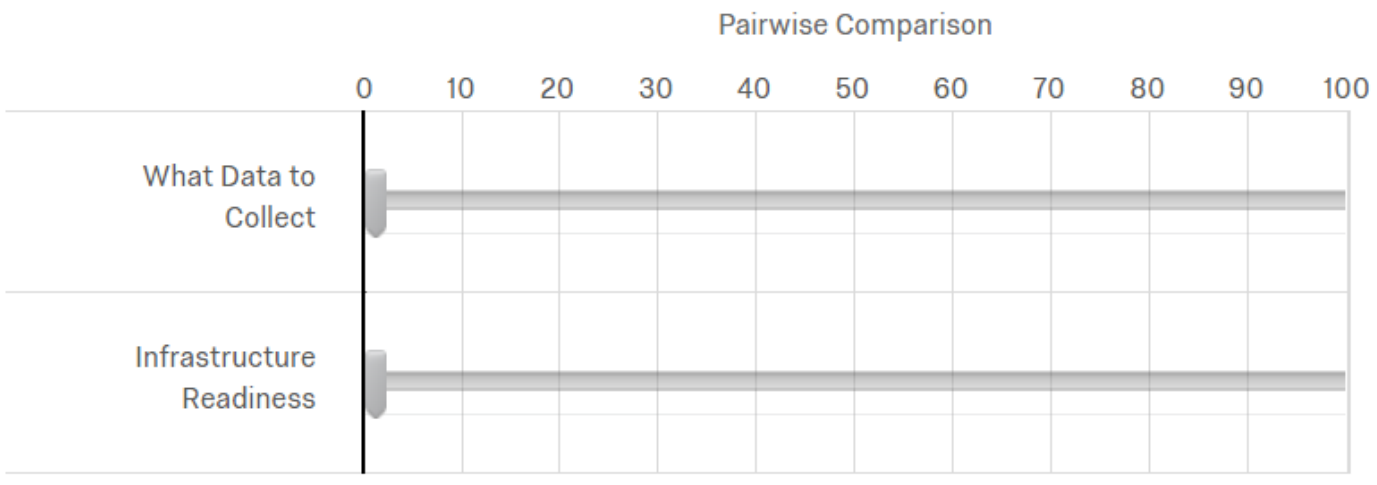

为 
Q50
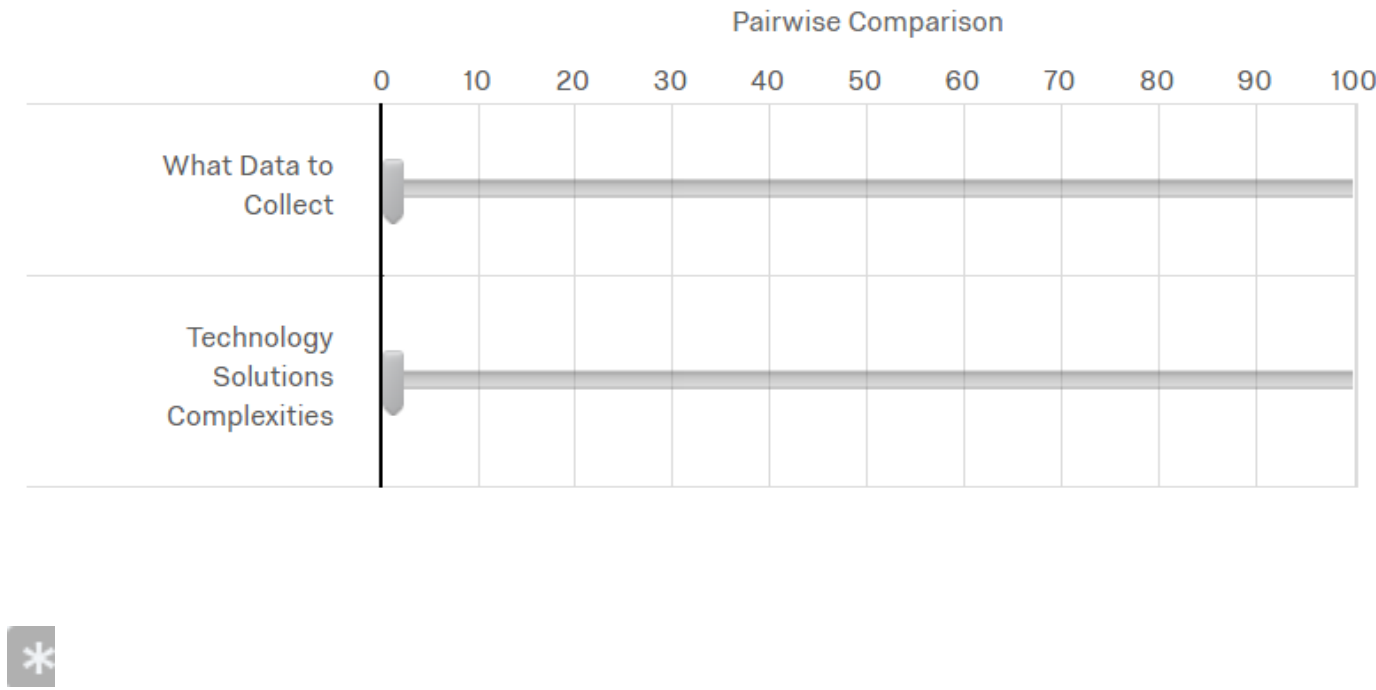

Q51

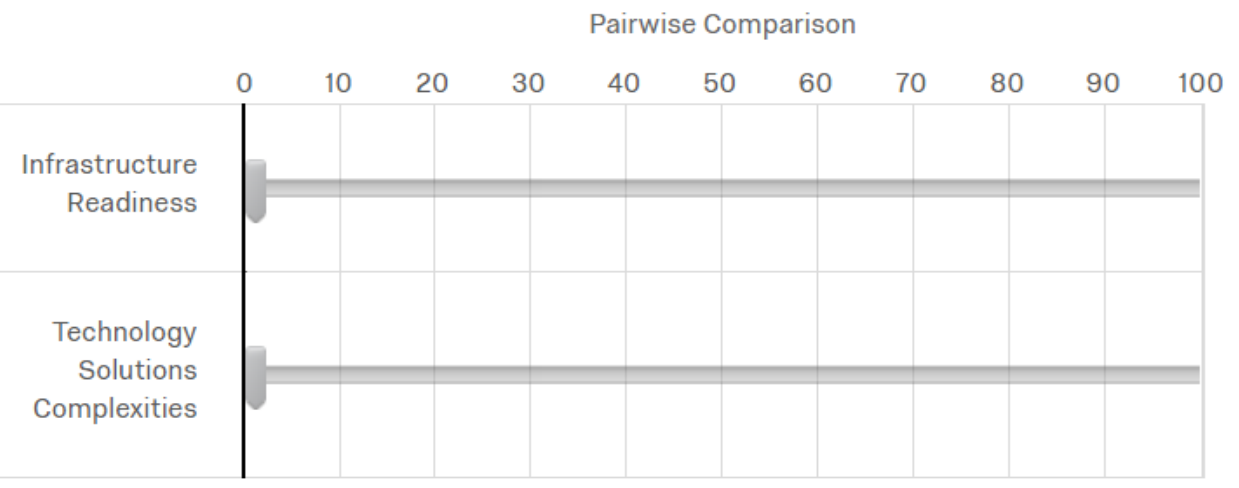

Q4_C If you have comments, please provide it here:

\section{End of Block: Technology}


Start of Block: Legal

P8_1 Big Data and Smart Cities Research - Survey

P8

\section{Legal Perspective}

External environment factors, mainly due to data being owned and managed by external entities, as well as, affecting external entities

\begin{tabular}{|l|l|}
\hline Factors & Details \\
\hline $\begin{array}{l}\text { External Sources of } \\
\text { Data }\end{array}$ & $\begin{array}{l}\text { This factor considers accessibility to external sources of data needed for the project. Such data is available } \\
\text { at clients, suppliers, and other stakeholders ends. } \\
\text { Are they willing to share it or not? }\end{array}$ \\
\hline Data Ownership & $\begin{array}{l}\text { This factor considers how much freedom the city has in disseminating analytics generated by the big data } \\
\text { system based on data coming from external sources. }\end{array}$ \\
\hline $\begin{array}{l}\text { Data security and } \\
\text { privacy }\end{array}$ & $\begin{array}{l}\text { This factor considers the level of security and privacy the system must have, versus the value it can } \\
\text { generate. }\end{array}$ \\
\hline $\begin{array}{l}\text { Policy and Regulatory } \\
\text { Issues }\end{array}$ & $\begin{array}{l}\text { This factor considers policy and regulatory issues that might have impact on the project and the city's ability } \\
\text { to address them including issues like privacy, open data, surveillance technology, Al, contracting methods, } \\
\text { and so on. Such policies and regulations might be internal to the city or external (like GDPR). }\end{array}$ \\
\hline
\end{tabular}

You will quantify the importance of each factor through pairwise comparisons. Please read the instructions below:

- Items will be compared against each other, in pairs. Assign the points according to your opinion.

- $\quad$ The assignment of points should reflect the importance of each item. Example: if $\mathrm{A}$ is $3 \mathrm{x}$ more important than $\mathrm{B}$, A should receive 75 points and $\mathrm{B}$ should receive 25 points.

- $\quad$ Note that for each pairwise comparison, the total of points assigned must be 100 .

- $\quad$ Please try to be logically consistent in your choices, i.e., if $\mathrm{A}$ is better than $\mathrm{B}$, and $\mathrm{B}$ is better than $\mathrm{C}, \mathrm{A}$ must be better than $\mathrm{C}$.

Note: Please refer to the above table for summary about each factor

Q52 Please judge the importance of the following factors dividing 100 points between them. Drag the bars below assigning more points to the one you deem more important. 


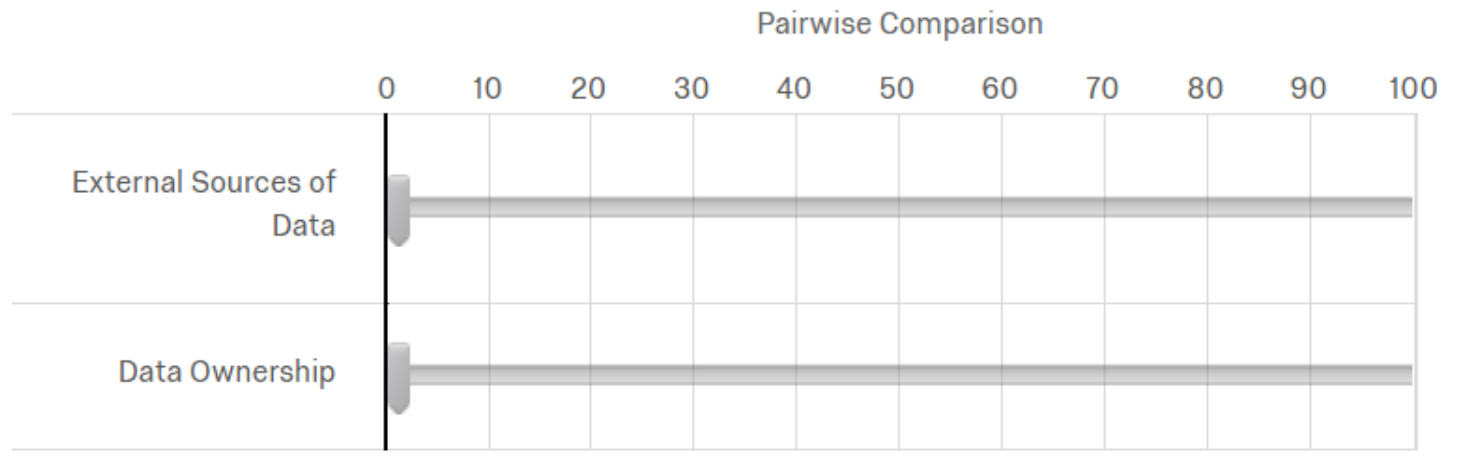

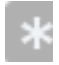

Q58

Pairwise Comparison

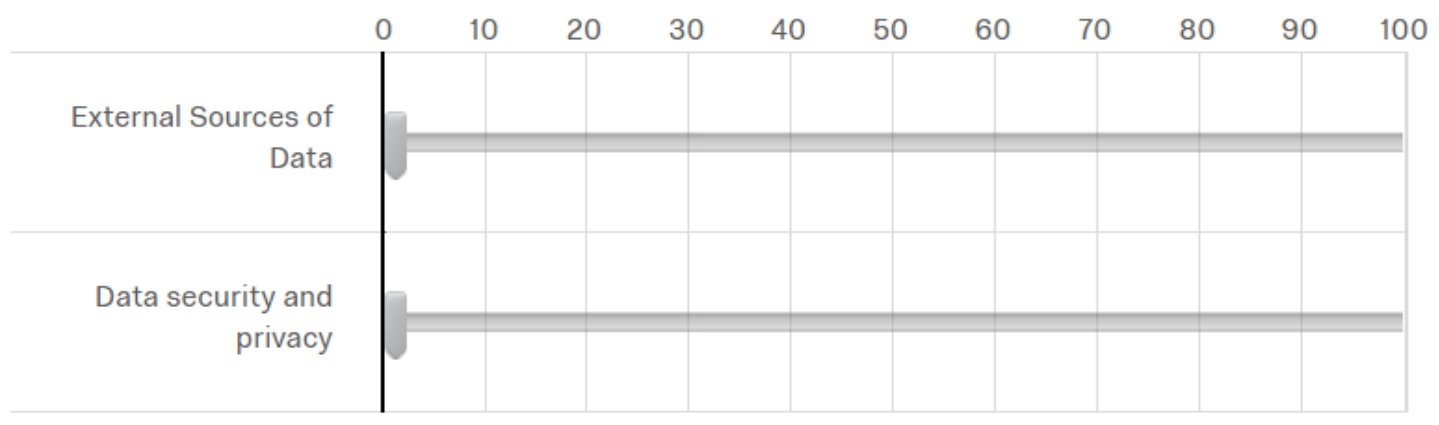

*

Q59 
Pairwise Comparison

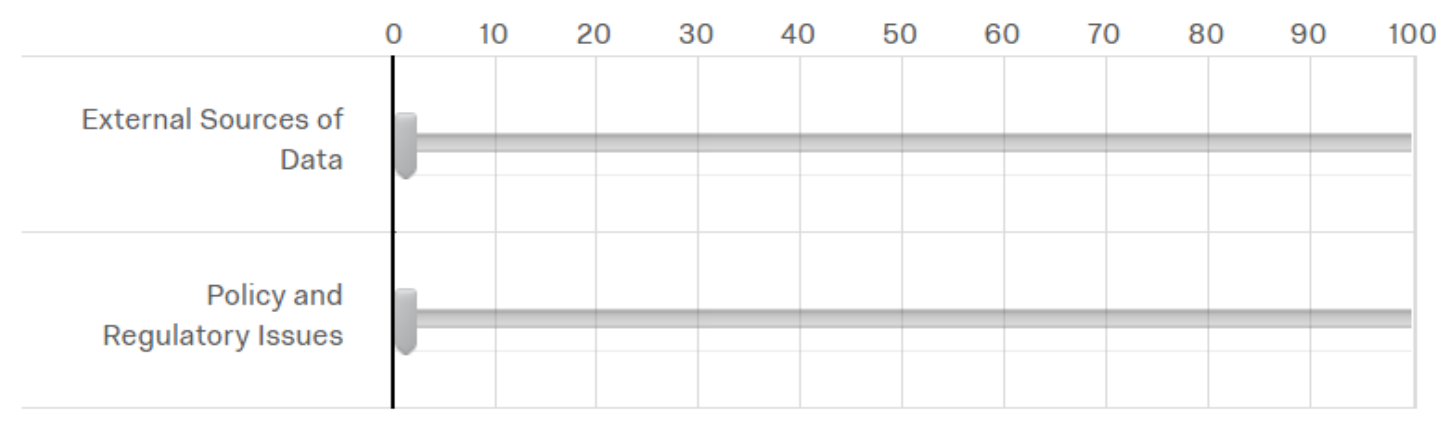

3

Q60

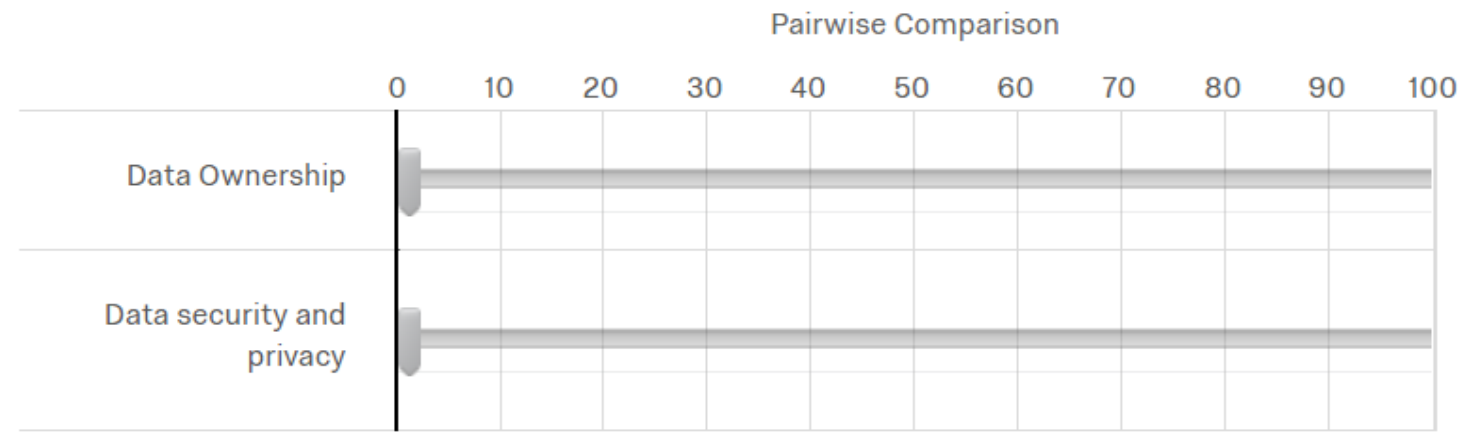



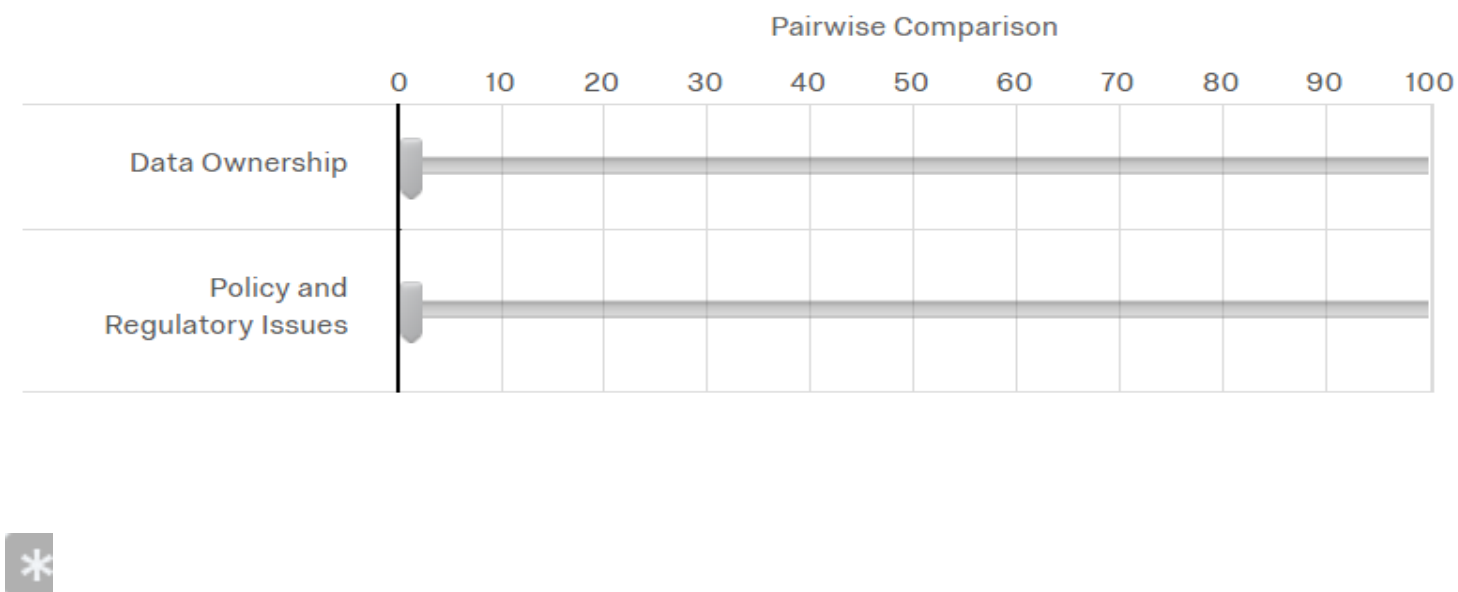

Q63

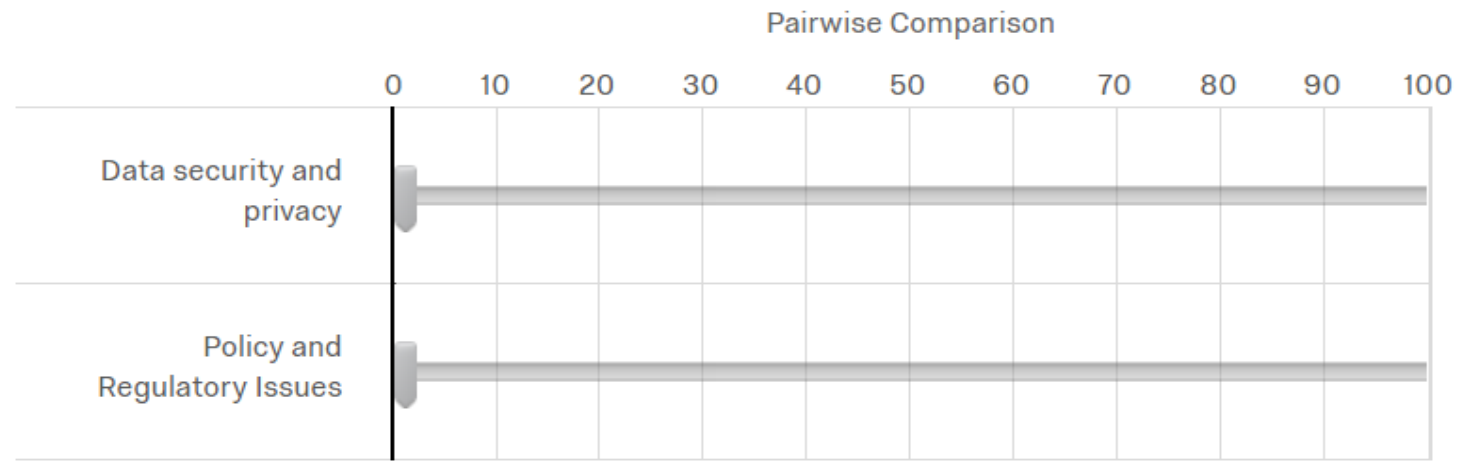

Q6_C If you have comments, please provide it here:

End of Block: Legal

Start of Block: Organization

P9_1 Big Data and Smart Cities Research - Survey 


\section{Organization Perspective}

What need to be considered by management to enable successful and sustainable big data adoption within the organization and to overcome barriers to this adoption.

Factors

Management Support

Data Strategies and

Governance

Clarity of Objectives and

Use Cases

ROI

Availability of Resources

and Long-term Funding

\section{Details}

Leadership support for any project plays a significant role in whether the project will be successful. This is even more true in the case of big data projects that require a lot of changes within the organization. Furthermore, a receptivity towards data and analytics is important for the success of big data projects. Such attitudes can be driven by management. This factor considers management level of support to the upcoming big data project.

This factor considers the maturity of strategies and governance regarding how to handle data within the city, including things like versioning, federalization, security, portability, user management and so on.

This factor considers the clarity of the project objectives and how they are related to organizational mission and vision and how the project outcome is facilitating the achievement of organizational strategic goals. Also, this factor considers the project's use cases and whether they include things like: clear and measurable goals and whether stakeholders are clearly identified and their needs are addressed.

This factor considers the ROI of the project. ROI is not necessarily financial but rather it could be service or image related. In other words, do the project realizes benefits that are important to related stakeholders and contribute to the smart-city aims of enhancing quality of life in the city and improving operational efficiency.

Due to budget constraints, many cities follow an incremental approach with smaller delivery milestones and incremental/rapid addition, big data projects require costly operational management. So, this factor considers the city's ability to provide long-term funding and resources to support related future projects and provide sustainability to the current project's deliverables.

You will quantify the importance of each factor through pairwise comparisons. Please read the instructions below:

- $\quad$ Items will be compared against each other, in pairs. Assign the points according to your opinion.

- The assignment of points should reflect the importance of each item. Example: if $\mathrm{A}$ is $3 \mathrm{x}$ more important than $\mathrm{B}$, A should receive 75 points and $\mathrm{B}$ should receive 25 points.

- Note that for each pairwise comparison, the total of points assigned must be 100 .

- $\quad$ Please try to be logically consistent in your choices, i.e., if $\mathrm{A}$ is better than $\mathrm{B}$, and $\mathrm{B}$ is better than $\mathrm{C}, \mathrm{A}$ must be better than $\mathrm{C}$.

Note: Please refer to the above table for a summary about each factor 
Q53 Please judge the importance of the following factors dividing 100 points between them. Drag the bars below assigning more points to the one you deem more important.

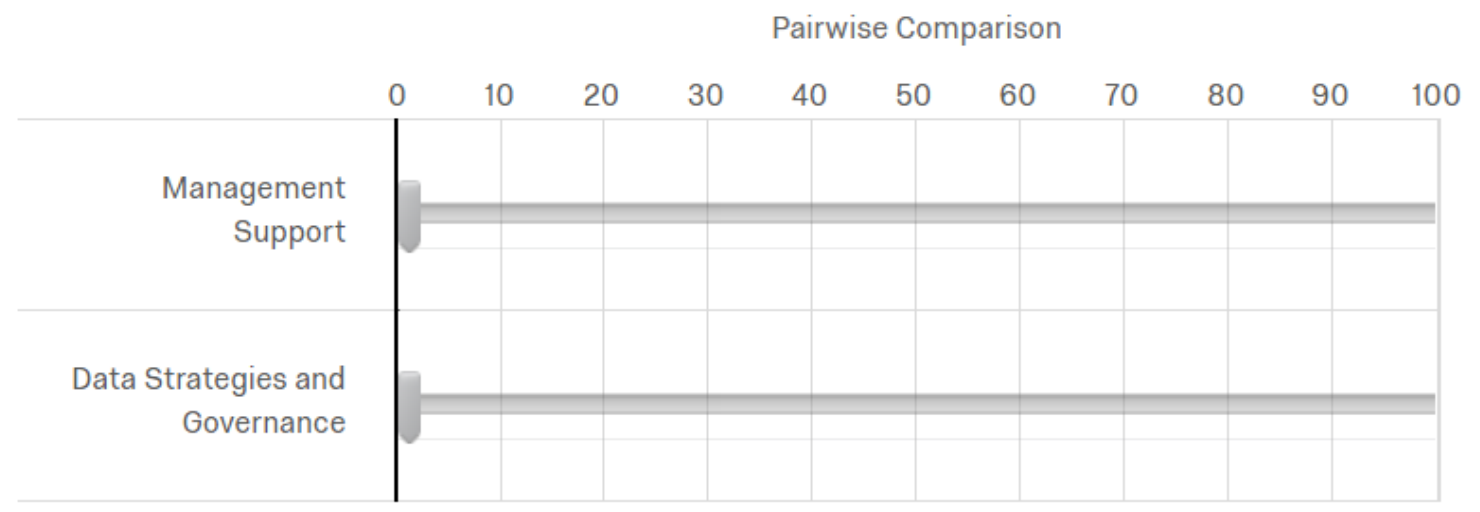

is

Q64

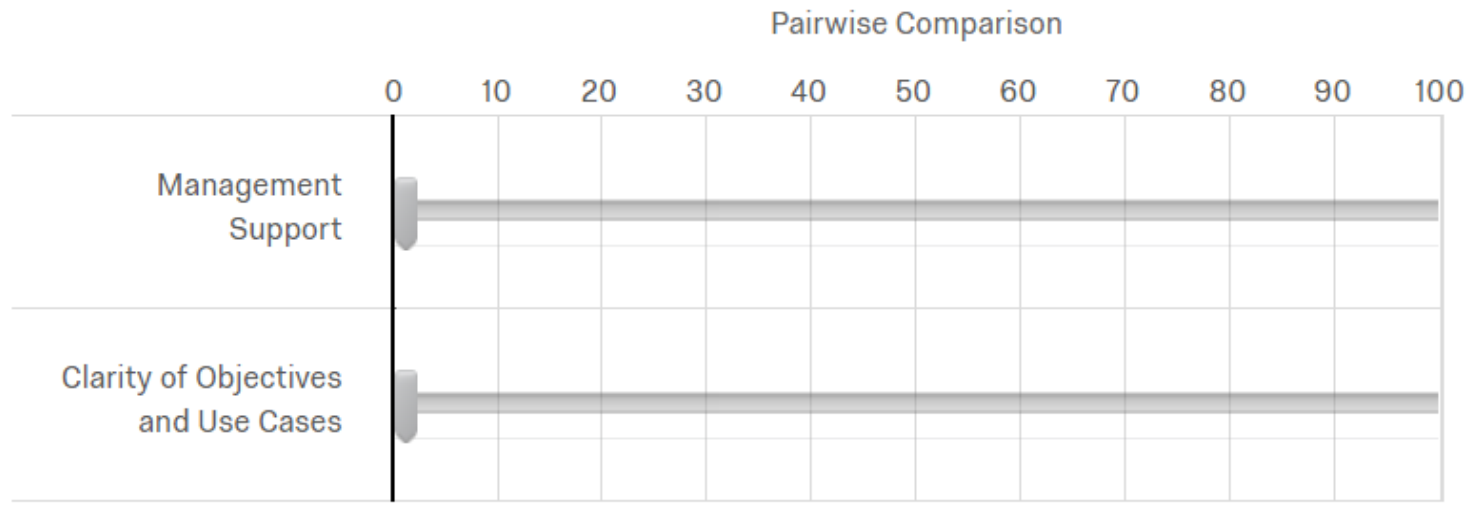




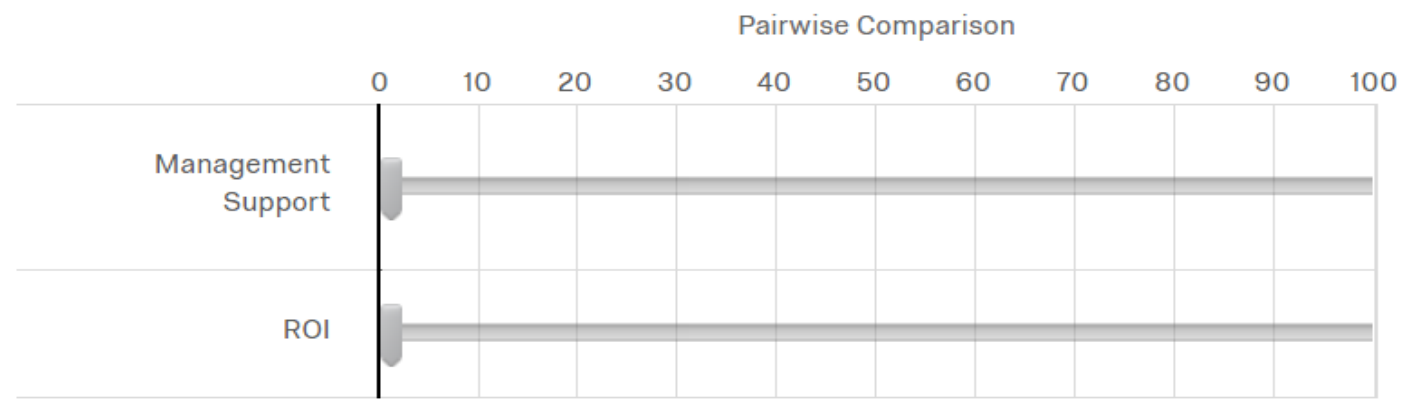

is

Q66

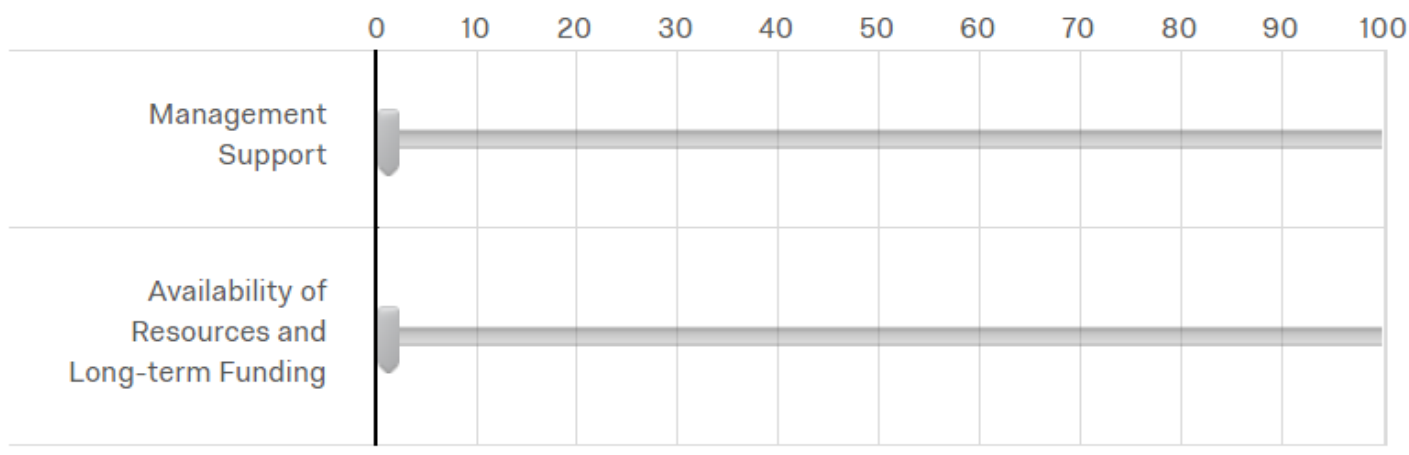


Q67

Pairwise Comparison

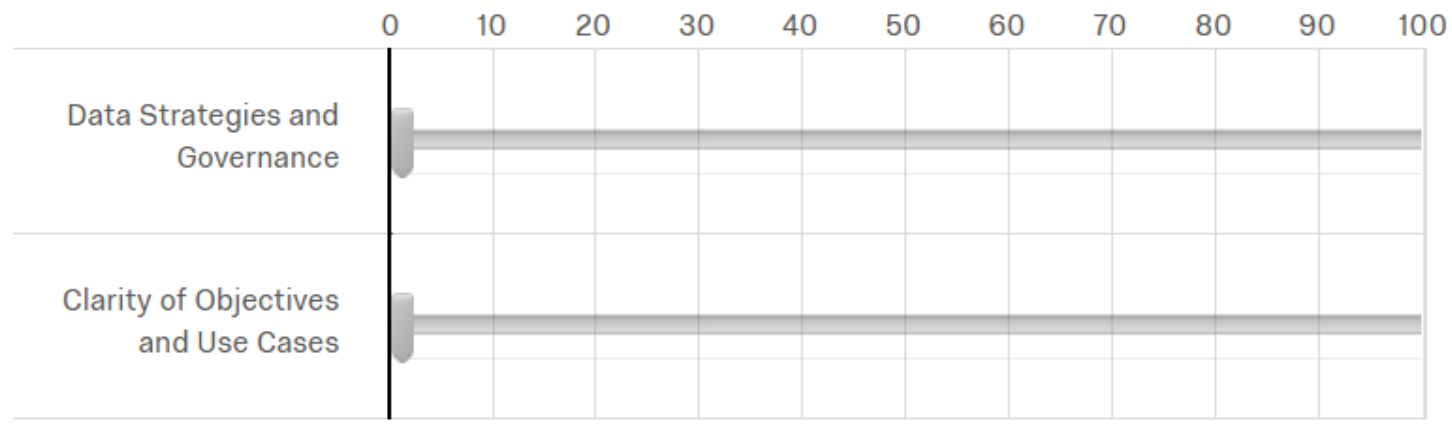

*

Q69

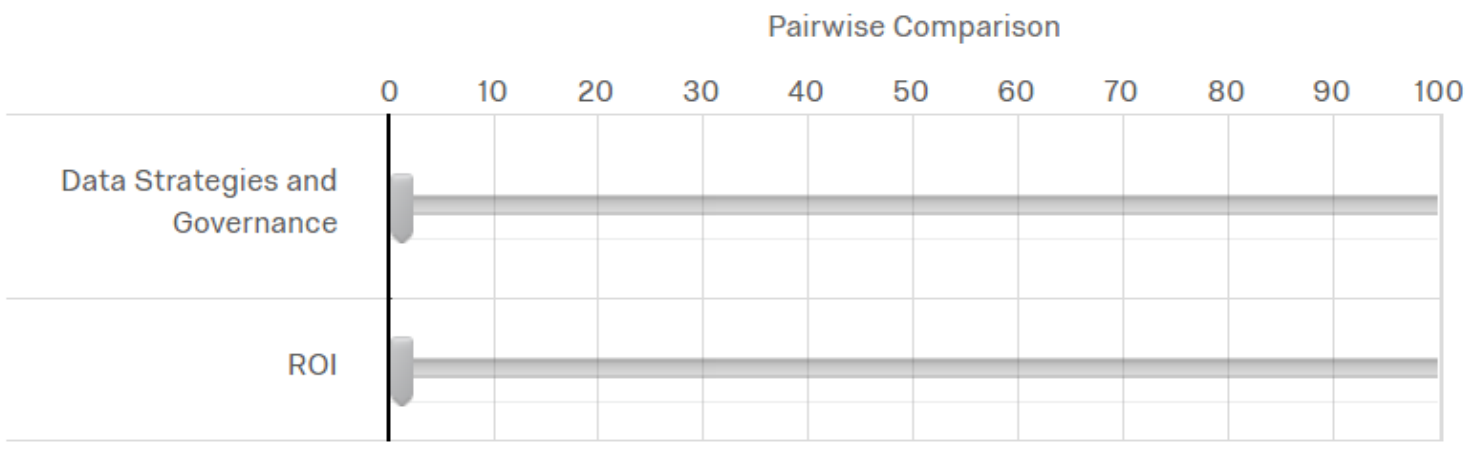


Q68

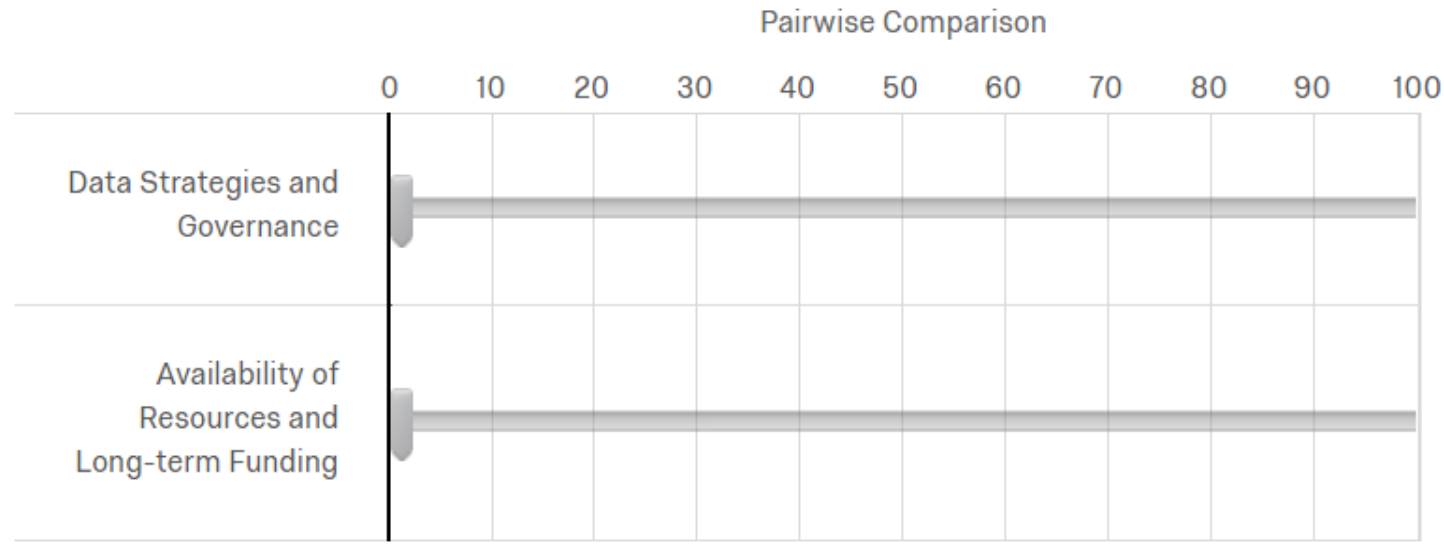

*

Q70

Pairwise Comparison

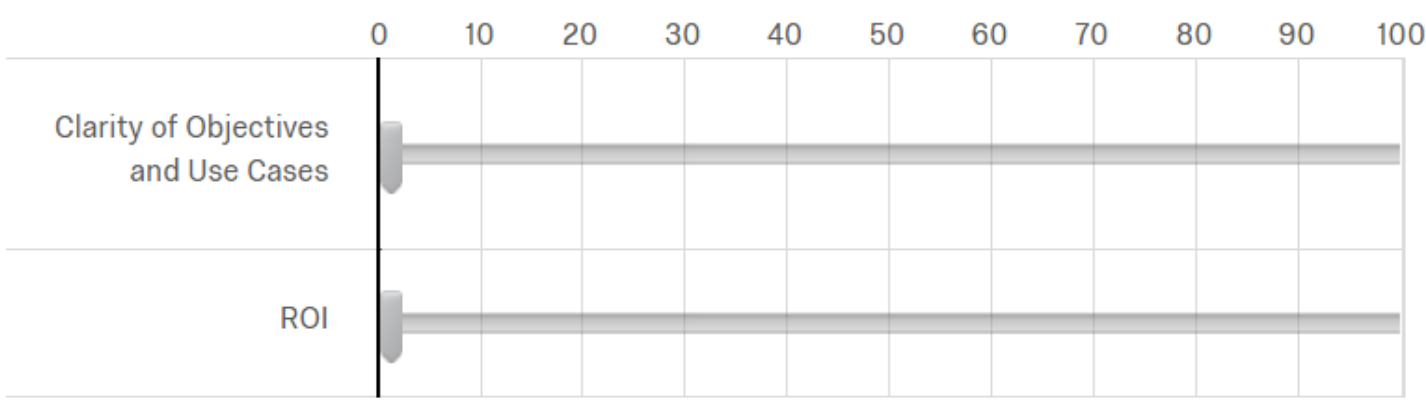

* 


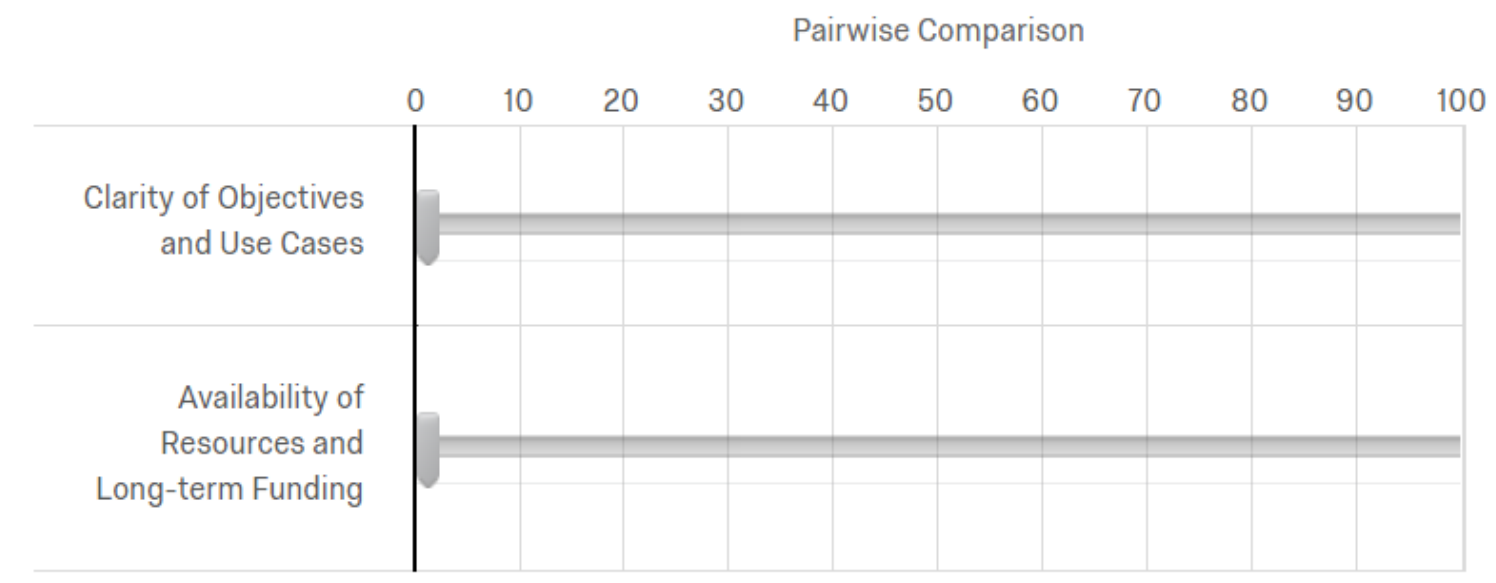

*

Q72

Pairwise Comparison

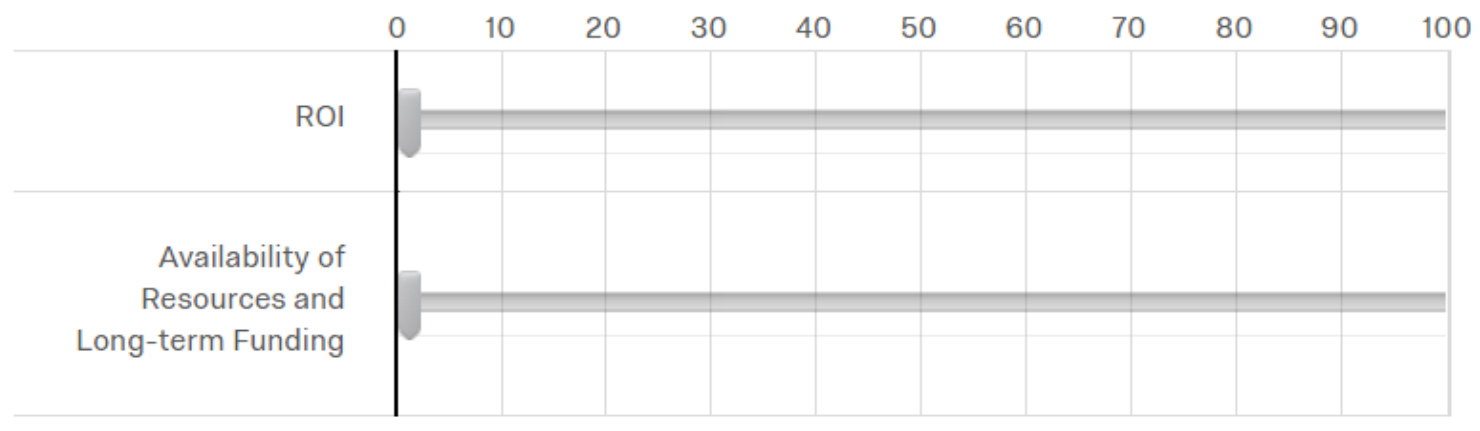

Q8_C If you have comments, please provide it here:

\section{End of Block: Organization}


Start of Block: Perspectives

P10_1 Husam Barham Ph.D. research - Survey

P10

The perspectives (classifications) of the factors affecting big data projects as part of a smart city initiative:

Please rank the perspectives considering the factors under each perspective. 


\section{P11}

\section{Perspectives}

\begin{tabular}{|l|l|}
\hline Perspective & Details \\
\hline People Perspective & Factors related to people, including skills and perception \\
\hline Technology Perspective & $\begin{array}{l}\text { Technical factors that are unique to big data projects due to the nature of } \\
\text { big data itself, and its characteristics (volume, velocity, variety, value, and so } \\
\text { on.) }\end{array}$ \\
\hline Legal Perspective & $\begin{array}{l}\text { External environment factors, mainly due to data being owned and managed } \\
\text { by different external entities, as well as, affecting external entities }\end{array}$ \\
\hline Organization Perspective & $\begin{array}{l}\text { What need to be considered by management to enable successful and } \\
\text { sustainable big data adoption within the organization and to overcome } \\
\text { barriers to this adoption. }\end{array}$ \\
\hline
\end{tabular}

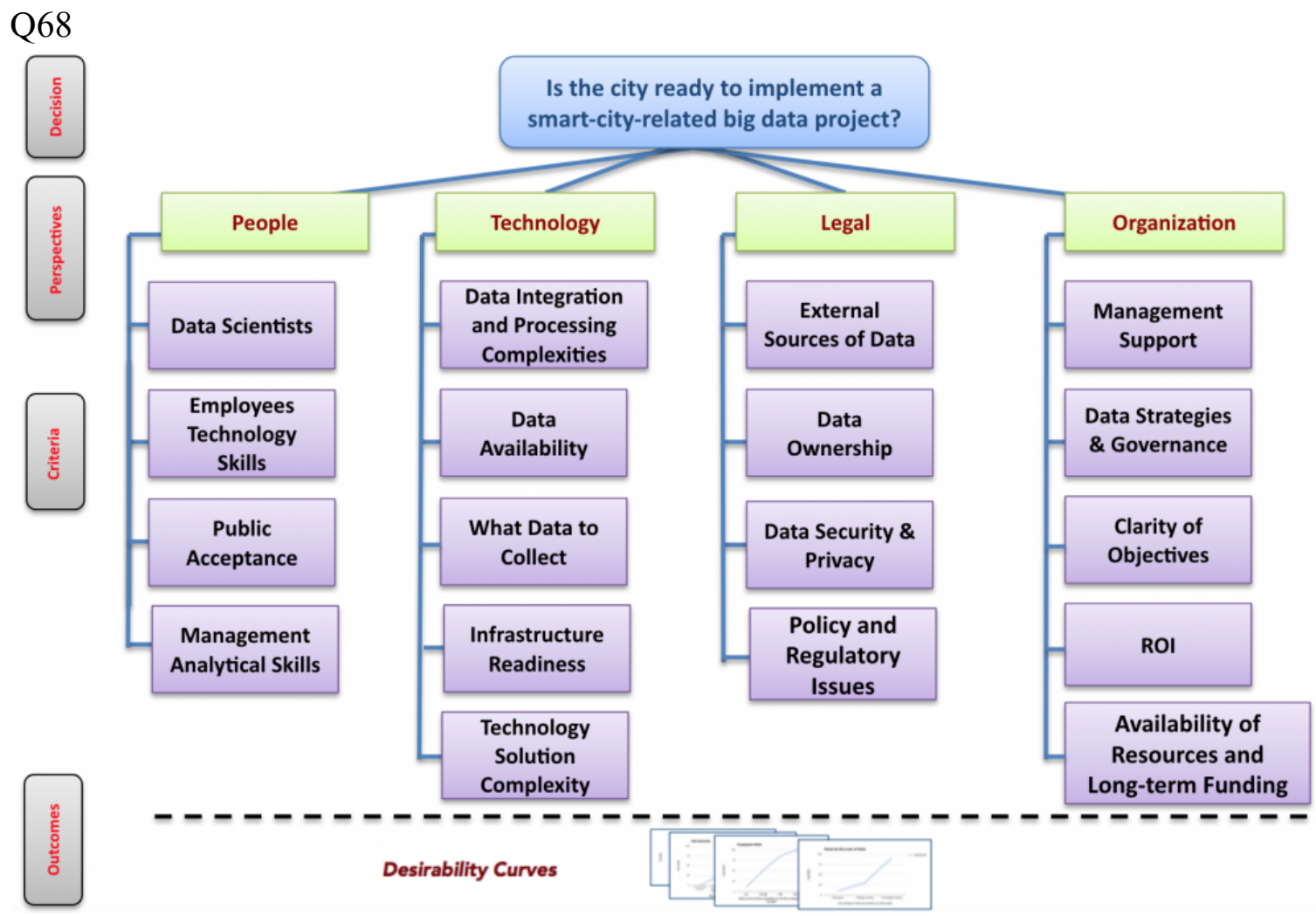


You will quantify the importance of each perspective through pairwise comparisons. Please read the instructions below:

- $\quad$ Items will be compared against each other, in pairs. Assign the points according to your opinion.

- $\quad$ The assignment of points should reflect the importance of each item. Example: if $\mathrm{A}$ is $3 \mathrm{x}$ more important than $\mathrm{B}$, $\mathrm{A}$ should receive 75 points and $\mathrm{B}$ should receive 25 points.

- $\quad$ Note that for each pairwise comparison, the total of points assigned must be 100 .

- $\quad$ Please try to be logically consistent in your choices, i.e., if $\mathrm{A}$ is better than $\mathrm{B}$, and $\mathrm{B}$ is better than $\mathrm{C}, \mathrm{A}$ must be better than $\mathrm{C}$.

Note: Please refer to the above table for a summary about each factor

Q54 Please judge the importance of the following perspectives dividing 100 points between them. Drag the bars below assigning more points to the one you deem more important.

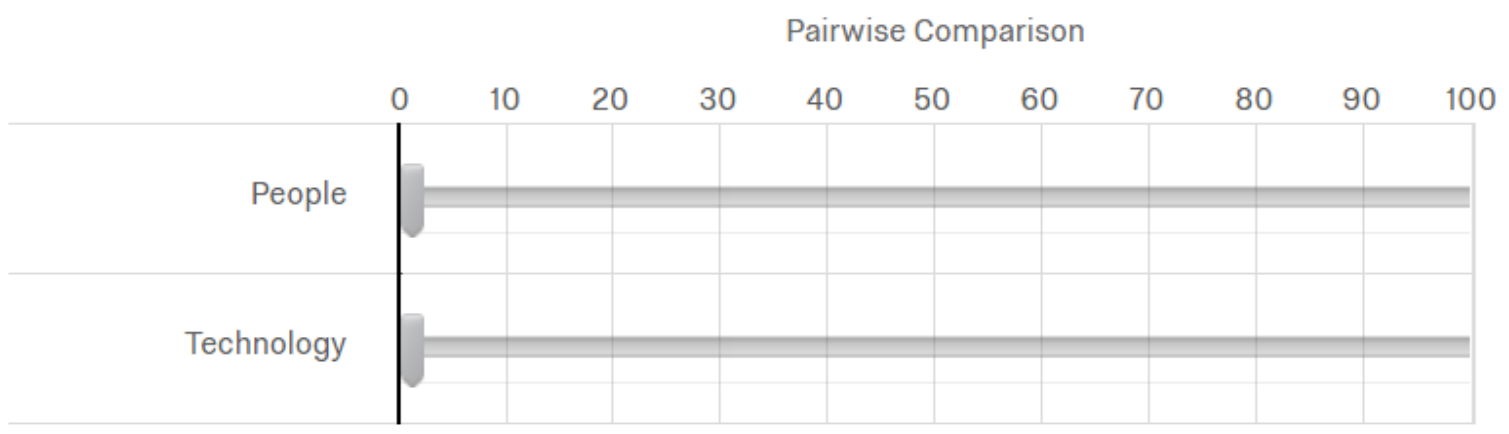


Q73

Pairwise Comparison

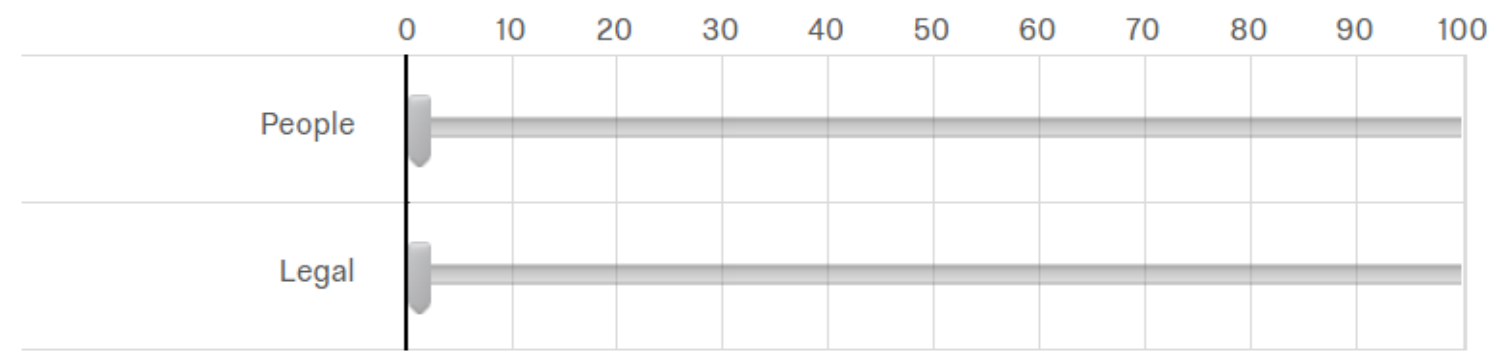

3

Q74

Pairwise Comparison

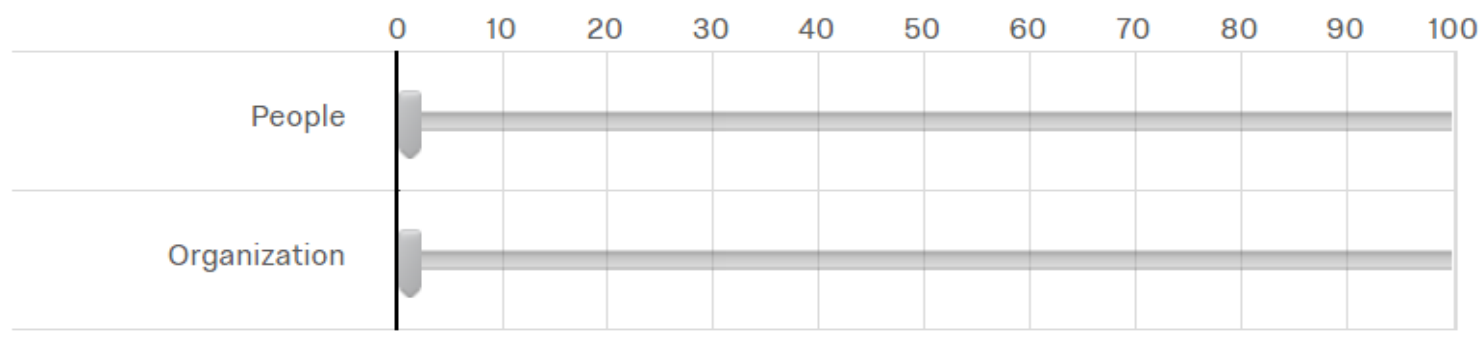

3

Q75

Pairwise Comparison

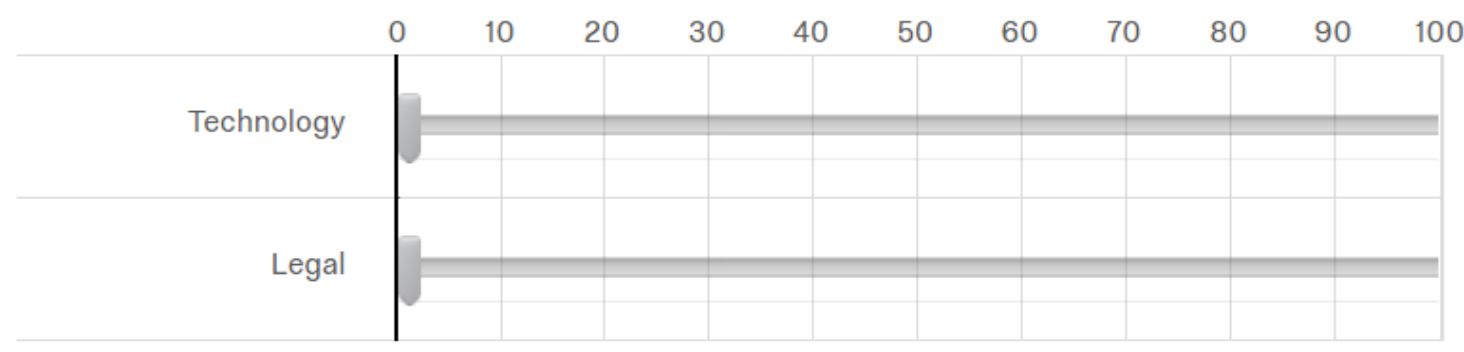


Q76

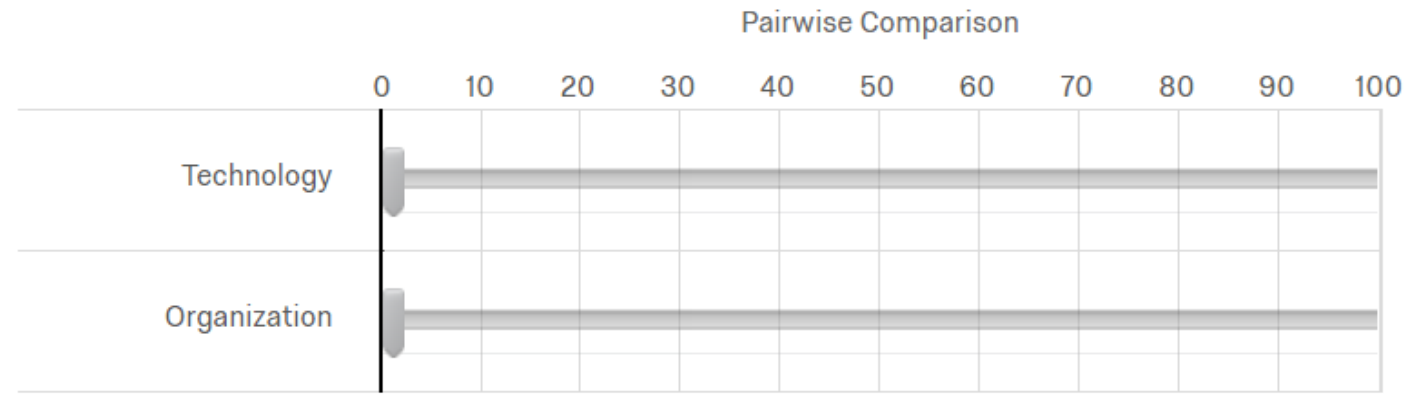

*

Q77

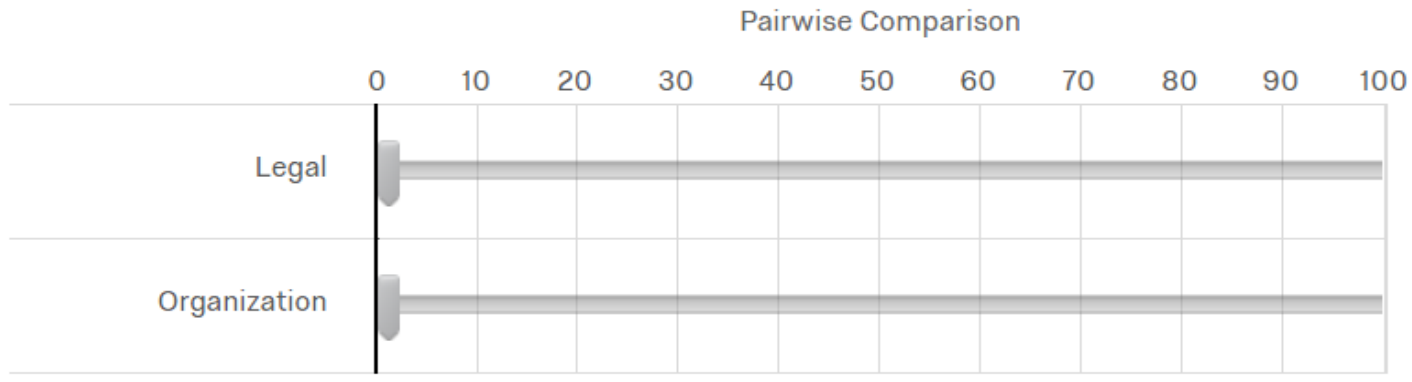

Q2 P

If you have comments, please provide it here:

End of Block: Perspectives

Start of Block: Block 6 
P12

Submission Confirmation

By clicking on the " -->" button, your answers will be submitted.

Thanks.

End of Block: Block 6 
APPENDIX C: HDM Software Tool

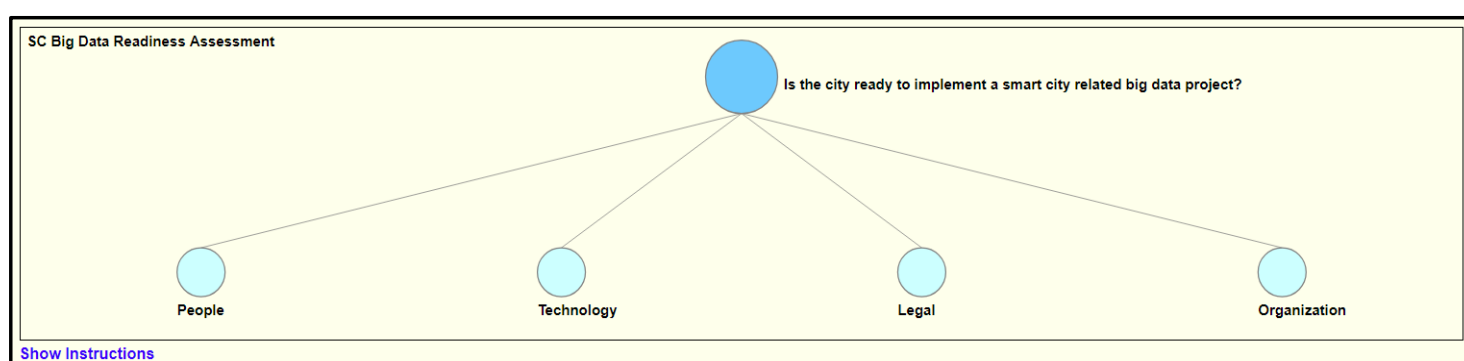

Show Instruction

Please give your judgment for each pair of nodes below toward Is the city ready to implement a smart city related big data project?:

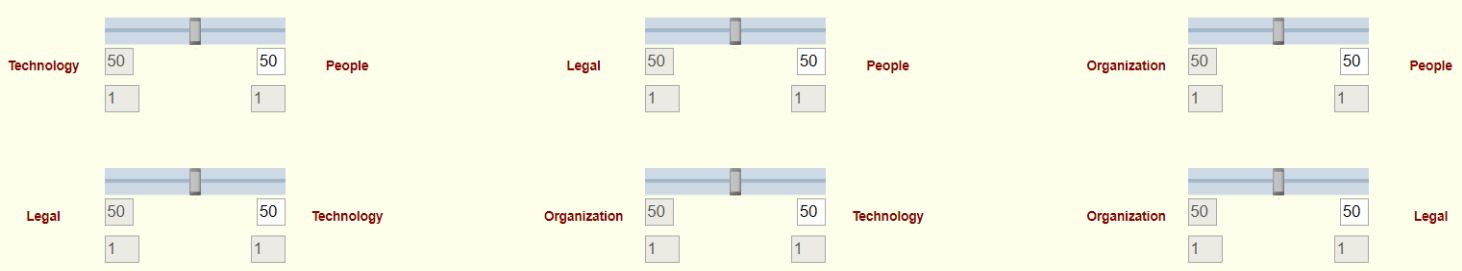

Save $\&$ Go to the Main Page Cancel

sC Big Data Readiness Assessment

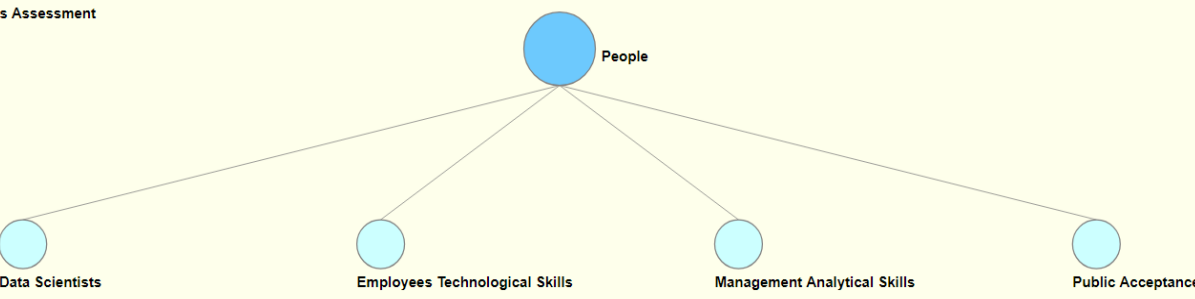

Show Instructions

Please give your judgment for each pair of nodes below toward People

Employees
Technological
Skills

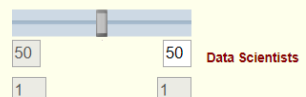

Management
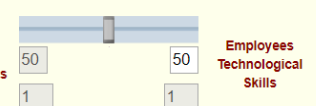

Employees
Technological
skills

1

Save \& Go to the Main Page Cancel

Employees Technological Skills

Management Analytical Skills

Public Acceptance

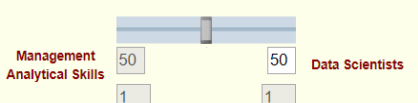

\begin{tabular}{c|c|c|c|}
$\begin{array}{c}\text { Public } \\
\text { Acceptance }\end{array}$ & 50 & 50 & $\begin{array}{c}\text { Employees } \\
\text { Technological } \\
\text { Skills }\end{array}$ \\
\cline { 1 - 1 } & 1 & 1 &
\end{tabular}

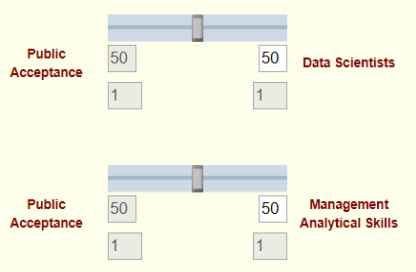




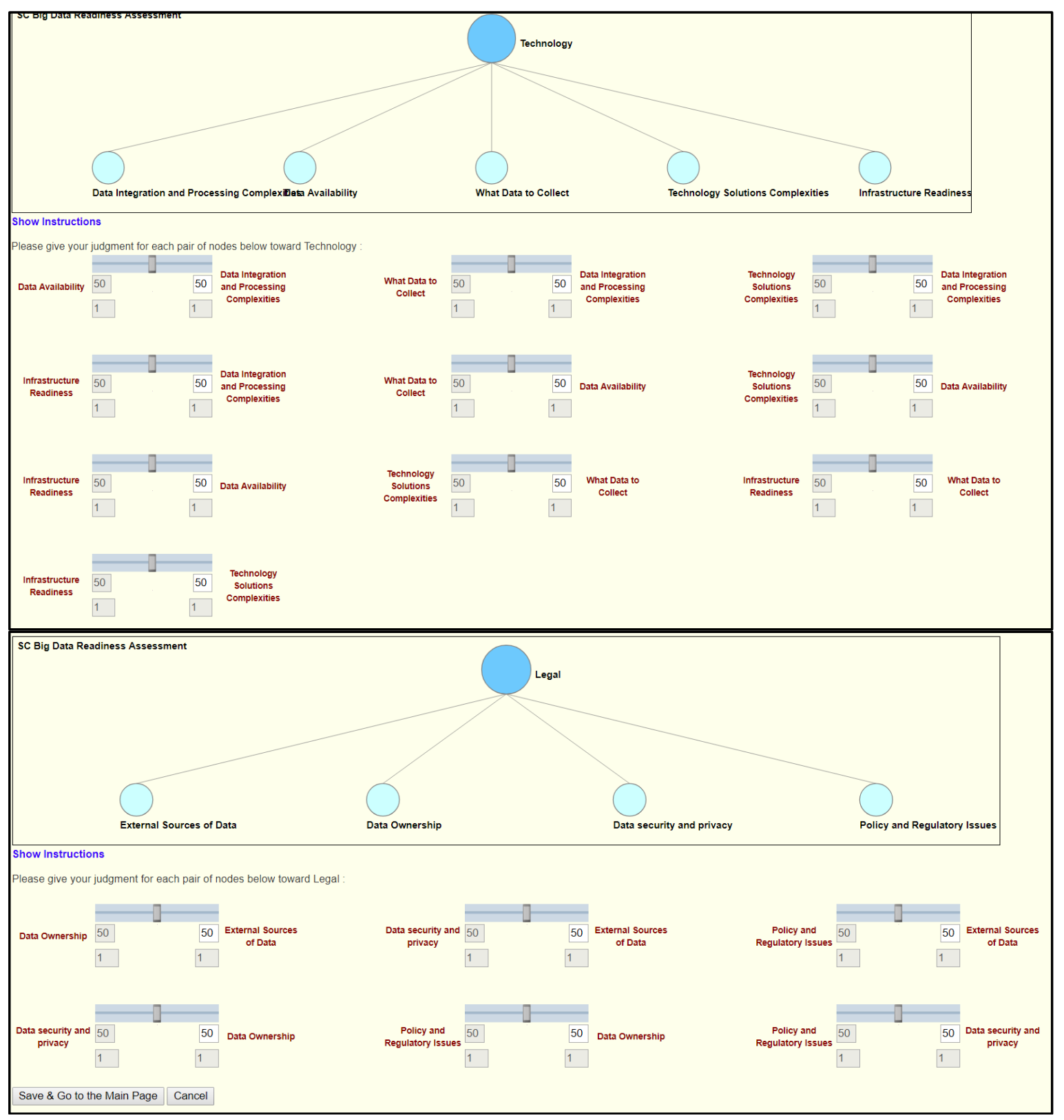




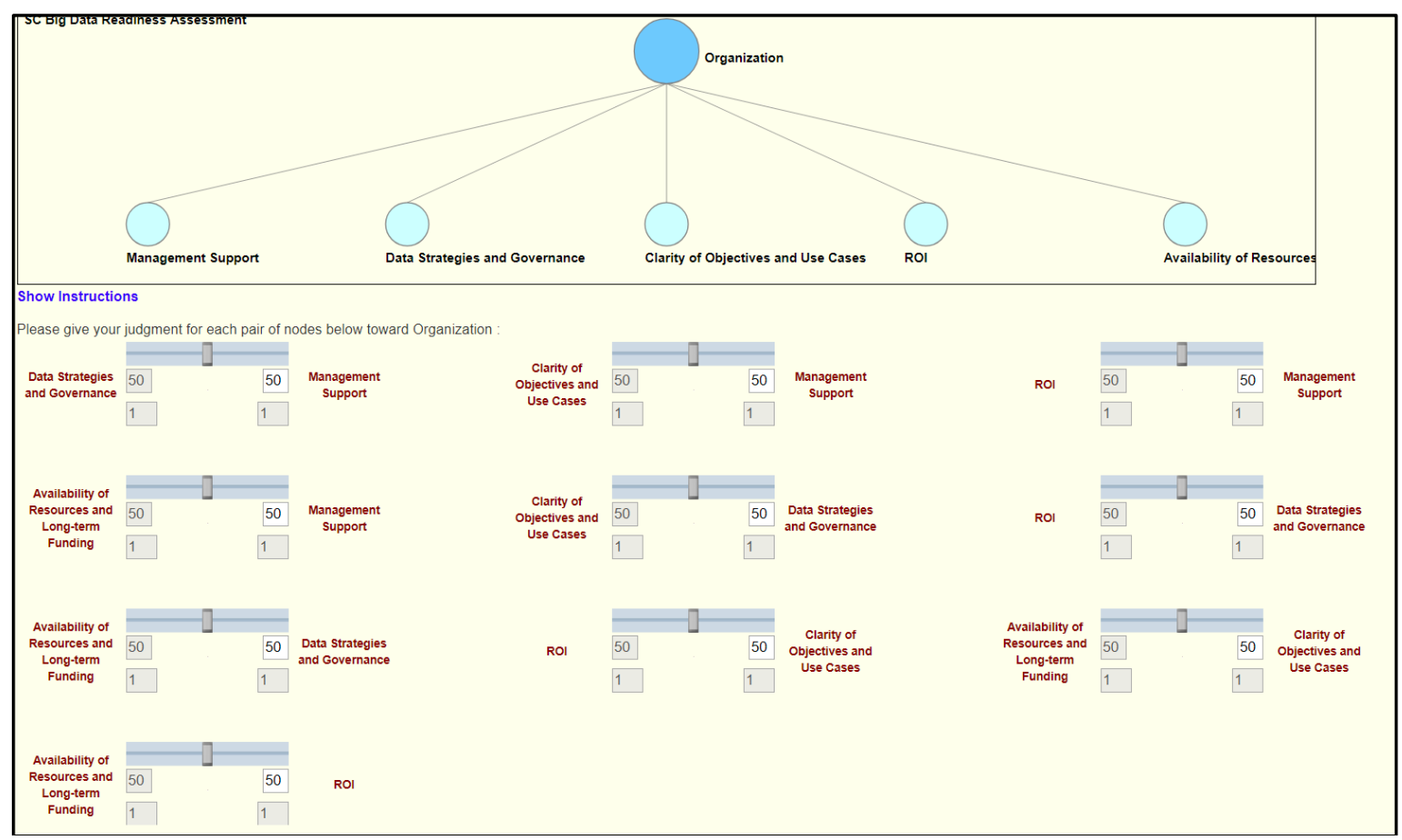




\section{APPENDIX D: R PACKAGE FOR BIBLIOMETRIC AND SNA ANALYSIS}

Following manual about how to conduct SNA analysis was prepared by Edwin Garcias for the "Technology Analytics Working" group, a subgroup under TERA research group. I used it to conduct SNA analysis for Q4.

General Information:

- Social Network Analysis (SNA): Mapping and measuring relationships and flows between nodes.

- Centrality Metrics: Degree, Betweenness, Closeness, Eigenvector.

- SNA Methodology: (Applied for the current software)

- Based on Co-authoring.

- Nodes relationship: Undirected.

The main measures of centrality to be considered are: Degree and betweenness.

Criteria of author selection:

- Higher level of betweenness.

- Degree together with the frequency of number of publications.

High levels of degree are related to the direct number of co-author connections.

Authors in the network with high betweenness and high closeness are authors that have easy access to others in the network and are able to control the information through other sections of the network.

\section{Process of expert identification}

It is recommended to follow three steps in the SNA for identifying experts, authors, or any subject of the analyzed network as follow [Appendix D.1]: 


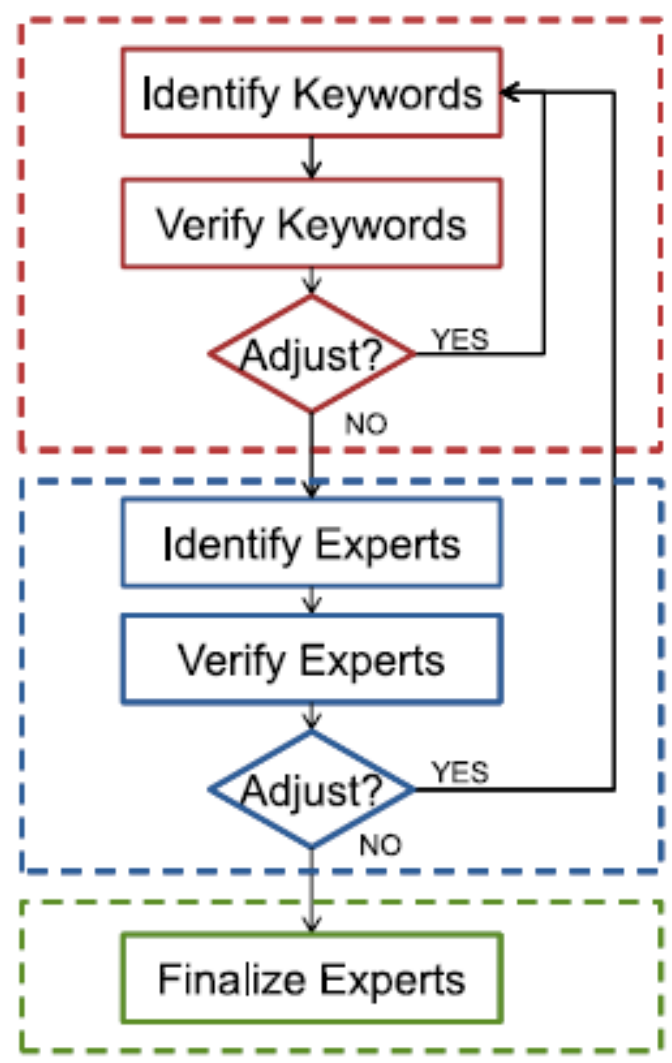

\section{STEP 1}

STEP 2

STEP 3

Source: [Appendix D.1]

Step 1: Keyword identification and database Selection [Appendix D.1]:

The use of the correct keywords is directly associated to the quality of the database that will be used in the SNA. It is important to find the relevant keywords and structure them logically using boolean operators.

The SNA is focused on three research stages [Appendix D.2]:

- Basic research, using Web of Science Database

- Applied research, using Compendex Database

- Development, using patents Sumobrain Databse.

Step 2: Social network analysis [Appendix D.1]

SNA, using this software is based on co-authoring. There are many centrality metrics that can be used. Since it is a co-authoring approach, Betweenness can be used as the main centrality; however, a combination or Degree centrally and number of publications can be used too. Which centrality metric will be used to analyzed the results depends on the objective of the analysis. Therefore it is important to stablish and define clearly the objective of the analysis, prior to selecting the keywords, or analyzing the results. 
Step 3: Finalization of experts [1]

Generally, SNA used to identify experts or authors, etc., does not finish only identifying the central nodes (actors), but it is needed to verify the final results, the information corresponding to each actor, or contact information, etc.

Instructions for Downloading and Analyzing Web of Science, Compendex data, and Patents

Downloading Data:

- Web of Science:

- Search for results under Web of Science,

- Click on "Save to Other File Formats" -> Select Record Content: "Full Record and Cited References", File Format: "Tab-delimited (Win, UTF8)",

- Click Send and save to local drive,

- Repeat until all article entries downloaded.

- Compendex:

- Search for results under Compendex,

- Click Select -> Maximum (up to 500) and then click "Save to my PC",

- Select Location: "My PC", Format: "CSV", Output: "Detailed Record" and download,

- Repeat until all article entries downloaded.

- Due to recent changes in Compendex, the structure of the data changed. This caused the incompatibility of the software and data. To solve this, follow the steps "a" to "d" and restructure your data according to the template in Excel "SNA Compendex Template.csv " (CVS format). This means that columns and titles need to be moved and edited according to the template. Save the template as CSV (comma delimited). NOTE: you do not need to change the internal structure of the cells, you just need to move the columns and be sure that the tittle is identical as the template.

- Patents (Sumobrain)

- Go to www.sumobrain.com and Signup. Once account is created Login,

- Search for US patents on relevant topic, (choose as date the last 20 years)

- Save the results to a new portfolio (this only shows when you have logged in)

- Once the portfolio is created, select the results and then click on the Export button on the right. You can only export 250 results at a time so you have to download them separately and combine the results into one file later

- Open the downloaded xls files, delete the first empty row, and then save as a csv file,

- Go to http://rstudio.cecs.pdx.edu:3838/users/kevin9/Patent/ and upload the csv file,

- Wait for the download links to show on the right, 
○ Download the authors.csv file and select ten authors with the highest number of patents. You will need to search for their contact details through a Google search.

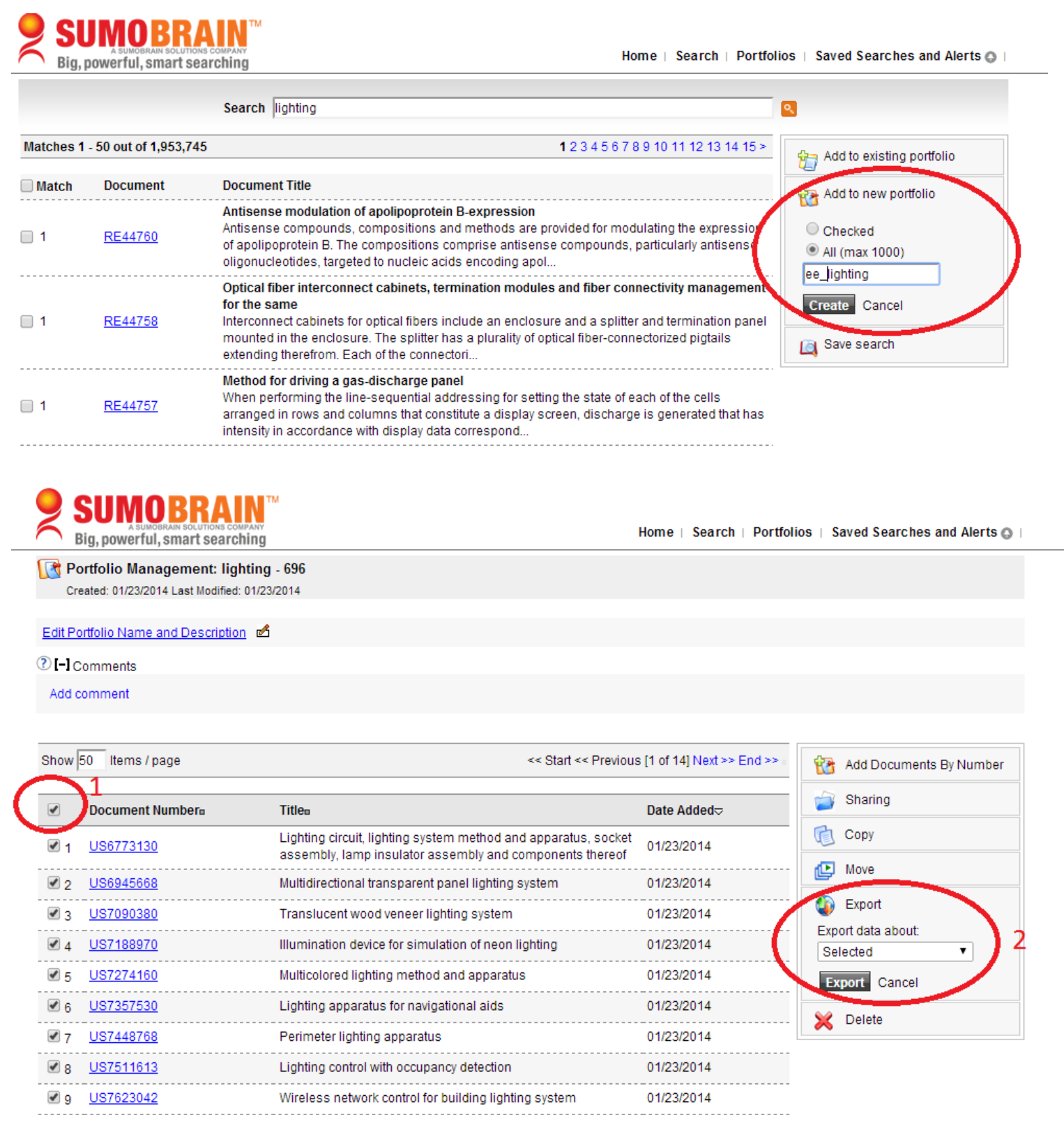




\section{Patent Count}

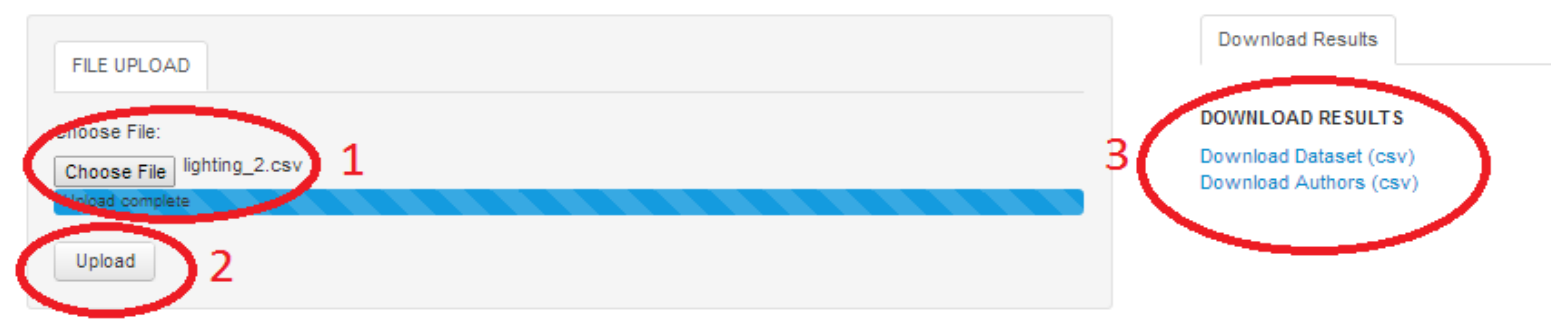

Installing the software:

- Download and Install R -> select base option (http://cran.rstudio.com/),

- Download and Install RStudio (http://www.rstudio.com/products/rstudio/download/),

- In RStudio go to Menu, Tools, Install Packages. Look for "Shiny" package and install it.

- For visualization purposes, Gephi software needs to be installed. Download and install the last version of Gephi (http://gephi.github.io/users/download/).

Analyzing Data:

- In the Console type "shiny::runGitHub("Expert_Identification", "kevinvanb")". The first time RStudio will install the additional needed packages and then opens a new windows. This new window (called "expert identification") is the SNA interface that will be used for uploading the data, running the SNA, and visualizing the results.

- In the expert identification window, choose the type of source data to be uploaded. There are three options: Web of Science, Compendex, and Patent.

- In the expert identification windows, select "choose files" to load your data file. The software allows uploading one or multiple files.

- The final step is to run "Analyze" option; which is located on the lower left corner of the window.

Results

- The results will be showed in the window "expert identification". The results shows the all used data, main centrality indicators including frequency, betweenness, degree, closeness, and so on.

- For printing and saving the results, use the alternative browser interface. This can be found on the top of the windows.

For results graph visualization, use the "edges file" and open it in Gephi. 


\section{Appendix D References:}

[1] E. Garces, K. van Blommestein, J. Anthony, J. Hillegas-Elting, T. Daim, and B.-S. Yoon, "Technology domain analysis: A case of energy-efficient advanced commercial refrigeration technologies," Sustain. Prod. Consum., vol. 12, no. August, pp. 221-233, 2017.

[2] Martino, J.P., 2003. A review of selected recent advances in technological forecasting. Technol. Forecast. Soc. Change 70 (8), 719-733. 